\title{
Guanylatkinase:
}

\section{Von einem aktiven Enzym zu einem inaktiven}

\author{
Multidomänen-Protein
}

\author{
Dissertation \\ Zur Erlangung des Doktorgrades \\ der Mathematisch-Naturwissenschaftlichen Fakultäten \\ der Georg-August-Universität zu Göttingen
}

vorgelegt von

Oliver Spangenberg

aus Kassel

Göttingen 2001 
D7

Referent:

Korreferent:

Tag der mündlichen Prüfung:
Prof. Dr. G. Braus

Prof. Dr. D. Gallwitz

02.05.2001 
Die vorliegende Arbeit wurde in der Abteilung Molekulare Genetik am Max-Planck-Institut für Biophysikalische Chemie in Göttingen angefertigt.

Teile dieser Arbeit wurden bereits veröffentlicht:

Kuhlendahl, S., Spangenberg, O., Konrad, M., Kim, E., and Garner, C. C. (1998) Functional analysis of the guanylate kinase-like domain in the synapse-associated protein SAP97. Eur. J. Biochem. 252, 305-313.

Prinz, H., Lavie, A., Scheidig, A. J., Spangenberg, O., and Konrad, M. (1999) Binding of nucleotides to guanylate kinase, p2 ${ }^{\text {ras }}$, and nucleoside-diphosphate kinase studied by nanoelectrospray mass spectrometry. J. Biol. Chem. 274, 35337-35342.

Kumar, V., Spangenberg, O., and Konrad, M. (2000) Cloning of the guanylate kinase homologues AGK-1 and AGK-2 from Arabidopsis thaliana and characterization of AGK-1. Eur. J. Biochem. 267, 606-615. 


\section{INHALTSVERZEICHNIS}

1 EINLEITUNG $\quad 1$

1.1 Nukleosidphosphatstoffwechsel 2

1.2 Guanylatkinasen 3

1.2.1 Rolle der Guanylatkinase im Purinnukleotid-Stoffwechsel von S. cerevisiae 3

1.2.2 Struktur 5

1.2.3 Katalytischer Mechanismus 7

1.2.4 Phosphorylierung von Nukleosidanaloga 8

1.3 Membran-assoziierte Guanylatkinasen 9

$\begin{array}{lll}\text { 1.3.1 MAGUK-Subfamilien } & 10\end{array}$

$\begin{array}{ll}\text { 1.3.1.1 Dlg-ähnliche } & 10\end{array}$

1.3.1.2 ZO-1-ähnliche 12

1.3.1.3 p55-ähnliche 12

1.3.1.4 Lin2-ähnliche 13

1.3.2 MAGUK-Domänen 13

1.3.2.1 PDZ-Domäne $\quad 14$

1.3.2.2 SH3-Domäne $\quad 14$

1.3.2.3 GK-Domäne $\quad 15$

1.3.3 Funktion von MAGUKs am Beispiel von CASK und PSD-95 17

$\begin{array}{lll}1.4 & \text { Zielsetzung } & 20\end{array}$

2 MATERIAL 21

$\begin{array}{lll}2.1 & \text { Escherichia coli-Stämme } & 21\end{array}$

$\begin{array}{lll}2.2 & \text { Saccharomyces cerevisiae-Stämme } & 21\end{array}$

$\begin{array}{lll}2.3 & \text { Plasmide } & 22\end{array}$

$\begin{array}{lll}2.4 & \text { Oligonukleotide } & 24\end{array}$

$\begin{array}{lll}2.5 & \text { Enzyme und Kits } & 27\end{array}$

$\begin{array}{lll}2.6 & \text { Chemikalien und Medienzusätze } & 27\end{array}$

$\begin{array}{lll}2.7 & \text { Verbrauchsmaterialien } & 28\end{array}$

$\begin{array}{lll}2.8 & \text { Geräte } & 28\end{array}$

$\begin{array}{lll}2.9 & \text { Lösungen und Puffer } & 29\end{array}$

3 METHODEN $\quad 32$

$\begin{array}{lll}3.1 & \text { Kultivierung von } E \text {. coli } & 32\end{array}$

3.1.1 Nährmedien für E.coli $\quad 32$

3.1.2 Anzucht von E.coli-Kulturen 32

3.2 Kultivierung von $S$. cerevisiae 32

3.2.1 Nährmedien für Hefekulturen $\quad 32$ 
3.2.2 Anzucht von Hefekulturen 33

3.3 Präparation von DNA 33

3.3.1 Analytische Plasmidisolierung aus E. coli 33

3.3.2 Präparative Plasmidisolierung aus E. coli 34

3.3.3 Isolierung genomischer DNA aus $S$. cerevisiae $\quad 34$

3.3.4 Isolierung von Plasmid-DNA aus S. cerevisiae $\quad 34$

3.3.5 Bestimmung der Konzentration und Reinheit von DNA

3.4 Enzymatische Behandlungen von DNA $\quad 35$

3.4.1 Fragmentierung von Doppelstrang-DNA mit Restriktionsenzymen 35

3.4.2 Behandlung von linearisierter DNA mit alkalischer Phosphatase 35

3.4.3 Auffüllen von 5'-überhängenden DNA-Enden 36

3.5 Gelelektrophoretische Auftrennung von DNA 36

3.5.1 Analytische und präparative Agarose-Gelelektrophorese 36

3.5.2 Isolierung von DNA aus präparativen Gelen 37

$\begin{array}{lll}\text { 3.6 Klonierung rekombinanter DNA in E.coli } & 37\end{array}$

$\begin{array}{lll}\text { 3.6.1 Ligation von DNA-Doppelstrang-Fragmenten } & 37\end{array}$

3.6.2 Herstellung kompetenter E. coli-Zellen 37

3.6.3 Transformation von E. coli-Zellen 38

3.7 DNA-Amplifikation durch die Polymerase-Kettenreaktion 38

3.7.1 Kolonie-PCR-Screening 39

3.8 Gerichtete Mutagenese mit der PCR 39

3.8.1 Gerichtete PCR-Mutagenese durch lineare Plasmid-Amplifikation 40

3.9 Methoden zur Hefegenetik $\quad 4$

3.9.1 Klassische Transformation von Hefezellen 41

3.9.2 Elektroporation von Hefezellen $\quad 42$

$\begin{array}{lll}3.9 .3 & \text { Sporulation diploider Hefezellen } & 42\end{array}$

$\begin{array}{lll}3.9 .4 & \text { Tetradenanalyse } & 42\end{array}$

3.9.5 Kreuzung von Hefezellen $\quad 43$

3.9.6 Nachweis von sekretiertem $\alpha$-Pheromon mit dem „Halo“-Test 43

3.10 Isolierung von Proteinen aus $E$. coli-Zellen $\quad 44$

3.10.1 Analytische Proteinexpression in kleinem Kulturvolumen 44

3.10.2 Expression und affinitätschromatographische Reinigung von
Histidin-Fusionsproteinen aus E. coli-Zellen

3.10.2.1 Proteinaufreinigung von Histidin-Fusionsproteinen 44

3.10.3 Expression und affinitätschromatographische Reinigung von
GST-Fusionsproteinen aus E. coli-Zellen

3.10.3.1 Expression von GST-Fusionsproteinen $\quad 46$

$\begin{array}{ll}\text { 3.10.3.2 Aufreinigung von GST-Fusionsproteinen } & 47\end{array}$

3.10.4 Expression und affinitätschromatographische Reinigung von
MBP-Fusionsproteinen aus E. coli-Zellen

3.10.4.1 Aufreinigung von MBP-Fusionsproteinen 48

3.10.5 Aufreinigung von Proteinen durch Denaturierung und Renaturierung 49

3.11 Herstellung von Proteinextrakten aus S. cerevisiae 49

3.11.1 Mechanischer Aufschluß von Hefezellen mit Glasperlen 49 
3.11.2 Alkalischer Aufschluß von Hefezellen 50

3.12 Bestimmung von Proteinkonzentrationen $\quad 50$

$\begin{array}{lll}3.12 .1 & \text { Bradford-Assay } & 50\end{array}$

3.12.2 Bestimmung der Proteinkonzentration durch UV-Absorption 50

3.13 Konzentrieren und Entsalzen von Proteinen $\quad 51$

3.14 Analyse von Proteinen durch SDS-PAGE nach Laemmli 51

3.15 Immunologischer Nachweis von Proteinen durch Western-Blot-Analyse 52

$\begin{array}{lll}3.16 & \text { Gelfiltration } & 53\end{array}$

$\begin{array}{lll}3.17 & \text { Analytische Ultrazentrifugation } & 53\end{array}$

$\begin{array}{lll}\text { 3.18 Kinetische Methoden } & 57\end{array}$

3.18.1 Messung der Enzymaktivität $\quad 57$

3.18.2 Michaelis-Menten Parameter $\quad 59$

3.19 Untersuchung von Protein-Ligand Wechselwirkungen $\quad 60$

3.19.1 Nano-Elektrospray-Massenspektrometrie (Nano-ESMS) 60

$\begin{array}{lll}3.19 .2 & \text { Gleichgewichtsdialyse } & 61\end{array}$

3.19.3 Filter-Assay mit radioaktiv markierten Nukleotiden 62

\section{ERGEBNISSE $\quad 63$}

$\begin{array}{lll}\text { 4.1 } & \text { Guanylatkinasen } & 63\end{array}$

4.1.1 Hefegenetische Untersuchungen an der Guanylatkinase $\quad 63$

4.1.1.1 Die Bäckerhefe S. cerevisiae als in vivo-System zur Detektion von
Guanylatkinase-Aktivität

4.1.1.2 Die Guanylatkinase unter Kontrolle des Tetracyclin-regulierbaren

4.1.1.3. Unterbrechung des NDK1-Gens in S. cerevisae und Konstruktion von
$a d k 1 / n d k 1$-sowie gukl-3/ndkl-Doppelmutanten

4.1.2 Kinetische Eigenschaften von GUK1-Mutanten mit veränderter
ATP-Bindungsstelle

4.1.3 Die Guanylatkinase des Menschen und der Maus $\quad 83$

4.1.3.1 Aufreinigung von hGUK und mGUK aus E. coli $\quad 84$

4.1.3.2 Kinetische Eigenschaften von hGUK und mGUK 85

$\begin{array}{lll}\text { 4.1.3.3 Untersuchung der Nukleotidbindung an hGUK und p21 } & \text { ras } \\ & \text { mit der } & \\ & \text { Nano-Elektrospray-Massenspektrometrie (Nano-ESMS) }\end{array}$

4.1.4 Die Arabidopsis thaliana Guanylatkinasen AGUK1 und AGUK2 91

4.1.4.1 Komplementations-Analyse von AGUK1 in S. cervisiae 93

4.1.4.2 Aufreinigung von AGUK1 und AGUK1(137-330) aus E. coli 94

4.1.4.3 Kinetische Eigenschaften von AGUK1 und AGUK1(137-330) 96

4.2 Die Membran-assoziierten Guanylatkinasen SAP97 und hCASK 99

4.2.1 Biochemische und hefegenetische Untersuchungen zum Nachweis von
Guanylatkinase-Aktivität der GK-Domänen von SAP97 und hCASK

4.2.2 Versuch der Rekonstruktion einer aktiven Guanylatkinase aus SAP97-GK 103

4.2.2.1 Biochemische Charakterisierung von SAP97-GK-Mutanten 103

4.2.2.2 Komplementations-Analyse von SAP97-GK-Mutanten in S. cerevisiae 109

4.2.3 Nukleotidbindungs-Eigenschaften von SAP97-GK 110 
4.2.3.1 Untersuchung der Bindung einzelner Nukleotide an SAP97-GK mit der Nano-ESMS

4.2.3.2 Identifikation der Nukleotidbindungsstellen von SAP97-GK mit der Nano-ESMS

4.2.3.3 Bestimmung der Dissoziationskonstanten für die Nukleotid-Bindung an SAP97-GK und hCASK-GK

4.3 Intramolekulare Interaktion zwischen SH3 und GK in SAP97

4.3.1 Konstruktion eines Sensormoleküls

4.3.1.1 Biochemische Charakterisierung von SAP97-SH3/GK und SAP97-SH3/GUK

4.3.1.2 Katalytische Aktivität von SAP97-SH3/GK und SAP97-SH3/GUK 126

4.3.2 Einfluß von Purin-Nukleotiden auf intramolekulare Interaktionen in SAP97 128

4.3.2.1 Assoziationsverhalten von SAP97-SH3/GK in Lösung 128

4.3.2.1.1 Gelfiltration $\quad 128$

4.3.2.1.2 Gleichgewichtszentrifugation 130

4.3.2.2 Sedimentationsanalyse von SAP97-SH3/GK 137

5 DISKUSSION 140

5.1 Funktionelle Rolle der GUK1 in S. cerevisiae 140

5.2 Hefe-in vivo-System zum Auffinden von Guanylatkinasen 140

5.2.1 Konditionale Guanylatkinase-Mutanten 140

5.2.2 adkl/ndkl-und gukl-3/ndkl-Doppelmutanten 143

5.3 Funktion signifikanter Aminosäuren der ATP-Bindungsregion von GUK1 145

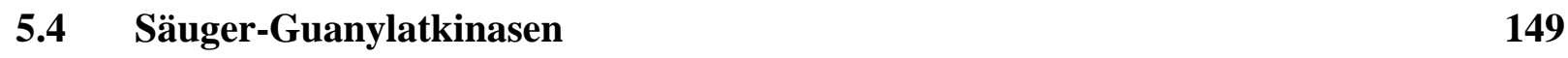

$\begin{array}{lll}\text { 5.5 } & \text { Guanylatkinasen der Pflanze } & 151\end{array}$

5.5.1 Die Arabidopsis-Guanylatkinase als evolutionäres Bindeglied zwischen aktiven Guanylatkinasen und inaktiven MAGUK-Proteinen 152

5.6 Funktionelle Charakterisierung der GK-Domäne von SAP97 und hCASK 154

5.6.1 In vitro-Analyse zum Nachweis von Guanylatkinase-Aktivität 154

5.6.2 Rekonstruktion der Guanylatkinase-Aktivität in SAP97-GK 156

5.7 Nukleotidbindungs-Eigenschaften von SAP97-GK 157

$\begin{array}{lll}\text { 5.7.1 Selektivität der GK-Domäne } & 159\end{array}$

$\begin{array}{ll}\text { 5.7.2 Bindungsparameter } & 160\end{array}$

5.8 Intramolekulare Interaktion der SH3/U5- und GK-Domäne in SAP97 161

5.8.1 Die intramolekulare SH3/GK-Interaktion in SAP97 verläuft über ein untypisches SH3-Bindungsmotiv

5.9 Funktionelle Rolle von GMP 166

$\begin{array}{ll}\text { 6. ZUSAMMENFASSUNG } & 168\end{array}$

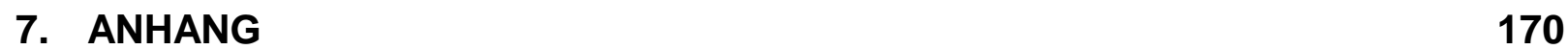

8 LITERATURVERZEICHNIS $\quad 175$ 


\section{$1 \quad$ Einleitung}

\section{$1.1 \quad$ Nukleosidphosphatstoffwechsel}

Ribonukleotide spielen eine zentrale Rolle im Stoffwechsel der Zelle. Sie werden nicht nur für die Energiebereitstellung (ATP/GTP), die chemische Aktivierung von Substraten durch Phosphorylierung (ATP/GTP) und den Fett- und Lipidstoffwechsel (CTP/UTP) benötigt, sondern sind auch die Bausteine der RNA (ATP, UTP, GTP, CTP)- und in der Desoxy-Form (dATP, dTMP, dCTP, dGTP) der DNA-Synthese. Desoxyribonukleotide werden in der Zelle auf zwei unterschiedlichen Wegen synthetisiert: Erstens durch Neusynthese im de novoStoffwechsel und zweitens durch Wiederverwertung im Salvage-Stoffwechsel (Van Rompay et al., 2000; siehe Abb. 1.1). Die Neusynthese der Purinribonukleotide und Pyrimidinnukleotide verläuft auf zwei unterschiedlichen Wegen: Im de novo-Weg werden die Purinribonukleotide GMP und AMP aus dem IMP, welches seinerseits aus Phosphoribosylpyrophosphat (PRPP) und Glutamin gebildet wird, hergestellt (Zalkin und Dixon, 1992; Elion, 1989). Im Gegensatz zur de novo-Synthese des Purinringes wird der Pyrimidinring zuerst zusammengefügt und dann durch Bindung an Ribosephosphat in ein Pyrimidinnukleotid überführt. Die Pyrimidinnukleotide CMP und TMP (existiert nur als Desoxyderivat dTMP) gehen aus dem Uridylat (UMP) hervor, welches seinerseits aus Orotat und PRPP gebildet wird (Jones, 1980). PRPP dient folglich sowohl bei der Synthese der Purin-, als auch der Pyrimidinnukleotide als Donor der Ribosephosphat-Einheit. Die synthetisierten Ribonukleosid-Monophosphate (NMPs) werden durch einen Phosphorylierungsschritt, katalysiert durch die Nukleosidmonophosphatkinasen (NMKs, NMPkinasen) in Ribonukleosid-Diphosphate (NDPs) umgewandelt. Die Ribonukleosid-Diphosphate werden in einem abschließenden Schritt durch das Enzym Ribonukleosid-Reduktase (RR) zu den Desoxyribonukleosid-Diphosphaten (dNDPs) reduziert (Reichard, 1993). Beim hydrolytischen Abbau von Nukleinsäuren und Ribonukleotiden bzw. Desoxyribonukleotiden gebildete Nukleoside werden in der Wiederverwertungsreaktion in drei aufeinanderfolgenden Phosphorylierungsschritten, welche durch die Enzyme Ribonukleosidkinase (rNK), Nukleosidmonophosphatkinase (NMK) und Nukleosiddiphosphatkinase (NDK, NDPkinase) katalysiert werden, wieder in die TriphosphatFormen überführt (siehe Abb. 1.1). Im Gegensatz zur Ribonukleosidkinase-Reaktion sind die Reaktionen der NMKs und NDPKs reversibel. Die nach dem ersten Phosphorylierungsschritt gebildeten Monophosphate können allerdings durch die 5'-Nukleotidasen wieder dephosphoryliert werden. 
Aufgrund ihrer essentiellen Funktion sowohl im de novo-, als auch im salvage-Stoffwechsel zur Synthese von Ribonukleotiden und Desoxyribonukleotiden, besitzen die Nukleosidmonophosphatkinasen eine herausragende Stellung in der Nukleinsäure-Synthese.

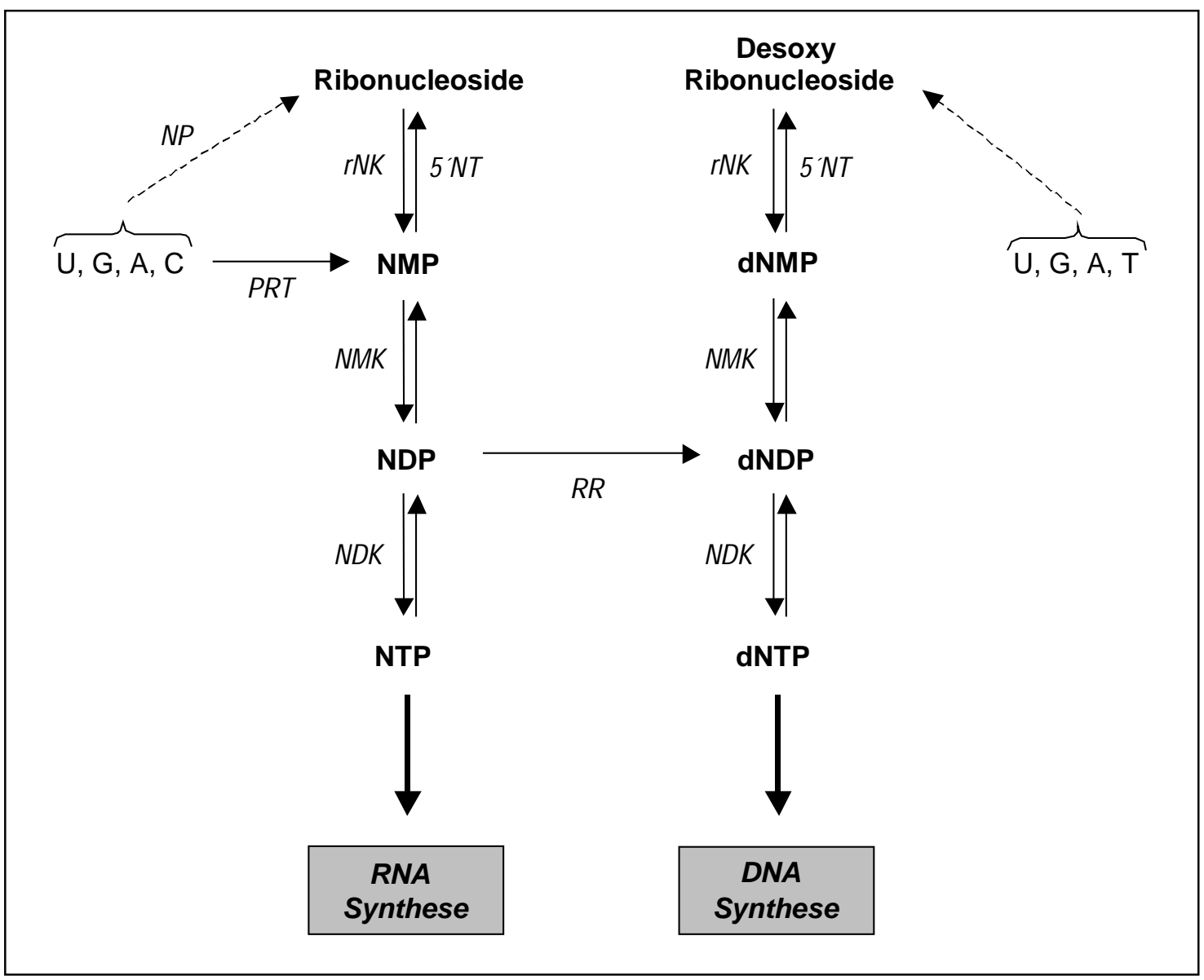

Abb. 1.1 Schema des Salvage-Stoffwechsels zur Synthese von Ribo- und Desoxyribonukleotiden. A, Adenin; C, Cytidin; G, Guanin; T, Thymidin; U, Uridin; (d)NMP, (Desoxy)Nukleosidmonophosphat; (d)NDP, (Desoxy)Nukleosiddiphosphat; (d)NTP; (Desoxy)Nukleosidtriphosphat; NMK, Nukleosid-monophosphatkinase; $N D K$, Nukleosiddiphosphatkinase; NP, Purin/Pyrimidin-Nukleosidphosphorylase; $5^{\prime} N T, 5^{\prime}$-Nukleotidase; PRT, Phosphoribosyltransferase; $r N K$, Ribonukleosidkinase; $R R$, Ribonukleotidreduktase.

Alle NMPkinasen haben einen ähnlichen Katalysemechanismus und zeichnen sich durch eine hohe Substratspezifität aus. In Säugerzellen sind bisher eine Thymidylatkinase (dTMK), eine Uridylat-Cytidylatkinase (UMP-CMPK), 5 Isozyme der Adenylatkinase (AK1-5) und verschiedene Guanylatkinasen identifiziert worden (Van Rompay et al., 2000). Die Guanylatkinasen können in 2 große Gruppen unterteilt werden. Die erste Gruppe umfaßt die echten, kleinen Guanylatkinasen (Agarwal et al., 1978a; Hall und Kühn, 1986, Brady et al., 1996) und die zweite Gruppe die Membran-assoziierten Guanylatkinasen (MAGUKs), welche größer und im Gegensatz zu den kleinen Guanylatkinasen nicht im Cytosol lokalisiert sind (siehe 1.3; Woods und Bryant, 1991; Garner und Kindler, 1996; Dimitratos et al., 1999). 


\subsection{Guanylatkinasen}

Das Enzym Guanylatkinase (GUK, ATP:GMP Phosphotransferase, EC 2.7.4.8) katalysiert die reversible Übertragung der terminalen Phosphatgruppe von ATP und dATP zu GMP und dGMP nach folgendem Reaktionsschema (Miech und Parks, 1965):

$$
(\mathrm{d}) \mathrm{GMP}+\mathrm{Mg}^{2+} \cdot(\mathrm{d}) \mathrm{ATP} \rightleftarrows(\mathrm{d}) \mathrm{GDP}+\mathrm{Mg}^{2+} \cdot(\mathrm{d}) \mathrm{ADP}
$$

In der Hefe ist die Guanylatkinase essentiell für das Überleben der Zelle, da es das einzige Enzym ist, welches GMP phosphorylieren kann (Konrad, 1992). Neben der bereits zuvor erwähnten Schlüsselstellung in der DNA-Synthese kommt ihm eine entscheidende Rolle in dem Guanosinphosphat-Kreislauf (cGMP-Zyklus siehe Abb. 1.2), zur Wiedergewinnung von cyclischem Guanosinmonophosphat (cGMP) aus GMP über GTP, zu (Hall und Kühn, 1986).

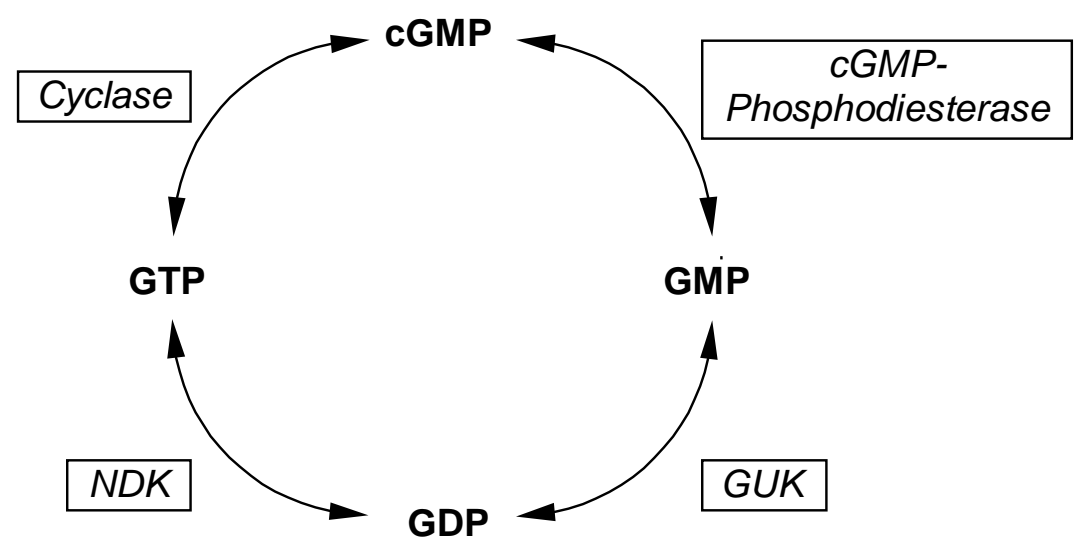

Abb. 1.2 Darstellung des cGMP-Zyklus, GUK = Guanylatkinase, NDK = Nukleosiddiphosphatkinase

Über den cGMP-Zyklus übt die Guanylatkinase eine zentrale Funktion in der Bereitstellung von Guanosinnukleotiden für an Signaltransduktionsprozessen beteiligte Proteine, z.B. p21 ${ }^{\text {ras }}$ und andere GTP bindende Proteine, aus (Gaidarov et al., 1993; Woods und Bryant, 1991).

\subsubsection{Rolle der Guanylatkinase im Purinnukleotid-Stoffwechsel von}

\section{S. cerevisiae}

Insbesondere Studien an S. cerevisiae, einem Modellorganismus der Molekularbiologie, führten zu bedeutenden Fortschritten in der Aufklärung der Funktion der Guanylatkinase in vivo. So konnte nicht nur gezeigt werden, daß die Guanylatkinase (GUK1) essentiell für das Überleben der Hefezelle ist (Konrad, 1992). Durch die Identifikation von GUK1-Mutanten der Hefe wurde 
direkt nachgewiesen, daß ein Defekt des Enzyms drastische Auswirkungen auf das Wachstum, das Purin-Nukleotid-Gleichgewicht sowie die Zellwandsynthese besitzt. (Lecoq et al., 2000; Shimma et al., 1997). In Mikroorganismen, wie z.B. in S. cerevisae, wird die Synthese der Stoffwechselenzyme zur de novo-Synthese der Purinnukleotide durch extrazelluläre Purine reguliert (siehe Abb. 1.3). Liegen die Purine Adenin und Hypoxanthin (Daignan-Fornier und Fink, 1992; Denis et al., 1998) im Medium vor, so nutzt die Hefe diese statt sie neu zu synthetisieren, d.h. die Transkription der Gene, welche für die Enzyme zur Neusynthese von AMP codieren ( $A D E$-Gene) wird reprimiert.

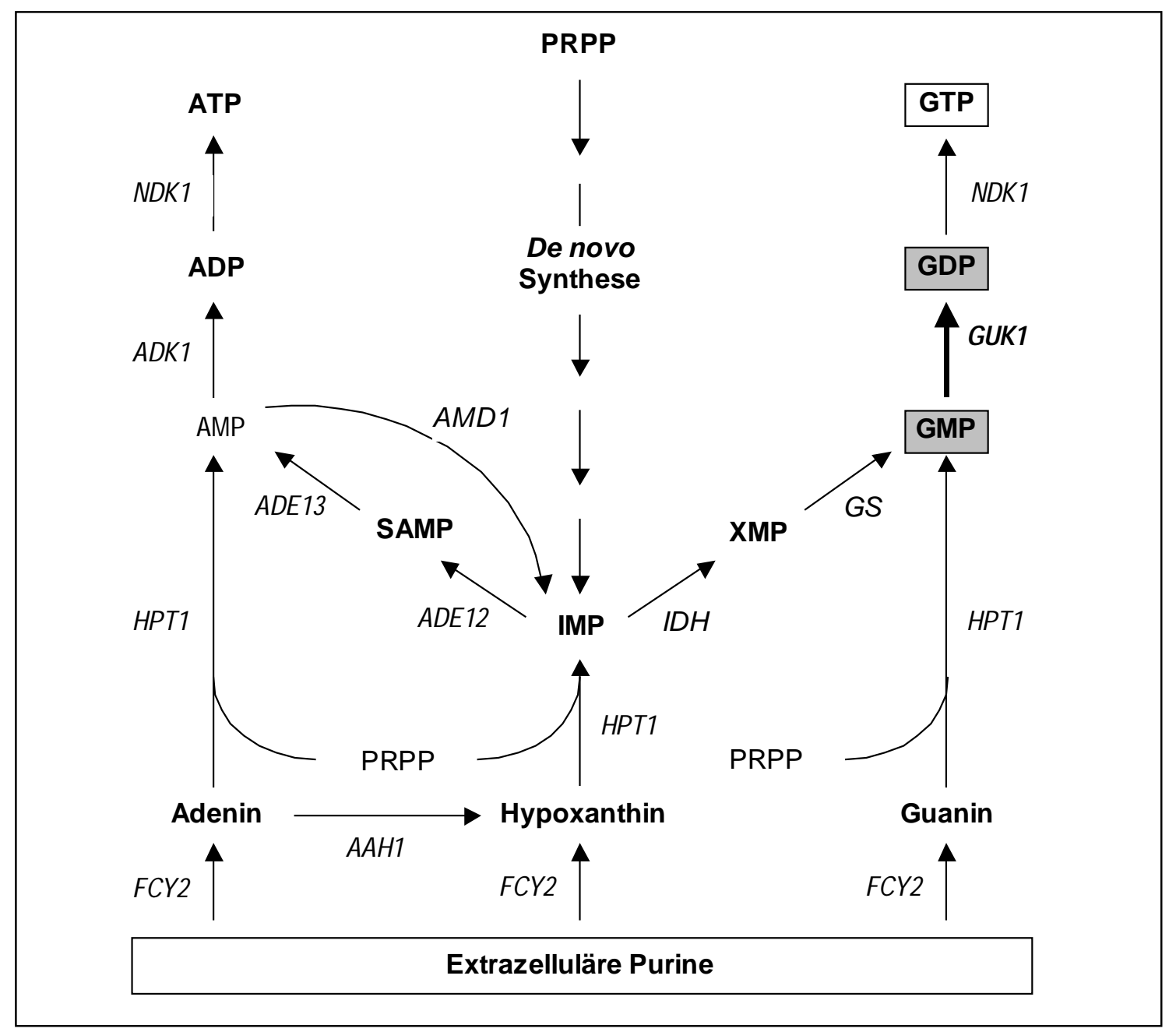

Abb. 1.3 Schema der Purinnukleotid-Synthese in S. cerevisiae. PRPP, 5-Phosphorybosyl-1-Pyrophosphat; AMP, Adenosinmonophosphat; GMP, Guanosinmonophosphat; GDP, Guanosindiphosphat; IMP, Inosinmonophosphat; SAMP, Adenylosuccinat; XMP, Xanthosinmonophosphat; AAH1, Adenindeaminase; ADE12, Adenylosuccinatsynthetase; $A D E 13$, Adenylosuccinatlyase; $A D K 1$, Adenylatkinase; AMD1, AMP-Deaminase; APT1, Adeninphosphoribosyltransferase; FCY2, Purin-Cytosinpermease; GS, GMP-Synthase; GUK1, Guanylatkinase; HPT1, Hypoxanthinphosphoribosyltransferase; IDH, IMP-Dehydrogenase.

Guetsova et al. (1997) isolierten Mutanten, in welchen die Purinsynthese-Gene auch in Gegenwart extrazellulären Adenins nicht länger reprimiert wurden. Durch Komplementations- 
Experimente wurde eine Gruppe der Mutanten (BRA3) als Allele des GUK1-Gens identifiziert. Einhergehend mit einer stark reduzierten Aktivität der Guanylatkinase waren die Mutanten durch verlangsamtes Wachstum und Purinexkretion gekennzeichnet. Lecoq et al. (2000) konnten darüberhinaus nachweisen, daß in den GUK1-Mutanten, vermutlich durch einen erhöhten Spiegel an GMP, direkt die Aktivität der Hypoxanthin-Guanin-PhosphoribosylTransferase (HGPRT) inhibiert wird. Es ist bekannt, daß Mutationen der HGPRT in Zellen des menschlichen Organismus eine erhöhte Purinexkretion zur Folge haben, welche zu den pathologischen Krankheitsbildern der Hyperurikämie und Gicht führt (Kelley et al., 1969). Die übereinstimmenden Phänotypen können ein Indiz dafür sein, daß die in S. cerevisiae entdeckte HGPRT-Feedback-Inhibition auch im menschlichen Organismus existiert und die Ursache für die beiden Stoffwechselerkrankungen ist.

\subsubsection{Struktur}

Guanylatkinase-Aktivität wurde zuerst von Klenow und Lichtler (1957) beschrieben, die Strukturaufklärung und die Veröffentlichung der ersten Aminosäuresequenz von Saccharomyces cerevisiae erfolgte jedoch erst sehr viel später (Berger et al., 1989). Die Guanylatkinase aus S. cereviae (GUK1) ist das bisher am eingehendsten genetisch und biochemisch untersuchte Enzym der Familie der Guanylatkinasen (Konrad, 1992; Li et al., 1996; Schüle, 1997). Außer der GUK1 konnten bisher unter anderem die Aminosäuresequenzen der Guanylatkinasen aus E. coli (EcGUK), sowie der Maus (mGUK) und des Menschen (hGUK) aufgeklärt werden. Im Vergleich zur prokaryontischen Guanylatkinase aus E. coli, die nur als Dimer und Tetramer existiert (Gentry et al., 1993), sind alle eukaryontischen Guanylatkinasen kleine globuläre Monomere mit einem Molekulargewicht von 20 bis 22 kDa (Berger et al., 1989; Brady et al., 1996; Fitzgibbon et al., 1996). Die Sequenz-Identität zwischen den Guanylatkinasen aus S. cerevisiae und E. coli beträgt 48,6\%, zwischen S. cerevisiae und Säugern 52 bis $54 \%$ und zwischen zwei Säugern bis zu 90\%. Ein Sequenzvergleich verschiedener Guanylatkinasen ist in Abbildung 1.4 dargestellt.

Im Gegensatz zu den sowohl biochemisch, als auch strukturell intensiv studierten Adenylat(Dreusicke et al., 1988; Müller und Schulz, 1988; Diederichs und Schulz, 1991; Abele und Schulz, 1995), Uridylat-/Cytidylat- (Müller-Dieckmann und Schulz, 1995; Scheffzek et al., 1996) und Thymidylatkinasen (Lavie et al., 1997b; Lavie et al., 1998; Ostermann et al., 2000) ist die Guanylatkinase erst wenig erforscht. Bisher konnte nur die Kristallstruktur der GUK1 aus S. cerevisiae in Komplex mit dem Substrat GMP aufgeklärt werden (Stehle und Schulz, 1990). 


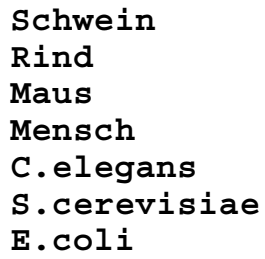

\section{P-Loop}

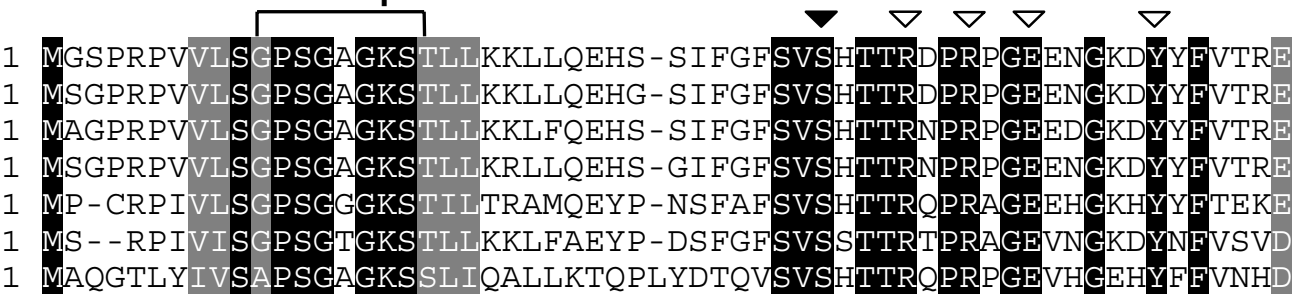

$1 \mathrm{M}$

S PSG GKS

SVS TTR PR GE G Y F e

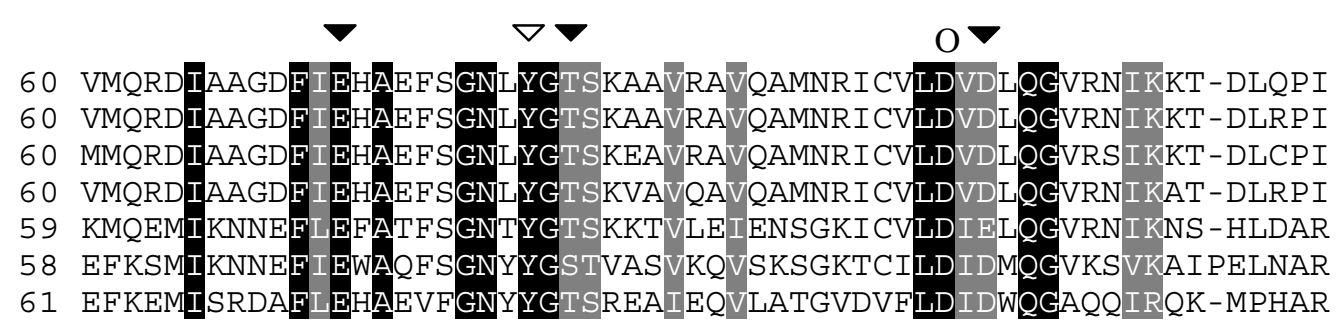
61 EFKEMISRDAFLEHAEVFGNYYGTSREAIEQVLATGVDVFLDIDWQGAQQIRQK-MPHAR
61
I
$F E A$
GN YG
LD QG

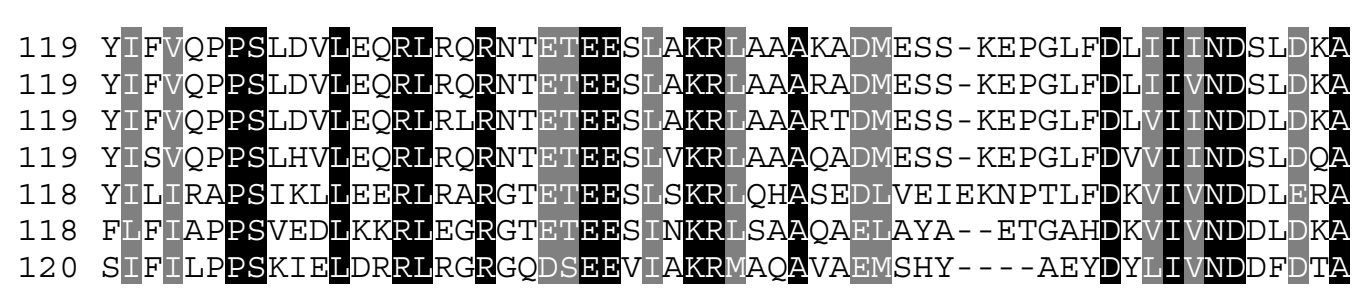

$$
\begin{array}{llllllllllllll}
121 & \text { PS } & \text { L } & \text { RL } & \text { R } & \text { EE } & \text { KR } & \text { A } & \text { D } & \text { ND } & \text { A }
\end{array}
$$

Abb. 1.4 Sequenzvergleich verschiedener Guanylatkinasen. Identische Aminosäuren sind schwarz und konservativ substituierte grau unterlegt. Der P-Loop ist das ATP-Bindungsmotiv, welches mit dem $\beta$ - und $\gamma$-Phosphat des Substrats ATP interagiert. Aminosäuren, die mit dem Guaninring ( $)$, der Phosphatgruppe ( $\nabla)$ von GMP und dem komplexierten $\mathrm{Mg}^{2+}$-Ion $(\mathrm{O})$ interagieren, sind markiert.

Obwohl die Aminosäuresequenz der humanen GUK nur eine Ähnlichkeit von 13\% zur humanen AK1 besitzt, weisen beide Kinasen in ihrem jeweiligen Aufbau aus 5 zentralen $\beta$ Faltblättern, die von 6 $\alpha$-Helices umgeben sind, dennoch einen hohen Grad an Übereinstimmung auf. Ebenso wie beispielsweise die Adenylatkinase, $F_{1}$-ATPase und Myosin (Dreusicke und Schulz, 1986) besitzt die Guanylatkinase das charakteristische ATPBindungsmotiv GXXGXGK(S/T), welches den sogenannten glycinreichen-Loop (oder P-Loop) bildet, in dem das $\beta$ - und $\gamma$-Phosphat von ATP gebunden wird (Müller und Schulz, 1992; 
Saraste et al., 1990). Darüberhinaus zeigt die Faltungstopologie der GUK1, insbesondere in der Nukleosidtriphosphat-Bindungsregion eine große Ähnlichkeit zu GTP-Bindungsproteinen (GProteinen; DeVos et al., 1988; Pai et al., 1990; Tong et al., 1991). G-Proteinen fehlen allerdings die zur Bindung von Nukleosidmonophosphaten aus der Guanylatkinase und der Adenylatkinase bekannten Aminosäuren (Stehle und Schulz, 1992). Während das P-LoopMotiv zur Bindung des Nukleosidtriphosphats hochkonserviert ist, weicht die Faltungstopologie der GMP-Bindungsregion deutlich von jener der AMP-Bindungsregion der Adenylatkinase ab (Stehle und Schulz, 1992).

\subsubsection{Katalytischer Mechanismus}

Die ersten kinetischen Untersuchungen von Guanylatkinasen wurden von Agarwal et al. (1978a) an aus Säugergewebe gereinigten Enzymen durchgeführt. Erst durch Studien mit rekombinanter S. cerevisiae-Guanylatkinase (GUK1) konnte der katalytische Mechanismus der Guanylatkinase weitestgehend aufgeklärt werden (Li et al., 1996). In Übereinstimmung zu den anderen NMPkinasen erfolgt die Katalyse auf Grundlage eines sequentiellen Mechanismus, d.h. beide Substrate binden an das Enzym und bilden einen ternären Komplex bevor das erste Produkt gebildet wird. Die Bindung der beiden Substrate ATP (genauer Mg.ATP) und GMP erfolgt ebenso wie die Freisetzung der Produkte ADP und GDP zufällig, sodaß der Reaktionsmechanismus vollständig als bi-bi-random Mechanismus bezeichnet wird (siehe Abb. $1.5)$.

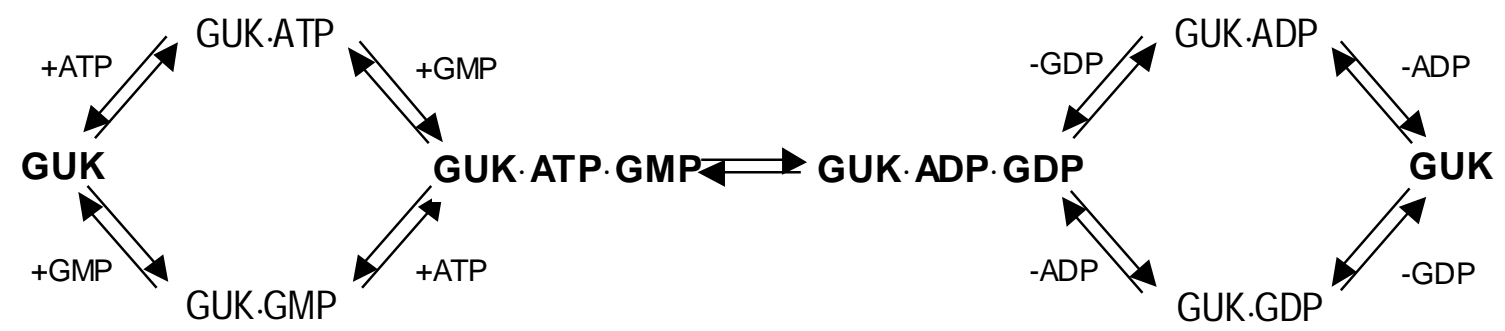

Abb. 1.5 Schema des bi-bi-random-Reaktionsmechanismus der Guanylatkinase. Das $\mathrm{Mg}^{2+}$-Ion des Mg·ATPKomplexes wurde aus platzsparenden Gründen weggelassen.

Die Substrat-Bindungsdomänen der Guanylatkinase sind durch einen hohen Grad an Flexibilität gekennzeichnet (Stehle und Schulz, 1992). Es wird angenommen, daß die katalytischen Zentren von NMPkinasen sich durch die Bindung der Substrate zusammenlagern und nach der Substratfreisetzung wieder trennen, sodaß das Enzym nach Substratbindung und -freisetzung in unterschiedlichen Konformationen vorliegt (Müller-Dieckmann und Schulz, 1995). Im 
Gegensatz zu den eukaryontischen Guanylatkinasen zeigt die E. coli-Guanylatkinase kooperative Bindung von GMP (Gentry et al., 1993).

\subsubsection{Phosphorylierung von Nukleosidanaloga}

Nukleosid-Analoga spielen in der klinischen Behandlung von bestimmten viralen Infektionen und Krebserkrankungen eine große Rolle, da sie direkt in die DNA-Synthese eingreifen (Forth et al., 1996). Hervorzuheben sind insbesonders die beiden Guaninosin-Analoga Aciclovir (ACV) und Ganciclovir (GCV), welche zunächst speziell zur Bekämpfung von Viren der Herpesgruppe entwickelt wurden, später allerdings auch in der Gentherapie eingesetzt wurden (Moolten et al., 1986). Beide inhibieren die DNA-Synthese auf unterschiedlichem Wege. ACV führt zu einer Termination der Elongation, da mit der acyclischen Seitenkette keine weiteren Nukleotide mehr verknüpft werden können und in GCV führt die Seitengruppe mit dem modifizierten Desoxyribose-Derivat nach Einbau zu einer erhöhten Sensitivität der DNA gegenüber Nukleasen. Um in der Zelle antiviral wirksam zu werden, müssen beide Substanzen zunächst über die Phosphorylierungskaskade in die Triphosphate überführt werden. Während die Phosphorylierung des GCV zum Triphosphat ausschließlich von zelleigenen Nukleosidkinasen, u.a. der Guanylatkinase, katalysiert wird, erfolgt der erste Phosphorylierungsschritt des ACV durch die virale Thymidinkinase (Miller et al., 1980; Boehme, 1984). Diese hohe Selektivität von ACV in viralen Zellen wird in gentherapeutischen Anwendungen ausgenutzt (Moolten et al., 1986) Die Phosphorylierung des Monophosphats durch die NMPkinasen ist häufig der geschwindigkeitsbestimmende Schritt in der Umsetzung von Nukleosid-Analoga (Balzarini et al., 1998; Lavie et al., 1997a). Eine Aufklärung der Struktur und Funktion menschlicher NMPkinasen ist somit die Voraussetzung einerseits zur Entwicklung effizienterer Nukleosid-Analoga andererseits zum Design von Mutanten mit erhöhter Umsatzrate der antiviralen Substanzen (Brundiers et al., 1999). 


\subsection{Membran-assoziierte Guanylatkinasen}

Membran-assoziierte Guanylatkinasen (MAGUKs) wurden als eine neue Familie von Gerüstoder Adapterproteinen an speziellen Kontaktstellen von epithelialen und neuronalen Zellen in verschiedenen Organismen entdeckt. Die Rolle von Gerüstproteinen besteht allgemein darin, verschiedene Komponenten von Signal-Stoffwechselwegen, wie z.B. Plasma-Rezeptoren und cytosolische Signalproteine, in makromolekularen Komplexen zu organisieren und dadurch eine schnelle zelluläre Antwort auf extrazelluläre Signale zu gewährleisten. Durch die Organisation der an Signal-Transduktions-Prozessen beteiligten Proteine in Komplexe wird die Distanz des Transports von Stoffwechselmetaboliten verkürzt, wodurch die Effizienz der Signalübermittlung erhöht wird (Kaech et al., 1998; Tsunoda et al., 1997).

Gerüstproteine zeichnen sich durch einen charakteristischen Aufbau aus, welcher ihre Funktion der Zusammenlagerung von großen Multiprotein-Komplexen unterstreicht. Sie sind zusammengesetzt aus Domänen mit bekannten Protein-Protein-Interaktionsmotiven. $\mathrm{Zu}$ den bekannten Proteinbindungs-Modulen gehören die SH3- (Src-homology 3), die PTB(Phosphotyrosine-binding) und die PDZ- (PSD-95/Dlg/ZO-1) Domäne (Harrison, 1996; Yu et al., 1994; Feng et al., 1994; Tsunoda et al., 1997). Gerüstproteine können sowohl mehrere Kopien einer dieser Module, als auch verschiedene Module besitzen. Eines der bekanntesten Beispiele eines Gerüstprotein ist InaD. InaD setzt sich aus 5 PDZ-Domänen zusammen, mit denen es die Komponenten einer G-Protein gekoppelten Signalkaskade im Photorezeptor von Drosophila zu einem Komplex zusammenführt (Tsunoda et al., 1997).

Membran-assoziierte Guanylatkinasen wurden aufgrund eines homologen strukturellen Aufbaus und der offensichtlichen gemeinsamen Funktion in der Organisation von NeurotransmitterRezeptoren, Ionen-Kanälen, Zelladhäsions-Molekülen und Signaltransduktions-Molekülen in multimolekulare Komplexe zu einer neuen Familie von Adapter-Proteinen zusammengefaßt (Kim, 1995; Anderson, 1996; Garner und Kindler, 1996). Sie wurden in den bisher untersuchten Vielzellern, Drosophila, Caenorhabditis, Xenopus, Zebrafisch und Säugern entdeckt und scheinen sowohl in Vertebraten, als auch in Invertebraten konserviert zu sein (Dimitratos et al., 1999).

MAGUK-Proteine besitzen eine charakteristische Multi-Domänenstruktur und setzen sich aus einer zentralen Einheit von einer bis drei PDZ-Domänen (Kim, 1995; Fanning und Anderson, 1999, Hata et al., 1998; Garner et al., 2000), einer SH3-Domäne (Pawson, 1995; Garner et al., 2000) und einer C-terminalen GK-Domäne (Fanning und Anderson, 1998; Garner et al., 2000) 
mit Strukturhomologie zu authentischen Guanylatkinasen der Hefe und von Säugern (Stehle und Schulz, 1990; Brady et al., 1996) zusammen.

\subsubsection{MAGUK-Subfamilien}

Obwohl alle MAGUK-Proteine einen übereinstimmenden Aufbau aus PDZ-, SH3- und GKDomänen besitzen, können sie aufgrund charakteristischer Unterschiede in vier Subfamilien eingeteilt werden (siehe Abb. 1.6):

\subsubsection{Dlg-ähnliche}

Die Dlg-ähnliche MAGUK-Subfamilie ist nach dem zuerst entdeckten MAGUK-Protein, dem Produkt des Tumorsuppressor-Gens lethal(1)discs-large (dlg) aus Drosophila (Woods und Bryant, 1991) benannt. Das Genprodukt Dlg wurde in den septate junctions der Epithelien von Imaginalscheiben in der Drosophila-Larve identifiziert. Da der Funktionsverlust von Dlg (genetische Dlg-Nullmutante: $d l g^{m 52}$ ) zu der Ausbildung von Tumoren in den Epithelien der Larven führte, wurde ursprünglich vermutet, daß das MAGUK-Protein eine tumorsuppressive Funktion innehat. Die ursprünglich von Woods und Bryant (1991) aufgestellte Hypothese, daß Dlg als aktive Guanylatkinase lokal die Guanylat-Spiegel (erhöhtes GTP:GDP-Verhältnis) in den Epithelzellen regulieren und dadurch indirekten Einfluß auf membrangebundene Komponenten G-Protein-gekoppelter Signalkaskaden, wie z.B. das an der Regulation der Zellproliferation beteiligte G-Protein p2 $1^{\text {ras }}$, Einfluß nehmen könnte, wurden bisher nicht bestätigt.

Alle Mitglieder der Dlg-ähnlichen MAGUK-Subfamilie besitzen eine übereinstimmende Domänen-Struktur: Sie bestehen aus drei PDZ-, einer SH3- und einer GK-Domäne. Weitere Mitglieder der MAGUK-Subfamilie sind die Dlg-Orthologen des Menschen und der Ratte, hDlg (Lue et al., 1994) und SAP97 (Synapse-associated protein97, Müller et al., 1995). hDlg wurde an der lateralen Zellmembran von B-Lymphozyten identifiziert und verfügt ebenso wie SAP97 über eine zusätzliche, zwischen der SH3- und GK-Domäne liegende HOOK-Domäne, welche auch als alternative Spliceregion U5 bekannt ist (Lue et al., 1994). SAP97 ist ebenso wie die weiteren bisher bekannten Mitglieder der MAGUK-Subfamilie SAP90/PSD-95 (Kistner et al., 1993; Cho et al., 1992), SAP102/NE-dlg (Müller et al., 1996) und PSD93/Chapsin-110 (Kim et al., 1996) im Cytoskelett neuronaler Zellen an Synapsen des zentralen Nervensystems von Säugern lokalisiert. SAP90 wurde zuerst in den präsynaptischen Nervenendigungen von inhibitorischen Synapsen im Cerebellum der Ratte entdeckt (Kistner et al., 1993) und konnte 
später, ebenso wie SAP102, im postsynaptischen Cytoskelett von excitatorischen Synapsen im Vorderhirn der Ratte nachgewiesen werden (Müller et al., 1996; Hunt et al., 1996).

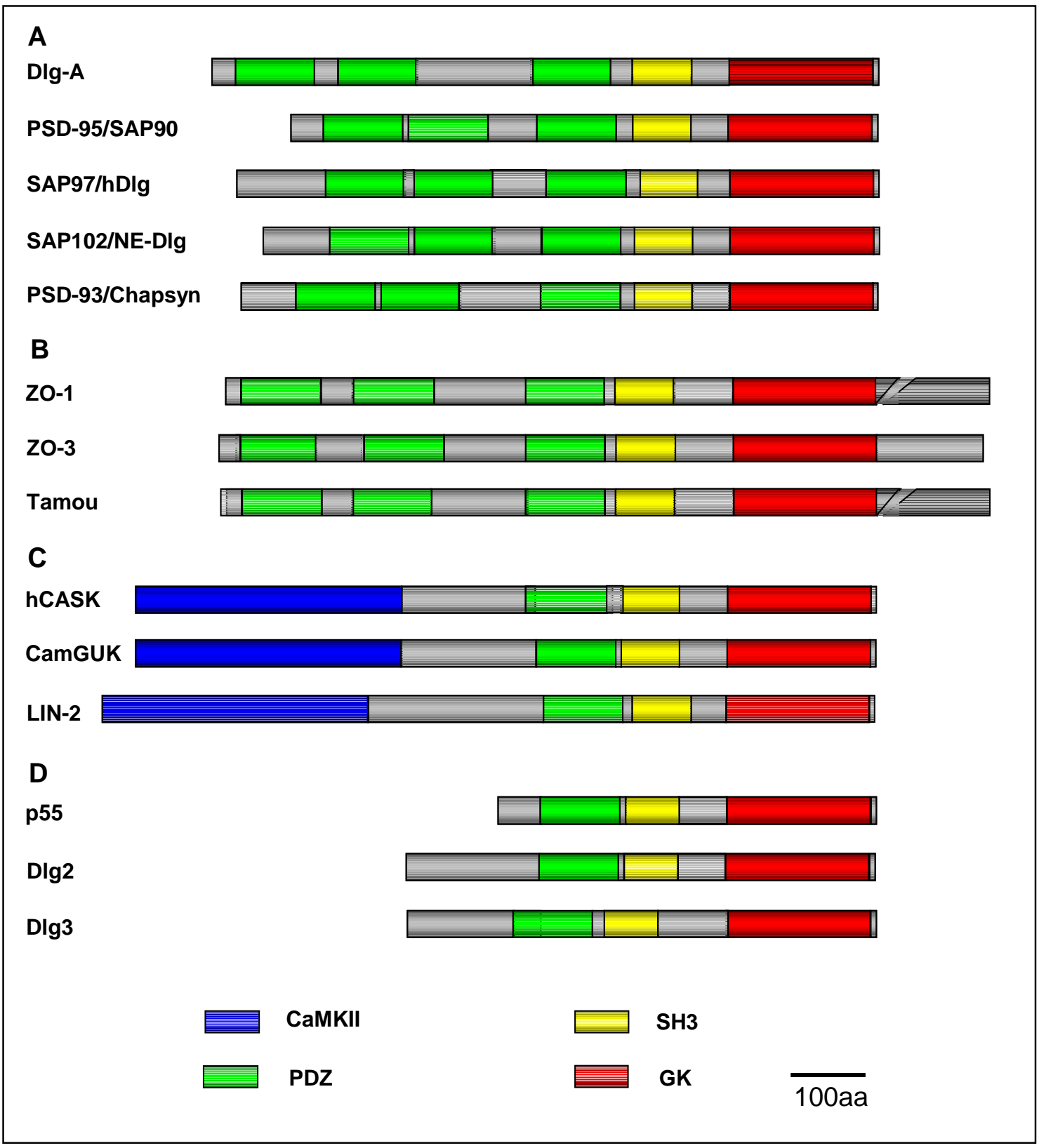

Abb. 1.6 Mitglieder der MAGUK-Proteinfamilie. $A$, Dlg-ähnliche; $B$, ZO-1-ähnliche; $C$, LIN-2-ähnliche; $D$, p55ähnliche. Die unterschiedlichen Domänen sind farblich hervorgehoben: PDZ-Domäne (grün), $\operatorname{src}$-homologe (SH3) Region (gelb); Ca2+/Calmodulin-abhängige Proteinkinase-homologe (CaMKII) Domäne (blau); Guanylatkinasehomologe (GK) Domäne (rot); aa, Aminosäuren

SAP97 wurde bisher sowohl in den präsynaptischen Nervenendigungen von excitatorischen Synapsen im Hippocampus, als auch entlang unmyelinierter Axons im gesamten Nervensystem (Müller et al., 1995) nachgewiesen. Als einziges der vier Synapsen-assoziierten Proteine wurde SAP97 zusätzlich an der lateralen Membran von Epithelzellen nicht neuronaler Gewebe entdeckt (Müller et al., 1995; Reuver und Garner, 1998). Sowohl hDlg, als auch SAP97 können 
den Funktionsverlust von Dlg in Drosophila wieder komplementieren und die Ausbildung von Tumoren der Epithelien supprimieren (Thomas et al., 1997). Die N-terminalen Proteinsequenzen (vor der 1. PDZ-Domäne) sowie Sequenzen der U5-Region von SAP97 und hDlg sind essentiell für die zielgerichtete cytoskeletale Assoziation der Proteine an die laterale Plasmamembran von Epithelzellen (Wu et al., 1998). Während die N-terminale Sequenz vermutlich die Bildung von Multimeren fördert (Marfatia et al., 2000), bindet die U5-Region an das Protein 4.1, einem Bestandteil des corticalen Cytosekeletts. Durch Bildung von cytoskeletalen Komplexen aus Protein 4.1 und Syndecan-2 an der Zellmembran besitzt hDlg vermutlich eine wesentliche Rolle für die Aufrechterhaltung der strukturellen Integrität von Epithelzellen (Cohen et al., 1998). Lue et al. (1994) identifizierten mehrere Splice-Varianten der U5-Region von hDlg. Von diesen war nur ein Teil in der Lage Protein 4.1 zu binden.

\subsubsection{ZO-1-ähnliche}

Die Säugerproteine ZO-1, ZO-2 und ZO-3 (zonula occludens-1 bis -3) und das Protein Tamou aus Drosophila bilden die zweite MAGUK-Subfamilie (Anderson et al., 1988; Jesaitis und Goodenough, 1994; Haskins et al., 1998; Takahisa et al., 1996). Alle vier Proteine liegen assoziiert an der inneren Oberfläche der cytoplasmatischen Membran an den Kontaktstellen epithelialer Zellen, den sog. tight junctions in Säugern und septate junctions in Drosophila vor und bilden Proteinkomplexe mit Komponenten dieser speziellen Regionen der basolateralen Plasmamembran (Furuse et al., 1994; Fanning und Anderson, 1998). Der strukturelle Aufbau der vier Proteine ähnelt jenem der Dlg-ähnlichen-Subfamilie. Auch sie besitzen drei PDZ-, eine SH3- und eine GK-Domäne. Im Gegensatz zu allen anderen MAGUK-Proteinen enthalten die ZO-Proteine dieser Subfamilie eine zusätzliche C-terminale prolinreiche Sequenz. ZO-1, ZO-2 und ZO-3 weichen allerdings in der Länge des C-Terminus stark voneinander ab. Diese Divergenz des C-Terminus deutet auf einen signifikanten Unterschied in der Funktion der drei Proteine hin. Der hohe Grad an Konservierung unter den Proteinen dieser Subfamilie wurde durch Komplementation des Funktionsverlustes von tamou, welcher den sog. supernumerary bristle Phänotyp in Drosophila verursacht, durch ZO-1 dokumentiert (Takahisa et al., 1996).

\subsubsection{3 p55-ähnliche}

Die dritte MAGUK-Subfamilie ist nach dem Protein p55 (Ruff et al., 1991) benannt. Das Protein wurde ursprünglich aus dem submembranen Cytoskelett von Erythrozyten isoliert, ist jedoch auch in anderen Zelltypen lokalisiert. MAGUK-Proteine dieser Subfamilie besitzen neben der SH3- und GK-Domäne nur eine PDZ-Domäne. In Übereinstimmung zu einigen 
MAGUK-Proteinen der ersten Subfamilie interagiert auch p55 über seine HOOK-Domäne mit dem Protein 4.1 (Marfatia et al., 1995). Ebenso wie hDlg scheint demnach auch p55 eine wichtige Funktion in der Verknüpfung des Cytoskeletts mit der Plasmamembran und demzufolge in der Aufrechterhaltung der Zellstruktur von Erythrozyten zu besitzen (Marfatia et al., 1997). Weitere Mitglieder dieser Subfamilie sind Dlg2 und Dlg3. Beide Proteine zeigen einen hohen Konservierungsgrad in der Aminosäuresequenz zu p55 (Mazoyer et al., 1995; Smith et al., 1996).

\subsubsection{Lin2-ähnliche}

Die vierte Subfamilie der MAGUK-Proteine besteht aus strukturhomologen Proteinen von Lin2 aus Caenorhabditis elegans. Lin-2 wurde in den Interzellularspalten von vulvalen Vorläuferzellen während der epidermalen Entwicklung entdeckt (Hoskins et al., 1996). Die ursprüngliche Modellvorstellung, nach der Lin-2 zusammen mit Lin-7 und Lin-10 einen Komplex bildet, der für die Verankerung der Rezeptor-Tyrosinkinase LET-23 in der basolateralen Membran der epidermalen Vorläuferzellen erforderlich ist, wurde später durch genetische und biochemische Studien von Kaech et al. (1998) bestätigt. Mutationen im lin2Gen haben eine diffuse Verteilung des LET23-Rezeptors zur Folge mit dem Ergebnis, daß eine Signaltransduktion (über den Ras-MAPkinase-Weg) nicht mehr stattfinden kann und die vulvale Entwicklung inhibiert wird (Hoskins et al., 1996). Der C-Terminus von Lin-2-ähnlichen MAGUKs setzt sich aus einer PDZ-, einer SH3- und einer GK-Domäne zusammen und ähnelt folglich dem strukturellen Aufbau p55-ähnlicher MAGUK-Proteine. Allen Mitgliedern dieser Subfamilie gemeinsam ist darüberhinaus der Besitz einer zusätzlichen N-terminalen Domäne mit hoher Sequenzähnlichkeit zur $\mathrm{Ca}^{2+} / \mathrm{CaM}$-abhängigen Proteinkinase II (CaMKII; Schulman, 1993). Die CaMKII-Domäne ist katalytisch nicht mehr aktiv, die Fähigkeit zur Bindung von Calmodulin ist aber dennoch konserviert (Hata et al., 1996; Dimitratos et al., 1997). Weitere Proteine dieser MAGUK-Subfamilie sind die Lin-2-Orthologen des Menschen und der Ratte, hCASK (Cohen et al., 1998) und rCASK (Hata et al., 1996), sowie CamGUK (Dimitratos et al., 1997) aus Drosophila. Das Säugerproteine rCASK wurde durch Interaktion mit Neurexin auf der präsynaptischen Seite neuronaler Synapsen identifiziert (Hata et al., 1996). Durch biochemische Studien konnten Butz et al. (1998) zeigen, daß die im Säugerhirn lokalisierten Lin-2-, Lin-7- und Lin-10-Homologen rCASK, Veli und Mint-1 sich ebenfalls zu einem Komplex zusammenlagern (siehe Abb. 1.8). Der Lin-2/-7/-10-Komplex ist folglich von Nematoden bis zu Säugern konserviert. 


\subsubsection{MAGUK-Domänen}

MAGUK-Proteine können mit jeder ihrer verschiedenen Domänen spezifisch mit Proteinen interagieren:

\subsubsection{PDZ-Domäne}

PDZ-Domänen sind Protein-Protein-Bindungsmotive von etwa 90 AS Länge, die zuerst in MAGUK-Proteinen entdeckt, mittlerweile allerdings als Bestandteile einer stetig anwachsenden Zahl von Proteinen identifiziert wurden (Fanning und Anderson, 1998; Garner et al., 2000). Der Bindungsmechanismus der PDZ-Domänen von MAGUK-Proteinen ist bisher im Vergleich zur SH3- und GK-Domäne am eingehendsten untersucht worden. PDZ-Domänen binden primär an den cytoplasmatischen C-Terminus von spezifischen Transmembran- und Ionenkanal-Proteinen. Mit biochemischen und genetischen Methoden wurde beispielsweise die Bindung der ersten und zweiten PDZ-Domänen von Dlg-ähnlichen MAGUKs an den $\mathrm{K}^{+}$-Kanal nachgewiesen (Kim et al., 1995; Tejedor et al., 1997). Als weiterer Bindungspartner dieser Subfamilie wurde darüberhinaus der NMDA-Rezeptor identifiziert (Niethammer et al., 1996). PDZ-Domänen zeichnen sich einerseits untereinander durch eine hohe Sequenzähnlichkeit und einen übereinstimmenden strukturellen Aufbau aus, weichen andererseits dennoch derart signifikant voneinander $a b$, daß eine selektive Bindung an die spezifischen Zielproteine ermöglicht wird. Durch Kristallstrukturanalysen (Cabral et al., 1996; Doyle et al., 1996) und mit biochemischen Bindungsassays (Songyang et al., 1997) konnte gezeigt werden, daß PDZ-Domänen an spezifische Sequenzmotive binden. Dlg-ähnliche MAGUK-Proteine favorisieren Bindungspartner mit einem C-terminalen $\mathrm{E}(\mathrm{S} / \mathrm{T}) \mathrm{X}(\mathrm{V} / \mathrm{I})$-Motiv, während Lin-2-ähnliche MAGUKs bevorzugt an EYYV-Motive und p55-ähnliche MAGUKs an EYFI-Motive binden (Songyang et al., 1997). PDZ-Domänen können auch miteinander interagieren, wie durch den Nachweis der Hetero-Dimer-Bildung von der zweiten PDZ-Domäne von SAP90/PSD-95 und der PDZ-Domäne der neuronalen NO-Synthase nNOS gezeigt wurde (Brenman et al., 1996).

\subsubsection{SH3-Domäne}

SH3- (Src homology 3) Domänen sind kleine Protein-Protein-Bindungsmodule von etwa 60 Aminosäuren Länge, welche spezifisch an kurze (7-9 AS) prolinreiche Sequenzen binden. Sie wurden ursprünglich in Src-Tyrosinkinasen entdeckt, sind bis heute allerdings bereits in mehr als 50 verschiedenen intrazellulären Proteinen identifiziert worden, unter ihnen Kinasen, Lipasen und GTPasen (Pawson, 1995). SH3-Domänen können in unterschiedlicher Orientierung an prolinreiche Sequenzen binden. Deshalb werden die Liganden der SH3-Domäne allgemein in 
2 Klassen unterteilt. Liganden der Klasse 1 besitzen die Consensussequenz RXLPPZP (X, jede Aminosäure; Z, Leu oder Arg), Liganden der Klasse 2 die Sequenz XPPLPXR (Feng et al., 1994). Durch Aufklärung der Kristallstrukturen mehrerer SH3-Domänen in Komplex mit prolinreichen Peptiden und Proteinen wurde der Mechanismus der SH3-Ligandenbindung weitestgehend aufgeklärt (Musacchio et al., 1992; Yu et al.,1994; Lee et al., 1996). Neben ihrer strukturellen Rolle als Liganden-Bindungsdomäne besitzt die SH3-Domäne eine wichtige regulatorische Funktion in Signalproteinen. In Src-Rezeptor-Tyrosinkinasen inhibiert sie im Zusammenspiel mit der SH2-Domäne die enzymatische Aktivität der C-terminalen KinaseDomäne. Während die SH2-Domäne an das C-terminale Phosphotyrosin bindet, interagiert die SH3-Domäne mit einem untypischen Klasse 2-ähnlichen Polyprolin-Motiv der Linkerregion zwischen der SH2 und der Kinase-Domäne. (Sicheri et al., 1997; Xu et al., 1997 ; Moarefi et al., 1997). Durch intramolekulare Bindung der SH3- und SH2-Domänen an die Kinase-Domäne umgebende Sequenzen wird die Kinase-Aktivität reprimiert. Liganden-Bindung an die SH3Domäne führt zur Aufhebung der intramolekularen Interaktion mit der Linkerregion und zu einer Reaktivierung der Kinase-Aktivität.

Im Gegensatz zu den Signalproteinen ist die Funktion der SH3-Domäne in MAGUKs noch nicht ausreichend erforscht. Bisher wurde mit der Kainatrezeptor-Untereinheit KA2 erst ein Bindungspartner der SH3-Domäne von SAP90/PSD-95 identifiziert (Garcia et al., 1998). Die charakteristische Anordnung der SH3-Domäne in direkter Nachbarschaft zur GK-Domäne in MAGUK-Proteinen kann ein Hinweis dafür sein, daß in diesen Proteinen ein ähnlicher intramolekularer Regulationsmechanismus existiert.

\subsubsection{GK-Domäne}

Die C-terminale GK-Domäne der MAGUK-Proteine besitzt eine hohe Sequenzähnlichkeit zu den authentischen, kleinen Guanylatkinasen von Säugern. Der Sequenzvergleich mit enzymatisch aktiven Guanylatkinasen zeigt jedoch, daß die GK-Domäne der MAGUK-Proteine in den Motiven der Substratbindungsregion zum Teil signifikant von den Enzymen abweicht (siehe Abb. 1.7). Auch Mitglieder der verschiedenen Subfamilien untereinander zeigen eine auffällige Divergenz insbesondere in der ATP-Bindungsregion, dem P-Loop. Während die p55ähnlichen und die Lin-2-ähnlichen MAGUK-Proteine auf den ersten Blick vollständig konservierte ATP- und GMP-Bindungsregionen zu besitzen scheinen, sind in dem P-Loop von Dlg- und ZO-1-ähnlichen MAGUK-Proteinen drei Aminosäuren deletiert. Im Vergleich zu den Dlg-ähnlichen MAGUKs fehlen der Gruppe ZO-1-ähnlicher MAGUKs darüberhinaus essentielle Reste zur Bindung von GMP. Aufgrund der strukturellen Abweichungen von 
authentischen Guanylatkinasen, insbesondere des Fehlens von für die Katalyse essentiellen Aminosäuren muß eine enzymatische Funktion der MAGUKs in Frage gestellt werden. Von den bisher untersuchten MAGUK-Proteinen konnte auch einzig in rekombinant in Bakterien überexprimiertem GST-p55 Fusionsprotein eine schwache katalytische GuanylatkinaseAktivität nachgewiesen werden. Diese war jedoch um den Faktor 190 schwächer als jene von Säuger-Guanylatkinasen (Marfatia und Chisti, 1995).

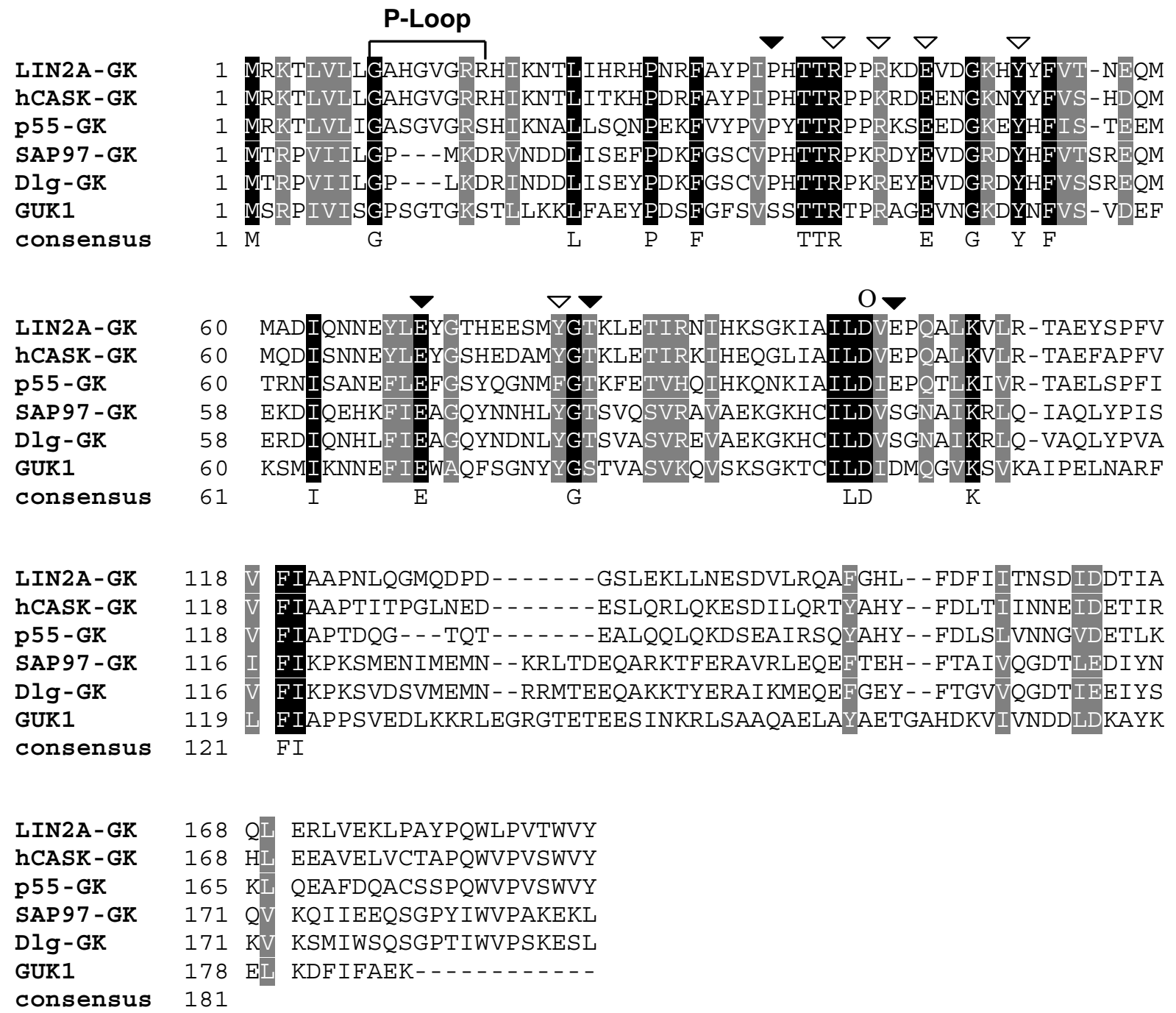

Abb. 1.7 Sequenzvergleich von GK-Domänen verschiedener MAGUK-Proteine. Der P-Loop ist das ATPBindungsmotiv, welches mit dem $\beta$ - und $\gamma$-Phosphat des Substrats ATP interagiert. Aminosäuren, die mit dem Guaninring $(\boldsymbol{\nabla})$, der Phosphatgruppe $(\nabla)$ von GMP und dem komplexierten $\mathrm{Mg}^{2+}$-Ion $(\mathrm{O})$ interagieren, sind markiert. Die Konsensus-Sequenz gibt diejenigen Aminosäuren an, die in allen dargestellten Sequenzen konserviert sind. Schwarze Box, identische Aminosäuren; graue Box, konservative Substitutionen.

Als GST-Fusionsproteine aus Bakterien aufgereinigte Dlg-ähnliche MAGUKs SAP90, SAP97 und hDlg sind hingegen enzymatisch inaktiv (Kistner und Garner, 1995; Kuhlendahl et al., 1998). Darüberhinaus wurde in weiteren Arbeiten gezeigt, daß SAP97 den Verlust der Guanylatkinase in S. cerevisiae in vivo nicht komplementieren kann (Kuhlendahl et al., 1998; 
Spangenberg, 1997). Die physiologische Bedeutung der Guanylatkinase-Aktivität von p55 ist bisher nicht bekannt. Einiges spricht jedoch dafür, daß die hypothetische schwache Guanylatkinase-Aktivität für die Funktion der p55-ähnlichen MAGUK-Proteine von eher untergeordneter Rolle ist. So konnten Hoskins et al. (1996) beispielsweise zeigen, daß eine Mutante von Lin-2, in der mehrere an der Bindung von GMP beteiligte hochkonservierte Aminosäuren in der GK-Domäne ausgetauscht wurden, weiterhin während der vulvalen Differenzierung in C. elegans funktionell blieb.

Die Entdeckung von Bindungspartnern der GK-Domäne von SAP90/PSD-95 und weiteren Mitgliedern der Dlg-ähnlichen Subfamilie führte zu einer vollkommen veränderten Definition ihrer Rolle in MAGUK-Proteinen. $\mathrm{Zu}$ diesen Interaktionspartnern zählen die Mitglieder der GKAP/SAPAP/DAP1 Familie, die durch Hefe-Zwei-Hybrid-Screen als spezifische Bindungsproteine der GK-Domäne von SAP90/PSD-95 von drei Forschungsgruppen unabhängig identifiziert wurden (Kim et al., 1997; Takeuchi et al., 1997; Satoh et al., 1997). Alle Mitglieder sind im postsynaptischen cortikalen Cytoskelett neuronaler Zellen lokalisiert und haben wahrscheinlich ebenfalls die Funktion von Gerüstproteinen, welche ihrerseits makromolekulare Komplexe mit dem Cytoskelett oder cytosolischen Signalproteinen verknüpfen. Weitere Bindungspartner der GK-Domäne von MAGUK-Proteinen der Dlgähnlichen Subfamilie sind das an Mikrotubuli dendritischer Zellen assoziierte Protein MAP1A (Brenman et al., 1998) und das im Säugerhirn lokalisierte Protein BEGAIN (Deguchi et al., 1998), dessen Funktion bisher noch ungeklärt ist. Die Entdeckung von Interaktionspartnern der GK-Domäne läßt den Schluß zu, daß diese in MAGUKs eine evolutive Veränderung vollzogen hat, in deren Verlauf sie ihre ursprünglich enzymatische Funktion verloren und sich zu einer Domäne mit struktureller Funktion entwickelt hat.

\subsubsection{Funktion von MAGUKs am Beispiel von CASK und PSD-95}

Die bisherigen Kenntnisse weisen auf eine duale Funktion von MAGUK-Proteinen hin. Einerseits scheinen sie durch Interaktion mit Komponenten des Cytoskeletts und Zelladhäsionmolekülen eine wichtige Funktion in der Stabilisierung der Zellstruktur und der Aufrechterhaltung der Morphologie von Zell-Zell-Kontaktstellen zu spielen. Andererseits gewährleisten sie durch Aggregation und Lokalisation von Rezeptoren und Ionenkanälen, sowie Signalproteinen, die effiziente Signaltransduktion an diesen speziellen Kontaktstellen. Exemplarisch für die Funktion von MAGUK-Proteinen kann die synergistische Rolle von PSD95/SAP90 und rCASK an Synapsen des zentralen Nervensystems der Ratte angesehen werden. Beide MAGUKs binden mit ihren PDZ-Domänen Neuronen-spezifische 
Transmembranproteine: CASK bindet an Neurexine und PSD-95 an Neuroligine (Hata et al., 1996; Irie et al., 1997). Durch Interaktion der extrazellulären Domänen von Neurexinen und Neuroliginen werden neuronale Kontaktstellen gebildet und stabilisiert (Nguyen und Südhof, 1997).

Auf Grundlage der Kenntnisse der Funktion der beiden MAGUK-Proteine CASK und PSD-95 als Adapterproteine in der Bildung von makromolekularen Komplexen an diesen neuronalen Kontaktstellen entwickelten Südhof und Mitarbeiter ein Modell, welches zu einem besseren Verständnis der synaptischen Plastizität führte (siehe Abb. 1.8; Butz et al., 1998). Demnach rekrutiert rCASK mit seiner N-terminalen CaMKII-Domäne das am Vesikeltransport beteiligte Protein Mint-1 und bindet mit der nachfolgenden Domäne an das Protein Veli, welches ein potentieller Bindungspartner von Rezeptor-Tyrosinkinasen ist.

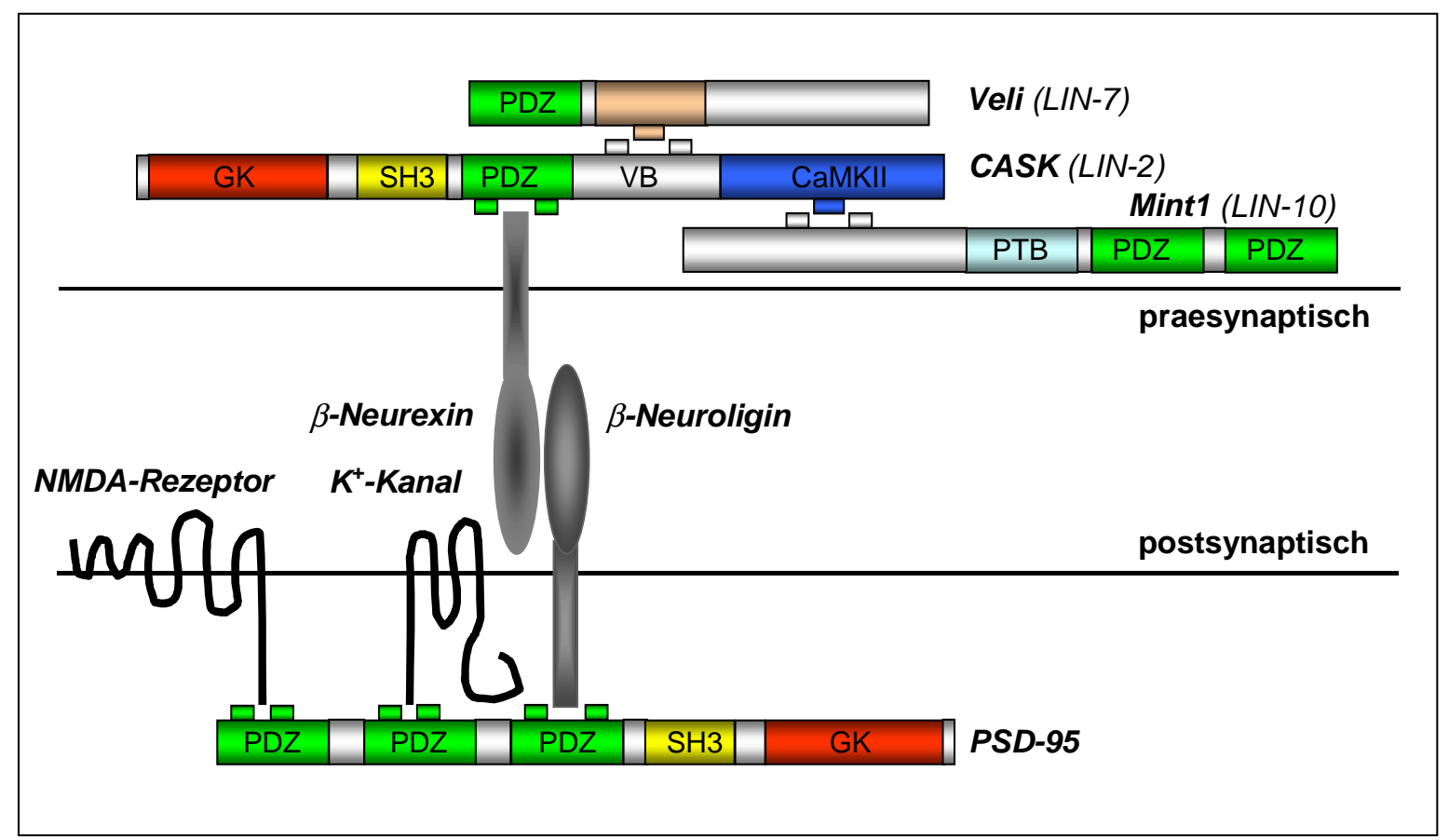

Abb. 1.8 Modell der Funktion von CASK und PSD-95 an Synapsen. Durch Rekrutierung und Bindung von intrazellulären und Transmembranproteinen tragen CASK und PSD-95 zur Ausbildung der asymmetrischen Morphologie an den neuronalen Kontaktstellen bei. Veli- und Mint-1 sind die Säugerhomologen von Lin-7 und Lin-10 aus Caenorhabditis. Der Lin-2/Lin-7/Lin-10-Komplex ist konserviert von Nematoden bis zu Säugern. Der NMDA-Rezeptor konkurriert mit dem $\mathrm{K}^{+}$-Kanal um die Bindung an die zweite PDZ-Domäne von PSD-95. Im Gegensatz zu dem präsynaptischen Komplex ist der ternäre Komplex aus PSD-95, NMDA-Rezeptor und $\mathrm{K}^{+}$-Kanal experimentell nicht bewiesen. Die C-Termini beider MAGUKs liegen frei vor und können mit cytoskeletalen Proteinen interagieren (verändert nach Butz et al., 1998).

In Analogie zur Funktion von CASK auf der präsynaptischen Seite rekrutiert PSD-95 mit der ersten und zweiten PDZ-Domäne NMDA-Rezeptoren und $\mathrm{K}^{+}$-Kanäle auf der postsynaptischen Seite. Über die Neurexin-Neuroligin-Wechselwirkung werden die Komplexe auf der prä- und postsynaptischen Seite der Synapse verankert. Die C-terminalen Domänen SH3, U5 und GK 
beider MAGUK-Proteine liegen frei vor und können ihrerseits durch Interaktionen mit Komponenten des Cytoskeletts den Komplex an der Plasmamembran mit dem Cytoskelett verknüpfen. Nach diesem Modell sind MAGUK-Proteine direkt an der Bildung der asymmetrischen Morphologie von Synapsen beteiligt (Butz et al., 1998).

Die bisherigen Kenntnisse von MAGUK-Proteinen deuten auf eine wichtige Funktion der Proteine als Organisatormoleküle makromolekularer Komplexe an speziellen Zell-ZellKontaktstellen hin, dennoch ist der zugrundeliegende molekulare Mechanismus zum großen Teil noch unbekannt. Die Präsenz von Domänen mit ursprünglich enzymatischen Funktionen zusätzlich zu bekannten Protein-Protein-Interaktionsdomänen weist den MAGUK-Proteinen eine Sonderrolle unter den bisher bekannten Gerüstproteinen, wie z.B. InaD zu. Auch wenn MAGUK-Proteine enzymatisch nicht mehr aktiv sind, könnten sie dennoch durch Bindung der ursprünglichen Substratmoleküle regulativ in Stoffwechselwege eingreifen. Es ist beispielsweise vorstellbar, daß MAGUK-Proteine durch Bindung von Nukleotiden die Funktion von Komponenten des Signal-Stoffwechsels modulieren. Auf eine potentielle regulatorische Funktion der GK-Domäne wurde bereits in früheren Arbeiten an Dlg hingewiesen (Hough et al., 1997). Deletionen der gesamten GK-Domäne sowie der letzten 32 Aminosäuren von Dlg führten beide zu einem Defekt in der Zusammenlagerung neuromuskulärer Verbindungen und zu einem Verlust der Proliferationskontrolle epithelialer Zellen. Jedoch waren die Phänotypen unterschiedlich stark ausgeprägt, wobei unerwarteterweise die Deletion der gesamten GKDomäne in $d l g^{v 52}$ eher dem Wildtyp entsprach, als die C-terminale Verkürzung in $d l g^{s w}$. Hough et al. (1997) folgerten aus diesen Beobachtungen, daß die GK-Domäne eine negativ regulatorische Rolle innerhalb des MAGUK-Proteins besitzt, infolgedessen sie die Funktion Nterminaler Domänen in Dlg inhibiert, was zu dem Verlust der Proliferationskontrolle in den tight junctions epithelialer Zellen führt. Sollte sich die Hypothese der regulatorischen Funktionen einzelner Domänen innerhalb der MAGUK-Proteine bestätigen, so ergäbe sich daraus weiterführend die Frage, ob diese die intermolekularen Interaktionen der einzelnen Domänen mit ihren Bindungspartnern beeinflußen. In Analogie zu der Familie der RezeptorTyrosinkinasen wäre es möglich, daß auch in MAGUK-Proteinen eine intramolekulare Interaktion der SH3 und GK-Domäne vorliegt und daß dadurch die Zugänglichkeit für etwaige Bindungspartner in trans, z.B. GKAP, reguliert wird. 


\subsection{Zielsetzung}

Die derzeitigen Kenntnisse der Struktur- und Funktion von Guanylatkinasen basieren beinahe ausschließlich auf dem Hefeenzym. Ein Schwerpunkt dieser Arbeit war deshalb die biochemische und kinetische Charakterisierung von weiteren Guanylatkinasen anderer Organismen, unter ihnen Enzyme aus Säugern und einer Pflanze. Darüberhinaus sollten die Voraussetzungen für die Auflösung der Kristallstruktur, insbesondere der therapeutisch relevanten Guanylatkinase des Menschen, geschaffen werden. $\mathrm{Zu}$ einem weiteren Verständnis der Funktion der Guanylatkinase in vivo sollten kinetische Untersuchungen an natürlich vorkommenden Mutanten der Hefe-Guanylatkinase beitragen.

Ein zweiter Schwerpunkt dieser Arbeit hatte zum Ziel eine hypothetische regulatorische Funktion der GK-Domäne in Membran-assoziierten Guanylatkinasen zu identifizieren. Hierzu sollten zunächst die GK-Domänen der zwei strukturell unterschiedlichen Vertreter dieser Proteinfamilie SAP97 und hCASK rekombinant aus E. coli aufgereinigt und anschließend biochemisch charakterisiert werden. Unter der Voraussetzung, daß die GK-Domänen beider Proteine katalytisch nicht aktiv sind, sollte in einem weiteren Schritt die NukleotidbindungsEigenschaften dieser MAGUKs untersucht und mögliche Liganden identifiziert werden. Zur Aufklärung einer hypothetischen intramolekularen Regulation der GK-Domäne durch sie umgebende Sequenzen (SH3, HOOK und C-Terminus) sollte versucht werden durch Ersatz der GK-Domäne gegen die authentische Hefe-Guanylatkinase in C-terminalen Konstrukten von SAP97 ein Sensormolekül zu konstruieren. Das Ziel weiterer biophysikalischer Ansätze war es einerseits, die Rolle der physiologisch relevanten letzten Aminosäuren des C-Terminus von SAP97 und andererseits den Einfluß von zuvor identifizierten Liganden auf die Konformation der C-terminalen SAP97-Fusionskonstrukte zu untersuchen.

In einem dritten Schwerpunkt dieser Arbeit sollte auf Basis des Modell-Systems Hefe die Grundlage für ein in vivo-Selektionssystem geschaffen werden, das es auf relativ einfache Weise gestattet, Proteine mit Guanylatkinase-Aktivität zu finden. 


\section{Material}

\subsection{Escherichia coli-Stämme}

\begin{tabular}{|c|c|c|}
\hline Stamm & Merkmale & Quelle \\
\hline XL1-Blue & $\begin{array}{l}\mathrm{F}^{-}:: T n 10 / \text { proA }^{+} B^{+} \text {lacl }^{q} \Delta(\text { lacZ }) M 15 / \text { recAl endAl } \\
\left.\text { gyrA96(Nal }{ }^{r}\right) \text { thi-, hsdR17 }\left(\mathrm{r}_{\mathrm{K}}{ }^{-} \mathrm{m}_{\mathrm{K}}^{+}\right) \text {supE44 relA1 lac }\end{array}$ & Bullock et al., 1987 \\
\hline DH5 $\alpha$ & $\begin{array}{l}\left.\text { F/endAl hsdR17( } \mathrm{r}_{\mathrm{K}}^{-} \mathrm{m}_{\mathrm{K}}^{+}\right) \text {supE44 thi-1 recAl gyrA } \\
\left(\mathrm{Nal}^{r}\right) \text { relA1 } \Delta(\text { lacZYA-argF) U169 (m80lacZAM15) }\end{array}$ & $\begin{array}{l}\text { Gibco BRL } \\
\text { (Eggenstein) }\end{array}$ \\
\hline BL21(DE3) & $\begin{array}{l}\mathrm{F}^{-} \text {ompT [Ion] } h s d S_{B}\left(r_{B}^{-} m_{B}^{-} \text {; ein E.coli B-Stamm) mit }\right. \\
\text { DE3, ein } \square \text {-Prophage, der das T7-RNA-Polymerasegen } \\
\text { trägt }\end{array}$ & Studier et al., 1990 \\
\hline C41(DE3) & $\begin{array}{l}\text { Gleicher Genotyp wie BL21(DE3), mit reduzierter T7- } \\
\text { RNA-Polymerase Aktivität, 10fach geringere Menge an } \\
\text { mRNA-Transkript }\end{array}$ & $\begin{array}{l}\text { Miroux und Walker, } \\
1996\end{array}$ \\
\hline $\begin{array}{l}\text { BL21- } \\
\text { Codon+(DE3) }\end{array}$ & $\begin{array}{l}\mathrm{F}^{-} \text {ompT hsdS }\left(\mathrm{r}_{\mathrm{B}}^{-} \mathrm{m}_{\mathrm{B}}^{-}\right) d c m^{+} \mathrm{Tet}^{\mathrm{r}} \text { gald (DE3) endA Hte } \\
{\left[\arg U \text { ileY leuW } \mathrm{Cam}^{r}\right]}\end{array}$ & $\begin{array}{l}\text { Strategene } \\
\text { (La Jolla) }\end{array}$ \\
\hline
\end{tabular}

\subsection{Saccharomyces cerevisiae-Stämme}

\begin{tabular}{|c|c|c|}
\hline Stamm & Merkmale & Quelle \\
\hline AG430 & MATa/ $\alpha$, his3/his3, leu2/leu2 & Konrad, 1992 \\
\hline $\mathrm{AG} 430 \Delta \mathrm{GUK} 1$ & MATa/o, GUK1/guk1::HIS3, his3/his3, leu2/leu2 & Konrad, 1992 \\
\hline $\mathrm{AG} 430 \Delta \mathrm{ADK} 1$ & MATa/ $\alpha$, ADK1/adk1::LEU2, his3/his3, leu2/leu2 & Konrad, 1988 \\
\hline $\mathrm{AG} 215 \Delta \mathrm{ADK} 1$ & MATo, adk1::LEU2, his3, leu2 & diese Arbeit \\
\hline $\mathrm{AH} 215 \Delta \mathrm{NDK} 1$ & MATa, $n d k 1:: K A N^{R}$, his3, leu2 & diese Arbeit \\
\hline $\begin{array}{l}\mathrm{AGH} 430 \Delta \mathrm{ADK} 1 / \\
\Delta \mathrm{NDK} 1\end{array}$ & $\begin{array}{l}\text { MATa/ } \alpha, \text { ADK1/adk1::LEU2, NDK1/ndk1::KAN } \\
\text { his3/his3, leu2/leu2 }\end{array}$ & diese Arbeit \\
\hline PLY122 & MATa, leu2, lys2, ura3 & Lecoq et al., 2000 \\
\hline 129 & 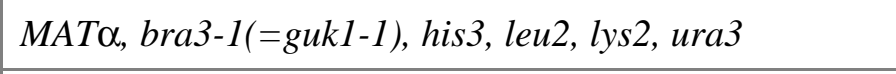 & Lecoq et al., 2000 \\
\hline 123 & 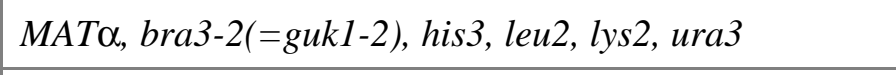 & Lecoq et al., 2000 \\
\hline 220 & MATa, bra3-3(=guk1-3), leu2, lys 2, ura3 & Lecoq et al., 2000 \\
\hline 239 & 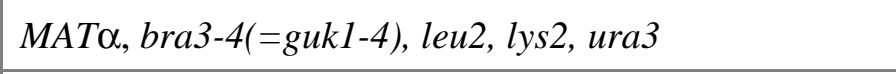 & Lecoq et al., 2000 \\
\hline AGP430 & $\begin{array}{l}\text { MATa/o, GUK1/guk1-3, NDK1/ndk1::KAN }{ }^{R} \text {, his3/HIS3, } \\
\text { LEU2/leu2, LYS2/lys2, URA3/ura3 }\end{array}$ & diese Arbeit \\
\hline YNS3-7A & MATa, och1::LEU2, mnn1, leu2, ura3, his 1 , his 3 & Shimma et al., 1997 \\
\hline NE759-11A & 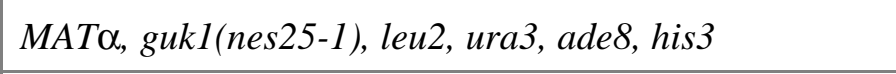 & Shimma et al., 1997 \\
\hline RC989 & MATa, bar1-1, sst2-1, leu1, trp5, ade2, can1 & H. Riezman, Basel \\
\hline
\end{tabular}




\section{$2.3 \quad$ Plasmide}

Escherichia coli-Vektoren:

\begin{tabular}{|c|c|c|}
\hline Plasmid & Beschreibung & Quelle \\
\hline \multicolumn{3}{|l|}{ Vektoren } \\
\hline pJC20 & Expressionsvektor & Clos et al., 1990 \\
\hline pJC20[HisN] & Expressionsvektor & T. Schüle, Göttingen \\
\hline pJC20[HisC $]$ & Expressionsvektor & T. Schüle, Göttingen \\
\hline pGEX-KG & Expressionsvektor & S. Albert, Göttingen \\
\hline pGEX-RB & Expressionsvektor & R. Brundiers, Göttingen \\
\hline pMAL-c2 & Expressionsvektor & New England Biolabs (Schwalbach) \\
\hline \multicolumn{3}{|l|}{ Guanylatkinasen } \\
\hline $\mathrm{pJC} 20-G U K 1$ & Expressionsvektor & T. Schüle, Göttingen \\
\hline PFL61-AGUK1 & Expressionsvektor & Kumar et al., 2000 \\
\hline pJC20[HisN]-GUK1 & Expressionsvektor & T. Schüle, Göttingen \\
\hline pJC20[HisN]-GUK1.1 $(\Delta N d e I)$ & Expressionsvektor & T. Schüle, Göttingen \\
\hline pJC20[HisN]-GUK1.1( $\triangle N d e I)(E 69 Q, D 100 N)$ & Expressionsvektor & T. Schüle, Göttingen \\
\hline pJC20[HisC]-GUK1.1(nes25-1) & Expressionsvektor & diese Arbeit \\
\hline pJC20[HisC]-GUK1.1( $\Delta N d e I)$ & Expressionsvektor & T. Schüle, Göttingen \\
\hline pJC20[HisC]-GUK1.1( $\Delta N d e I)(P 10 L)$ & Expressionsvektor & diese Arbeit \\
\hline pJC20[HisC]-GUK1.1( $\Delta N d e I)(G 12 S)$ & Expressionsvektor & diese Arbeit \\
\hline $\mathrm{pJC} 20[\mathrm{HisC}]-G U K 1.1(\Delta N d e I)(R 132 K)$ & Expressionsvektor & diese Arbeit \\
\hline pJC20[HisC]-hGUK & Expressionsvektor & Spangenberg, 1997 \\
\hline pJC20[HisC]- $m G U K$ & Expressionsvektor & Spangenberg, 1997 \\
\hline pGEX-2TN-GUKl & Expressionsvektor & diese Arbeit \\
\hline pGEX-RB- $h G U K$ & Expressionsvektor & diese Arbeit \\
\hline pGEX-RB-mGUK & Expressionsvektor & diese Arbeit \\
\hline pGEX-RB-AGUK1 & Expressionsvektor & diese Arbeit \\
\hline pGEX-RB-AGUK1(NC) & Expressionsvektor & diese Arbeit \\
\hline pGEX-RB-AGUK2 & Expressionsvektor & diese Arbeit \\
\hline pMAL-c2.1( $\Delta N d e I)-H s T K$ & Expressionsvektor & R. Brundiers, Göttingen \\
\hline pMAL-c2-AGUK1 & Expressionsvektor & diese Arbeit \\
\hline pMAL-c2-AGUK1(NC) & Expressionsvektor & diese Arbeit \\
\hline pMAL-c2-AGUK2 & Expressionsvektor & diese Arbeit \\
\hline \multicolumn{3}{|l|}{ Guanylatkinase-Homologe } \\
\hline pBluescriptII KS(+) & Klonierungsvektor & Stratagene, La Jolla, USA \\
\hline pBluescriptII KS(+)-SAP97 & Klonierungsvektor & $\begin{array}{c}\text { C.C. Garner, University of Alabama at } \\
\text { Birmingham, USA }\end{array}$ \\
\hline
\end{tabular}




\begin{tabular}{|c|c|c|}
\hline pCR2.3-hCASK & Klonierungsvektor & Cohen et al., 1998 \\
\hline pJC20-SAP97-GK(+22N) & Expressionsvektor & Spangenberg, 1997 \\
\hline pJC20-SAP97-GK(P-Loop) & Expressionsvektor & Spangenberg, 1997 \\
\hline pJC20[HisC $]-S A P 97-G K(+22 N)$ & Expressionsvektor & Spangenberg, 1997 \\
\hline pJC20[HisC]-SAP97-GK(P-Loop) & Expressionsvektor & Spangenberg, 1997 \\
\hline pJC20[HisC]-SAP97( $\Delta G K)$ & Expressionsvektor & Spangenberg, 1997 \\
\hline pJC20[HisC]-GUK1 $1^{s w}$ & Expressionsvektor & Spangenberg, 1997 \\
\hline pGEX-KG-SAP97( $\Delta G K)$ & Expressionsvektor & diese Arbeit \\
\hline pGEX-RB-SAP97-SH3/GK1(560-911) & Expressionsvektor & diese Arbeit \\
\hline pGEX-RB-SAP97-SH3/GK2(575-911) & Expressionsvektor & diese Arbeit \\
\hline pGEX-RB-SAP97-SH3/GK3(582-911) & Expressionsvektor & diese Arbeit \\
\hline pGEX-RB-SAP97-SH3/GK1( $\triangle C)(560-899)$ & Expressionsvektor & diese Arbeit \\
\hline pGEX-RB-SAP97-SH3/GK2( $\triangle C)(575-899)$ & Expressionsvektor & diese Arbeit \\
\hline pGEX-RB-SAP97-SH3/GK3( $\triangle C)(582-899)$ & Expressionsvektor & diese Arbeit \\
\hline pGEX-RB-SAP97-GK & Expressionsvektor & diese Arbeit \\
\hline pGEX-RB-SAP97-GK(P-Loop, ST) & Expressionsvektor & diese Arbeit \\
\hline pGEX-RB-SAP97-GK(P-Loop, ST, S100D) & Expressionsvektor & diese Arbeit \\
\hline $\begin{array}{l}\text { pGEX-RB-SAP97-GK(P-Loop, } S T, P 34 S \text {, } \\
S 100 D)\end{array}$ & Expressionsvektor & diese Arbeit \\
\hline pGEX-RB-GU/97C & Expressionsvektor & diese Arbeit \\
\hline pGEX-RB-SAP97-SH3/GUK1(560-918) & Expressionsvektor & diese Arbeit \\
\hline pGEX-RB-SAP97-SH3/GUK2(575-918) & Expressionsvektor & diese Arbeit \\
\hline pGEX-RB-SAP97-SH3/GUK3(582-918) & Expressionsvektor & diese Arbeit \\
\hline pGEX-RB-SAP97-SH3/GUK1( $\triangle C)(560-906)$ & Expressionsvektor & diese Arbeit \\
\hline pGEX-RB-SAP97-SH3/GUK2( $\Delta C)(575-906)$ & Expressionsvektor & diese Arbeit \\
\hline pGEX-RB-SAP97-SH3/GUK( $\Delta C)(582-906)$ & Expressionsvektor & diese Arbeit \\
\hline pGEX-RB-GUKI $1^{s w}$ & Expressionsvektor & diese Arbeit \\
\hline pGEX-RB- $h C A S K-G K^{s w}$ & Expressionsvektor & diese Arbeit \\
\hline pGEX-RB- $h C A S K-G K$ & Expressionsvektor & diese Arbeit \\
\hline pGHEB-GKAP & Expressionsvektor & $\begin{array}{c}\text { C.C. Garner, University of Alabama at } \\
\text { Birmingham, USA }\end{array}$ \\
\hline
\end{tabular}

Saccharomyces cerevisiae - Pendelvektoren:

\begin{tabular}{|l|c|c|}
\hline \multicolumn{1}{|c|}{ Plasmid } & Beschreibung & Quelle \\
\hline YEp512N & $\begin{array}{c}2 \mu \text {-Expressionsvektor GAL10- } \\
\text { Promoter, LEU2-Markergen }\end{array}$ & T. Schüle, Göttingen \\
\hline YEp512N-GUK1 & $\begin{array}{c}2 \mu \text {-Expressionsvektor GAL10- } \\
\text { Promoter, LEU2-Markergen }\end{array}$ & T. Schüle, Göttingen \\
\hline
\end{tabular}




\begin{tabular}{|c|c|c|}
\hline YEp512N-hGUK & $\begin{array}{l}2 \mu \text {-Expressionsvektor GAL10- } \\
\text { Promoter, LEU2-Markergen }\end{array}$ & $\begin{array}{c}\text { M. Black, Darwin Molecular Corp., } \\
\text { Washington, USA }\end{array}$ \\
\hline YEp512N-mGUK & $\begin{array}{l}2 \mu \text {-Expressionsvektor GAL10- } \\
\text { Promoter, LEU2-Markergen }\end{array}$ & $\begin{array}{c}\text { M. Black, Darwin Molecular Corp., } \\
\text { Washington, USA }\end{array}$ \\
\hline YEp512N-AGUK1(137-330) & $\begin{array}{l}2 \mu \text {-Expressionsvektor GAL10- } \\
\text { Promoter, } L E U 2 \text {-Markergen }\end{array}$ & diese Arbeit \\
\hline YEp512N-S.c.ADK1 & $\begin{array}{l}2 \mu \text {-Expressionsvektor GAL10- } \\
\text { Promoter, LEU2-Markergen }\end{array}$ & diese Arbeit \\
\hline YEp512N-H.s.AK & $\begin{array}{l}2 \mu \text {-Expressionsvektor GAL10- } \\
\text { Promoter, LEU2-Markergen }\end{array}$ & diese Arbeit \\
\hline YEp512N-SAP97-GK & $\begin{array}{l}2 \mu \text {-Expressionsvektor GAL10- } \\
\text { Promoter, LEU2-Markergen }\end{array}$ & diese Arbeit \\
\hline YEp512N-SAP97-GK(P-Loop) & $\begin{array}{l}2 \mu \text {-Expressionsvektor GAL10- } \\
\text { Promoter, LEU2-Markergen }\end{array}$ & diese Arbeit \\
\hline $\begin{array}{l}\text { YEp512N-SAP97-GK(P-Loop, } \\
S T, P 34 S, S 100 D)\end{array}$ & $\begin{array}{l}2 \mu \text {-Expressionsvektor GAL10- } \\
\text { Promoter, LEU2-Markergen }\end{array}$ & diese Arbeit \\
\hline YEp512N-GU97C & $\begin{array}{l}2 \mu \text {-Expressionsvektor GAL10- } \\
\text { Promoter, LEU2-Markergen }\end{array}$ & diese Arbeit \\
\hline YEp512N-hCASK-GK & $\begin{array}{l}2 \mu \text {-Expressionsvektor GAL10- } \\
\text { Promoter, LEU2-Markergen }\end{array}$ & diese Arbeit \\
\hline pCM189(URA3) & $\begin{array}{c}\mathrm{CEN}, \mathrm{ADH} 1\left(\text { tet }_{7}\right) \text {-Promoter, } \\
\text { URA3-Markergen }\end{array}$ & Gari et al., 1997 \\
\hline pCM189-GUK1(URA3) & $\begin{array}{c}\mathrm{CEN}, \mathrm{ADH} 1\left(\text { tet }_{7}\right) \text {-Promoter, } \\
\text { URA3-Markergen }\end{array}$ & diese Arbeit \\
\hline pCM189(LEU2) & $\begin{array}{c}\mathrm{CEN}, \mathrm{ADH} 1\left(\text { tet }_{7}\right) \text {-Promoter, } \\
\text { LEU2-Markergen }\end{array}$ & diese Arbeit \\
\hline pCM189-GUK1(LEU2) & $\begin{array}{c}\mathrm{CEN}, \mathrm{ADH} 1\left(\text { tet }_{7}\right) \text {-Promoter, } \\
\text { LEU2-Markergen }\end{array}$ & diese Arbeit \\
\hline pCM189-GUK1(K15R) & $\begin{array}{c}\mathrm{CEN}, \mathrm{ADH} 1\left(\text { tet }_{7}\right) \text {-Promoter, } \\
\text { LEU2-Markergen }\end{array}$ & diese Arbeit \\
\hline pCM189-GUK1(E69Q, D100N) & $\begin{array}{c}\mathrm{CEN}, \mathrm{ADH} 1\left(\text { tet }_{7}\right) \text {-Promoter, } \\
\text { LEU2-Markergen }\end{array}$ & diese Arbeit \\
\hline pUL9 $\left(L E U 2-K A N^{R}\right)$ & $\begin{array}{l}\text { Marker Swap Plasmid } \\
\quad(U R A 3 \rightarrow L E U 2)\end{array}$ & Cross, 1997 \\
\hline pUG6 & mit loxP-kanMX-loxP-Kassette & Güldener et al., 1996 \\
\hline
\end{tabular}

\subsection{Oligonukleotide}

Die verwendeten Oligonukleotide wurden bei der Firma NAPS in Göttingen in Auftrag gegeben. Es wurde in aller Regel ein Synthesemaßstab von $0,05-0,2 \mu$ mol gewählt.

\begin{tabular}{|l|l|l|}
\hline \multicolumn{1}{|c|}{ Bez. } & Sequenz des Oligonukleotids & \multicolumn{1}{c|}{ Zweck } \\
\hline Vektoren & $5^{-}$- CGT AAT ACG ACT CAC TAT AG-3'- & T7-Primer \\
\hline OSP7 & $5^{-}$-GAG TCG AAG GAA AGC CCG-3'- & ФT-Primer \\
\hline OSP8 & $5^{-}$-GGG CTG GCA AGC CAC GTT TGG TG-3'- & pGEX-5'-Primer \\
\hline OSP10
\end{tabular}




\begin{tabular}{|c|c|c|}
\hline OSP11 & $5^{-}$-CCG GGA GCT GCA TGT GTC AGA GG-3- & pGEX-3'-Primer \\
\hline OSP40 & $5^{-}-\mathrm{CGC}$ AGA CTA ATT CGA GCT CG-3- & pMAL-5'-Primer \\
\hline OSP41 & $5^{-}-\mathrm{GCG}$ ATT AAG TTG GGT AAC GC-3- & pMAL-3'-Primer \\
\hline \multicolumn{3}{|c|}{ Guanylatkinasen } \\
\hline OSP116 & $\begin{array}{l}5^{-}-\text {GGG CCC CAT ATG TCC CGT CCT ATC GTA } \\
\text { ATT TCT GG-3 }\end{array}$ & GUK1-NdeI-5' \\
\hline OSP117 & $\begin{array}{l}5^{-}-\mathrm{CGC} \text { GGA TCC TCA TTT TTC TGC AAA GAT } \\
\text { AAA ATC }{\mathrm{C}-3^{-}}^{-}\end{array}$ & GUK1-BamI-3' \\
\hline OSP118 & $\begin{array}{l}5^{-}-\mathrm{CGC} \text { GGA TCC TTT TTC TGC AAA GAT AAA } \\
\text { ATC C-3- }^{-}\end{array}$ & GUK1-BamII-3' \\
\hline OSP108 & 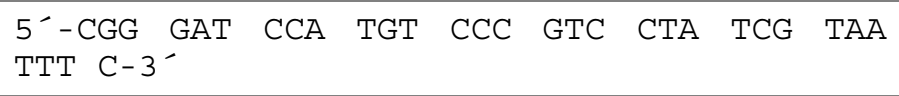 & GUK1-BamHI-5 \\
\hline OSP109 & $\begin{array}{l}5^{-}-\mathrm{AAC} \text { TGC AGT CAT TTT } \\
\text { AAA }^{-1 C}-3^{-}\end{array}$ & GUK1-PstI-3' \\
\hline OSP38 & $\begin{array}{l}5^{-}-\mathrm{CAA} \text { GCT GAA TTG GCA TAC GCT GAG ACA } \\
\text { GGT GCC C-3- }\end{array}$ & GUK1 $(\Delta \mathrm{NdeI})-5^{\prime}$ \\
\hline OSP39 & $\begin{array}{l}5^{-}-\text {GGG CAC CTG TCT CAG CGT ATG CCA ATT } \\
\text { CAG CTT G-3- }\end{array}$ & GUK1( $(\Delta$ NdeI $a n t i)-3^{\prime}$ \\
\hline OSP99 & $\begin{array}{l}5^{-} \text {-GGA ATT CCA TAT GTC CCG TCC TAT CGT } \\
\text { AAT TTC TGG CTT AAG TGG TAC AGG-3- }\end{array}$ & GUK1(P10L)-Nde1-5' \\
\hline OSP37 & $\begin{array}{l}5^{-} \text {-GGA ATT CCA TAT GTC } \\
\text { AAT TTC TGG CCC AAG TAG TAC TGG } \\
\text { TAC-3 }^{-}\end{array}$ & GUK1(G12S)-Nde1-5' \\
\hline OSP53 & $\begin{array}{l}5^{-}-\text {GGA ATT CCA TAT GTC } \\
\text { AAT TTC TGG CCC AAG TGG TAC AGG } \\
\text { TAC ACT G-3- }\end{array}$ & GUK1(K15R)-Nde1-5' \\
\hline OSP102 & 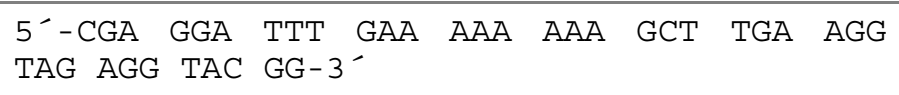 & GUK1(R132K)-5' \\
\hline OSP103 & $\begin{array}{l}5^{-}-\mathrm{CCG} \text { TAC CTC TAC CTT CAA GCT TTT TTT } \\
\text { TCA AAT CCT CG-3- }\end{array}$ & GUK1(R132K)-3' \\
\hline OSP15 & $\begin{array}{l}5^{-}-\mathrm{GGA} \text { ATT CCA TAT GTC GGG CCC CAG GCC } \\
\text { TGT GG-3- }\end{array}$ & hGUK-NdeI-5' \\
\hline OSP16 & $\begin{array}{l}5^{-}-\mathrm{CGC} \text { GGA TCC GGC GCC GGT CCT TTG AGC } \\
\text { TTT C-3 }\end{array}$ & hGUK-BamII-3' \\
\hline OSP16a & $\begin{array}{l}5^{-}-\mathrm{CGC} \text { GGA TCC TTA GGC GCC GGT CCT TTG } \\
\text { AGC TTT C-3- }\end{array}$ & hGUK-BamI-3' \\
\hline OSP17 & $\begin{array}{l}5^{-}-\mathrm{GGA} \text { ATT CCA TAT GGC AGG ACC TAG GCC } \\
\text { AGT AG-3 }\end{array}$ & mGUK-NdeI-5' \\
\hline OSP18 & $\begin{array}{l}5^{-}-\mathrm{CGC} \text { GGA TCC GGC GTG GCC AGT TCC CTG } \\
\text { TGC- } 3^{-}\end{array}$ & mGUK-BamII-3' \\
\hline OSP18a & $\begin{array}{l}5^{-}-\mathrm{CGC} \text { GGA TCC TTA GGC GTG GCC AGT TCC } \\
\text { CTG TGC-3- }^{-}\end{array}$ & mGUK-BamI-3' \\
\hline OSP47 & $\begin{array}{l}5^{-}-\mathrm{GGA} \text { ATT CCA TAT GGG AGA AGC TCC AGC } \\
\text { AGT ATT AG-3 }^{-}\end{array}$ & AGUK1-NdeI-5 \\
\hline OSP48 & $\begin{array}{l}5^{-}-\text {CGC GGA TCC CTA GAA CTT AAT GGC GTC G- } \\
3^{-}\end{array}$ & AGUK1-BamI-3' \\
\hline OSP42 & $5^{-}$-GGA ATT CCA TAT GGA GAA GCC TAT TG-3- & AGUK1(137N)-NdeI-5' \\
\hline OSP82 & $5^{-}-\mathrm{CGC}$ GGA TCC TCA TTC TAC ACC ATT G-3- & AGUK1(330C)-BamI-3' \\
\hline
\end{tabular}




\begin{tabular}{|c|c|c|}
\hline OSP49 & $\begin{array}{l}5^{-}-\mathrm{GGA} \text { ATT CCA TAT GGG AGA AGC ACC AGC } \\
\text { TTT C-3 }\end{array}$ & AGUK2-NdeI-5' \\
\hline OSP50 & $\begin{array}{l}5^{-}-\mathrm{CGC} \text { GGA TCC TCA ACT GGA CTT AAC CGT } \\
\text { GTC }{\mathrm{C}-3^{-}}^{-}\end{array}$ & AGUK2-BamI-3' \\
\hline \multicolumn{3}{|c|}{ Guanylatkinase-Homologe } \\
\hline OSP12 & 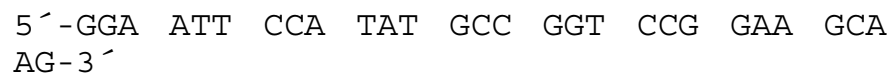 & SAP97-PDZ1-3/SH3-NdeI-5' \\
\hline OSP13 & $\begin{array}{l}5^{-}-\mathrm{CGC} \text { GGA TCC ATA ATT AAC TTC TTG CTG } \\
\text { ATT-3 }^{-}\end{array}$ & SAP97-PDZ1-3/SH3-BamI-3' \\
\hline OSP4 & $\begin{array}{l}5^{-}-\mathrm{CCT} \text { GAC AAA TTT GGC AGC TGT GTC CCT C- } \\
3^{-}\end{array}$ & SAP97-GK $\left(\Delta \mathrm{BamHI}^{\prime}\right)^{\prime}$ \\
\hline OSP5 & $\begin{array}{l}5^{-}-\mathrm{GAG} \text { GGA CAC AGC TGC CAA ATT TGT CAG G- } \\
3^{-}\end{array}$ & SAP97-GK( $\Delta{\text { BamHIanti })-3^{\prime}}^{\prime}$ \\
\hline OSP2 & 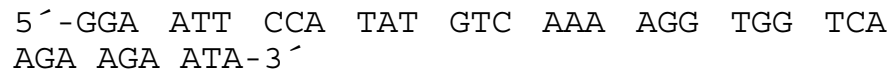 & SAP97-GK(+22N)-NdeI-5' \\
\hline OSP3 & $\begin{array}{l}5^{-}-\mathrm{GGA} \text { ATT CCA TAT GAC CCG ACC AGT CAT } \\
\text { CAT ATT AG-3 }\end{array}$ & SAP97-GK-NdeI-5' \\
\hline OSP1 & $\begin{array}{l}5^{-}-\mathrm{CGC} \text { GGA TCC AGA CTG CTC TTC TAT GAT } \\
\text { CTG CTT-3- }\end{array}$ & SAP97-GK-BamII-3' \\
\hline OSP25 & $\begin{array}{l}5^{-}-\mathrm{CGC} \text { GGA TCC TCA AGA CTG CTC TTC TAT } \\
\text { GAT CTG CTT-3- }\end{array}$ & SAP97-GK-BamI-3' \\
\hline OSP115 & 5--CGC GGA TCC TCA TAA TTT TTC TTT TGC-3- & SAP97-GK ${ }^{\text {SW }}$-BamI-3' \\
\hline OSP6 & $\begin{array}{l}5^{-}-\text {GGA ATT CCA TAT GAC } \\
\text { CAT ATT AGG ACC TAG } \\
\text { CAG AGT AAA TG-3- }\end{array}$ & $\begin{array}{l}\text { SAP97-GK(P-Loop)- } \\
\text { NdeI-5' }^{\prime}\end{array}$ \\
\hline OSP74 & $\begin{array}{l}5^{-}-\text {GGA ATT CCA TAT GAC } \\
\text { CAT ATT AGG ACC TAG TGG TAC AGG } \\
\text { TAC AGT AAA TGA TG-3 }\end{array}$ & $\begin{array}{l}\text { SAP97-GK(D16S, R17T)- } \\
\text { NdeI-5' }^{\prime}\end{array}$ \\
\hline OSP97 & $5^{-}$-GGC AGC TGT GTC TCT CAT ACA ACT AG-3- & SAP97-GK(P34S)-5' \\
\hline OSP98 & $5^{-}$-CTA GTT GTA TGA GAG ACA CAG CTG CC-3- & SAP97-GK(P34S)-3' \\
\hline OSP95 & $5^{-}$-CCT TGA TGT CGA CGG AAA TGC C-3- & SAP97-GK(S100D)-5' \\
\hline OSP96 & $5^{-}$-GGC ATT TCC GTC GAC ATC AAG G-3- & SAP97-GK(S100D)-3' \\
\hline OSP110 & $\begin{array}{l}5^{-}-\mathrm{GGA} \text { ATT CCA TAT GCG GGA GAC GAT GAT G- } \\
3^{-}\end{array}$ & SAP97-SH3/GK1-NdeI-5' \\
\hline OSP111 & $5^{-}-\mathrm{GGA}$ ATT CCA TAT GCT CCG AAC CAG $\mathrm{C}^{-} 3^{-}$ & SAP97-SH3/GK2-NdeI-5' \\
\hline OSP112 & $5^{-}-\mathrm{GGA}$ ATT CCA TAT GTC CCT CTA TGT CAG-3- & SAP97-SH3/GK3-NdeI-5' \\
\hline OSP113 & $\begin{array}{l}5^{-}-\mathrm{CAG} \text { CAA GAA GTT AAT TAT TCC CGT CCT } \\
\text { ATC GT-3 }\end{array}$ & SAP97-SH3/GUK1-5' \\
\hline OSP114 & $\begin{array}{l}5^{-}-\mathrm{ACG} \text { ATA } \text { GGA } \text { CGG GAA TAA TTA ACT } \\
\text { TGC TG } \text { TG }^{-}\end{array}$ & SAP97-SH3/GUK1-3' \\
\hline OSP9 & $\begin{array}{l}5^{-}-\mathrm{CGC} \text { GGA TCC TAA TTT } \\
\text { GAC CCA GAT GTA } \text { TGG ATC } \\
\text { GAT AAA ATC-3 }\end{array}$ & GUK $1^{\text {SW }}$-BamII-3' \\
\hline OSP125 & $5^{-}-\mathrm{AGT}$ GTT TCA TCC ACA ACT AGA CC-3- & GU/97C-5' \\
\hline OSP126 & $5^{-}-\mathrm{GGT}$ CTA GTT GTG GAT GAA ACA CT-3- & GU/97C-3' \\
\hline OSP54 & $5^{-}$-GGA ATT CCA TAT GAG GAA AAC ACT AG-3- & hCASK-GK-NdeI-5' \\
\hline OSP59 & $\begin{array}{l}5^{-}-\mathrm{CGC} \text { GGA TCC CTA GCA CAC GAG CTC AAC } \\
\text { AG- }^{-}\end{array}$ & hCASK-GK-BamI-3' \\
\hline
\end{tabular}




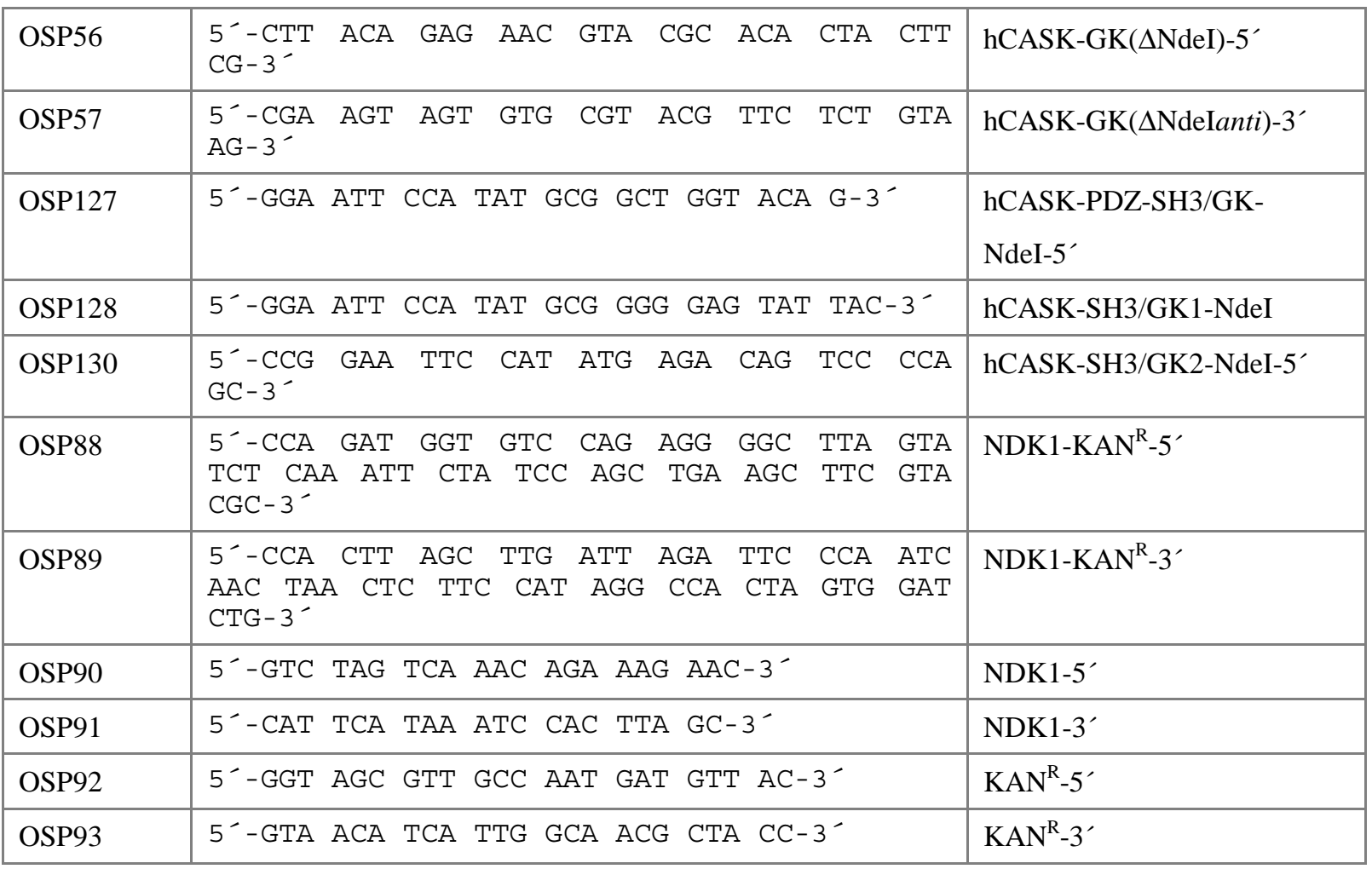

\subsection{Enzyme und Kits}

B-Glucuronidase/Arylsulfatase aus Helix pomatia von Boehringer (Mannheim)

$P f u$-DNA-Polymerase und $P f x$-DNA-Polymerase von Stratagene (La Jolla, USA)

Pwo-DNA-Polymerase von Boehringer (Mannheim)

AmpliTaq-DNA-Polymerase von Roche (Branchburg, USA)

Zymolyase-6000 aus Arthrobacter luteus von Seikagaku Kogyo Company (Tokyo, Japan)

Lysozym von Serva (Heidelberg)

Lytikase (Grad: "partially purified") aus Arthrobacter luteus von Sigma (Deisenhofen)

T4-DNA-Ligase und alkalische Phosphatase (aus Kälberdarm) von Boehringer (Mannheim)

Restriktionsendonukleasen von Boehringer (Mannheim), New England Biolabs (Schwalbach) und Promega (Heidelberg)

Pyruvatkinase und Lactatdehydrogenase von Boehringer (Mannheim)

JETstar Plasmid Purification Kit von Genomed (Bad Oeynhausen)

QIAprep Spin Miniprep Kit von Qiagen (Düsseldorf)

QIAquick PCR Purification Kit von Qiagen (Düsseldorf)

QIAquick Gel Extraction Kit von Qiagen (Düsseldorf)

QuikChange Site-directed Mutagenesis Kit von Stratagene (La Jolla, USA)

Protein Refolding-Kit von Novagen (Madison, USA)

TA-Cloning Kit von Invitrogen (Carlsbad, USA)

ECL Western Blotting Detection Kit von Amersham-Buchler (Buckinghamshire, England)

\subsection{Chemikalien und Medienzusätze}

Es wurden handelsübliche Chemikalien der Qualitätsstufe p.A. der Firmen J. T. Baker (Deventer, Holland), Serva (Heidelberg), Merck AG (Darmstadt) und Sigma-Aldrich (Deisenhofen) verwendet. Zusätzlich wurden spezielle Chemikalien von folgenden Firmen bezogen:

Farbmarkierter Protein-Molekulargewichtsstandard („,Rainbow-standard“) von Amersham Buchler (Braunschweig) sowie Benchmark Protein Ladder von GibcoBRL (Karlsruhe)

Isopropyl-ß-D-thiogalaktopyranosid (IPTG) von Biomol (Ilvesheim)

Desoxynukleosidtriphosphate (dNTP Master Mix) von Eurogentec (Seraing, Belgien) 
Adenosin-5'-Triphosphat (ATP), Nukleosidmonophosphate (NMPs), Nicotinsäureamid-AdeninDinukleotid (NADH), Phosphoenolpyruvat (PEP), reduziertes Glutathion und Rinderserumalbumin (BSA) von Sigma (Deisenhofen) $\left[\alpha^{32} \mathrm{P}\right]$ ATP $(3000 \mathrm{Ci} / \mathrm{mmol}),\left[\alpha^{32} \mathrm{P}\right]$ GTP $(3000 \mathrm{Ci} / \mathrm{mmol}),\left[{ }^{3} \mathrm{H}\right]$ AMP $(30 \mathrm{Ci} / \mathrm{mmol}),\left[{ }^{3} \mathrm{H}\right] \mathrm{cAMP}$ $(28 \mathrm{Ci} / \mathrm{mmol}),\left[{ }^{3} \mathrm{H}\right] \mathrm{cGMP}(12 \mathrm{Ci} / \mathrm{mmol})$ von ICN (Eschwege)

$\left[{ }^{3} \mathrm{H}\right] \mathrm{GMP}$ von Hartmann (Göttingen)

Szintillationsflüssigkeiten Filter-Count und Ultima Gold von Packard (Groningen, Niederlande)

Nickel-NTA-Harz von Qiagen (Düsseldorf)

Glutathion Sepharose 4B von Pharmacia Biotech (Freiburg)

Amylose-Harz von New England Biolabs (Schwalbach)

Flüssiger Stickstoff von Messer/Griesheim (Kassel)

Agar Bacteriological, Select Pepton 140 und Select Yeast Extract von GibcoBRL (Karlsruhe)

Yeast Nitrogen Base w/o Amino Acids von Difco (Detroit, USA)

Ampicillin Natriumsalz von Appli Chem, Biolith Diagnostica (Göttingen), Geneticin G418 von

Calbiochem (Schwalbach), Doxycyclin und Kanamycin von Sigma (Deisenhofen)

Adeninsulfat und Uracil von Merck AG (Darmstadt)

Aminosäuren (Adenin-Sulfat, L-Histidin, L-Leucin, L-Prolin, L-Tryptophan, Uracil) von Serva (Heidelberg)

\subsection{Verbrauchsmaterialien}

Allgemeine Glaswaren von Schütt (Göttingen)

Polypropylenröhrchen und Falcon-Tubes von Becton Dickinson (Heidelberg)

Reaktionsgefäße von Eppendorf (Hamburg)

Kulturschalen von Nunc (Wiesbaden) Reaktionsgefäße von Eppendorf (Hamburg)

Elektroporationsküvetten von Invitrogen (Carlsbad, USA)

Nitrocellulose-Membranfilter $(2,5 \mathrm{~cm}, 0,45 \mu \mathrm{m})$ und Nylon-Membranfilter NY13 Nitran von Schleicher und Schuell (Dassel)

Röntgenfilme X-Omat AR von Eastman Kodak (Rochester, USA)

\subsection{Geräte}

Analytische Ultrazentrifuge Optima XL-A von Beckmann Instruments (Fullerton, USA)

Autoklav, Sanoclav von Wolf (Geislingen)

Brutschränke von Heraeus (Hanau)

Eppendorf-Thermomixer und Eppendorf-Tischzentrifuge 5415 von Schütt (Göttingen)

Elektroporationsgerät von Biorad (Richmond, USA)

Gleichgewichts-Dialysegerät EMD101B von Pharmacia (Freiburg)

Inkubationsschüttler von New Brunswick (Edison, USA)

Lumi-Imager mit Software Lumi-Analyst von Boehringer (Mannheim)

Mikromanipulator von Singer Instruments (Watchet, England)

Mikroskope von Leitz (Wetzlar) und Zeiss (Göttingen)

PCR-Gerät Hybaid Omn-E von MWG-Biotech (Ebersberg)

PCR-Gerät RoboCycler 40 Gradient von Stratagene (La Jolla, USA)

Photometer Uvikon 810 und 943 Double Beam UV/VIS Spectrophotometer von BIO-TEK (Neufahrn)

PAGE-Gel-Elektrophoresekammern, Mini-PROTEAN 3 Cell von Biorad (Richmond, USA)

Röntgenfilmentwicklungsmaschine Gevamatik 60 von AGFA Gevaert (Hannover)

Sterilbank von Heraeus (Hanau)

Szintillationszähler 1500 Tri-Carb von Packard-Instrument Company (Meriden, USA)

Transilluminatoren (302 und 366nm) von Bachofer (Reutlingen)

Ultraschallgerät, Branson Sonifier Modell 250 von G. Heinemann (Schwäb.-Gmünd)

Zentrifugen Sorvall RC-5B, RC-3B und Rotoren von DuPont Instruments (Bad Homburg) 


\subsection{Lösungen und Puffer}

Analytische Plasmidisolierung aus E. coli:

$\begin{array}{lll}\text { E1-Lösung: } & \begin{array}{l}50 \mathrm{mM} \\ 10 \mathrm{mM} \\ 100 \mu \mathrm{g} / \mathrm{ml}\end{array} & \begin{array}{l}\text { Tris } \mathrm{HCl}, \mathrm{pH} 8 \\ \text { EDTA } \\ \text { RNase } \\ \text { bei } 4{ }^{\circ} \mathrm{C} \text { lagern }\end{array} \\ & \begin{array}{l}\text { SDS } \\ 1 \%(\mathrm{w} / \mathrm{v})\end{array} & \begin{array}{l}\mathrm{NaOH} \\ 0,2 \mathrm{M}\end{array} \\ \text { E2-Lösung: } & 5 \mathrm{M} & \begin{array}{l}\text { Kaliumacetat mit } 5 \mathrm{M} \text { Essigsäure auf } \\ \mathrm{pH} 4,8 \text { eingestellt }\end{array}\end{array}$

Gebräuchliche Puffer zur DNA-Analyse:

TE-Puffer:

$\begin{array}{ll}10 \mathrm{mM} & \text { Tris/HCl, pH 8,0 } \\ 1 \mathrm{mM} & \text { EDTA }\end{array}$

Phenol/Chloroform-Lösung

$25 \mathrm{vol}$

Phenol, pH 8,0

24 vol

Chloroform

$1 \mathrm{vol}$

Isoamylalkohol

Natriumacetat-Lösung:

$3 \mathrm{M}$

Natriumacetat mit Essigsäure auf $\mathrm{pH}$ 5,2 eingestellt

DNA-Auftragspuffer $(10 \mathrm{x})$ :

$\begin{array}{ll}30 \%(\mathrm{w} / \mathrm{v}) & \text { Ficoll (Typ 400) } \\ 0,25 \%(\mathrm{w} / \mathrm{v}) & \text { Bromphenolblau } \\ 0,25 \%(\mathrm{w} / \mathrm{v}) & \text { Xylencyanol } \\ 0,5 \mathrm{M} & \text { EDTA, pH 8,0 }\end{array}$

TAE-Puffer (20 x):

$\begin{array}{ll}800 \mathrm{mM} & \text { Tris-HCl, pH 8,0 } \\ 400 \mathrm{mM} & \text { Natriumacetat } \\ 20 \mathrm{mM} & \text { EDTA }\end{array}$

Dephosphorylierungs-Puffer (10x):

$\begin{array}{ll}10 \mathrm{mM} & \text { Tris- } \mathrm{HCl}, \mathrm{pH} 7,9 \\ 50 \mathrm{mM} & \mathrm{NaCl} \\ 10 \mathrm{mM} & \mathrm{MgCl}_{2} \\ 1 \mathrm{mM} & \text { DTT }\end{array}$

dNTP-Mix:

je 2,5 mM dATP, dCTP, dGTP und dTTP

Klenow-Puffer (10x):

$\begin{array}{ll}0,5 \mathrm{M} & \text { Tris-HCl, } \mathrm{pH} \mathrm{7,2} \\ 0,1 \mathrm{M} & \mathrm{MgCl}_{2} \\ 1 \mathrm{mM} & \text { DTT }\end{array}$

Herstellung von kompetenten E. coli-Zellen:
LiAc-Lösung:
$0,2 \mathrm{M}$
Lithiumacetat in TE-Puffer
PEG-Lösung:
$40 \%(\mathrm{w} / \mathrm{v}) \quad$ PEG 6000
0,1 M LiAc-Lösung 
Herstellung von kompetenten $S$. cerevisiae-Zellen:

Medium A:

$10 \mathrm{mM}$

$\mathrm{MgSO}_{4}$

$0,2 \%$

Glukose

in LB-Medium

Lösung B:

$\begin{array}{ll}36 \%(\mathrm{v} / \mathrm{v}) & \text { Glycerin } \\ 12 \%(\mathrm{v} / \mathrm{v}) & \mathrm{PEG} 8000 \\ 12 \mathrm{mM} & \mathrm{MgSO}_{4}\end{array}$

in LB-Medium, $\mathrm{pH}$ 7,0; sterilfiltrieren

SDS-PAGE-Gelelektrophorese:

\begin{tabular}{|c|c|c|}
\hline 30\% Acrylamid-Stammlösung: & $\begin{array}{l}30 \%(\mathrm{w} / \mathrm{v}) \\
0,8 \%(\mathrm{w} / \mathrm{v})\end{array}$ & $\begin{array}{l}\text { Acrylamid } \\
\text { N,N'-Methylenbisacrylamid }\end{array}$ \\
\hline Ammoniumpersulfat-Lösung: & $10 \%(\mathrm{w} / \mathrm{v})$ & Ammoniumpersulfat \\
\hline 4 x Tris-HCl-Lösung, $\mathrm{pH}$ 6,8: & $\begin{array}{l}0,5 \mathrm{M} \\
0,4 \%(\mathrm{w} / \mathrm{v})\end{array}$ & $\begin{array}{l}\text { Tris-HCl, pH } 6,8 \\
\text { SDS } \\
\text { Lösung bei } 4^{\circ} \mathrm{C} \text { lagern }\end{array}$ \\
\hline 4 x Tris-HCl-Lösung, $\mathrm{pH} 8,8$ : & $\begin{array}{l}1,5 \mathrm{M} \\
0,4 \%(\mathrm{w} / \mathrm{v})\end{array}$ & $\begin{array}{l}\text { Tris-HCl, pH 8,8 } \\
\text { SDS }\end{array}$ \\
\hline SDS-Elektrophorese-Puffer (10x): & $\begin{array}{l}250 \mathrm{mM} \\
1,9 \mathrm{M} \\
1 \%(\mathrm{w} / \mathrm{v})\end{array}$ & $\begin{array}{l}\text { Tris Base } \\
\text { Glycerin } \\
\text { SDS }\end{array}$ \\
\hline Färbelösung: & $\begin{array}{l}50 \%(\mathrm{v} / \mathrm{v}) \\
10 \%(\mathrm{v} / \mathrm{v}) \\
40 \%(\mathrm{v} / \mathrm{v}) \\
0,05 \%(\mathrm{w} / \mathrm{v})\end{array}$ & $\begin{array}{l}\text { Methanol } \\
\text { Essigsäure } \\
\mathrm{H}_{2} \mathrm{O} \\
\text { Coomassie-Blau R250 }\end{array}$ \\
\hline Entfärbelösung: & $\begin{array}{l}5 \%(\mathrm{v} / \mathrm{v}) \\
7 \%(\mathrm{v} / \mathrm{v}) \\
88 \%(\mathrm{v} / \mathrm{v})\end{array}$ & $\begin{array}{l}\text { Methanol } \\
\text { Essigsäure } \\
\mathrm{H}_{2} \mathrm{O}\end{array}$ \\
\hline Lämmli-Auftragspuffer (2 x): & $\begin{array}{l}0,1 \mathrm{M} \\
2 \%(\mathrm{w} / \mathrm{v}) \\
2 \%(\mathrm{v} / \mathrm{v}) \\
20 \%(\mathrm{v} / \mathrm{v}) \\
0,002 \%(\mathrm{w} / \mathrm{v})\end{array}$ & $\begin{array}{l}\text { Tris/HCl, pH 6,8 } \\
\text { SDS } \\
\text { B-Mercaptoethanol } \\
\text { Glycerin } \\
\text { Bromphenolblau }\end{array}$ \\
\hline
\end{tabular}

Western-Blot-Analyse:

Waschpuffer A:

$\begin{array}{ll}1,37 \mathrm{mM} & \mathrm{NaCl} \\ 30 \mathrm{mM} & \mathrm{KCl} \\ 60 \mathrm{mM} & \mathrm{Na}_{2} \mathrm{HPO}_{4} \\ 10 \mathrm{mM} & \mathrm{NaH}_{2} \mathrm{PO}_{4} \\ 15 \mathrm{mM} & \mathrm{KH}_{2} \mathrm{PO}_{4} \\ 0,1 \%(\mathrm{v} / \mathrm{v}) & \text { Triton X-100 } \\ 3 \% & \text { Milchpulver }\end{array}$


Transfer-Puffer:

$\begin{array}{ll}20 \mathrm{mM} & \text { Tris-Base } \\ 150 \mathrm{mM} & \text { Glycin } \\ 20 \%(\mathrm{v} / \mathrm{v}) & \text { Methanol }\end{array}$

Aufreinigung von Histidin-Fusionsproteinen:

IPTG-Lösung:

$1 \mathrm{M}$

Isopropyl-1-thio- $\beta$-galactopyranosid steril filtriert und bei $-20^{\circ} \mathrm{C}$ gelagert

Puffer U:

$\begin{array}{ll}0,05 \mathrm{mM} & \text { Tris-HCl, } \mathrm{pH} 8,0 \\ 0,6 \mathrm{M} & \mathrm{NaCl} \\ 10 \mathrm{mM} & \text { Imidazol }\end{array}$

Puffer W:

$\begin{array}{ll}0,05 \mathrm{M} & \text { Tris-HCl, } \mathrm{pH} 8,0 \\ 0,3 \mathrm{M} & \mathrm{NaCl} \\ 20 \mathrm{mM} & \text { Imidazol } \\ 10 \%(\mathrm{v} / \mathrm{v}) & \text { Glycerin }\end{array}$

Aufreinigung von GST-Fusionsproteinen:

Glutathion-Elutions-Puffer:

$50 \mathrm{mM}$

Tris-HCl, $\mathrm{pH} 8,0$

$10 \mathrm{mM}$

reduziertes Glutathion

Lagerung in $1 \mathrm{ml}$ Aliquots bei $-20^{\circ} \mathrm{C}$

PBS-Puffer $(1 \mathrm{x})$ :

$\begin{array}{ll}140 \mathrm{mM} & \mathrm{NaCl} \\ 2,7 \mathrm{mM} & \mathrm{KCl} \\ 10 \mathrm{mM} & \mathrm{Na}_{2} \mathrm{HPO}_{4} \\ 1,8 \mathrm{mM} & \mathrm{KH}_{2} \mathrm{PO}_{4}, \mathrm{pH} 7,3\end{array}$

Aufreinigung von MBP-Fusionsproteinen:

MBP-Puffer:

$\begin{array}{ll}20 \mathrm{mM} & \text { Tris-HCl, pH 7,5 } \\ 200 \mathrm{mM} & \mathrm{NaCl} \\ 1 \mathrm{mM} & \text { EDTA }\end{array}$

Aufschluß von S. cerevisiae-Zellen:

Aufschluß-Puffer:

$\begin{array}{ll}20 \mathrm{mM} & \text { Tris-HCl, pH 7,9 } \\ 10 \mathrm{mM} & \mathrm{MgCl}_{2} \\ 1 \mathrm{mM} & \text { EDTA } \\ 5 \%(\mathrm{v} / \mathrm{v}) & \text { Glycerin } \\ 1 \mathrm{mM} & \text { DTT } \\ 0,3 \mathrm{M} & \left(\mathrm{NH}_{4}\right)_{2} \mathrm{SO}_{4}\end{array}$

Alkalischer-Lyse-Puffer

$\begin{array}{ll}2 \mathrm{M} & \mathrm{NaOH} \\ 5 \%(\mathrm{v} / \mathrm{v}) & \beta-\text { Mercaptoethanol }\end{array}$

NMP-Kinase-Assay:

Assay-Puffer (2x):

$\begin{array}{ll}200 \mathrm{mM} & \text { Tris-HCl, } \mathrm{pH} 7,5 \\ 200 \mathrm{mM} & \mathrm{KCl} \\ 20 \mathrm{mM} & \mathrm{MgCl}_{2}\end{array}$




\section{Methoden}

\subsection{Kultivierung von E. coli}

\subsubsection{Nährmedien für E.coli}

Alle Medien wurden 20 Minuten bei $120^{\circ} \mathrm{C}$ autoklaviert und bei $4^{\circ} \mathrm{C}$ gelagert.

L-Broth-Medium:

$\begin{array}{ll}5 \mathrm{~g} / \mathrm{l} & \text { Select Yeast-Extrakt } \\ 10 \mathrm{~g} / \mathrm{l} & \text { Trypton } \\ 5 \mathrm{~g} / \mathrm{l} & \mathrm{NaCl} \\ 5 \mathrm{ml} / \mathrm{l} & \mathrm{NaOH}\end{array}$

L-Broth(Amp)-Medium:

$100 \mu \mathrm{g} / \mathrm{ml}$ Ampicillin in L-Broth-Medium

Für Agarplatten wurde dem Medium 20 g/l Agar hinzugefügt. Die Zugabe von Ampicillin erfolgte nach dem Autoklavieren und Abkühlen des Mediums auf ca. $42^{\circ} \mathrm{C}$. Nach dem Erstarren des Agars wurden die Platten bei $4{ }^{\circ} \mathrm{C}$ gelagert.

\subsubsection{Anzucht von E.coli-Kulturen}

Die Anzucht von E. coli-Kulturen erfolgte durch Ausstreichen von Bakterien aus einer Dauerkultur auf Agarplatten. Zur Anreicherung von E. coli-Stämmen in Flüssigkultur wurden Zellen einer Einzelkolonie mit einer sterilen Impföse von einer Platte aufgenommen und in $5 \mathrm{ml} \mathrm{LB-Medium} \mathrm{inokuliert.} \mathrm{Zur}$ selektiven Anreicherung von E. coli-Transformanden wurde dem LB-Medium Ampicillin zugefügt. Die Platten wurden bei $37^{\circ} \mathrm{C}$ inkubiert, Flüssigkulturen zusätzlich mit mindestens $200 \mathrm{rpm}$ geschüttelt. Für das Anlegen einer E. coli-Dauerkultur wurden $5 \mathrm{ml}$ einer Übernachtkultur abzentrifugiert, das Zellpellet

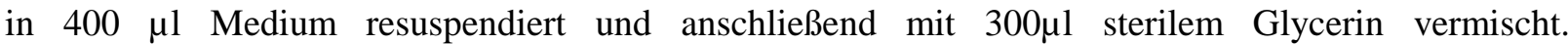
Dauerkulturen wurden bei $-80^{\circ} \mathrm{C}$ gelagert.

\subsection{Kultivierung von S. cerevisiae}

\subsubsection{Nährmedien für Hefekulturen}

Vollmedien:

YEPG(YEPGal)-Medium:

$10 \mathrm{~g} / \mathrm{l}$

$20 \mathrm{~g} / 1$

Select Yeast-Extract

$20 \mathrm{~g} / 1$

Select Pepton 140

Glukose (Galaktose)

Minimalmedien:

SD(SGal)-Medium:

$\begin{array}{ll}1,7 \mathrm{~g} / 1 & \text { Yeast Nitrogen Base } \\ 5 \mathrm{~g} / \mathrm{l} & \text { Ammoniumsulfat } \\ 20 \mathrm{~g} / \mathrm{l} & \text { Glukose (Galaktose) }\end{array}$


Den Minimalmedien wurden nach dem Autoklavieren und Abkühlen auf $42^{\circ} \mathrm{C}$ je nach Bedarf folgende, steril filtrierte Zusätze zugefügt:

$20 \mathrm{mg} / \mathrm{l}$ Adenin Sulfat

$20 \mathrm{mg} / \mathrm{l} \mathrm{L}-\mathrm{Histidin}-\mathrm{HCl}$

$20 \mathrm{mg} / \mathrm{L} \mathrm{L}-\mathrm{L} y \sin -\mathrm{HCl}$

$\underline{\mathrm{SC}^{-\mathrm{HIS}}-\mathrm{Medium}}$

Sporulationsmedium:
$20 \mathrm{mg} / \mathrm{l} \mathrm{Uracil}$

$30 \mathrm{mg} / \mathrm{l} \mathrm{L}$-Leucin

$20 \mathrm{mg} / \mathrm{l} \mathrm{L-Tryptophan}$

SD-Medium mit „Drop-out“-Mixtur ohne Histidin (Herstellung siehe Rose, 1990)

$10 \mathrm{~g} / \mathrm{l} \quad$ Kaliumacetat

Für Agarplatten wurden dem Medium 20 g/l Agar hinzugefügt. Die Medien wurden 20 Minuten bei $120^{\circ} \mathrm{C}$ autoklaviert und bei $4^{\circ} \mathrm{C}$ gelagert.

\subsubsection{Anzucht von Hefekulturen}

S. cerevisiae-Stämme wurden aus Dauerkulturen oder von einer Einzelkolonie durch Inkubation bei $30^{\circ} \mathrm{C}$ in flüssigem Vollmedium bzw. auf den entsprechenden Agarplatten herangezogen. Flüssigkulturen wurden zur gleichmäßigen Belüftung bei $180 \mathrm{rpm}$ geschüttelt. S. cerevisiaeTransformanden wurden unter selektiven Bedingungen in Minimalmedien mit den entsprechenden Aminosäurezusätzen kultiviert.

Zur Induktion der Sporulation von diploiden Hefezellen wurden exponentiell wachsende Hefekulturen auf Kaliumacetat-Agarplatten ohne Stickstoffquelle ausgestrichen und bei $30^{\circ} \mathrm{C}$ oder $25^{\circ} \mathrm{C}$ mindestens 5 Tage inkubiert. Dauerkulturen von S. cerevisiae wurden in gleicher Weise wie E. coli-Dauerkulturen (siehe 3.1.2) angelegt.

\subsection{Präparation von DNA}

\subsubsection{Analytische Plasmidisolierung aus E. coli}

Zur Isolierung kleiner Mengen bakterieller Plasmid-DNA für analytische Zwecke wurde eine modifizierte Form der Vorschrift von Birnboim und Doly (1979) angewendet.

Rekombinante Einzelkolonien wurden in $1,8 \mathrm{ml} \mathrm{LB}(\mathrm{Amp})$-Medium angeimpft und über Nacht bei $37^{\circ} \mathrm{C}$ inkubiert. Die herangewachsenen Zellen wurden in einer Tischzentrifuge für 1 Minute bei $16000 \mathrm{~g}$ abzentrifugiert und das Pellet in $100 \mu \mathrm{l}$ Puffer E1 resuspendiert. Der Aufschluß der Zellen erfolgte durch Zugabe von $200 \mu 1$ Lösung E2, vorsichtigem Invertieren und 5minütiger Inkubation auf Eis. Die Extrakte der lysierten Zellen wurden anschließend durch Zugabe von $150 \mu$ lösung E3 neutralisiert, das Eppendorf-Gefäß auf einem Vortex-Schüttler für 2 Sekunden bei maximaler Geschwindigkeit geschüttelt und danach für 5 Minuten auf Eis inkubiert. Die bei diesem Schritt ausgefallenen Proteine und die chromosomale DNA wurden durch erneute Zentrifugation für 10 Minuten bei $16000 \mathrm{~g}$ und $4^{\circ} \mathrm{C}$ 
pelletiert und der Überstand mit Plasmid-DNA in ein neues Reaktionsgefäß überführt. Die PlasmidDNA wurde dann durch Zugabe von $0,8 \mathrm{ml}$ 96\%igem Ethanol für mindestens 10 Minuten bei $-20^{\circ} \mathrm{C}$ gefällt, für 10 Minuten bei $16000 \mathrm{~g}$ und $4^{\circ} \mathrm{C}$ abzentrifugiert und mit $1 \mathrm{ml} 70 \%$ igem Ethanol gewaschen. Das Pellet wurde anschließend im Vakuumrotor oder an der Luft getrocknet und in $30 \mu 1$ TE-Puffer aufgenommen. Für analytische Verdaus mit Restriktionsendonukleasen (siehe 3.4.2) wurden jeweils 3 $4 \mu 1$ dieser DNA-Lösung eingesetzt.

\subsubsection{Präparative Plasmidisolierung aus E. coli}

Größere Mengen an Plasmid-DNA wurden nach dem JETSTAR-Protokoll für PlasmidMidipräparationen (Kit von Genomed, Bad Oeynhausen) aus $100 \mathrm{ml}$ rekombinanter E. coli-Kultur isoliert. Der Zellaufschluß erfolgte durch alkalische Lyse unter Verwendung von Puffern und Lösungen des Midiprep-Kits. Zur Isolierung und Aufreinigung der Plasmid-DNA wurden AnionenaustauscherSäulen sowie Wasch- und Elutionspuffer der Firma Genomed verwendet. Durch präparative Plasmidisolierung konnten 100-200 $\mu \mathrm{g}$ DNA aus einer E.coli-Kultur gewonnen werden. Die DNA wurde in $100 \mu \mathrm{TE}$-Puffer aufgenommen und bei $-20^{\circ} \mathrm{C}$ gelagert.

\subsubsection{Isolierung genomischer DNA aus S. cerevisiae}

Die Zellen einer $50 \mathrm{ml}$ Hefekultur wurde durch Zentrifugation bei $3000 \mathrm{~g}$ geerntet und das Zellpellet einmal mit $5 \mathrm{ml} 1 \mathrm{M}$ Sorbitol gewaschen. Nach erneuter Zentrifugation wurden die Zellen in $150 \mu \mathrm{l} 1 \mathrm{M}$ Sorbitol aufgenommen und durch Zugabe von 2000 Einheiten Lytikase sphäroblastiert. Nach einstündiger Inkubation bei $37^{\circ} \mathrm{C}$ wurden die Sphäroblasten vorsichtig abzentrifugiert ( $5 \mathrm{~min}, 4000 \mathrm{~g}$ ) und das Pellet in 0,5 ml Lysepuffer (50mM Tris-HCl, pH 7,5 und $20 \mathrm{mM}$ EDTA) resuspendiert. Dann wurden $50 \mu 110 \%$ ige SDS-Lösung zugegeben und 30 Minuten bei $65^{\circ} \mathrm{C}$ inkubiert. Das Ausfällen der Proteine erfolgte durch Zugabe von $150 \mu 15 \mathrm{M}$ Kaliumacetat und einstündiger Inkubation auf Eis. Die Proteine wurden dann durch 20minütige Zentrifugation bei $14000 \mathrm{~g}$ sedimentiert. Der Überstand wurde in ein neues Reaktionsgefäß überführt und die DNA durch Zugabe von 1 vol Isopropanol bei Raumtemperatur gefällt. Die präzipitierte DNA wurde abzentrifugiert und in $400 \mu \mathrm{l}$ TE-Puffer aufgenommen. Nach einem 30 minütigen RNase $(30 \mu \mathrm{g} / \mathrm{ml})$-Verdau bei $37^{\circ} \mathrm{C}$ erfolgte eine weitere Isopropanolfällung der DNA. Die pelletierte DNA wurde zum Schluß in $400 \mu$ l TE-Puffer aufgenommen und konnte nun direkt für PCR-Reaktionen eingesetzt werden.

\subsubsection{Isolierung von Plasmid-DNA aus S. cerevisiae}

Zur Isolierung von analytischen Mengen an Plasmid-DNA aus Hefezellen wurden $5 \mathrm{ml}$ Übernachtkultur abzentrifugiert, die Zellen mit $1 \mathrm{ml} 1 \mathrm{M}$ Sorbitol gewaschen und das Pellet anschließend in $150 \mu \mathrm{l} 1 \mathrm{M}$ Sorbitol resuspendiert. Nach Zugabe von $30 \mu \mathrm{l}$ Zymolyase $100 \mathrm{~T}(10 \mathrm{mg} / \mathrm{ml})$ und Inkubation für 1-2 Stunden bei $37^{\circ} \mathrm{C}$ wurden die Hefezellen sphäroblastiert. Danach wurden $20 \mu \mathrm{l}$ TE-Puffer und $50 \mu 1$ 10\%ige SDS-Lösung zugegeben und 30 Minuten bei $65^{\circ}$ inkubiert. Die Proteinausfällung erfolgte durch 
Zugabe von $200 \mu 15$ M Kaliumacetat und einstündiger Inkubation auf Eis. Die präzipitierten Proteine wurden 15 Minuten bei $14.000 \mathrm{~g}$ und $4^{\circ} \mathrm{C}$ abzentrifugiert und der Überstand in einem neuen EppendorfGefäß mit $1 \mathrm{ml}$ eiskaltem 96 \%igem Ethanol versetzt. Die so gefällte DNA wurde anschließend durch 20minütige Zentrifugation bei $14000 \mathrm{~g}$ pelletiert und danach in $50 \mu \mathrm{l}$ TE-Puffer aufgenommen. Zur weiteren Amplifikation von Hefe-Plasmiden wurden komptetente E. coli-Zellen mit $1 \mu 1$ der DNALösung transformiert.

\subsubsection{Bestimmung der Konzentration und Reinheit von DNA}

Die Konzentrationen von DNA wurde entweder im Ethidiumbromid-gefärbten Agarosegel durch Vergleich der Fluoreszenz unter UV-Licht mit einem Standard ( $\lambda$-DNA verdaut mit Restriktionsenzymen HindIII/EcoRI) oder photometrisch durch Messung der Lichtabsorption bei einer Wellenlänge von $260 \mathrm{~nm}$ bestimmt. Dabei entspricht eine $\mathrm{OD}_{260}$ von 1,0 einer DNA-Konzentration von $50 \mu \mathrm{g} / \mathrm{ml}$ für Doppelstrang-DNA, $40 \mu \mathrm{g} / \mathrm{ml}$ für Einzelstrang-DNA oder RNA und $20 \mu \mathrm{g} / \mathrm{ml}$ für Oligonukleotide.

\subsection{Enzymatische Behandlungen von DNA}

\subsubsection{Fragmentierung von Doppelstrang-DNA mit Restriktionsenzymen}

In dieser Arbeit wurden Restriktionsendonukleasen eingesetzt, um definierte DNA-Fragmente für Klonierungsansätze herzustellen oder für analytische Zwecke, um bestimmte Restriktionsmuster nach Spaltung von Plasmid-DNA zu identifizieren. Bei der Spaltung von doppelsträngiger DNA können je nach Enzym glatte Enden (blunt ends) oder Fragmente mit 3'-oder 5'-überhängenden, kohäsiven Enden (sticky ends) entstehen, wobei am 3'-Ende die Hydroxyl- und am 5'-Ende die Phosphatgruppe erhalten bleibt.

Die Restriktionsenzyme wurden nach den jeweiligen Angaben der Hersteller und in entsprechenden Pufferlösungen eingesetzt. Für einen analytischen Restriktionsverdau wurden ca. $1 \mu \mathrm{g}$ DNA in einem Volumen von $20 \mu \mathrm{l}(50 \mu \mathrm{l})$ Reaktionsansatz mit 1 - 2 Units (5 Units) Enzym bei erforderlicher Temperatur 2 - 3 Stunden inkubiert. Für einen präparativen Restriktionsverdau wurde die Menge des verwendeten Enzyms und das Volumen des Reaktionsansatzes entsprechend der größeren DNA-Menge erhöht.

\subsubsection{Behandlung von linearisierter DNA mit alkalischer Phosphatase}

Die alkalische Phosphatase (Calf Intestinal Phosphatase, CIP, Boehringer, Mannheim) katalysiert die Abspaltung der endständigen 5'-Phosphatgruppe von DNA- und RNA-Fragmenten. Das Enzym wurde bei einigen Klonierungen eingesetzt, um eine Religation des Vektors mit glatten oder kompatiblen kohäsiven Enden ohne ein eingefügtes DNA-Fragment zu verhindern und somit die Effizienz der Ligation zu erhöhen. 
Für die Abspaltung der Phosphatgruppe wurden $5 \mu \mathrm{g}$ der Vektor-DNA in $90 \mu_{1} \mathrm{H}_{2} \mathrm{O}$ gelöst und mit 10 $\mu 110$ x Dephosphorylierungs-Puffer versetzt. Nach der Zugabe von einer Unit alkalischer Phosphatase wurde der Reaktionsansatz für 60 Minuten bei $37^{\circ} \mathrm{C}$ inkubiert und die Reaktion anschließend durch Zugabe von EDTA in einer Endkonzentration von $5 \mathrm{mM}$ und 10 minütigem Erhitzen auf $75^{\circ} \mathrm{C}$ gestoppt. Die DNA wurde mit dem „QIAquick PCR Purification Kit“ von Qiagen oder durch präparative Agarose-Gelelektrophorese aufgereinigt.

\subsubsection{Auffüllen von 5'-überhängenden DNA-Enden}

Um nach der Behandlung von doppelsträngiger DNA den Gegenstrang an 5'-überhängenden Enden neu zu synthetisieren und somit glatte DNA-Enden zu bilden, wurde das Klenow-Fragment verwendet. Das Klenow-Fragment entsteht bei der proteolytischen Spaltung der DNA-Polymerase I (Klenow und Henningsen, 1970). Nach Behandlung mit Klenow-Enzym konnten DNA-Fragmente ligiert werden, welche zunächst keine kompatiblen 5'-überhängenden DNA-Enden besaßen.

Für die Auffüllreaktion wurden $1-2 \mu \mathrm{g}$ DNA in $20 \mu \mathrm{H}_{2} \mathrm{O}$ und 2,5 $\mu \mathrm{l} 10$ x Klenow-Puffer aufgenommen und nach Zugabe von 2,5 $\mu \mathrm{l}$ dNTP-Mix mit 1 - $2 \mathrm{U}$ des Klenow-Fragments (Boehringer, Mannheim) 15 Minuten bei $37^{\circ} \mathrm{C}$ inkubiert. Durch 10 minütiges Erhitzen auf $75^{\circ} \mathrm{C}$ wurde das Enzym inaktiviert. Die DNA wurde mit dem „QIAquick PCR Purification Kit“" von Qiagen oder durch präparative Agarose-Gelelektrophorese aufgereinigt.

\subsection{Gelelektrophoretische Auftrennung von DNA}

Die Agarose-Gelelektrophorese wurde zur Reinigung, zur Auftrennung und zur Identifizierung von Plasmid-DNA und DNA-Fragmenten genutzt. Im elektrischen Feld wandern DNA-Moleküle aufgrund der negativen Ladung ihrer Phosphatgruppen zur Anode. Die Wanderungsgeschwindigkeit von linearer und doppelsträngiger DNA in der Agarose-Gelmatrix ist umgekehrt proportional zum Logarithmus ihres Molekulargewichts (Helling et al., 1974).

\subsubsection{Analytische und präparative Agarose-Gelelektrophorese}

Zur analytischen und präparativen Auftrennung von DNA-Fragmenten wurden Agarose-Flachbettgele benutzt. In Abhängigkeit der Größe der aufzutrennenden DNA-Fragmente wurden AgaroseKonzentrationen von 0,7 bis 2,0 \% gewählt, wobei sich DNA-Fragmente mit einer Größe von 0,8 - 10,0 $\mathrm{kb}$ in 0,7 \%iger Agarose trennen ließen, während in 2,0 \%iger Agarose der optimale Trennbereich für DNA-Fragmente von $0,1-2,0 \mathrm{~kb}$ lag.

Die Agarose wurde durch Aufkochen in TAE-Puffer gelöst und in entsprechende Gelkammern gegossen, die mit einem taschenbildenden Kamm versehen war. Nach dem Abkühlen und der Verfestigung wurde das Gel in der Elektrophoresekammer mit TAE-Puffer überschichtet und der Kamm entfernt. Die DNA-Proben wurden mit 1/5 Volumen Auftragspuffer versetzt und in die Geltaschen 
pipettiert. Zusätzlich wurde ein Molekulargewichts-Standard (zumeist $1 \mu \mathrm{g}$ EcoRI/HindIII geschnittene DNA des Phagen $\lambda$ ) aufgetragen. Als Elektrophoresepuffer wurde 1 x TAE-Puffer verwendet. Die Elektrophorese erfolgte bei konstanter Spannung von 80 bis 120 Volt. Die aufgetrennten, mit Ethidiumbromid-gefärbten DNA-Fragmente konnten anschließend durch Bestrahlung mit UV-Licht (302 nm) unter einem Transilluminator als Banden sichtbar gemacht werden. Präparative Gele wurden möglichst kurzzeitig in Ethidiumbromid angefärbt und nur längerwelligem UV-Licht (366 nm) ausgesetzt, um mutagene Schäden in der DNA zu vermeiden.

\subsubsection{Isolierung von DNA aus präparativen Gelen}

Nach der elektrophoretischen Trennung wurden die DNA-Fragmente nach dem „QIAquick Gel Extraction“-Protokoll (Kit von Qiagen, Düsseldorf) aus dem Gel präpariert. Dazu wurde die unter längerwelligem UV-Licht sichtbare Bande des zu isolierenden DNA-Fragments mit einem Skalpell möglichst genau aus dem Gel geschnitten. Die DNA-Fragmente wurden dann in Puffer QG durch 10minütiges Erhitzen auf $50^{\circ} \mathrm{C}$ aus dem Agarosegel herausgelöst und über Anionenaustauscher-Säulen mit entsprechenden Puffern der Firma Qiagen gereinigt.

\subsection{Klonierung rekombinanter DNA in E.coli}

Die Vektoren wurden für die Ligation durch geeignete Restriktionsenzyme linearisiert. Entstanden durch das Restriktionsenzym glatte oder kompatible kohäsive Enden, wurden die 5'-Phosphatreste an den Enden der Vektor-DNA entfernt, um eine Religation des Vektors ohne den Einbau eines DNAFragmentes zu verhindern. Die zu klonierende DNA wurde mit geeigneten Restriktionsendonukleasen geschnitten und isoliert. Wenn keine komplementären Schnittstellen des Vektors und des DNAFragments vorhanden waren, wurden 5'-überhängende Enden mit Klenow-Enzym aufgefüllt.

\subsubsection{Ligation von DNA-Doppelstrang-Fragmenten}

Linearisierte DNA-Moleküle können durch die Bildung von Phosphodiesterbindungen zwischen benachbarten 3'-Hydroxyl- und 5'-Phosphatenden miteinander verbunden werden. Diese Reaktion wird durch das Enzym T4-DNA-Ligase unter Hydrolyse von ATP katalysiert.

In dem Ligationsansatz wurde das zu integrierende DNA-Fragment in 2- bis 5fachem molaren Überschuß (200-500 fmol) zu der lineasrisierten Vektor-DNA (100-200 fmol) hinzugegeben. In einem Reaktionsansatz von $20 \mu \mathrm{l}$ wurden $2 \mu 110$ x Ligase-Puffer und 2 Units T4-DNA-Ligase (Boehringer, Mannheim) eingesetzt. Der Ligationsansatz wurde 12 bis 15 Stunden bei $15^{\circ} \mathrm{C}$ inkubiert und anschließend direkt zur Transformation kompetenter E. coli-Zellen eingesetzt.

\subsubsection{Herstellung kompetenter E. coli-Zellen}

Zur Herstellung von kompetenten Zellen nach Nishimura et al. (1990) wurden 50 ml Medium A mit 0,5 $\mathrm{ml}$ einer E. coli-Übernachtkultur angeimpft und bis zu einer Zelldichte von $\mathrm{OD}_{600}=0,3-0,5$ inkubiert. 
Danach wurden die Zellen 10 Minuten auf Eis gestellt und durch 10minütige Zentrifugation bei $1500 \mathrm{~g}$ und $4^{\circ} \mathrm{C}$ geerntet. Das Zellpellet wurde vorsichtig in 0,5 $\mathrm{ml}$ eiskaltem Medium A resuspendiert und nach Zugabe von 2,5 ml Lösung B vorsichtig gemischt. Die Zellsuspension wurde in Aliquots von 100 $\mu \mathrm{l}$ aufgeteilt und bei $-80^{\circ} \mathrm{C}$ gelagert.

\subsubsection{Transformation von E. coli-Zellen}

Für die Transformation wurden $100 \mu \mathrm{l}$ der kompetenten $E$. coli-Zellen auf Eis aufgetaut und sofort mit 5 $\mu \mathrm{l}$ des Ligationsansatzes oder 0,1 bis $1,0 \mu \mathrm{g}$ Plasmid-DNA gemischt. Nach 30minütiger Inkubation auf Eis wurden die Zellen 1 Minute im Wasserbad auf $42^{\circ} \mathrm{C}$ erhitzt („Hitzeschock“) und danach 1 bis 2 Minuten auf Eis abgekühlt. Nach der Zugabe von $1 \mathrm{ml}$ vorgewärmten LB-Medium wurden die transformierten Zellen 60 Minuten bei $37^{\circ} \mathrm{C}$ inkubiert. Anschließend wurden $20 \mu \mathrm{l}$ der Zell-Suspension auf einer LB-Amp-Agarplatte ausgestrichen und die restlichen Zellen durch 2minütige Zentrifugation bei $3000 \mathrm{~g}$ und RT geerntet. Das Zellpellet wurde in $100 \mu \mathrm{LB}(\mathrm{Amp})$-Medium resuspendiert und ebenfalls auf einer LB(Amp)-Agarplatte ausgestrichen. Beide Platten wurden über Nacht bei $37^{\circ} \mathrm{C}$ inkubiert.

\subsection{DNA-Amplifikation durch die Polymerase-Kettenreaktion}

Die Polymerase-Kettenreaktion (PCR) ist ein zyklischer Prozeß, mit dem selektiv DNA-Sequenzen in vitro vervielfältigt werden können. Die PCR wurde vor allem zur ortsspezifischen Mutagenese, z.B. zur Erzeugung von Punktmutationen, Deletionen und Insertionen, zur Einführung von Schnittstellen für Restriktionsenzyme, sowie zur Amplifikation von Genen aus genomischer Hefe-DNA eingesetzt. Ein weiteres Anwendungsgebiet war die analytische Überprüfung von Ligationen und Genom-Integrationen. Die PCR wurde entweder mit der $P f x$-, der $P f u$ - (Stratagene, La Jolla, USA) oder der AmpliTaq-DNAPolymerase (Roche, Branchburg, USA) unter Verwendung der firmeneigenen 10 x konzentrierten Puffer durchgeführt. Die $P f u$ - und die $P f x$-DNA-Polymerasen besitzen eine 3'-Exonukleaseaktivität und weisen aufgrund ihrerer Proofreading-Eigenschaften eine höhere Replikationsgenauigkeit auf als die Taq-DNA-Polymerase. Als DNA-Matrize für die Polymerase-Reaktion diente entweder Vektor-DNA oder genomische Hefe-DNA. Es wurden 20 - 50 ng der entsprechenden Vektor- bzw. 1 - $3 \mu \mathrm{g}$ chromosomale DNA und jeweils 50 pmol der beiden Oligonukleotide pro $100 \mu$ l Reaktionsansatz eingesetzt. Nach der PCR-Amplifikation wurden $4 \mu \mathrm{l}$ des Reaktionsansatzes durch AgaroseGelelektrophorese getestet. Die restlichen Ansätze konnten für weitere Klonierungen eingesetzt werden.

Die Hybridisierungstemperatur $\left(48-54^{\circ} \mathrm{C}\right)$ richtete sich nach der Schmelztemperatur der eingesetzten Oligonukleotide und die Polymerisationszeit nach der Länge des zu amplifizierenden DNA-Fragments (1 min pro $1000 \mathrm{bp})$ 
$\underline{\text { Standard-PCR }}$

\begin{tabular}{|c|c|c|}
\hline Reaktionsansatz $(100 \mu \mathrm{l})$ : & $\begin{array}{l}20-50 \mathrm{ng} \\
(\text { oder } 1 \mu \mathrm{g} \\
50 \mathrm{pmol} \\
50 \mathrm{pmol} \\
5 \mu \mathrm{l} \\
10 \mu \mathrm{l} \\
1 \text { Unit }\end{array}$ & $\begin{array}{l}\text { Vektor-DNA } \\
\text { genomische DNA) } \\
\text { Oligonukleotid } 1 \\
\text { Oligonukleotid } 2 \\
\text { dNTP-Mix ( je } 2,5 \mathrm{mM} \text { ) } \\
10 \text { x PCR-Reaktionspuffer } \\
\text { DNA-Polymerase } \\
\text { ad } 100 \mu 1 \text { mitH }_{2} \mathrm{O}\end{array}$ \\
\hline
\end{tabular}

Reaktionsbedingungen:

$\begin{array}{lllr}\text { 1 Zyklus: } & \text { Denaturierung: } & 1 \mathrm{~min} & 94^{\circ} \mathrm{C} \\ & \begin{array}{l}\text { Hybridisierung: } \\ \text { Polymerisation: }\end{array} & 1 \mathrm{~min} & 42-54^{\circ} \mathrm{C} \\ & & 1 \mathrm{~min} / 1000 \mathrm{bp} \text { DNA } & 72^{\circ} \mathrm{C} \\ \text { 25 Zyklen: } & \begin{array}{l}\text { Denaturierung: } \\ \text { Hybridisierung: }\end{array} & 1 \mathrm{~min} & \\ & \text { Polymerisation: } & 1 \mathrm{~min} & 94^{\circ} \mathrm{C} \\ & & (P f u: 2 \mathrm{~min} / 1000 \mathrm{bp}) & \\ & & 1 \mathrm{~min} & 74^{\circ} \mathrm{C} \\ 1 \text { Zyklus: } & \text { Denaturierung: } & 1 \mathrm{~min} & 94^{\circ} \mathrm{C} \\ & \text { Hybridisierung: } & 10 \mathrm{~min} & 42-54^{\circ} \mathrm{C} \\ & \text { Polymerisation: } & 72^{\circ} \mathrm{C}\end{array}$

\subsubsection{Kolonie-PCR-Screening}

Um aus der Vielzahl der nach einer Transformation unter den selektiven Bedingungen überlebenden Klone, diejenigen zu identifizieren, welche die gewünschte rekombinierte DNA besaßen, wurde das Verfahren des Kolonie-PCR-Screenings angewendet. Dazu wurden Einzelkolonien mit einem Zahnstocher zunächst in ein Eppendorf-Gefäß mit $50 \mu \mathrm{l}$ PCR-Reaktionsansatz und von dort in ein Eppendorf-Gefäß mit 1,8 ml Medium zur Herstellung von Übernachtkulturen überführt. Zum Schluß wurden die Zellen der jeweiligen Einzelkolonie auf einer LB(Amp)-Platte ausgestrichen. Der PCRReaktionsansatz enthielt die zur integrierten DNA-Sequenz spezifischen Oligonukleotid-Primer. In Transformanden, welche die gesuchte rekombinierte DNA besaßen, konnte die integrierte Zielsequenz amplifiziert und die entstandenen DNA-Fragmente über Agarose-Gelelektrophorese nachgewiesen werden. Mit Hilfe dieser zeitsparenden Kontroll-PCR konnte die gewünschte rekombinierte DNA schnell gefunden werden.

\subsection{Gerichtete Mutagenese mit der PCR}

Die Methode der ortsspezifischen Mutagenese wurde zur gezielten Einführung von Mutationen in Gene angewendet. Mutation nahe dem 5'- oder 3'-Ende der DNA-Sequenz wurden direkt über die spezifischen Oligonukleotid-Primer, welche die geänderte Nukleotidsequenz besaßen, in einer PCR- 
Reaktion eingeführt. Da Primer von über 60 Nukleotiden Länge nur schwer zu synthetisieren sind, ist diese Methode nur sinnvoll bei Mutationen der ersten bzw. letzten 20 Aminosäuren.

Weiter vom N- bzw. C-Terminus entfernt liegende Mutationen wurden über die PCR-Fusionsmethode („Overlap Extension PCR“ nach Ho et al., 1989) erzeugt. Bei dieser Methode werden zunächst mit Hilfe von komplementären Mutagenese-Primern sowie den spezifischen 5'- und 3'-OligonukleotidPrimern und dem Wildtyp-Gen als Template zwei PCR-Fragmente produziert, welche überlappende Enden von etwa 30 Nukleotiden Länge mit der gewünschten Mutation besitzen. Zusammen mit den spezifischen 5'- und 3'-Oligonukleotid-Primern werden diese beiden Fragmente in einer darauffolgenden zweiten PCR-Reaktion zu dem vollständigen Gen fusioniert, wobei die überlappenden Enden der beiden Fragmente als Megaprimer für die 3'-Ausdehnung des komplementären Stranges dienen. Das amplifizierte PCR-Fusionsprodukt wurde danach in den gewünschten Vektor kloniert. Zur Vermeidung von 3'-überhängenden Nukleotiden (zumeist Adenin) wurde zur Konstruktion der beiden überlappenden Fragmente üblicherweise eine DNA-Polymerase mit 3'-5'-Exonukleaseaktivität benutzt ( $P f u$ - oder $P f x$-DNA-Polymerase). Darüberhinaus mussten die im ersten Schritt hergestellten Fragmente vor Beginn der zweiten PCR durch Aufreinigung über ein präparatives Agarose-Gel von restlicher Wildtyp-DNA getrennt werden, um eine unerwünschte Amplifizierung des Wildtyp-Gens mit Hilfe der 5'- und 3'-terminalen Oligonukleotid-Primer zu verhindern.

In der Regel wurden neben den für die Veränderung der DNA-Sequenz notwendigen Mutationen an der betreffenden Stelle noch zusätzlich noch weitere Mutationen eingeführt, welche eine Erkennungssequenz für Restriktionsenzyme bilden. Dadurch konnten Mutanten auch ohne aufwendige Sequenzierung schnell identifiziert werden.

\subsubsection{Gerichtete PCR-Mutagenese durch lineare Plasmid-Amplifikation}

Für die Einführung von Mutationen in Plasmide ohne aufwendige Einzelstrang-Präparationen und Klonierungen wurde der „QuikChange Site-directed Mutagenesis“-Kit von Stratagene (La Jolla, USA) verwendet.

Ausgangspunkt für diese Mutagenese ist normale doppelsträngige Plasmid-DNA. Zur linearen Amplifizierung des gesamten Plasmids wurden zwei komplementäre Mutagenese-Primer, welche die gewünschte Mutation in ihrem Überlappungsbereich enthielten und Pfu-DNA-Polymerase benutzt. Durch die Zugabe von Dpn I, einer Restriktionsendonuklease, die methylierte und semimethylierte DNA spaltet, wird die parentale DNA abgebaut. Nur die in vitro synthetisierten Stränge, welche unmethyliert sind und die Mutation besitzen, bleiben erhalten und können anschließend zur Transformation von E. coli benutzt werden. Die parentale Plasmid-DNA-Matrize wurde anschließend

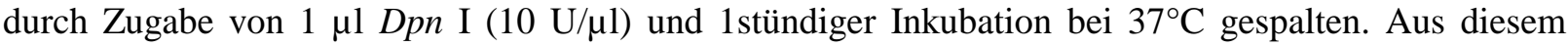
Ansatz wurde dann $1 \mu \mathrm{l}$ zur Transformation von E. coli XL1-Blue Zellen eingesetzt. 
Standard PCR nach dem „QuikChange Site-directed Mutagenesis“-Protokoll:

Reaktionsansatz

$\begin{array}{ll}25 \mathrm{ng} & \text { Plasmid-DNA } \\ 20 \mathrm{pmol} & \text { Mutageneseprimer 1 } \\ 20 \mathrm{pmol} & \text { Mutageneseprimer 2 } \\ 5 \mu \mathrm{l} & \text { 10x Reaktionsbuffer (Stratagene) } \\ 5 \mu \mathrm{l} & \text { dNTP-Mix (je } 2,5 \mathrm{mM}) \\ 1 \mu \mathrm{l} & \text { Pfu-DNA-Polymerase }(2,5 \mathrm{U} / \mu \mathrm{l}) \\ & \text { mit Wasser auf } 50 \mu \mathrm{l} \text { aufgefüllt }\end{array}$

Reaktionsbedingungen:

$\begin{array}{lll}\text { 1 Zyklus: } & 30 \mathrm{~s} & 95^{\circ} \mathrm{C} \\ \text { 16 Zyklen: } & 30 \mathrm{~s} & 95^{\circ} \mathrm{C} \\ & 1 \mathrm{~min} & 55^{\circ} \mathrm{C} \\ & 1 \mathrm{~min} / \mathrm{kb} & 68^{\circ} \mathrm{C}\end{array}$

\subsection{Methoden zur Hefegenetik}

\subsubsection{Klassische Transformation von Hefezellen}

Die Hefe-Transformation mit der Lithiumacetat-Methode wurde nach Ito et al. (1983) durchgeführt. Zur Selektion der transformierten Zellen auf Minimalmedium enthielten die verwendeten DNA-Vektoren ein entsprechendes Markergen (z. B. das LEU2-, das HIS3-Gen, oder das Kanamycin-Resistenzgen, $K A N^{R}$ ). Ist der verwendete Hefestamm auxotroph für den entsprechenden Marker, so können transformierte Hefezellen auf Minimalmedium selektiert werden. Zur Konstruktion von GenUnterbrechungen im Genom von S. cerevisiae wurden Hefe-Zellen mit linearen DNA-Fragmenten, welche neben einem Markergen 5'- und 3'-terminale komplementäre Sequenzen des Zielgens enthielten, transformiert. Durch homologe Rekombination können die entsprechenden Marker dann an spezifischer Stelle in das Hefegenom integriert werden (Rothstein, 1983).

Eine Hefe-Kultur wurde bis zur späten exponentiellen Phase $\left(\mathrm{OD}_{600}=0,7-1,2\right)$ bei $30^{\circ} \mathrm{C}$ herangezogen. Durch Zentrifugation bei $4000 \mathrm{~g}$ für 5 Minuten wurden die Zellen geerntet und danach mit $20 \mathrm{ml}$ TEPuffer gewaschen. Die pelletierten Zellen wurden anschließend in $500 \mu 1$ Lithiumacetat-Lösung und $500 \mu \mathrm{l}$ TE-Puffer resuspendiert und für 30 bis 60 Minuten unter Schütteln bei $30^{\circ} \mathrm{C}$ inkubiert. Die Hefesuspension wurde dann in Aliquots von jeweils $100 \mu \mathrm{l}$ in Eppendorf-Gefäße aufgeteilt.

Für die Transformation wurden jeweils $100 \mu \mathrm{l}$ der Zellsuspension mit 0,1 bis $1 \mu \mathrm{g}$ Plasmid-DNA vermischt und der Transformations-Ansatz für 30 Minuten unter Schütteln bei $30^{\circ} \mathrm{C}$ inkubiert. Nach der Zugabe von $700 \mu \mathrm{l}$ der PEG-Lösung und gründlicher Durchmischung wurde der Ansatz erneut für 30 bis 60 Minuten bei $30^{\circ} \mathrm{C}$, ohne gleichzeitiges Schütteln, inkubiert. Danach folgte eine 5minütige Erwärmung des Ansatzes auf $42^{\circ} \mathrm{C}$ („Hitzeschock“). Zum Schluß wurden die Zellen 5 Minuten bei 4000 $g$ abzentrifugiert, mit $1 \mathrm{ml}$ sterilem $\mathrm{H}_{2} \mathrm{O}$ gewaschen und in $100 \mu 1$ TE-Puffer aufgenommen. Jeweils 50 
$\mu l$ der Zellsuspension wurden auf selektiven Agarplatten ausgestrichen. Nach 2-3tägiger Inkubation bei $30^{\circ} \mathrm{C}$ konnten Einzelkolonien zur Überprüfung der Eigenschaften auf andere Agarplatten überimpft werden.

\subsubsection{Elektroporation von Hefezellen}

Um eine höhere Transformationseffizienz zu erzielen, kann Plasmid-DNA mit einem Gene Pulser (BioRad, Richmond, USA) durch Elektroporation in die Hefezellen eingeschleust werden. Dazu wurden zunächst die Zellen einer exponentiell $\left(\mathrm{OD}_{600}=0,7-1,3\right)$ wachsenden $500 \mathrm{ml}$ Hefekultur abzentrifugiert, mehrfach mit sterilem, kaltem Wasser und anschließend mit 1 M Sorbitol gewaschen. Das Zellpellet wurde in $1 \mathrm{ml}$ eiskaltem Sorbitol aufgenommen. $40 \mu \mathrm{l}$ dieser Hefesuspension wurden dann mit 0,1 bis $1 \mu \mathrm{g}$ Plasmid-DNA gemischt und kurz auf Eis inkubiert. Die Elektroporation wurde bei $1,5 \mathrm{kV}, 20 \mu \mathrm{F}$ und $200 \mathrm{~W}$ durchgeführt. Anschließend wurden die Zellen in $100 \mu$ l kalter SorbitolLösung aufgenommen und auf selektiven Agarplatten ausplattiert.

\subsubsection{Sporulation diploider Hefezellen}

Diploide S. cerevisiae-Zellen gehen unter Hungerbedingungen, d.h. bei Stickstoffmangel, in den meiotischen Zellzyklus über, wobei sie vier haploide Sporen ausbilden, die von einer gemeinsamen Ascuswand umgeben sind. Die vier haploiden Sporen eines Ascus werden auch als Tetrade bezeichnet. Zur Sporulation wurden zunächst diploide Hefe-Transformanden in $3 \mathrm{ml}$ Vollmedium über Nacht bei $30^{\circ} \mathrm{C}$ bis zur frühen exponentiellen Wachstumsphase herangezogen. Die Zellen wurden dann 5 Minuten bei $2000 \mathrm{~g}$ abzentrifugiert und der Überstand dekantiert. Die Hefezellen wurden mit dem im Zentrifugenröhrchen verbliebenen Rest an Medium resuspendiert und als Tropfen in die Mitte einer Kaliumacetat-Agarplatte gegossen. Die Hefen bildeten nach 5 bis 7 Tagen Sporen.

\subsubsection{Tetradenanalyse}

Die vier Sporen eines Ascus wurden mit der Spitze der Glasnadel des Mikromanipulators getrennt und einzeln auf einer Vollmedium-Agarplatte ausgelegt. Nachdem die Sporen zu Zellkolonien herangewachsen waren, konnte ihr jeweiliger Phänotyp durch Überimpfen auf selektive Agarplatten mit entsprechenden Aminosäurezusätzen bestimmt werden.

Für eine Tetradenanalyse wurden sporulierende Hefezellen zunächst mit einer Impföse von der Kaliumacetat-Platte abgenommen und in $500 \mu$ l einer wässrigen $\beta$-Glucuronidase/Arylsulfatase Lösung (ca. 0,1 U/ml) für 10 Minuten bei RT inkubiert. Während der Inkubationszeit wurden die Ascuswände zum Teil abgebaut. Danach wurde der Ansatz durch Zugabe von $10 \mathrm{ml}$ sterilem $\mathrm{H}_{2} \mathrm{O}$ verdünnt, die Zellen durch 4minütige Zentrifugation bei $3000 \mathrm{~g}$ pelletiert und der Überstand dekantiert. Die Zellen wurden dann in dem im Glasröhrchen verbliebenen Rest an Medium resuspendiert. Von dieser Zellsuspension wurden $20 \mu \mathrm{l}$ auf eine Vollmedium-Platte pipettiert und mit einer Impföse zu einer geraden Linie am Rand der Agarplatte ausgestrichen. Unter dem Lichtmikroskop wurde eine Tetrade 
mit der Spitze der Glasnadel des Mikromanipulators zunächst vereinzelt, die vier Sporen des Ascus mit der Glasnadel getrennt und schließlich in definierten Abständen einzeln auf der Agarplatte ausgelegt. Zum Auskeimen der Sporen wurden die Platten für 2 bis 3 Tage bei $30^{\circ} \mathrm{C}$ inkubiert. Nachdem die Sporen zu Zellkolonien herangewachsen waren, konnte ihr jeweiliger Phänotyp durch Überimpfen auf selektive Agarplatten mit entsprechenden Aminosäurezusätzen bestimmt werden.

\subsubsection{Kreuzung von Hefezellen}

Die vier aus einer Tetradenanalyse hervorgegangenen Sporen besitzen unterschiedliche Paarungstypen. Jeweils zwei Sporen sind vom Typ a (MATa) bzw. vom Typ $\alpha$ (MAT $\alpha$ ). Eine Konjugation von haploiden Hefezellen geschieht nur bei Mischung von Zellen unterschiedlicher Paarungstypen. Die Verschmelzung führt zur Bildung einer diploiden Zygote. Die im Labor verwendeten heterothallischen Hefestämme behalten ihren Paarungstyp stabil bei und können daher dauerhaft als haploide Kultur herangezogen werden.

Zur Kreuzung wurden haploide Hefestämme mit unterschiedlichen Paarungstypen in Flüssigkultur herangezogen. Jeweils $20 \mu$ l beider Kulturen wurden linienförmig auf eine YEPG-Platte ausgestrichen und am unteren Ende mit der Impföse vermischt. Nach Inkubation über Nacht bei $30^{\circ} \mathrm{C}$ wurden die gewachsenen Zellen zur Selektion der diploiden Zellen auf SD-Minimalmedium überstempelt. Die diploiden Zellen, welche die Marker beider Ausgangsstämme enthielten, konnten nach einem weiteren Tag Inkubation bei $30^{\circ} \mathrm{C}$ als Kolonien identifiziert werden.

\subsubsection{Nachweis von sekretiertem $\alpha$-Pheromon mit dem „Halo“-Test}

Zur Bestimmung des Paarungstyps von Tetraden konnte die Sekretion des $\alpha$-Faktors mit dem „Halo“ (Hof)-Test quantifiziert werden (Julius et al., 1984). Der Test beruht auf der Sensitivität des MATaTeststammes RC989, der in der Gegenwart von $\alpha$-Faktor in der G1-Phase des Zellzyklus arretiert wird und deshalb in der Nähe von $\alpha$-Faktor sekretierenden Zellen nicht wachsen kann.

Zunächst wurden 1 g Agar in 100 ml-YEPG-Medium durch kurzes Aufkochen in der Mikrowelle und vorsichtigem Schwenken gelöst. Nach Abkühlung auf $40^{\circ} \mathrm{C}$ wurde das Medium mit $1 \mathrm{ml}$ einer stationären RC989-Kultur vermischt und in Kulturschalen gegossen. Die Agarplatten können bei $4^{\circ} \mathrm{C}$ ca. 10 Tage gelagert werden. Zur Identifizierung von $\alpha$-sekretierenden Stämmen wurden Zellen der zu untersuchenden Kultur als Tropfen auf die „Halo“-Platten aufgebracht und anschließend bei $30^{\circ} \mathrm{C}$ inkubiert. Um MAT $\alpha-Z e l l e n$ bildet sich nach einigen Tagen ein klarer Hof. 


\subsection{Isolierung von Proteinen aus E. coli-Zellen}

\subsubsection{Analytische Proteinexpression in kleinem Kulturvolumen}

Vor Beginn der Proteinreinigung in einem größeren Maßstab wurde die Proteinexpression zunächst in einem kleineren Kulturvolumen überprüft. Dazu wurde $1 \mathrm{ml}$ einer Übernachtkultur von transformierten E. coli BL21(DE3)-Zellen in $5 \mathrm{ml} \mathrm{LB}(\mathrm{Amp})$-Medium verdünnt und die Zellen bis zu einer $\mathrm{OD}_{600}=0,7$ 0,9 bei $37^{\circ} \mathrm{C}$ unter Schütteln inkubiert. Zur Induktion der Expression des Gens wurde der Kultur IPTG in einer Endkonzentration von $1 \mathrm{mM}$ zugesetzt und die Kultur weiter bei $37^{\circ} \mathrm{C}$ (bzw. $30^{\circ} \mathrm{C}$ oder $25^{\circ} \mathrm{C}$ ) inkubiert. Sowohl vor der Induktion als auch nach Wachstum von 2, 4 und 6 Stunden sowie nach einer Nacht wurden der Kultur jeweils ein Volumen an Zellen entnommen, welches der $\mathrm{OD}_{600}=1,0$ entsprach. Die einzelnen Proben wurden 3 Minuten bei $4000 \mathrm{~g}$ in einer Eppendorf-Tischzentrifuge abzentrifugiert, der Überstand verworfen und das Zellpellet in $100 \square 1$ Laemmli-Puffer resuspendiert. Nach 5- bis 10 minütigem Erhitzen auf $95^{\circ} \mathrm{C}$ (zur Denaturierung der Proteine) wurden 10 bis $20 \square 1$ der Proben durch analytische SDS-Polyacrylamid-Gelelektrophorese auf einem 12\% (15\%) -igen Gel überprüft oder bis zur weiteren Verwendung eingefroren.

\subsubsection{Expression und affinitätschromatographische Reinigung von Histidin- Fusionsproteinen aus E. coli-Zellen}

Rekombinante Proteine mit mindestens 6 Histidinresten am amino- oder carboxyterminalem Ende können durch Bindung an Nickel-Ionen, welche ihrerseits an eine Immobilisationsmatrix aus NTA-Harz (Nickelagarose von der Firma Qiagen, Düsseldorf) kovalent gebunden sind, und anschließender Elution mit Imidazol aus einem Bakterienlysat gereinigt werden (Hochuli, 1990). Diese Methode der MetallChelat-Affinitätschromatographie ist zur Reinigung sowohl von nativen, als auch von denaturierten Proteinen anwendbar.

Für die Expression von Histidin-Fusionsproteinen in E. coli BL21(DE3) wurde das Gen, welches für das entsprechende Protein codiert, über die Restriktionsschnittstellen NdeI/BamHI in die PlasmidVektoren pJC20[HisC] oder pJC20[HisN] integriert. Der Vektor pJC20[HisN] enthält eine Sequenz, welche für 10 Histidinreste $\left(\operatorname{His}_{10}\right)$ und eine Enterokinase-Schnittstelle, im gleichen Leserahmen wie die rekombinierte DNA, codiert; er wurde zur Konstruktion von Proteinen mit N-terminalem Histidinende eingesetzt. Der Vektor pJC20[HisC] enthält eine Sequenz, die für 6 Histidinreste $\left(\mathrm{His}_{6}\right)$ und ein abschließendes Stopcodon (TAG) codiert; er wurde zur Konstruktion von Proteinen eingesetzt, welche die Histidin-Sequenz am C-Terminus tragen.

\subsubsection{Proteinaufreinigung von Histidin-Fusionsproteinen}

Für die Proteinaufreinigung im größeren Kultur-Maßstab von $250 \mathrm{ml}$ bis 11 wurden 10 bzw. 20 ml LBAmp-Medium mit E. coli BL21(DE3)-Zellen einer Einzelkolonie, die kurz zuvor mit dem 
entsprechenden Expressionsvektor transformiert wurden, angeimpft und über Nacht bei $37^{\circ} \mathrm{C}$ inkubiert. Am nächsten Tag wurde die Übernachtkultur 1:50 mit frischem LB-Amp-Medium verdünnt und die Zellen bis zu einer $\mathrm{OD}_{600}=0,7-0,9$ bei $37^{\circ} \mathrm{C}$ unter Schütteln inkubiert. Nach Induktion der Expression durch Zugabe von IPTG in einer Endkonzentration von $1 \mathrm{mM}$ wurde die Kultur für weitere 4 bis 6 Stunden bei $37^{\circ} \mathrm{C}$ (bzw. über Nacht bei $30^{\circ} \mathrm{C}$ oder $25^{\circ} \mathrm{C}$ ) inkubiert. Sowohl vor, als auch nach der Induktion wurde jeweils ein Volumen an Zellen entnommen, das einer $\mathrm{OD}_{600}$-Einheit entsprach. Die Zellen wurden durch 3minütige Zentrifugation bei $4000 \mathrm{~g}$ pelletiert, in $100 \mu 11 \mathrm{x}$ Laemmli-Puffer resuspendiert und 5 bis 10 Minuten auf $95^{\circ} \mathrm{C}$ erhitzt, bevor sie bis zur weiteren Verwendung bei $-20^{\circ} \mathrm{C}$ eingefroren wurden. Die Zellen der Hauptkultur wurden ebenfalls durch 20minütige Zentrifugation bei $4000 \mathrm{~g}$ geerntet, in dem 2- bis 5 fachem Volumen des Pellet-Naßgewichtes in Puffer U resuspendiert und über Nacht oder bis zur weiteren Verwendung bei $-20^{\circ} \mathrm{C}$ eingefroren.

Der Aufschluß der Bakterienzellen erfolgte entweder bereits durch das Auftauen der Zellen bei RT und Zugabe von $1 \mathrm{mg} / \mathrm{ml}$ Lysozym oder durch zusätzliche Behandlung mit Ultraschall (3 Schritte à 30 - 60 Sekunden, $50 \%$ Pulse, 200 Watt) und abwechselnder Kühlung auf Eis (30 - 60 Sekunden). Die Freisetzung der Nukleinsäuren, ein Kriterium für den Zellaufschluß, konnte durch Messung der Absorption bei $260 \mathrm{~nm}$ verfolgt werden. Die Zelltrümmer wurden durch 20minütige Zentrifugation bei $>10000 \mathrm{~g}$ pelletiert, der Überstand mit dem löslichen Protein über eine zuvor mit Puffer U äquilibrierte

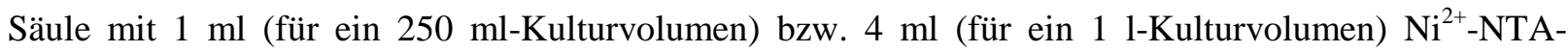
Agarose (50\%ige Suspension, äquilibriert in Puffer U) gegeben und der gesamte Durchlauf aufgefangen (Durchflußrate 0,5 ml/min). Danach wurde die $\mathrm{Ni}^{2+}$-Agarose mit 100 bzw. $200 \mathrm{ml}$ Puffer W gewaschen (Durchflußrate 0,5 ml/min), bis der $\mathrm{A}_{280}$-Wert des Durchlaufs unter 0,01 lag. Das an die Matrix aus $\mathrm{Ni}^{2+}$-Agarose gebundene Protein wurde mit $10 \mathrm{ml}$ (bei einem $250 \mathrm{ml}-$ Kulturvolumen) bis $20 \mathrm{ml}$ (bei einem 1 1-Kulturvolumen) eines Gradienten von 0 - 0,5 M Imidazol in Puffer W eluiert. Die Volumina und Konzentrationen der einzelnen Stufen des Imidazolgradienten wurden für die Reinigung unterschiedlicher Proteine entsprechend verändert und optimiert.

Zur Kontrolle der Proteinaufreinigung wurden sowohl aus den einzelnen Fraktionen mit eluiertem Protein, als auch aus dem Zell-Lysat mit dem gesamten löslichen Protein vor und nach der Induktion entsprechende Volumina von 10 bis $40 \mu \mathrm{l}$ entnommen und nach der Zugabe von 6 x Laemmli-Puffer 5 bis 10 Minuten auf $95^{\circ} \mathrm{C}$ erhitzt. Um weiter Informationen zur Effizienz der Aufreinigung zu erhalten, wurde zudem in einigen Fällen auch der Durchlauf mit der Gesamtheit des nicht an die $\mathrm{Ni}^{2+}$-NTAAgarose gebundenen Proteins (sowie evtl. einigen Waschschritten) entsprechend den obigen Angaben präpariert. Durch Analyse der entnommenen Proben von der nichtinduzierten Kultur bis zu den einzelnen Fraktionen des gereinigten Proteins auf 12\% (15\%) -igem Polyacrylamid-Gel konnte der gesamte Prozeß von der Proteinexpression in E. coli bis zur vollständigen Reinigung verfolgt und hinsichtlich der Qualität und Quantität des gereinigten Proteins beurteilt werden. 


\subsubsection{Expression und affinitätschromatographische Reinigung von GST- Fusionsproteinen aus E. coli-Zellen}

Eine zweite Methode der affinitätschromatographischen Reinigung von Proteinen aus Bakterienlysaten bietet das Glutathion-S-Transferase- (GST-) System (Smith und Johnson, 1988; Guan und Dixon, 1991). Bestandteile dieses Systems sind die pGEX-Plasmidvektoren, welche die für die Glutathion-STransferase codierende cDNA enthalten, die Bindungsmatrix aus Glutathion-Sepharose 4B und der GST-Detektions-Kit (Pharmacia, Freiburg). In dieser Arbeit wurde standardmäßig der Vektor pGEXRB (siehe Abb. 3.1, Brundiers, 1999) verwendet. Er basiert auf dem Vektor pGEX-TT (Smith und Johnson., 1988), besitzt jedoch eine modifizierte Multiple Cloning Site (MCP). Der Vektor besitzt nach dem GST-Anhang eine Sequenz, welche für eine Thrombin-Schnittstelle codiert.

Die Expression von GST-Fusionsproteinen in E. coli unterliegt der Kontrolle des tac-Promoters, welcher durch das Thiogalactosid Isopropyl-1-thio- $\beta$-galactopyranosid (IPTG) induziert wird. Die Bildung des GST-Fusionsproteins erfolgt wenige Stunden nach der Induktion. Nach mechanischem Aufschluß der Bakterienzellen kann das GST-Fusionsprotein durch Bindung an die GlutathionSepharose 4B und anschließender Elution mit $10 \mathrm{mM}$ Glutathion aus dem Lysat affinitätschromatographisch gereinigt werden.

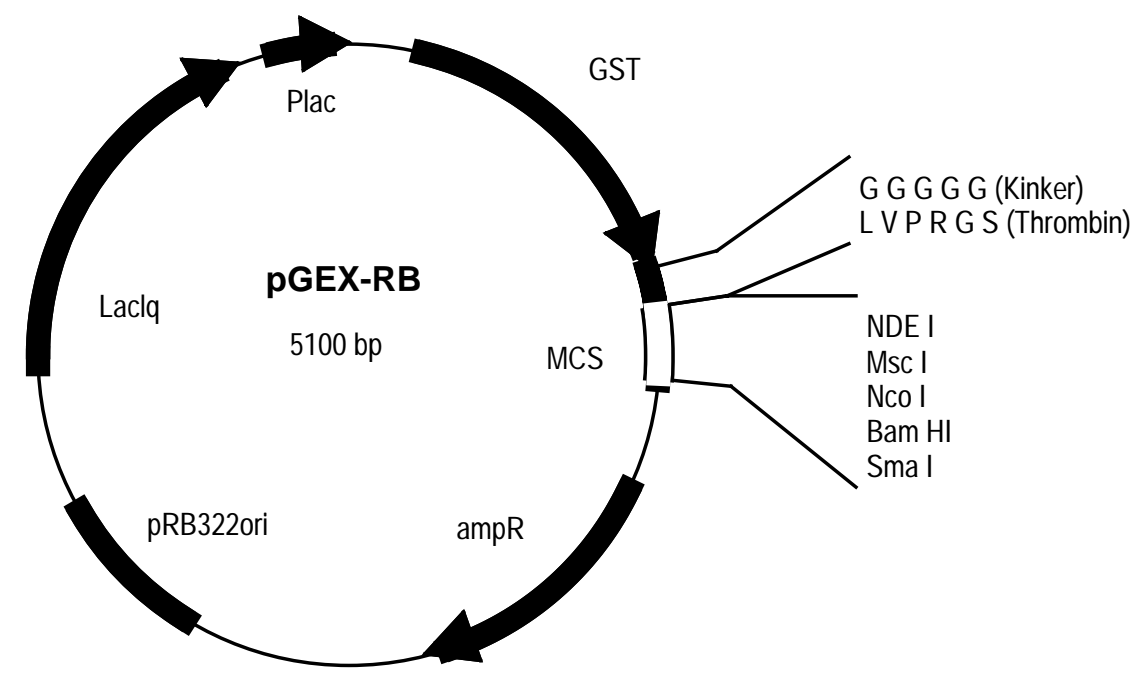

Abb. 3.1 Schema des E. coli Expressionsvektors pGEX-RB

\subsubsection{Expression von GST-Fusionsproteinen}

Bevor mit der Expression von GST-Fusionsproteinen in E. coli-Kulturen in größerem Maßstab begonnen wurde, erfolgte zunächst eine Überprüfung der Expression in kleinerem Kulturmaßstab. Dazu wurden mit einem rekombinanten Plasmidvektor pGEX-RB transformierte E. coli-BL21(DE3)-Zellen wie unter 3.10.1 beschrieben behandelt. Abweichend von dem Protokoll wurden die Zellen erst bei einer $\mathrm{OD}_{600}=1,0$ - 2,0 mit IPTG in einer Endkonzentration von 0,1 mM induziert. 
Die Expression von GST-Fusionsproteinen in 1 Liter Kulturvolumen erfolgte wie unter 3.10.2.1 beschrieben. Das Zellpellet wurde zum Schluß in $50 \mathrm{ml}$ eiskaltem PBS-Puffer resuspendiert und bis zur weiteren Verwendung bei $-20^{\circ} \mathrm{C}$ eingefroren.

\subsubsection{Aufreinigung von GST-Fusionsproteinen}

E. coli-Zellen einer 1 Liter-Kultur wurden durch Behandlung mit Ultraschall (30 - 60 Sekunden, 50\% Pulse, 200 Watt) und abwechselnder Kühlung auf Eis (jeweils abwechselnd 30 - 60 Sekunden Ultraschall und 30 Sekunden Kühlung, insgesamt 3 Schritte) aufgeschlossen. Zur Erhöhung der Effizienz des Zellaufschlusses, sowie der Löslichkeit des GST-Fusionsproteins, wurde das Bakterienlysat nach Zugabe von Lysozym (Endkonzentration $1 \mathrm{mg} / \mathrm{ml}$ ) und Triton X-100 (Endkonzentration 1\%) 30 - 60 Minuten vorsichtig bei $4^{\circ} \mathrm{C}$ geschüttelt. Anschließend wurden die Zelltrümmer durch 10minütige Zentrifugation bei $12000 \mathrm{~g}$ und $4^{\circ} \mathrm{C}$ pelletiert und der Überstand von 50 $\mathrm{ml}$ mit dem löslichen Protein in ein neues Reaktionsgefäß überführt. $\mathrm{Zu}$ dem Überstand wurden $2 \mathrm{ml}$ 50\%ige Glutathion Sepharose 4B-Lösung, die mit PBS-Puffer äquilibriert wurde, hinzugefügt und der gesamte Ansatz 30 Minuten bei RT unter vorsichtigem Schütteln inkubiert. Die gesamte Matrix mit absorbiertem Fusionsprotein wurde nun in eine 10 ml-Säule überführt und der Durchlauf mit dem ungebundenen Protein aufgefangen. Die Glutathion Sepharose 4B-Matrix wurde danach mit mindestens 3 x $10 \mathrm{ml}$ PBS-Puffer gewaschen. Die exprimierten Proteine konnten auf zwei unterschiedliche Arten eluiert werden:

\section{A. Elution als GST-Fusionsprotein}

Das gebundene Fusionsprotein wurde in 3 Schritten durch Zufügen von jeweils $1 \mathrm{ml}$ GlutathionElutionspuffer und daran anschließender mindestens 10minütiger Inkubation bei RT eluiert. Die drei Fraktionen mit gereinigtem Fusionsprotein wurden zum Schluß vereinigt.

\section{B. Thrombin-Verdau zur Freisetzung des Proteins ohne GST-Anhang}

Durch Einwirkung der Protease Thrombin auf das noch an die Sepharose 4B-Matrix gebundene Fusionsprotein war es möglich, das Protein vom N-terminalen GST-Anteil, welcher an die Matrix gebunden bleibt, abzuspalten und direkt zu eluieren. Dazu wurde die Matrix mit einem 1 vol Thrombinlösung (50 U Thrombin in $1 \mathrm{ml}$ PBS-Puffer) 2 - 12 Stunden bei $4^{\circ} \mathrm{C}$ inkubiert. Ein Unit der Thrombinlösung spaltet $100 \mu \mathrm{g}$ eines Testproteins in 16 Stunden bei $22^{\circ} \mathrm{C}$. Dieser Schritt wurde mindestens zweimal wiederholt, bis das gesamte gebundene Proteine von der Säule abgespalten war. Die Kontrolle der Menge an eluiertem Protein erfolgte durch den Bradford-Assay (siehe 3.12.1) oder durch Messung der Absorption bei $280 \mathrm{~nm}$ (siehe 3.12.2). Zur Kontrolle der Proteinaufreinigung wurden jeweils Aliquots der einzelnen Aufreinigungsschritte entnommen, nach der Zugabe von $6 \mathrm{x}$ Laemmli-Puffer 5 bis 10 Minuten auf $95^{\circ} \mathrm{C}$ erhitzt und durch Gelelektrophorese auf einem 12\% (15\%) - 
igen Polyacrylamidgel qualitativ und quantitativ analysiert. Gereinigte Proteine wurden üblicherweise aliquotiert, in flüssigem Stickstoff eingefroren und bei $-80^{\circ} \mathrm{C}$ gelagert.

\subsubsection{Expression und affinitätschromatographische Reinigung von MBP- Fusionsproteinen aus E. coli-Zellen}

Ein weiteres System zur affinitätschromatographischen Aufreinigung von Fusionsproteinen aus E. coli ist das pMAL-System. Der N-terminale Fusionspartner des aufzureinigenden Proteins ist in diesem System das Maltose-Bindungsprotein (MBP). Die Expression des Fusionsproteins unterliegt auch hier der Kontrolle des tac-Promoters, welcher durch IPTG induziert werden kann. Durch Bindung an eine Amylose-Matrix kann das MBP-Fusionsprotein in einem Schritt affinitätschromatographisch aus E. coli aufgereinigt werden (Guan et al., 1987; Riggs, 1990).

Zur Konstruktion des Fusionsproteins wird das Gen in einen pMAL-Vektor (New England Biolabs, Schwalbach) kloniert. Die pMAL-Vektoren besitzen das malE-Gen, welches für das MBP-Protein codiert, im gleichen Leserahmen wie das zu fusionierende Gen, so daß dieses mit dem malE-Gen am 5'Ende als MBP-Fusionsprotein in E. coli-Zellen überexprimiert werden kann. In dieser Arbeit wurde der Vektor pMAL-c2( $\Delta$ NdeI)-HsTK (Brundiers, 1999) verwendet. Er basiert auf dem Vektor pMAL-c2 (Riggs, 1990), enthält jedoch das Insert Hs-TK, welches eine Klonierung über die Schnittstellen NdeI/BamHI ermöglicht. Die Bildung des MBP-Fusionsproteins erfolgt wenige Stunden nach der Induktion. Nach mechanischem Aufschluß der Bakterienzellen kann das MBP-Fusionsprotein durch Bindung an die Amylose-Matrix und anschließender Elution mit Maltose aus dem Lysat aufgereinigt werden.

\subsubsection{Aufreinigung von MBP-Fusionsproteinen}

Vor Beginn der Proteinreinigung in einem größeren Maßstab wurde die Proteinexpression zunächst in einem kleineren Kulturvolumen überprüft. Dabei wurde wie unter 3.10 .1 beschrieben, vorgegangen. Abweichend von dem Protokoll erfolgte die Induktion der Expression mit IPTG in einer Endkonzentration von $0,3 \mathrm{mM}$ bereits bei einer $\mathrm{OD}_{600}$ von 0,5 .

Zur präparativen Aufreinigung von MBP-Fusionsprotein wurden 1 Liter LB(Amp)-Medium mit $10 \mathrm{ml}$ einer E. coli-Übernachtkultur angeimpft. Zur Unterdrückung der Expression der wirtseigenen chromosomalen Amylase, welche zu einem Abbau der Amylose-Matrix bei der späteren Aufreinigung führen würde, wurden dem Medium 0,2\% Glucose zugefügt. Die Kultur wurde bis zum Erreichen einer $\mathrm{OD}_{600}$ von $0,5-0,7$ bei $37^{\circ} \mathrm{C}$ unter Schütteln inkubiert. Nach Induktion der Expression durch Zugabe von IPTG in einer Endkonzentration von $0,3 \mathrm{mM}$ wurde die Kultur noch weitere 2 Stunden bei $37^{\circ} \mathrm{C}$ inkubiert. Die Zellen wurden anschließend durch 20minütige Zentrifugation bei $4000 \mathrm{~g}$ geerntet und das Pellet in $50 \mathrm{ml}$ MBP-Puffer resuspendiert. Der Zellaufschluß erfolgte durch Einfrieren der Suspension über Nacht bei $-20^{\circ} \mathrm{C}$ und durch Ultraschallbehandlung (abwechselnd jeweils 30 - 60 Sekunden, $50 \%$ Pulse, 200 Watt und 30 - 60 Sekunden Kühlung auf Eis). Die Zelltrümmer wurden anschließend durch 
30minütige Zentrifugation bei $9000 \mathrm{~g}$ vom Proteinextrakt getrennt und der Überstand nach Überführung in ein neues Reaktionsgefäß 1:5 mit MBP-Puffer verdünnt. Die Konzentration an MBP-Fusionsprotein im Proteinextrakt sollte etwa $2,5 \mathrm{mg} / \mathrm{ml}$ betragen. Der verdünnte Überstand wurde langsam (Flußrate 1 $\mathrm{ml} / \mathrm{min}$ ) über eine Säule mit 10 - $15 \mathrm{ml}$ Amylose-Matrix, die kurz zuvor mit 8 vol MBP-Puffer äquilibriert wurde, gegeben und der Durchlauf mit dem ungebundenen Protein aufgefangen. Die Amylose-Matrix wurde dann zunächst mit mindestens 12 vol MBP-Puffer gewaschen. Die gebundenen MBP-Fusionsproteine wurden anschließend in 10 Fraktionen von je $2 \mathrm{ml}$ mit $10 \mathrm{mM}$ Maltose in MBPPuffer eluiert. Der Proteingehalt der einzelnen Fraktionen wurde mit dem Bradford-Assay (siehe 3.12.1) oder durch Bestimmung der UV-Absorption bei $280 \mathrm{~nm}$ (siehe 3.12.2) bestimmt. Während der Proteinexpression und der -reinigung entnommene Aliquots wurden danach auf ein 12\% (15\%) -iges Polyacrylamidgel aufgetragen und die Effizienz der Proteinreinigung durch anschließende Elektrophorese quantitativ abgeschätzt.

\subsubsection{Aufreinigung von Proteinen durch Denaturierung und Renaturierung}

Die Einführung von Mutationen führte in einigen Fällen zur Unlöslichkeit von Proteinen. Diese Proteine waren unter nativen Bedingungen mit den diversen Aufreinigungs-Systemen nicht zu isolieren. Zur Solubilisierung der rekombinanten, jedoch als Einschlußkörper in der Zelle angehäuften, FusionsProteine und anschließender Zurückfaltung in die native Form wurde der „Protein Refolding“-Kit von Novagen (Madison, USA) verwendet. Dazu wurden die nach Zellaufschluß und anschließender Zentrifugation im Bakterienpellet vorliegenden Einschlußkörper zunächst unter milden denaturierenden Bedingungen mit einem alkalischen Puffer bestehend aus einer Kombination von CAPS und Lauroylsarcosin solubilisiert und die denaturierten Proteine nach Verdünnung der Proteinsuspension anschließend durch schrittweise Dialyse gegen einen neutralen Puffer unter anderem in Gegenwart des Redoxpaares GSSG-GSH (oxidiertes und reduziertes Glutathion) in ihren nativen Zustand zurückgefaltet. Die Denaturierung und Renaturierung der rekombinanten Proteine wurde strikt nach Vorschrift und mit den Lösungen des „Protein Refolding“-Kits durchgeführt.

Die auf dem oben genannten Weg isolierten Fusions-Proteine wurden nach Beendigung des letzten Dialyseschritts entsprechend ihres fusionierten Taqs (His- oder GST-Taq) affinitätschromatographisch wie unter Punkt 3.10.2.1 bzw. 3.10.3.2 beschrieben, aufgereinigt.

\subsection{Herstellung von Proteinextrakten aus S. cerevisiae}

\subsubsection{Mechanischer Aufschluß von Hefezellen mit Glasperlen}

Proteinextrakte aus S. cerevisiae wurden nach der Methode von Ausubel et al. (1987) hergestellt. Zellen einer S. cerevisiae-Einzelkolonie wurden in 50 oder $100 \mathrm{ml}$ Vollmedium (bzw. Minimalmedien mit den entsprechenden Aminosäurezusätzen) bei $30^{\circ} \mathrm{C}$ unter Schütteln bis zur mittleren exponentiellen Phase inkubiert $\left(\mathrm{OD}_{600}\right.$ ca. 1,0$)$ und danach durch 5 minütige Zentrifugation bei $1500 \mathrm{~g}$ und $4^{\circ} \mathrm{C}$ geerntet. Alle 
folgenden Schritte wurden bei $4^{\circ} \mathrm{C}$ durchgeführt, um einen proteolytischen Abbau von Proteinen zu vermeiden. Die Zellen wurden zunächst mit dem 2- bis 4fachen Volumen (1,0 - 4,0 ml) des PelletNaßgewichtes mit eiskaltem $\mathrm{H}_{2} \mathrm{O}$ gewaschen und anschließend in drei Volumen Aufschluß-Puffer resuspendiert. Nach dem Zufügen von 1 Volumen Glasperlen $(0,45-0,55 \mathrm{~mm})$, welche zuvor eine Stunde mit konzentrierter salpetriger Säure gewaschen und nach Neutralisation im Ofen getrocknet wurden, erfolgte der mechanische Aufschluß der Hefezellen durch abwechselndes Vortexen (1 Minute) und Kühlen auf Eis (1 Minute, 3 bis 5 Durchgänge insgesamt). Die Zellsuspension wurde anschließend erneut für 20 Minuten bei $12000 \mathrm{~g}$ und $4^{\circ} \mathrm{C}$ zentrifugiert und der Überstand mit dem löslichen Protein in ein neues Reaktionsgefäß überführt. 5 bis $10 \mu l$ des Proteinextrakts wurden sofort für Aktivitätsmessungen (siehe 3.17.1.1) eingesetzt.

\subsubsection{Alkalischer Aufschluß von Hefezellen}

Zellen einer logarithmisch wachsenden Hefe-Kultur wurden durch Zentrifugation bei $5000 \mathrm{~g}$ geerntet. Eine Menge an Zellen, welche $5 \mathrm{OD}_{600}$-Einheiten entsprach, wurde in $200 \mu 1$ alkalischem Lyse-Puffer suspendiert und 10 Minuten auf Eis inkubiert. Anschließend wurde TCA bis zu einer Endkonzentration von $10 \%(w / v)$ zugegeben und die Proteine durch 10minütige Inkubation auf Eis gefällt. Die gefällten Proteine wurden anschließend durch 5minütige Zentrifugation bei $16000 \mathrm{~g}$ pelletiert und durch Zugabe von $200 \mu \mathrm{l}$ 1M Tris-HCl, pH 8,0 neutralisiert. Nach erneuter Zentrifugation wurde das Protein-Pellet in $100 \mu 12$ x Laemmli-Auftrags-Puffer aufgenommen. Damit entsprachen $10 \mu$ l Proteinsuspension 0,5 $\mathrm{OD}_{600}$ Zellen. Vor dem Auftragen auf ein SDS-PAGE-Gel wurden die Proben 5 Minuten auf $95^{\circ} \mathrm{C}$ erhitzt. Im Gegensatz zum mechanischen Aufschluß (siehe 3.11.1) erfolgte der alkalische Aufschluß von Hefezellen nur vor Western-Blot-Analysen (Kap. 3.15).

\subsection{Bestimmung von Proteinkonzentrationen}

\subsubsection{Bradford-Assay}

Die Bestimmung von Proteinkonzentrationen erfolgte nach der Methode von Bradford (Bradford, 1976). Das Prinzip des Bradford-Assays beruht auf dem Wechsel des Absorptionsmaximum einer sauren Coomassie Brilliant Blue G-250-Lösung nach Bindung an Proteine von $465 \mathrm{~nm}$ nach $595 \mathrm{~nm}$. Die quantitative Bestimmung von Proteinen in Lösung wurde mit einer Farblösung und nach Vorschrift der Firma BioRad (Richmond, USA) durchgeführt. Eichkurven wurden unter Verwendung definierter Konzentrationen von Rinderserumalbumin hergestellt.

\subsubsection{Bestimmung der Proteinkonzentration durch UV-Absorption}

Da sich bei Proteinbestimmung mit dem Bradford-Assay die Proteinkonzentration einer unbekannten Probe im wesentlichen von der Konzentration an Rinderserumalbumin ableitet, ist die Abweichung von der tatsächlichen Proteinkonzentration manchmal sehr hoch. Für quantitative Messungen von Protein- 
Ligand Wechselwirkungen, sowie zur Bestimmung von Michaelis-Menten- und Dissoziationskonstanten, muß jedoch die Konzentration an aufgereinigtem Protein möglichst genau bekannt sein. In diesen Fällen wurde daher der molare Extinktionskoeffizient $\left(\varepsilon_{\mathrm{M}}\right)$ eines Proteins mit bekannter Aminosäuresequenz aus der Anzahl an aromatischen Aminosäuren nach Gill und Hippel (1989) berechnet $\left(\varepsilon_{\mathrm{M}}\right.$ der in dieser Arbeit verwendeten Proteine, siehe Anhang). War der Extinktionskoeffizient bekannt, so konnte die Konzentration einer homogenen Proteinsuspension durch Bestimmung der Absorption bei $280 \mathrm{~nm}$ mit Hilfe des Lambert-Beer'schen Gesetzes $(\mathrm{E}=\varepsilon \cdot c \cdot d$ mit $\mathrm{d}$ $=1 \mathrm{~cm})$ ermittelt werden.

\subsection{Konzentrieren und Entsalzen von Proteinen}

Für weiterführende Untersuchungen aufgereinigter Proteine mußten diese zum Teil noch höher konzentriert werden. Die Konzentrierung von Proteinen in Lösung wurde üblicherweise mit Amicon Centricon-Filtern (Millipore, Bedford, USA) nach Angaben des Herstellers durchgeführt. Für einige Untersuchungen mußte das Protein nach der Aufreinigung entsalzt werden. Zur Entsalzung oder Umpufferung wurde das Verfahren der Gelfiltration mit Sephadex G-25 angewendet. Dazu wurden 2 - 3 $\mathrm{ml}$ des eluierten Proteins über eine zuvor äquilibrierte PD-10-Säule (von Pharmacia, Freiburg) gegeben und das Protein in $1 \mathrm{ml}$-Schritten im neuen Puffer eluiert. Aufgereinigte Proteine wurden üblicherweise in flüssigem Stickstoff eingefroren und anschließend bis zur weiteren Verwendung bei $-80^{\circ} \mathrm{C}$ gelagert.

\subsection{Analyse von Proteinen durch SDS-PAGE nach Laemmli}

Die SDS-Polyacrylamid-Gelelektrophorese (SDS-PAGE) nach Laemmli (1970) ist eine Methode zur Auftrennung von Proteinen unter denaturierenden Bedingungen im elektrischen Feld. Zur Auftrennung von Proteinen mit einer Größe von 60 bis 200 kDa wurden Gele mit einem Polyacrylamid-Anteil von 6 $\%$ verwendet; mit 12 \% (15\%) -igen Polyacrylamid-Gelen konnten Proteine mit einer Größe von 15 bis $60 \mathrm{kDa}$ aufgetrennt werden. Die Denaturierung der Proteine erfolgt durch das in dem Laemmli-Puffer vorhandene anionische Detergenz Natriumdodecylsulfat (SDS), welches von Proteinen in großen Mengen gebunden wird, sowie durch $\beta$-Mercaptoethanol, welches die Disulfidbindungen in Proteinen reduziert. Durch die negative Ladung der Sulfatgruppe des SDS ist der gebildete SDS-Proteinkomplex stark negativ geladen, so daß die native Ladung des Proteins vernachlässigbar ist. Die Wanderungsgeschwindigkeit von Proteinen in der SDS-PAGE wird somit hauptsächlich durch den Siebeffekt der Gelmatrix und von der angelegten Stromstärke bestimmt und korreliert mit dem Molekulargewicht der Proteine. Die Porengröße der Gelmatrix kann durch Veränderung des Gehalts an Acrylamid-N,N'-Methylenbisacrylamid variiert werden.

Die SDS-PAGE wurde als diskontinuierliche Gelelektrophorese, d.h. mit Sammel- und Trenngel in unterschiedlichen Konzentrationen, in Mini-Elektrophoresekammern „Protean 3“ von Biorad (Richmond, USA) durchgeführt. Die Herstellung der SDS-PAGE-Gele erfolgte mit den Komponenten 
des „Protean 3“-Systems nach Angaben des Herstellers. Die Elektrophorese erfolgte bei konstanter Stromstärke von 30 bis $45 \mathrm{~mA}$ und war beendet, sobald der untere Farbmarker Bromphenolblau die untere Kante des Gels erreicht hatte. Das Gel wurde bei RT unter leichtem Schütteln 1 Stunde in der Färbelösung inkubiert und zum Schluß mehrere Stunden in Entfärbelösung gelegt.

Zusammensetzung des Sammelgels:

\begin{tabular}{lcc}
\hline Acrylamid [\%] & \multicolumn{2}{c}{5} \\
\hline Volumen [ml] & 0,65 & 10 \\
\hline $30 \%$ Acrylamid/N,N'-Methylen-Bisacrylamid $[\mathrm{ml}]$ & 1,25 & 2,30 \\
4 x Tris-HCl/SDS, pH 6,8 [ml] & 3,05 & 6,10 \\
$\mathrm{H}_{2} \mathrm{O}[\mathrm{ml}]$ & 25 & 50 \\
$10 \%$ Ammoniumperoxodisulfat $[\mu \mathrm{l}]$ & 5 & 10 \\
TEMED $[\mu \mathrm{l}]$ & & \\
\hline
\end{tabular}

Zusammensetzung des Trenngels:

\begin{tabular}{lcccc}
\hline Acrylamid [\%] & \multicolumn{2}{c}{12} & \multicolumn{2}{c}{15} \\
\hline Volumen [ml] & 15 & 25 & 15 & 25 \\
\hline $30 \%$ Acrylamid/N,N'-Methylen-Bisacrylamid $[\mathrm{ml}]$ & 6,00 & 10,00 & 7,50 & 12,50 \\
4 x Tris-HCl/SDS, pH 8,8 [ml] & 3,75 & 6,25 & 3,75 & 6,25 \\
$\mathrm{H}_{2} \mathrm{O}[\mathrm{ml}]$ & 5,19 & 8,65 & 3,69 & 6,15 \\
$10 \%(\mathrm{w} / \mathrm{v})$ Ammoniumperoxodisulfat $[\mu \mathrm{l}]$ & 50 & 83 & 50 & 83 \\
TEMED $[\mu \mathrm{l}]$ & 10 & 17 & 10 & 17 \\
\hline
\end{tabular}

\subsection{Immunologischer Nachweis von Proteinen durch Western- Blot-Analyse}

Für den immunologischen Nachweis von Proteinen wurden die aufgetrennten Proteine nach der Vorschrift von Burnette (1981) elektrophoretisch auf eine Nitrozellulose-Membran transferiert. Der Transfer der Proteine aus der Gelmatrix auf die Nitrozellulose-Membran erfolgte in einer speziellen Western-Blot-Apparatur (Mini Trans-Blot Kammer von Biorad) bei einer angelegten Stromspannung von $150 \mathrm{~mA}$ innerhalb von 2 - 12 Stunden.

Nach dem Transfer wurde die Nitrozellulose-Membran mit Ponceau-Rot reversibel gefärbt, um die Qualität der Proteintrennung und des Transfers zu überprüfen. Dazu wurde die Membran 2 - 5 Minuten in Ponceau-Rot-Lösung gefärbt und anschließend so lange mit destilliertem Wasser entfärbt, bis die Proteinbanden sichtbar hervortraten. Zur Absättigung der unspezifischen Bindungsstellen wurde die Nitrozellulose-Membran zunächst für eine Stunde bei RT in $100 \mathrm{ml}$ Puffer A unter leichtem Schütteln inkubiert. Danach wurde die Membran zunächst in $30 \mathrm{ml}$ Puffer A mit der entsprechenden Menge des 
spezifischen Antiserums (Verdünnung: 1:2000 bis 1:5000) für eine Stunde bei RT geschüttelt und anschließend 3 x mit Puffer A ohne Milchpulver gewaschen. Die Markierung der gebundenen Antikörper erfolgte durch einstündige Inkubation der Membran in $30 \mathrm{ml}$ Puffer A mit einem sekundären, Peroxidase-gekoppelten Antikörper (Verdünnung: 1:10000). Anschließend wurde die Membran nochmals 7 x mit Puffer A ohne Milchpulver und 3 x mit Puffer A ohne Triton X-100 und Milchpulver gewaschen.

Zur Detektion immunoreaktiver Proteine wurde das Reaktionssystem ECL der Firma Amersham Buchler (Braunschweig) nach Angaben des Herstellers eingesetzt (Prinzip des Nachweissystems, siehe Durrant, 1992). Hierzu wurde die Nitrozellulose-Membran für eine Minute in einem 1:1 Gemisch aus ECL-Lösung 1 und 2 (jeweils 2,5 ml) geschwänkt. Danach wurde die Membran auf WhatmanFilterpapier gelegt, mit Frischhaltefolie abgedeckt und zur Detektion der Chemilumineszenz ein Röntgenfilm aufgelegt. Je nach Intensität des Peroxidase-Signals wurde der Film nach 1 - 5 Minuten entwickelt.

\subsection{Gelfiltration}

Das Molekulargewicht von gereinigten Proteinen $(5-10 \mu \mathrm{g})$ wurde durch GelfiltrationsChromatographie über eine Superose 12-Säule mit dem Smart-System von Pharmacia bestimmt (Flußrate 0,1 $\mathrm{ml} / \mathrm{min}$ ). Die Säule wurde zuvor mit PBS-Puffer äquilibriert. Die Kalbrierungskurve wurde mit den Molekulargewichts-Markern Thyroglobulin (670 kDa), $\gamma$-Globulin (158 kDa), Ovalbumin (44 kDa), Myoglobin (17 kDa) und Vitamin B-12 (1350 Da) unter gleichen Bedingungen erstellt.

\subsection{Analytische Ultrazentrifugation}

Die analytische Ultrazentrifugation mißt die Reinheit, das Molekulargewicht und andere Eigenschaften von Makromolekülen in Lösung (Ralston, 1993, Van Holde, 1975). In dieser Arbeit wurde zur Bestimmung des Molekulargewichts sowie des Sedimentationskoeffizienten von nativen und denaturierten Proteinen die analytische Ultrazentrifuge Optima XL-A (von Beckman) ausgerüstet mit einem UV-Absorpionsoptik.

Das Prinzip der Methode beruht darauf, durch Zentrifugation ein starkes Schwerkraftfeld an eine Makromoleküllösung (Protein- oder DNA-Lösung) anzulegen. Bei einer bestimmten Feldstärke bewegt sich ein Makromolekül mit bestimmter Geschwindigkeit. Das Verhältnis von Geschwindigkeit zu Zentrifugalkraft wird der Sedimentationskoeffizient $(s)$ des Moleküls genannt. In einem Zentrifugalfeld hängt die Geschwindigkeit, mit der sich ein Proteinmolekül in Lösung bewegt, von drei Kräften ab: 
1.) Sedimentationskraft $F_{s}$ :

$$
F_{s}=\mathrm{m} \omega^{2} \mathrm{r}
$$

m: Masse des Moleküls [g]

r: Radiale Distanz zwischen Molekül und Rotationszentrum [cm]

$\omega: \quad$ Winkelgeschwindigkeit $\left[\mathrm{rad} \cdot \mathrm{s}^{-1}\right]$

2.) Auftriebskraft $F_{b}$ :

$$
\begin{aligned}
& F_{b}=-\mathrm{m}_{0} \omega^{2} r \text { wobei } \\
& \mathrm{m}_{0}=\mathrm{m} \bar{v} \rho
\end{aligned}
$$
$\overline{\mathrm{v}}$ : Partielles spezifisches Volumen (1/Dichte) des Moleküls $\left[\mathrm{cm}^{3} / \mathrm{g}\right]$
$\rho: \quad$ Dichte des Lösungsmittels $\left[\mathrm{g} / \mathrm{cm}^{3}\right]$

3.) Reibungskraft $F_{f}$ :

$$
F_{f}=-f u
$$

f: Reibungskoeffizient $\left[\mathrm{g} \cdot \mathrm{s}^{-1}\right]$

$\mathrm{u}$ : Geschwindigkeit des Moleküls $\left[\mathrm{m} \cdot \mathrm{s}^{-1}\right.$ ]

Sowohl Auftriebskraft, als auch Reibungskraft wirken der Sedimentationskraft entgegen. Im Zentrifugalfeld befinden sich alle drei Kräfte sehr schnell im Geichgewicht:

$$
F_{s}+F_{b}+F_{f}=0 \quad \text { oder } \quad \mathrm{m}(1-\bar{v} \rho) \omega^{2} \mathrm{r}-\mathrm{f} u=0
$$

Daraus ergibt sich die Definition des Sedimentationskoeffizienten (s):

$$
s \equiv \frac{\mathrm{m}(1-\bar{v} \rho)}{\mathrm{f}}=\frac{\mathrm{u}}{\omega^{2} \mathrm{r}}
$$

Der Sedimentationskoeffizient hängt von den Eigenschaften (Größe, Form) des Moleküls ab. Moleküle können grundsätzlich nur dann sedimentieren, wenn die Sedimentationsgeschwindigkeit größer als die Diffusion, d.h. die Rotationsgeschwindigkeit ausreichend groß, ist. Der Sedimentationskoeffizient hat die Einheit Svedberg, $\mathrm{S}\left(1 \mathrm{~S}=1 \cdot 10^{-13} \mathrm{~s}\right)$. Die meisten Moleküle haben einen Sedimentationskoeffizienten zwischen 1 und 100. In dieser Arbeit wurde der Sedimentationskoeffizient zur Dokumentation von Konformationsänderungen innerhalb eines Proteins nach Ligandenbindung bestimmt (siehe dazu auch Durchschlag et al., 1996).

Bei der Gleichgewichtszentrifugation werden Moleküle in Lösung so lange einem Zentrifugalfeld ausgesetzt, bis sich ein Gleichgewicht über einem Konzentrationsgradienten ausgebildet hat. Das ist dann der Fall, wenn der Sedimentationsprozess mit der in entgegengesetzter Richtung wirkenden Diffusion im Gleichgewicht steht. Die Verteilung der Konzentrationen ist alleine von der Masse des Moleküls, $M=m \cdot(1-\bar{v} \rho)$, abhängig. Im Gegensatz zur Bestimmung des Sedimentationskoeffizienten erfolgt die Gleichgewichtszentrifzugation bei moderaten Rotationsgeschwindigkeiten. Die Konzentration bei Erreichen des Gleichgewichts der Sedimentation gehorcht folgender Funktion: 


$$
\begin{aligned}
& M_{w}=\frac{2 \mathrm{RT}}{(1-\bar{v} \rho) \omega^{2}} \cdot \frac{\mathrm{d}(\ln \mathrm{c})}{\mathrm{d} \mathrm{r}^{2}} \quad \begin{array}{ll}
\mathrm{M}_{\mathrm{w}}: & \begin{array}{l}
\text { Molekulargewicht }[\mathrm{g} / \mathrm{mol}] \\
\text { R: }
\end{array}
\end{array} \\
& \text { T: } \quad \text { Absolute Temperatur }(293,2 \mathrm{~K}) \\
& \text { c: Konzentration }[\mathrm{g} / \mathrm{l}] \\
& \text { r: Radiale Distanz der Rotationsachse (cm) }
\end{aligned}
$$

In dieser Arbeit wurde die Gleichgewichtszentrifugation zur Bestimmung des Molekulargewichts und Oligomerisierungsgrades von Proteinen in nativen Lösungsmitteln und denaturierenden Lösungsmitteln, z.B. 6 M Guanidinhydrochlorid, eingesetzt.

\section{Bestimmung des Sedimentationskoeffizienten}

Der Sedimentationskoeffizient eines Proteins läßt sich durch ein SedimentationsgeschwindigkeitsExperiment bestimmen. Hierbei betrachtet man die Sedimentation einer homogenen Proteinfraktion von der Radiusposition der Lösungsoberfläche (Meniskus) zum Boden der Meßzelle. Die Proteinmoleküle reichern sich im Lauf des Experiments am Boden an und es bildet sich eine sedimentierende Grenzschicht zwischen Lösungsmittel und gelöster Substanz. Die Lage dieser Genzschicht kann zeitabhängig durch Absorptionsmessung bestimmt werden. Es ergeben sich sigmoidale Kurven (Auftragung: $\mathrm{c} \rightarrow \mathrm{r}$ ), aus denen durch nichtlineare Regression der Sedimentationskoeffizient bestimmt werden kann (Ralston, 1993). Die Kurven wurden mit der Software Origin (MicroCal, Northampton, USA) ausgewertet. In dieser Arbeit wurden die Parameter $\omega$ und $\mathrm{r}$ automatisch durch die MicroCalSoftware aus den Datenfiles bestimmt. Demgegenüber mußten die Konstanten $\rho$ und $\bar{v}$ manuell bestimmt werden. Die Dichte $\rho$ und Viskosität $\eta$ des Lösungsmittels wurden mit einem Pyknometer und einem Kapillarviskosimeter (Schott) bei $20^{\circ} \mathrm{C}$ ermittelt. Das spezifische Volumen ( $\bar{v}$ ) der Moleküle in Lösung wurde auf Grundlage der Aminosäuresequenz der untersuchten Proteinmoleküle berechnet (McRorie und Voelker, 1993) $\bar{v}$ der untersuchten Proteine, siehe Anhang). Vor Beginn der einzelnen Läufe wurden die Proteine zunächst mindestens 12 Stunden gegen den experimentellen Puffer PBS dialysiert und die $\mathrm{OD}_{280}$ auf einen Wert zwischen 0,2 und 1,0 (entsprach $1-10 \mu \mathrm{M}$ ) eingestellt. $280 \mu \mathrm{l}$ der Proteinlösung und $320 \mu 1$ der Referenzlösung (Dialysat) wurden in die Meßzellen eingefüllt und die Proteine bei $20^{\circ} \mathrm{C}$ und $42000 \mathrm{U} / \mathrm{min}$ für 2 bis 3 Stunden sedimentiert.

Die oben aufgeführten Berechnungen liefern $s_{\text {obs }}$, d.h. den beobachteten Sedimentationskoeffizienten. Zum Vergleich von Werten in anderen Lösungsmitteln (z.B. $6 \mathrm{M}$ Guanidinhydrochlorid) oder bei anderen Temperaturen müssen alle Sedimentationskoeffizienten nach internationaler Vereinbarung auf den theoretischen Sedimentationskoeffizienten in Wasser bei $20^{\circ} \mathrm{C}$ umgerechnet werden: 


$$
s_{20, w}=\frac{\eta_{t}}{\eta_{20}} \cdot \frac{\eta_{c}}{\eta_{0}} \cdot \frac{\left(1-\bar{v} \rho_{20, w}\right)}{\left(1-\bar{v} \cdot \rho_{t}\right)} \cdot s_{o b s}
$$

$\eta_{\mathrm{t}}$ : Viskosität von Wasser bei Temperatur $\mathrm{t}$

$\eta_{20}$ : Viskosität von Wasser bei Temperatur $20^{\circ} \mathrm{C}$

$\eta_{\mathrm{c}}$ : Viskosität des Puffers bei t

$\eta_{0}$ : Viskosität von Wasser bei $t$

$\rho_{20, w}$ : Dichte von Wasser bei $20^{\circ} \mathrm{C}$

$\rho_{\mathrm{t}}$ : $\quad$ Dichte des Puffers bei $t$

Hydrodynamische Berechnungen

Der Sedimentationskoeffizient $s$ steht über die Svedberg-Gleichung in Bezug zum Diffusionskoeffizient $D\left[\mathrm{~cm}^{2} \mathrm{~s}^{-1}\right]$ :

$$
D=\frac{s \cdot \mathrm{R} \cdot \mathrm{T}}{\mathrm{M} \cdot(1-\rho \cdot \bar{v})}
$$

Die Stokes-Einstein-Gleichung verknüpft den Diffusionskoeffizient $(D)$ mit dem Stokes-Radius des hydratisierten Moleküls $R_{\mathrm{S}}[\AA]$ :

$$
D=\frac{k \cdot T}{6 \cdot \pi \cdot \eta \cdot R_{\mathrm{S}}}
$$

Bestimmung des Molekulargewichts und Assoziierungszustandes

Bei der Gleichgewichtszentrifugation zur Bestimmung des Molekulargewichts wurden die gleichen Zwei-Sektoren-Meßzellen $(1,2 \mathrm{~cm})$ mit Quarzfenster wie bei der Ermittlung von $s$ verwendet. Jedoch wurden die Volumina von Proteinlösung und Referenz auf ein Drittel $(120 \mu 1)$ verringert. Nach etwa 40stündiger Zentrifugation bei 15000 und 18000 U/min blieb der Konzentrationsgradient konstant. Die Absorptionsprofile wurden mit der Software Origin (MicroCal), nach dem Modell einer monomeren, homogenen, idealen Proteinspezies analysiert

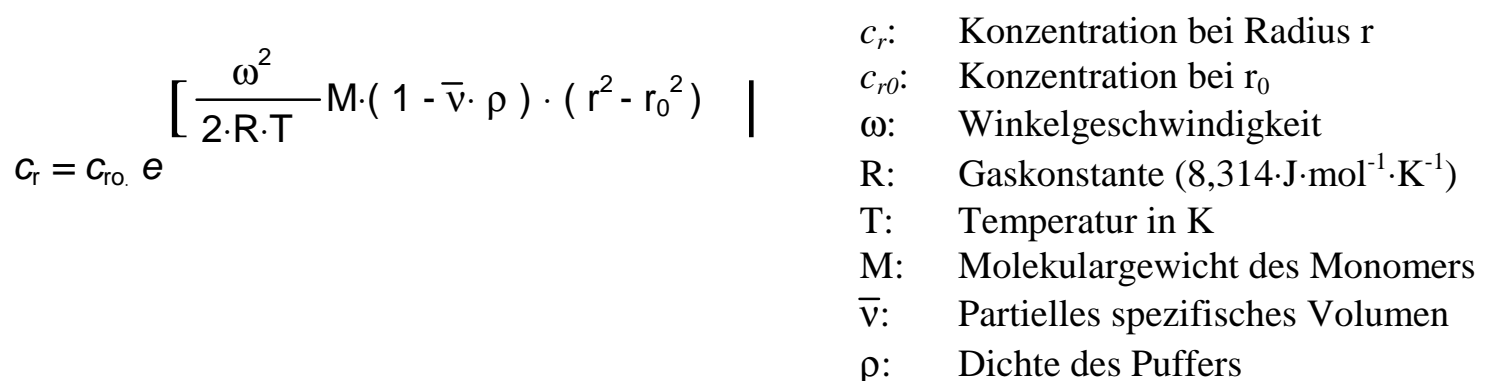

In Fällen, in denen das nach obigem Modell eines idealen Monomers erhaltene apparente Molekulargewicht $\left(\mathrm{M}_{\mathrm{w}}\right.$, app $)$ signifikant über dem berechneten lag, wurde Selbst-Assoziation des Proteins angenommen. Aus diesem Grund wurden weitere Gleichgewichtsmodelle (Monomer-Tetramer, Monomer-Dimer-Tetramer, siehe 4.3.2.1.2) zur Beschreibung des Oligomerisierungszustandes herangezogen. 


\subsection{Kinetische Methoden}

\subsubsection{Messung der Enzymaktivität}

Sowohl die Messungen der spezifischen Aktivität, als auch die Bestimmung der Michaelis-MentenParameter (siehe 3.18.2) von Guanylatkinasen (GUK) wurden ausnahmslos unter steady-state Bedingungen in einem gekoppelten Enzym-Assay mit den Enzymen Lactatdehydrogenase (LDH) und Pyruvatkinase (PK) bestimmt (Agarwal et al., 1978). durchgeführt. Das Enzym Pyruvatkinase katalysiert in diesem Enzym-System die Übertragung von 2 Phosphatresten des Substrats Phosphoenolpyruvat (PEP) auf ADP und GDP, die Produkte der Guanylatkinasereaktion. Neben ATP und GTP werden bei dieser Reaktion 2 Moleküle Pyruvat gebildet, die in einer darauffolgenden, durch das Enzym Lactatdehydrogenase katalysierten Reaktion unter Verbrauch von 2 Molekülen $\mathrm{NADH}+\mathrm{H}^{+}$ zu 2 Molekülen Lactat reduziert werden. Im Gegensatz zu NADH absorbiert das während dieser Reaktion gebildete $\mathrm{NAD}^{+}$bei einer Wellenlänge von $340 \mathrm{~nm}$ fast nicht mehr und kann deshalb spektrophotometrisch nachgewiesen werden. Eine Einheit (Unit, U) ist definiert als die Menge an Guanylatkinase, die notwendig ist, um $1 \mu \mathrm{mol}$ Phosphat in 1 Minute bei $25^{\circ} \mathrm{C}$ und $\mathrm{pH}$ 7,6 von ATP auf GMP zu übertragen.

$\underline{\text { Reaktionsschema: }}$

$$
\begin{aligned}
& \mathrm{ATP}+\mathrm{GMP} \stackrel{\mathrm{GK}}{\rightleftarrows} \mathrm{ADP}+\mathrm{GDP} \\
& \mathrm{ADP}+\mathrm{GDP}+2 \mathrm{PEP} \stackrel{\mathrm{PK}}{\rightleftharpoons} \mathrm{ATP}+\mathrm{GTP}+2 \text { Pyruvat } \\
& 2 \text { Pyruvat }+2 \mathrm{NADH}+2 \mathrm{H}^{+} \stackrel{\mathrm{LDH}}{\rightleftharpoons} 2 \mathrm{~L}-\text { Lactat }+2 \mathrm{NAD}^{+}
\end{aligned}
$$

$\begin{array}{lcl}\text { Testlösung: } & 100 \mathrm{mM} & \text { Tris-HCl, } \mathrm{pH} 7,5 \\ 100 \mathrm{mM} & \mathrm{KCl} \\ 10 \mathrm{mM} & \mathrm{MgCl}_{2} \\ 2 \mathrm{mM} & \text { ATP } \\ 1 \mathrm{mM} & \text { GMP } \\ 0,5 \mathrm{mM} & \text { PEP } \\ 0,25 \mathrm{mM} & \text { NADH } \\ 5 \mathrm{U} & \text { LDH } \\ 4 \mathrm{U} & \text { PK }\end{array}$

Zu 0,5 ml (bzw. $1 \mathrm{ml}$ ) an Testlösung wurden jeweils 1 bis $5 \mu \mathrm{l}$ der unbekannten Proteinlösung oder, vorausgesetzt die Konzentration war bekannt, gereinigtes Protein in nanomolarer Konzentration gegeben und die Änderung der Absorption bei $340 \mathrm{~nm}$ (Absorptionsmaximum von NADH) und $25^{\circ} \mathrm{C}$ über einen Zeitraum von 3 bis 5 Minuten mit einem Uvikon 943-Photometer gemessen. Die Messung wurde unter sättigenden Bedingungen durchgeführt, d.h. im Assay waren alle Substrate im Überschuß 
vorhanden. Dadurch war eine lineare Abnahme der Absorption bei $340 \mathrm{~nm}$ im Anfangsbereich gewährleistet. Mit Hilfe einer eingebauten Software zur Berechnung von zeitabhängigen Kinetiken war es dann möglich, aus dem linearen Bereich des Reaktionsablaufes die Steigung zu berechnen, die der Abnahme der Absorption pro Minute entsprach $\left(\Delta \mathrm{A}_{340} / \mathrm{min}\right)$. Die spezifische Aktivität wurde nach folgender Formel berechnet:

$$
\begin{aligned}
\text { Volumen-Aktivität (in der Testlösung) } & =\frac{\Delta \mathrm{A}_{340} / \Delta \mathrm{t}}{2 \cdot \varepsilon \cdot \mathrm{d}} \\
\text { Volumen-Aktivität (in der Proteinprobe) } & =\frac{\Delta \mathrm{A}_{340} / \Delta \mathrm{t} \cdot \mathrm{V}}{2 \cdot \varepsilon \cdot \mathrm{d} \cdot \mathrm{v}} \\
\text { Spezifische Aktivität } & =\frac{\text { Volumen-Aktivität }}{\text { Proteinkonzentration (c) }}
\end{aligned}
$$

Hierbei ist:

$$
\begin{aligned}
\Delta \mathrm{A}_{340} / \Delta \mathrm{t}= & \text { Absorptionsänderung pro Zeiteinheit } \\
\varepsilon & \text { molarer Absorptionskoeffizient von NADH }\left(6,2 \mathrm{mM}^{-1} \mathrm{~cm}^{-1} \text { bzw. } 6,2 \mathrm{~cm}^{2} \mu \mathrm{mol}^{-1}\right. \\
& \text { bei } 340 \mathrm{~nm}) \\
\mathrm{d} & \text { Lichtweg (Schichtdicke der Meßküvette) }[\mathrm{cm}](\text { i.a. } 1 \mathrm{~cm}) \\
\mathrm{V} & \text { Reaktionsvolumen }[\mathrm{ml}] \\
\mathrm{v} & \text { Enzym-Probevolumen }[\mathrm{ml}] \\
\mathrm{c} & = \\
\mathrm{U} \quad & \text { Proteinkonzentration }[\mathrm{mg} / \mathrm{ml}] \\
& \text { Enzym-Einheit, definiert als die Menge Enzym, welche die Umwandlung von } 1 \\
& \mu \text { Mol GMP in GDP pro Minute unter den vorgegebenen Reaktionsbedingungen } \\
& \text { katalysiert. }
\end{aligned}
$$

Da das Hilfsenzym Pyruvatkinase (PK) die Nukleotide ADP und GDP gleichermaßen als Substrate annimmt, werden bei der Umwandlung von einem Mol GMP zu GDP zwei Mol NADH oxidiert; daher geht der Faktor 2 in die obigen Formeln ein.

Ein weiteres Maß zur Bestimmung der Aktivität eines Enzyms unter steady-state Bedingungen ist die Umsatzrate. Sie gibt die maximale Anzahl an Substratmolekülen an, welche bei vollständiger Substratsättigung von einem Molekül des Enzyms (bzw. seines aktiven Zentrums) pro Sekunde umgesetzt werden kann. Die Umsatzrate wird mit $k_{c a t}$ (katalytische Konstante) abgekürzt und hat die Einheit $\mathrm{s}^{-1}$ :

$$
k_{\text {cat }}=\frac{\mu \mathrm{mol}(\text { Substrat })}{\mu \mathrm{mol}(\text { Enzym }) \cdot \mathrm{s}}\left[\mathrm{s}^{-1}\right]
$$




\subsubsection{Michaelis-Menten Parameter}

Michaelis und Menten (1913) haben Reaktionen von Enzym und Substrat unter steady-state Bedingungen charakterisiert. Unter der Voraussetzung, daß das Enzym im Vergleich zum Substrat in vernachlässigbar geringer Konzentration vorliegt, kann eine Enzym-Substrat Reaktion sehr vereinfacht als Reaktion pseudo-erster Ordnung durch folgendes Schema beschrieben werden:

$$
\mathrm{E}+\mathrm{S} \stackrel{K_{S}}{\longrightarrow} \mathrm{ES} \stackrel{k_{\text {cat }}}{\longrightarrow} \mathrm{E}+\mathrm{P}
$$

Zunächst bilden Enzym (E) und Substrat (S) den Enzym-Substrat-Komplex (ES). Es wird vorausgesetzt, daß dieser Schritt schnell und reversibel erfolgt. Im Komplex werden Enzym und Substrat durch nichtkovalente Kräfte zusammengehalten. Die chemische Reaktion erfolgt dann in einem zweiten Schritt mit der Umsetzungsrate $k_{\text {cat }}$ (Konstante 1. Ordnung). Wenn der geschwindigkeitsbestimmende Schritt der gesamten Reaktion $k_{c a t}$ ist, dann ist die Reaktionsgeschwindigkeit von der Konzentration des gebildeten Komplexes abhängig, d.h.:

und

$$
\frac{[\mathrm{E}][\mathrm{S}]}{[\mathrm{ES}]}=K_{S} \quad \text { (Gleichung 1) }
$$

$$
v=k_{\text {cat }}[\mathrm{ES}]
$$

Die Konzentration des gesamten Enzyms $[E]_{0}$ ist mit der Konzentration an freiem Enzym [E] über folgenden Term verbunden:

$$
[E]=[E]_{0}-[E S]
$$

Aus Gleichung 1 und 3 folgt:

$$
[E S]=\frac{[E]_{0}[S]}{K_{S}+[S]}
$$

Aus Gleichung 2 und 4 folgt:

$$
\mathrm{v}=\frac{[\mathrm{E}]_{0}[\mathrm{~S}] k_{\text {cat }}}{K_{S}+[\mathrm{S}]}
$$

In der Michaelis-Menten-Gleichung entspricht die Dissoziationskonstante des Enzym-SubstratKomplexes $K_{S}$ dem Parameter $K_{M}$. Unter der Annahme, daß [S] sehr viel größer als $K_{M}$ ist, erhält man aus Gleichung 5 die Definition der maximalen Reaktionsgeschwindigkeit:

$$
\mathrm{v}_{\max }=k_{\text {cat }}[\mathrm{E}]_{0}
$$

(Gleichung 6)

Eingesetzt in Gleichung 5 ergibt sich die Michaelis-Menten-Gleichung:

$$
v=\frac{[S] v_{\max }}{K_{M}+[S]}
$$

Die Konstante $\mathrm{K}_{\mathrm{M}}$ hat die Dimension einer Konzentration [M]. Setzt man in Gleichung 7 [S] = $K_{M}$, dann ist $\mathrm{v}=\mathrm{v}_{\max } / 2 . K_{M}$ entspricht daher der Substratkonzentration, bei der die halbe maximale 
Geschwindigkeit erreicht ist bzw. bei der das Enzym zur Hälfte mit Substrat gesättigt ist. Ein niedriger $K_{M}$-Wert zeigt demnach eine hohe Affinität des Enzyms zum Substrat an. Die Michaelis-MentenParameter können experimentell bestimmt werden, indem unter steady-state Bedingungen die Substratkonzentrationen variiert werden. Die Reaktionsgeschwindigkeit $\mathrm{v}$ ist dann, wie Gleichung 7 zeigt, hyperbolisch von [S] abhängig.

Die Michaelis-Menten Parameter $K_{M}$ und $\mathrm{v}_{\max }$ verschiedener Guanylatkinasen für die Substrate ATP und GMP wurden mit Hilfe des gekoppelten, spektrophotometrischen Assays (siehe 3.18.1) bestimmt. Zur Ermittlung des $K_{M}$ von GMP (ATP) wurde die Konzentration von ATP (GMP) konstant im Überschuß von $2 \mathrm{mM}(1 \mathrm{mM})$ gehalten, während GMP (ATP) in mindestens 5 Ansätzen in verschiedenen Konzentrationen (GMP: $2 \mu \mathrm{M}-1 \mathrm{mM}$, ATP: $2 \mu \mathrm{M}-4 \mathrm{mM}$ ) hinzutitriert wurde. Die Reaktionsgeschwindigkeiten wurden für jeden Ansatz bestimmt und graphisch gegen die eingesetzten Substratkonzentrationen aufgetragen. Die Michaelis-Menten Parameter konnten dann mittels der Software Origin aus der hyperbolischen Auftragung bestimmt werden.

\subsection{Untersuchung von Protein-Ligand Wechse/wirkungen}

In dieser Arbeit wurden vor allem Proteine der MAGUK-Familie (Garner und Kindler, 1996), auf ihre Nukleotidbindungs-Eigenschaften untersucht. Dies geschah zunächst in einem qualitativen Ansatz mit der Nano-Elektrospray-Massenspektrometrie (Nano-ESMS, siehe 3.19.1). Die Dissoziationskonstanten wurden mit der Gleichgewichtsdialyse (siehe 3.19.2) und dem Filter-Assay (siehe 3.19.3) bestimmt.

\subsubsection{Nano-Elektrospray-Massenspektrometrie (Nano-ESMS)}

Die Massenspektrometrie stellt eine wichtige Methode zur Bestimmung der molekularen Massen von Makromolekülen, wie z. B. von Proteinen und Nukleinsäuren, dar. Das Prinzip der Massenspektrometrie beruht auf der Ionisierung und anschließenden Trennung der ionisierten Moleküle in gasförmiger Phase aufgrund ihres Masse-Ladungs-Verhältnisses. Bei der ElektrosprayMassenspektrometrie (ES-MS) wird die Probe zunächst angesäuert (z.B. mit Methanol und Ameisensäure) und als feiner Spray in das Massenspektrometer gebracht. Die Ionisierung der Moleküle geschieht in einem elektrischen Feld. Aufgrund des im Massenspektrometer anliegenden Vakuums verdampft die Lösung sehr schnell und hinterläßt die positiv geladenen Moleküle. Nicht-kovalente Bindungen, mit Ausnahme elektrostatischer Wechselwirkungen, können unter den im Massenspektrometer vorherrschenden Bedingungen nicht aufrechterhalten werden. Die geladenen Moleküle werden zunächst durch das elektrische Feld beschleunigt und dann durch ein magnetisches Feld abgelenkt. Sie werden anschließend nach dem Verhältnis ihrer Masse/Ladungszahl (m/z) voneinander getrennt und detektiert. Das Spektrum eines reinen Moleküls zeigt eine Schar von Peaks, welche die Verteilung der unterschiedlich geladenen Proteinspezies angibt. Die Meßgenauigkeit der ESMS liegt bei 0,005-0,01\%. 
Die Nano-Elektrospray-Massenspektrometrie (Nano-ESMS) stellt eine einfache Modifikation der Elektrospray-Massenspektrometrie dar (Wilm und Mann, 1996). Bei der Nano-ESMS ist der Durchmesser der Nanospray-Kapillare auf wenige Micrometer reduziert, folglich sind freigesetzte Nano-Elektrospray-Tropfen sehr viel kleiner im Vergleich zur ES-MS. Je kleiner der Tropfen desto geringer ist der Salzgehalt/Tropfen. Salzaddukte stellen ein großes Hindernis bei der Beurteilung von Massenspektren dar. Mit der Nano-ESMS ist es jedoch möglich, Proteine in wässrigen Lösungen, ohne Zugabe von organischen Lösungsmitteln, im nativen Zustand zu untersuchen. In dieser Arbeit wurde die Nano-ESMS zur Untersuchung von nichtkovalenten Bindungen zwischen Proteinen und Nukleotiden herangezogen.

Die NS-MS wurde am MPI für Molekulare Physiologie (Dortmund) unter Anleitung von Heino Prinz mit einem Finnigan LCQ Massenspektrometer, ausgerüstet mit einem Mikromanipulator für die korrekte Positionierung der Nanospray-Nadel, durchgeführt. Die Nanospray-Nadeln wurden nach Protokoll von Mann und Wilm (1995) angefertigt und mit $1-4 \mu \mathrm{l}$ der zu untersuchenden wässrigen Proteinlösung (hier: $10 \mu \mathrm{M}$ Protein mit 5 oder $10 \mu \mathrm{M}$ Ligand) gefüllt. Sie wurden dann auf dem Mikromanipulator fixiert und in die Nähe des Eingangs des MS gebracht. Zur Initialisierung des Elektrosprays wurde zunächst ein Tropfen der Probe pneumatisch aus der Nadel herausgedrückt und anschließend eine Spannung von $900 \mathrm{~V}$ angelegt. Die erhaltenen Original-Daten (Auftragung: Verteilung der verschieden geladenen Proteinspezies $\rightarrow m / z)$ wurden mit der Software BioExplore (MicroCal) in Massenspektren (Auftragung: Relative Verteilung der Proteinspezies $\rightarrow$ Masse) umgewandelt.

\subsubsection{Gleichgewichtsdialyse}

Die Bindung verschiedener Nukleotide an Membran-assoziierte Guanylatkinasen wurde zum Teil durch Gleichgewichtsdialyse bestimmt. Das Dialysegerät (Equilibrium Dialyzer EMD 101B, PharmaciaBiotech) wurde nach Angaben des Herstellers verwendet. Die Dialysekammern (2 x 8 Halbschalen) sind durch eine Membran, welche für Proteine über $4 \mathrm{kDa}$ undurchlässig war, getrennt. In eine Hälfte der Dialysekammer lag das Protein in definierter Konzentration vor, die andere Hälfte wurde mit Nukleotiden in verschiedenen Konzentrationen gefüllt. In dieser Arbeit wurden Proteine in einer Konzentration von 1 oder $5 \mu \mathrm{M}$ und Nukleotide in Konzentrationsgradienten von $0-100 \mu \mathrm{M}$ (NMP) und $10 \mu \mathrm{M}-10 \mathrm{mM}$ (NTP) eingesetzt. Nach mindestens 24 stündiger Rotation bei $4^{\circ} \mathrm{C}$ wurden die Kammern geleert, das Protein durch Erhitzen auf $80^{\circ} \mathrm{C}$ präzipitiert und abzentrifugiert $(14000 \mathrm{~g}, 10$ Minuten). Die Konzentration der Nukleotide in allen 16 Proben wurde spektrophotometrisch durch Absorption bei $252 \mathrm{~nm}$ (GMP, cGMP) bzw. $259 \mathrm{~nm}$ (ATP) bestimmt (Extinktionskoeffizienten der Nukleotide, siehe Anhang). Die Konzentrationen der Nukleotide in jeder Hälfte einer Kammer wurden verglichen. Der Überschuß von Nukleotid in der Hälfte mit Protein entsprach dem Anteil an gebundenem Nukleotid. In der gegenüberliegenden Hälfte war die Konzentration des freien Nukleotids 
direkt meßbar. Der $K_{\mathrm{d}}$-Wert wurde anschließend aus der graphischen Auftragung des gebundenen Nukleotids gegen das freie Nukleotid bestimmt. Die Auswertung erfolgte mit der Software Origin 4.1 von MicroCal.

\subsubsection{Filter-Assay mit radioaktiv markierten Nukleotiden}

Die Bindung von radioaktiv markierten Nukleotiden $\left(\left[\alpha^{32} \mathrm{P}\right] \mathrm{ATP}\right.$ und $\left[\alpha^{32} \mathrm{P}\right] \mathrm{GTP}$, sowie $\left[{ }^{3} \mathrm{H}\right] \mathrm{AMP}$, $\left[{ }^{3} \mathrm{H}\right] \mathrm{GMP},\left[{ }^{3} \mathrm{H}\right] \mathrm{cAMP}$ und $\left.\left[{ }^{3} \mathrm{H}\right] \mathrm{cGMP}\right)$ an Proteine der MAGUK-Familie wurde mit dem NitrocelluloseFilter-Assay bestimmt. Im Gegensatz zur Gleichgewichts-Dialyse ist der Filter-Assay in kurzer Zeit durchführbar. Für den Assay wurden $1 \mu \mathrm{M}$ oder $10 \mu \mathrm{M}$ Protein mit der entsprechenden Menge an Nukleotid in einem Probevolumen von $20 \mu$ l Bindungs-Puffer gemischt und für 15 Minuten bei RT inkubiert. Dann wurde das Reaktionsgemisch mit Hilfe einer Membranpumpe (Vacuubrand, Wertheim) durch einen feuchten Nitrocellulose-Filter (Durchmesser $25 \mathrm{~mm}$, Porengröße 0,45 $\mu \mathrm{M}$, von Schleicher und Schuell, Dassel) filtriert. Der Filter wurde anschließend dreimal mit jeweils 2,5 ml Bindungspuffer $\left(20 \mathrm{mM}\right.$ Tris/ $\mathrm{HCl}, \mathrm{pH}$ 7,6, $100 \mathrm{mM} \mathrm{KCl}, 10 \mathrm{mM} \mathrm{MgCl}_{2}$ ) gewaschen und nach dem Abtrocknen in Plastikfläschchen mit $3 \mathrm{ml}$ Szintillationsflüssigkeit (Ultima Gold, Packard, Groningen, Niederlande) (bei $\left[\alpha^{32} \mathrm{P}\right]$-markiertem Triphosphat) überführt. Bei Verwendung von $\left[{ }^{3} \mathrm{H}\right]$-markiertem Monophosphat wurde der Filter in Plastikfläschchen mit $5 \mathrm{ml}$ Szintillationsflüssigkeit (Filter-Count, Packard) unter 30minütigem Schütteln aufgelöst. Die Radioaktivität der jeweiligen Probe wurde zum Schluß mit einem Szintillationszähler (1500 Tri-Carb Liquid Scintillation Analyzer, Packard-Instrument Company) bestimmt. Die Berechnung des $K_{\mathrm{d}}$-Wertes erfolgte wie unter 3.19.2 beschrieben, mit der Software Origin 4.1 von MicroCal. 


\section{ERGEBNISSE}

\subsection{Guanylatkinasen}

\subsubsection{Hefegenetische Untersuchungen an der Guanylatkinase}

\subsubsection{Die Bäckerhefe S. cerevisiae als in vivo-System zur Detektion von Guanylatkinase-Aktivität}

Auf Grundlage der Bäckerhefe Saccharomyces cerevisiae, eines Modellorganismus in der Molekularbiologie, wurde in unserer Arbeitsgruppe ein in vivo-System zur Detektion von Guanylatkinase-Aktivität etabliert. Die Guanylatkinase (GUK) ist ein essentielles Enzym von Saccharomyces cerevisiae. Wie bereits in früheren Arbeiten durch Konstruktion des GUK1defizienten Stammes AG430(GUK1/guk1::HIS) (Konrad, 1992) gezeigt wurde, führt ihr Verlust zu rezessiver Lethalität. In diploiden AG430(GUK1/guk1::HIS3)-Zellen ist die codierende Region des GUK1-Gens auf einem Chromosom partiell deletiert (Nukleotide 245 - 645). Der fehlende Sequenzbereich wurde durch ein 1,8 kb DNA-Fragment, welches das HIS3-Markergen enthält, ersetzt. Diploide AG430(GUK1/guk1::HIS3)-Zellen besitzen den Phänotyp leu2', d.h. die Zellen können aufgrund eines Enzymdefektes (LEU2 codiert für das Enzym $\beta$ Isopropymalatdehydrogenase) die Aminosäure Leucin nicht synthetisieren. Sie bleiben auf Vollmedium bzw. Minimalmedium mit dem Zusatz von Leucin lebensfähig. Da die Deletion von GUK1 in AG430(GUK1/guk1::HIS3) nur auf ein Allel beschränkt ist, sind nach meiotischer Teilung 2 der 4 haploiden Sporen lebensfähig. Die GUK1-Deletion kann allerdings durch ein über einen Vektor in die Hefezelle eingeführtes Guanylatkinasegen komplementiert werden (Spangenberg, 1997). In diesem Fall sind wieder alle vier Sporen eines Ascus lebensfähig. Die haploiden Zellen, welche das Vektor-gebundene komplementierende Gen besitzen, können durch HIS-Marker-Segregation nach Trennung der Sporen identifiziert werden.

Zur effizienten heterologen Expression von rekombinanten Guanylatkinase- bzw. GUKhomologen Genen unter der Kontrolle des GAL10-Promoters in S. cerevisiae wurde der Vektor YEp512N (Konrad, 1992) verwendet. Gene unter Kontrolle des GAL-Promoters können durch Wechsel der Kohlenstoffquelle von Glukose auf Galaktose bis zu 1000fach überexprimiert werden (Johnston und Carlson, 1992). Der in der Komplementationsanalyse eingesetzte Pendelvektor YEp512N geht aus dem episomalen Plasmid YEp51 (Broach et al., 1983) hervor 
und besitzt neben dem Ampicillinresistenzgen und dem Replikations-Ursprung ColE1 zur Replikation in E. coli auch das LEU2-Markergen sowie den Replikationsstartpunkt $2 \mu$ zur Replikation in Hefezellen. Im Gegensatz zu YEp51 enthält er jedoch eine neu konstruierte NdeI-Schnittstelle in der Polyklonierungsregion, während die beiden anderen ursprünglichen NdeI-Schnittstellen entfernt wurden. Rekombinante Gene konnten folglich standardmäßig über die NdeI- und BamHI-Schnittstellen in den Vektor kloniert werden.

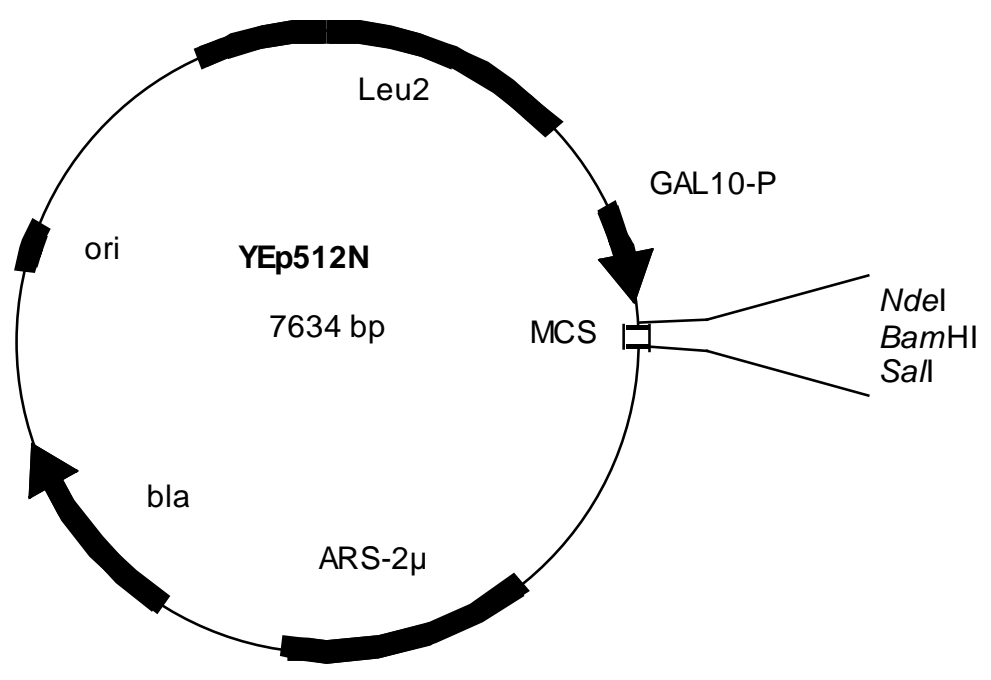

Abb. 4.1 Schema des Hefe-Expressions-Vektors YEp512N (aus Brundiers, 1999).

Zur genetischen Überprüfung der Komplementation des in AG430(GUK1/guk1::HIS3) deletierten chromosomalen Guanylatkinase-Gens durch Fremdgene wurden transformierte Zellen zunächst auf Kaliumacetat-Medium zur Sporulation gebracht und die 4 Sporen der Asci anschließend auf YEPGal-Vollmedium vereinzelt. Für den Fall, daß das rekombinante Gen den Defekt des essentiellen GUK1-Gens ausgleichen konnte, sollten alle vier haploiden Zellen auf galaktosehaltigem Nährmedium wachsen.

Das auf Basis der Hefe aufgebaute in vivo-System besitzt gegenüber E. coliExpressionssystemen einen entscheidenden Vorteil: Die Hefe ist ein Eukaryot und folglich mit der Fähigkeit zur posttranslationalen Modifizierung von Proteinen ausgestattet. Ein häufiges Problem der heterologen Überexpression rekombinanter Proteine in E. coli ist hingegen die Bildung von unlöslichen Protein-Aggregaten. Diese sogenannten Einschlußkörper sind falsch gefaltete Proteine, welche sich nach Überexpression in der Zelle anhäufen und zusammenlagern (Schein, 1989). Solche Protein-Aggregate treten häufig in prokaryontischen, normalerweise nicht aber in eukaryontischen Zellen auf (Rudolph und Lilie, 1996; Ausnahme: Prionen bilden 
pathologische Aggregate in Säugerzellen; Prusiner et al., 1998), da unkorrekt gefaltete Proteine in diesen Zellen durch Proteasen abgebaut oder aber durch Hilfsproteine (Chaperone) in ihre native Struktur zurückgefaltet werden können (Wickner et al., 1999). Die Bakterienzelle besitzt keinen derart komplexen posttranslationalen Qualitäts-Kontrollmechanismus, weshalb es oftmals nach Überexpression von eukaryontischen Proteinen zur Bildung der Einschlußkörper kommt. Das Hefe-Expressionssystem sollte demnach eindeutig Vorteile in der Translation von rekombinanten Genen aus Säuger- oder Pflanzenzellen besitzen. In der Tat konnte mit diesem in vivo-System bereits früher gezeigt werden, daß die Guanylatkinase des Menschen (hGUK), welche nach Überexpression in E. coli Einschlußkörper bildete und katalytisch inaktiv war (Brady et al., 1996), den letalen GUK1-defizienten Phänotyp in der Hefe supprimieren konnte (Spangenberg, 1997). Die Polypeptidkette der hGUK war folglich in der Hefe in die enzymatisch aktive Form gefaltet. In dieser Arbeit wurde das System zur Überprüfung von Säuger- und pflanzlichen Guanylatkinasen sowie von GUK-homologen Säugerproteinen eingesetzt, welche sich nicht aus E. coli aufreinigen ließen bzw. nach Isolierung aus dem Bakterium keine Aktivität zeigten.

\subsubsection{Die Guanylatkinase unter Kontrolle des Tetracyclin-regulierbaren Promoters tetO-tTA}

Da bei der Vielzahl der zu untersuchenden Gene eine Tetradenanalyse zur Analyse auf genetische Komplementation des deletierten chromosomalen Guanylatkinase-Gens in AG430(GUK1/guk1::HIS3) zu zeitaufwendig ist, wurden in dieser Arbeit erste Schritte zur Etablierung eines einfacheren in vivo-Systems zur Detektion von Guanylatkinase-Aktivität unternommen.

Hierzu wurde das Tetracyclin-regulierbare Promotersystem tetO-tTA, welches ursprünglich zur regulierbaren Expression von Genen in Säugerzellen (Gossen und Bujard, 1992; Gossen et al., 1993) entwickelt, später jedoch von Gari et al. (1997) für die Genexpression in Hefezellen adaptiert wurde, eingesetzt. Vorangestellt sei, daß neben dem in dieser Arbeit verwendeten aktivierten System (siehe Abb. 4.2), in welchem die Transkription konstitutiv angeschaltet ist, auch ein reverses Tetracyclin-regulierbares System existiert, in welchem die Transkription erst nach Zugabe von Tetracyclin (bzw. Tetracyclinderivaten) angeschaltet wird und eine 1000fache Überexpression des Reportergens erlaubt (Gossen et al., 1995). Basis des in dieser Arbeit verwendeten Systems zur Tetracyclin-regulierten Transkription eines Gens unter Kontrolle des tetO-Operators ist der tTA-Transaktivator (siehe Abb. 4.2). Der tTA-Transaktivator setzt sich aus der VP16 aktivierenden Domäne des Herpes-Simplex-Virus und dem Tetracyclin- 
induzierbaren Repressor (tetR) des Tetracyclin-resistenten Operons Tn10, zusammen (Gossen et al., 1993). In Abwesenheit des Effektormoleküls Tetracyclin bindet der tTA-Transaktivator an den Operator tet $O$ und ermöglicht die Transkription des nachfolgenden Gens. In Anwesenheit von Tetracyclin dissoziiert der tTA-Transaktivator von der Operator-Bindungsstelle und die Transkription wird effizient reprimiert.

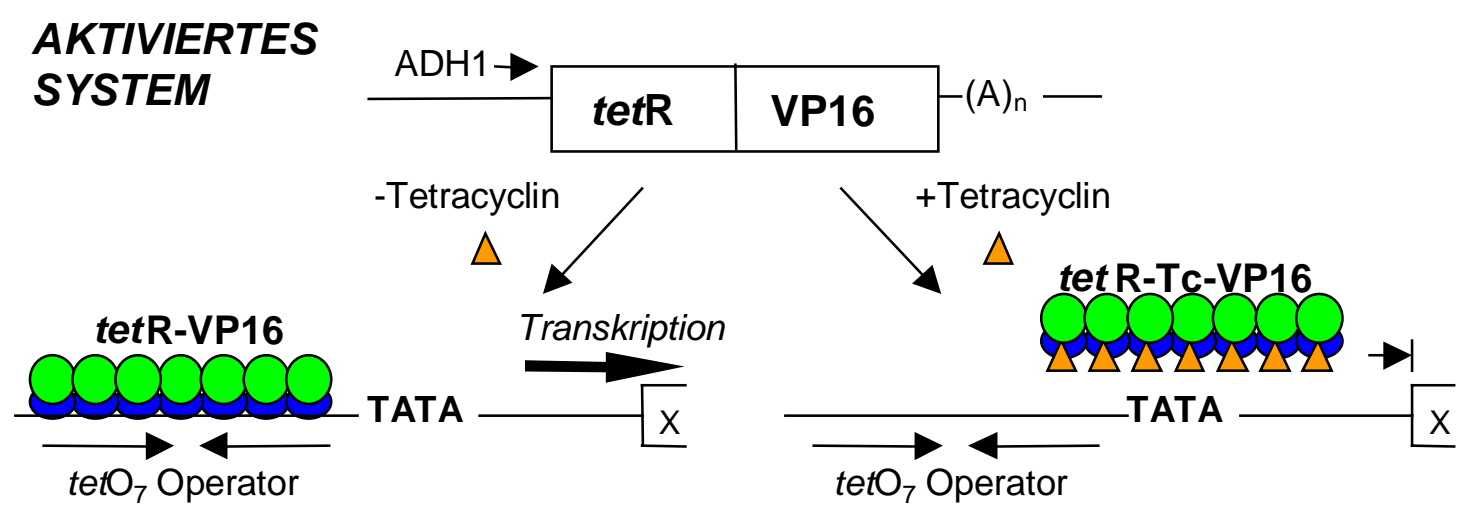

Abb. 4.2 Schema des konstitutiv aktivierten Tetracyclin-regulierten Promotersystems. Der Transaktivator, bestehend aus einer Repressor- (tetR, Kreise) und Aktivator-Domäne (VP16, Ellipsen) wird unter Kontrolle eines geeigneten Expressions-Signals gebildet. In Abwesenheit des Effektormoleküls Tetracyclin (Tc, Dreiecke) bindet der Transaktivator an den Operator und aktiviert die Transkription. In Gegenwart von Tetracyclin dissoziiert der Transaktivator von der spezifischen Bindungsstelle und die Transkription wird reprimiert. Das dargestellte Promoter-tet-Operator-Element setzt sich aus 7 tet $\mathrm{O}-O$ peratoreinheiten zusammen. Pro Operatoreinheit bindet eine Transaktivatoreinheit. $(\mathrm{A})_{\mathrm{n}}$, Polyadenylierungsregion

Der Vorteil des tet $O$-tTA-Systems gegenüber dem GAL-Promoter besteht darin, daß die Expression eines Gens in Abhängigkeit der vorliegenden Tetracyclinkonzentration moduliert werden kann. Darüberhinaus ist dazu im Gegensatz zum GAL-Promoter ein Wechsel der Kohlenstoffquelle nicht notwendig. Zur Transkription des GUK1-Gens unter Kontrolle des tet $\mathrm{O}_{7}$-tTA-Promoters wurde der Vektor pCM189 (Gari et al., 1997) eingesetzt. Der Vektor geht aus dem centromeren Plasmid Ycplac33 (Gietz und Sugino, 1988) hervor und enthält eine Kassette (siehe Abb. 4.3) mit allen in Abbildung 4.2 aufgeführten regulatorischen Elementen.

Ziel dieser Arbeit war es zunächst mit Hilfe des tetO-tTA-Promoters die Auswirkung einer fortschreitenden Repression der Guanylatkinase-Transkription auf die Hefezelle zu untersuchen und den zum Überleben der Hefezelle essentiellen Spiegel an Guanylatkinase-Aktivität zu bestimmen. Dazu mußte zunächst ein Hefe-Stamm konstruiert werden, in welchem die Expression des GUK1-Gens ausschließlich der Kontrolle des tet $\mathrm{O}_{7}$-tTA-Promoters unterlag.

Zur Etablierung eines neuen in vivo-Systems zur Detektion von Guanylatkinaseaktivität auf Basis des tet $\mathrm{O}_{7}$-tTA-Promoters war es jedoch notwendig, daß die Expression des GUK1-Gens in Gegenwart von Tetracyclin vollständig inhibiert wurde. In dem Zustand der vollständigen 
Repression könnten dann jene über ein zweites Plasmid in die Hefezelle eingeführten $G U K$ Mutanten bzw. unbekannten Gene als aktive Guanylatkinasen identifiziert werden, welche den letalen $g u k 1$-Phänotyp supprimierten.

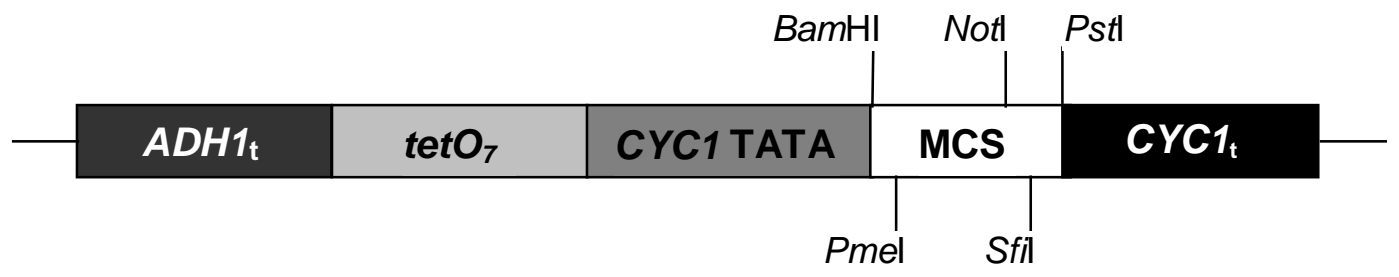

\begin{abstract}
Abb. 4.3 Schematische Darstellung der regulatorischen Elemente der tetO-Promoter-Kassette des Plasmids pCM189. $A D H 1_{\mathrm{t}}, A D H 1$-Terminatorregion; tet $_{7}$, Promoterregion, bestehend aus 7 tet $O$-Einheiten; $C Y C l$ TATA, TATA-Box von $C Y C l$; MCS, Polyklonierungsregion mit den angezeigten singulären Schnittstellen; $C Y C l_{\mathrm{t}}, C Y C l$ Terminatorregion
\end{abstract}

Das neue in vivo-System sollte auf Basis des Stammes AG430(GUK1/guk1::HIS3) aufgebaut und die GUK1-Expression unter Kontrolle des pCM189-gebundenen tetO-tTA-Promoters stehen. Zur Konstruktion von pCM189-GUK1 wurde das GUK1-Gen zunächst mit den spezifischen Oligonukleotiden OSP108 und OSP109 aus genomischer Hefe-DNA durch PCR amplifiziert und anschließend über die neu eingefügten Restriktionsschnittstellen BamHI und PstI in das centromere Plasmid pCM189 (Gari et al., 1997) kloniert. Da der Stamm AG430(GUK1/guk1::HIS3) auxotroph für die Aminosäure Leucin ist, mußte der URA3-Marker auf dem Plasmid pCM189-GUK1(URA3) gegen den LEU2-Marker ausgetauscht werden. Dazu wurden Zellen des haploiden Leucin- und Uracil-auxotrophen Hefestammes NE75911A(guk1(nes25-1)leu2, ura3, ade8, his3) (Shimma et al., 1997) mit dem Plasmid pCM189GUK1(URA3) und dem „Marker-Swap“-Plasmid pUL9 (Cross et al., 1997) transformiert und auf $\mathrm{SC}^{(-\mathrm{LEU})}$-Medium ausgestrichen. Auf dem selektiven Leu-Medium konnten nur diejenigen Zellen wachsen, in welchen der Austausch des URA3-Markers gegen den LEU2-Marker auf dem Plasmid pCM189-GUK1 durch homologe Rekombination stattgefunden hatte. Aus den Transformanden wurde das Plasmid isoliert und in E. coli DH5 $\alpha$ amplifiziert. Hefezellen des Stammes AG430(GUK1/guk1::HIS) wurden dann mit dem Plasmid pCM189-GUK1(LEU2) transformiert und auf SD-Medium ausgestrichen. Die haploiden Zellen AG215(guk1::HIS3/pCM189-GUK1), in welchen die chromosomale Deletion des GUK1-Gens durch das Wildtyp-Gen auf dem Plasmid pCM189-GUK1 komplementiert wurde, konnten anschließend durch Tetradenanalyse auf SD-Medium isoliert werden. Im haploiden Stamm AG215(guk1::HIS3/pCM189-GUK1) unterliegt die Kontrolle der Expression des GUK1-Gens dem Tetracyclin-regulierbaren Promoter tetO-tTA. 
Zur Überprüfung der Expression des Gens GUK1 wurden Zellen von drei unabhängigen Übernachtkulturen des Stammes AG215(guk1::HIS3/pCM189-GUK1), sowie des KontrollStammes AG215(GUK1/pCM189) in frisches SD-Medium mit der entsprechenden Konzentration des Tetracyclinderivats Doxycyclin inokuliert $($ Anfangs-OD $600=0,01)$. Doxycyclin wurde im Experiment eingesetzt, da es im Vergleich zu anderen getesteten Tetracyclinderivaten die höchste Affinität zum tetR-Repressor zeigte (Degenkolb et al., 1991). Die Kulturen wurden anschließend bis zur $\mathrm{OD}_{600}$ von 1,0 bei $30^{\circ} \mathrm{C}$ unter Schütteln inkubiert und in 4 Schritten jeweils $1: 10$ bis zur $\mathrm{OD}_{600}$ von 0,0001 verdünnt. $5 \mu \mathrm{l}$ der jeweiligen Verdünnungsstufe wurden anschließend als Tropfen auf SD-Platten ohne Doxycyclin, sowie mit $0,1,1$, und $5 \mu \mathrm{g} / \mathrm{ml}$ Doxycyclin aufgebracht und für 2 Tage bei $30^{\circ} \mathrm{C}$ inkubiert.
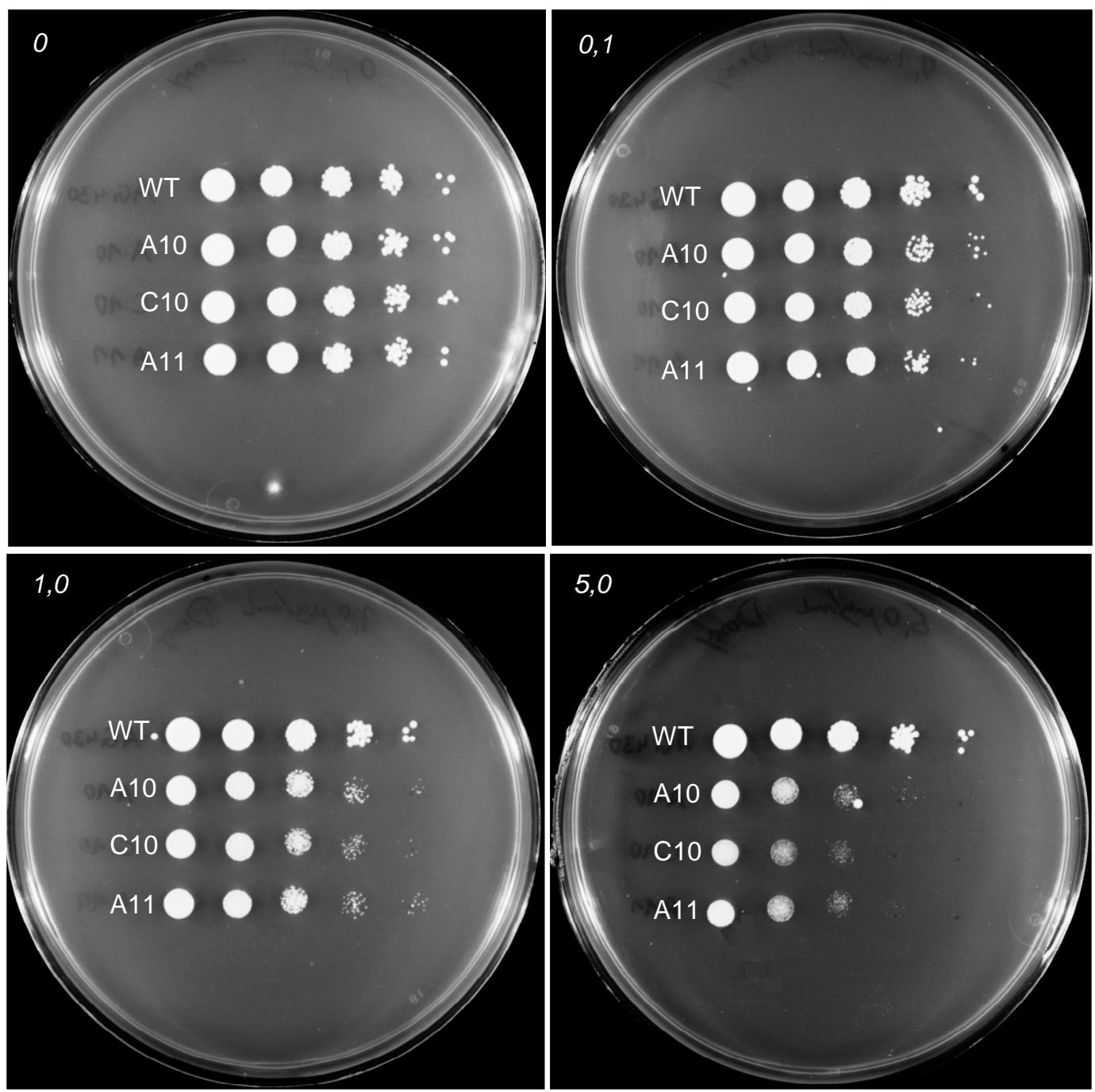

Abb. 4.4 Wachstumsdefekt von Hefe-Zellen, verursacht durch Inhibition der GUK1-Expression unter Kontrolle des tetO-tTA-Promoters in Gegenwart unterschiedlicher Konzentrationen an Doxycyclin. Eine Serie von 4 Verdünnungen (jeweils $1: 10$, bei einer Anfangs- $\mathrm{OD}_{600}$ von 1,0) der diploiden (WT: AG430(GUKl/guk1::HIS3/pCM189) und haploiden Stämme (A10, C10, A11: AG215(guk1::HIS3/pCM189GUK1) wurde auf SD-Medium mit den angezeigten Mengen $(0,1,1,0,5,0 \mu \mathrm{g} / \mathrm{ml})$ an Doxycyclin aufgetropft und die Platten 2 Tage bei $30^{\circ} \mathrm{C}$ inkubiert. 
Die Auswirkung der fortschreitenden Repression der Guanylatkinase-Transkription auf das Wachstum der Hefezellen in Gegenwart der zunehmenden Konzentration an Doxycyclin ist in Abbildung 4.4 dargestellt.

Bereits bei einer Konzentration von $1 \mu \mathrm{g} / \mathrm{ml}$ ist das Wachstum der Zellen stark beeinträchtigt. Die Generationszeit der Zellen AG215(guk1::HIS3/pCM189-GUK1) in der exponentiellen Wachstumsphase (nach $18 \mathrm{~h}) \quad\left(\mathrm{t}_{\mathrm{d}}=151,2-162,8 \mathrm{~min}\right)$ ist gegenüber der Kontrolle AG430(GUK1/guk1::HIS3/pCM189) $\left(\mathrm{t}_{\mathrm{d}}=136,2 \mathrm{~min}\right)$ um $10-20 \%$ erhöht. Nach wiederholter Beimpfung von frischem SD-Medium mit $1 \mu \mathrm{g} / \mathrm{ml}$ Doxycyclin stieg die Verdopplungszeit von AG215(guk1::HIS3/pCM189-GUK1) auf 166,4 - 271,8 min, also um 100\% im Vergleich zum Kontrollstamm, an. Das gleichbleibende Wachstum der AG430(GUK1/guk1::HIS3/pCM189)Zellen deutet daraufhin, daß das Antibiotikum in den gewählten Konzentrationen keinen toxischen Effekt auf die Hefezellen hat (siehe Abb. 4.4, WT). Die Menge an Guanylatkinase in Zellen des Stammes AG215(guk1::HIS3/pCM189-GUK1) wurde nach 20stündigem Wachstum in Gegenwart verschiedener Konzentrationen (0-10 $\mu \mathrm{g} / \mathrm{ml})$ Doxycyclin immunologisch mit einem antiGUK1-Antikörper bestimmt.

A

$\mathrm{c}($ Doxy) $[\mu \mathrm{g} / \mathrm{ml}]$

GUK1 [\%]
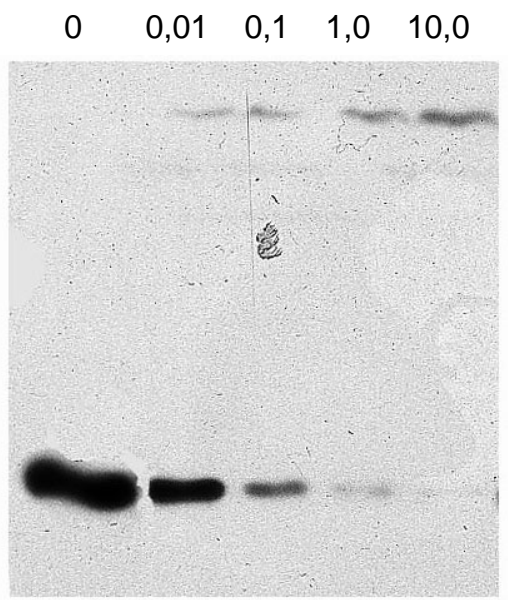

$100 \quad 22,8 \quad 4,3 \quad 1,8 \quad 0,4$
B
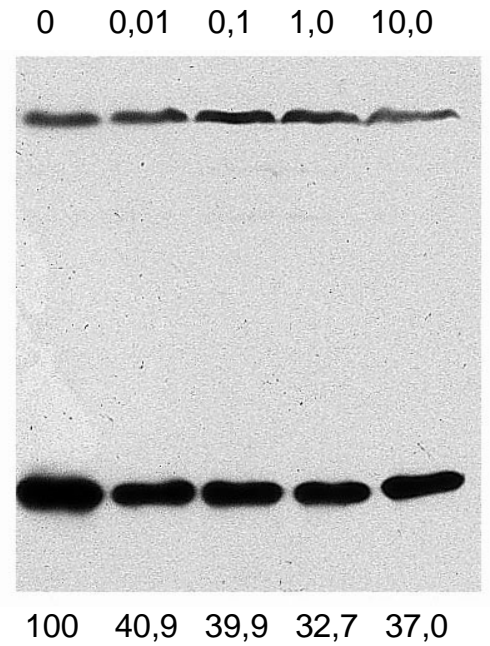

\begin{abstract}
Abb. 4.5 Immunoblot-Analyse der GUK1-Expression unter Kontrolle des tetO-tTA-Promoters im Hefestamm AG215(guk1::HIS3) (A) und AG215(GUK1) (B) in Gegenwart unterschiedlicher Konzentrationen an Doxycyclin $(\mu \mathrm{g} / \mathrm{ml})$. Die Proteinextrakte wurden auf einem 12\%igen SDS-PAGE-Gel elektrophoretisch aufgetrennt, auf eine Nitrozellulose-Membran transferiert und mit einem polyklonalen Anti-GUK1-Antikörper markiert. Die relative Menge an GUK1 wurde mit einem Lumi-Imager (Boehringer) bestimmt.
\end{abstract}

Wie der Immunoblot in Abbildung 4.5 zeigt, ist bereits eine Doxycyclin-Konzentration von 1 $\mu \mathrm{g} / \mathrm{ml}$ ausreichend, um die Menge an GUK1 in Zellen des Stammes AG215(guk1::HIS3/pCM189-GUK1) auf weniger als 2\% der Wild-Typ-Menge zu reduzieren. 
In Gegenwart von $5 \mu \mathrm{g} / \mathrm{ml}$ ist nur noch $0,4 \%$ der Wild-Typ-Menge immunologisch nachweisbar. Die Menge der GUK1 in Zellen des haploiden Stammes AG215(GUK1/pCM189GUK1) verändert sich nach Zugabe von Doxycyclin in einer Konzentration von mehr als 1 $\mu \mathrm{g} / \mathrm{ml}$ nicht mehr und pendelt sich auf einen basalen Wert zwischen 33-37\% der Menge an GUK1 im Vergleich zu AG215(GUK1/pCM189-GUK1)-Zellen, welche ohne Doxycyclin gewachsen sind, ein (siehe Abb. 4.5). Dieses Resultat deutet an, daß das Vektor-gebundene GUK1-Gen unter Kontrolle des tetO-tTA-Promoters im Vergleich zum chromosomalen GUK1Gen doppelt so stark exprimiert wird.

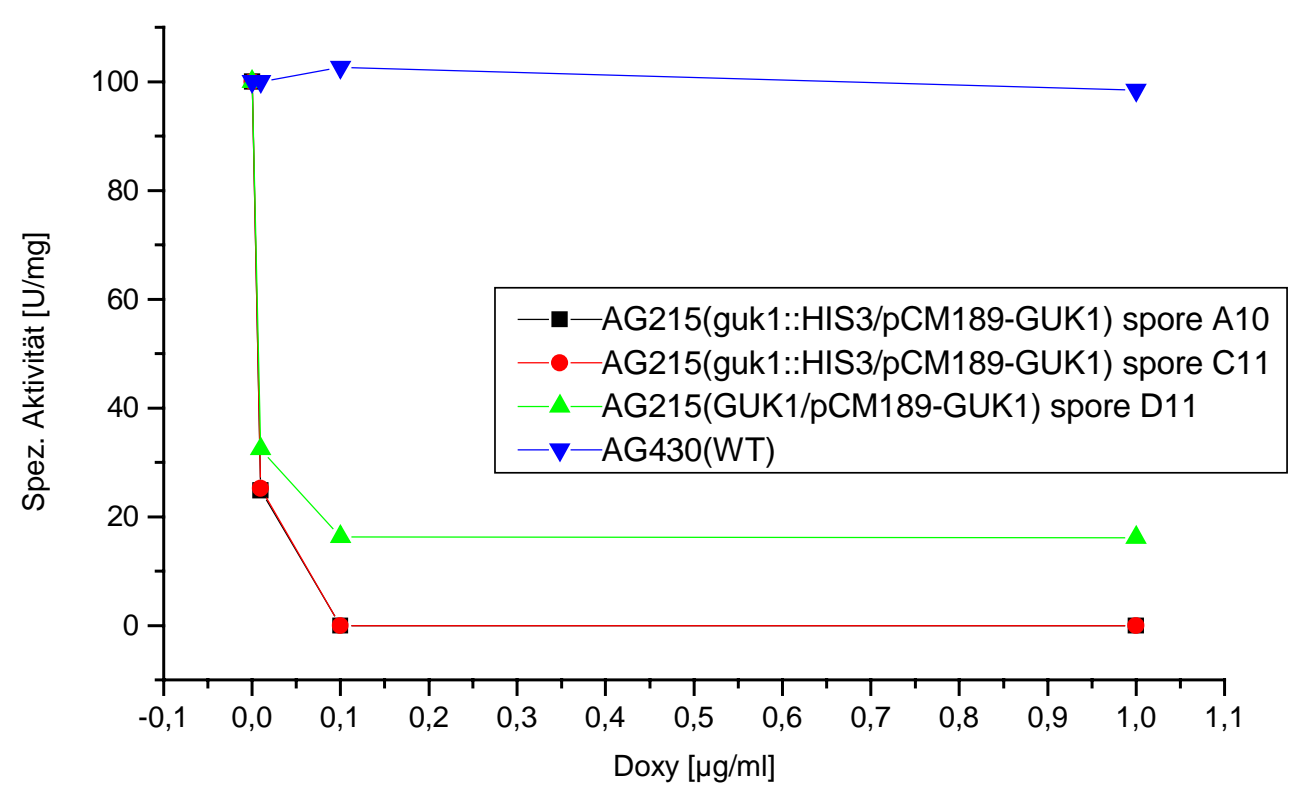

\begin{abstract}
Abb. 4.6 Relative Guanylatkinase-Aktivität von Zellextrakten der haploiden Hefestämme AG215(guk1::HIS3/pCM189-GUK1) (Sporen A10 und C11), AG215(GUK1/pCM189-GUK1) (Spore D11) sowie des diploiden Stammes AG430(GUK1/guk1::HIS3/pCM189) nach exponentiellem Wachstum in Gegenwart unterschiedlicher Konzentrationen an Doxycyclin.
\end{abstract}

Das Ergebnis des Immunoblots wird durch die Messung der Guanylatkinase-Aktivität von Proteinextrakten einer logarithmisch wachsenden Kultur des Stammes AG215(guk1::HIS3/pCM189-GUK1) bestätigt. Wie die Aktivitätskurve (siehe Abb. 4.6) veranschaulicht, ist die Guanylatkinase-Aktivität bereits bei einer Konzentration von $0,01 \mu \mathrm{g} / \mathrm{ml}$ Doxycyclin auf einen zumindest mit dem spektrophotometrischen Aktivitäts-Assay nicht mehr detektierbaren Wert abgefallen. Der einer hyperbolischen Kurve ähnelnde Abfall der Guanylatkinase-Aktivität zwischen 0 und $1 \mu \mathrm{g} / \mathrm{ml}$ Doxycyclin dokumentiert, daß die Expression des GUK1-Gens durch Veränderung der Doxycyclin-Konzentration im Medium effizient moduliert werden kann. Der in Abbildung 4.4 erkennbare Wachstumsdefekt ist folglich 
eindeutig auf die spezifische Inhibition der GUK1-Transkription zurückzuführen. Allerdings sind die Hefe-Zellen auch in Gegenwart von $10 \mu \mathrm{g} / \mathrm{ml}$ Doxycyclin, also bei einer Konzentration, bei der weder immunologisch noch mit dem spektrophotometrischen Assay Guanylatkinase-Aktivität nachweisbar war, lebensfähig, was darauf hindeutet, daß der basale GUK1-Transkriptionslevel immer noch ausreichend hoch, d.h. ein vollständiges Abschalten der GUK1-Expression mit dem tetO-tTA-System nicht möglich ist.

\subsubsection{Unterbrechung des NDK1-Gens in S. cerevisae und Konstruktion von} adk1/ndk1- sowie guk1-3/ndk1-Doppelmutanten

War die Zielsetzung der vorangegangenen Arbeiten die Hefe als „Werkzeug“ zur Detektion von Guanylatkinase-Aktivität einzusetzen, so sollten die folgenden Untersuchungen $\mathrm{zu}$ einem besseren Verständnis der fundamentalen Rolle der GUK1 im Nukleotidstoffwechsel der Hefe führen. Zu diesem Zweck wurde zunächst die Nukleosiddiphosphatkinase (NDK1) in der Hefe deletiert. Wie bereits in der Einleitung beschrieben, katalysiert das Enzym NDK in der Zelle den letzten, reversiblen Schritt der Übertragung des $\gamma$-Phosphatrestes von ATP auf alle Nukleosiddiphosphate in der Phosphorylierungskakade zur Synthese von NukleosidTriphosphaten (Desoxynukleosid-Triphosphaten) aus Nukleosiden (Desoxynukleosiden) (siehe Abb. 1.1). Im Vergleich zu den Nukleosidmonophosphatkinasen, wie z. B. der Guanylatkinase, wird das Enzym als unspezifisch charakterisiert. Während in einer früheren Arbeit die Phosphorylierung von Nukleosiddiphosphaten zur Synthese von Nukleinsäuren als wichtigste Funktion der NDK beschrieben wurde (Agarwal et al., 1978b), zeigen neuere Studien, daß die Rolle der NDK weitaus komplexer ist (Veron et al., 1994). Eine der wichtigsten Aufgaben der NDK scheint die Herstellung von GTP zu sein. Die NDK wird als der Hauptlieferant des GTP in der Zelle angesehen. Sie steht somit einerseits in enger Verbindung zu der Guanylatkinase, welche das Substrat GDP bereitstellt und andererseits übt sie über die Regulation des GDP/GTP-Verhältnisses in der Zelle einen direkten Einfluß auf GTP-bindende Proteine (GProteine), welche in der Signalübertragung eine wichtige Rolle spielen, aus (Bominaar et al., 1993). Neuere Studien belegen, daß die NDK, obschon sie in der Lage ist alle NukleosidDiphosphate als Substrate umzusetzen, dennoch eine eindeutig erhöhte Affinität zu Guanylaten besitzt (Schärtl et al., 1998).

Gemessen an ihrer wichtigen Funktion in Säugern scheint die Rolle der NDK1 in den Einzellern E. coli (Lu und Inouye, 1996) und S. cerevisiae (Fukuchi et al., 1993) eher untergeordnet zu sein, da die Deletion des NDK1- $(Y N K 1)$ Gens in beiden Organismen keinen Phänotyp zur Folge hat. Sowohl in E. coli, als auch in S. cerevisiae kann der Funktionsverlsut der NDK1 
wahrscheinlich durch andere Kinasen supprimiert werden. Ein Ziel dieser Arbeit war folglich, einen S. cervisiae-Stamm zu konstruieren, welcher nach Deletion des NDK1-Gens einen Phänotyp besaß. Die Idee war dabei folgende: Wenn die NDK1 auch in der Hefe die höchste Affinität für das Purinnukleotid GDP besitzt, so wäre es denkbar, daß der Verlust der NDK1 in Verbindung mit einer Verringerung des GDP-Levels in der Zelle zu einem Phänotyp führt. Diese Hypothese setzt jedoch voraus, daß der GDP-Level unterhalb der Affinität von Enzymen liegen mußte, welche unter normalen Bedingungen, d.h. nativen GDP-Konzentrationen, den NDK1-Verlust supprimieren.

Zusätzlich wurde in einem zweiten Ansatz überprüft, ob möglicherweise der Verlust des NDK1Gens zusätzlich zum ADK1-Gen Auswirkungen auf die adkl-Hefemutante (Konrad, 1988) hat.

Als Ausgangsstamm zur Konstruktion der NDK1-Deletion wurde der Hefestamm AG430(ADK1/adk1::LEU2), in dem eine Kopie des Adenylatkinase-Gens ADK1 partiell deletiert und durch das LEU2-Markergen ersetzt war (Konrad, 1988), verwendet. Die vier haploiden Zellen dieses Stammes wurden zunächst durch Tetradenanalyse getrennt und die beiden Deletionsmutanten durch Überstempeln auf selektives SD $^{+ \text {HIS }}$-Medium isoliert. In Abbildung $4.7 A$ ist das Wachstum der vier Sporen einer Tetrade auf YEPG-Vollmedium dargestellt. Die beiden adkl-Deletionsmutanten sind durch ein langsameres Wachstum gekennzeichnet. Für anschließende Kreuzungsexperimente wurde zunächst der Paarungstyp der vier Sporen ausgewählter Tetraden bestimmt. Dazu wurde der Halo-Test durchgeführt. Das Ergebnis des Halo-Tests einer Tetrade ist in Abbildung 4.7 B gezeigt.

A

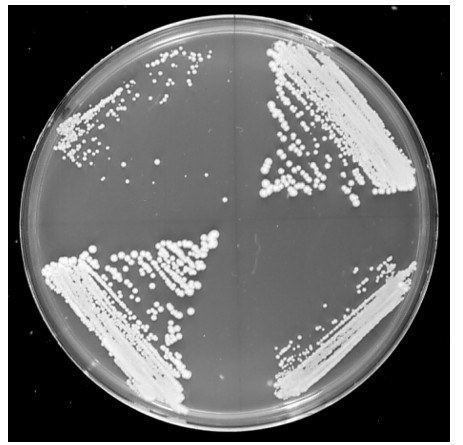

B

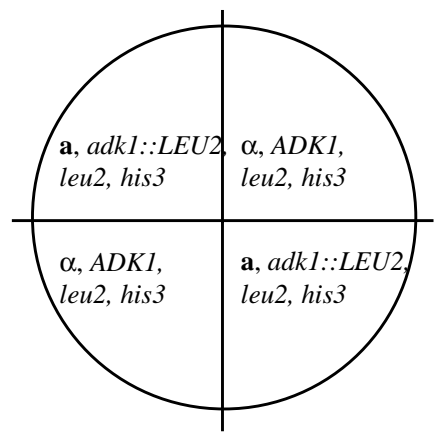

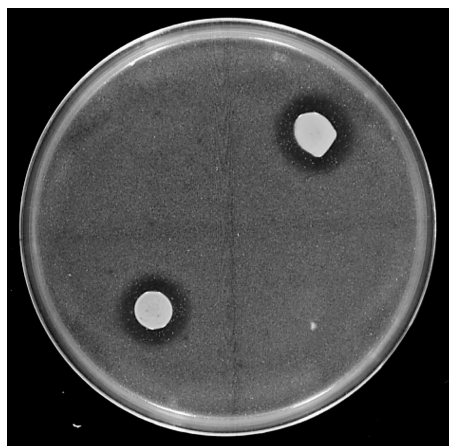

Abb. 4.7 Identifikation des Paarungs-Typs der vier Sporen einer Tetrade nach Unterbrechung des ADK1-Gens in $\operatorname{AG} 430(\mathbf{a} / \alpha$, his 3 , leu2). A, Wachstum der hapoliden Zellen auf YEPG-Vollmedium. B, Identifikation des Paarungs-Typs auf Halo-Platten. Die klaren Höfe um die Kolonien indizieren sekretiertes $\alpha$-Pheromon. Die Reihenfolge der Auftragung in $A$ und $B$ ist identisch.

Wie in der Abbildung erkennbar, bildete sich nur um die beiden Deletionsmutanten AG215(adk1::LEU2, his3, leu2) nach 2tägigem Wachstum ein Hof, als Indiz für die Sekretion 
des $\alpha$-Pheromons. Von allen ausgewählten Tetraden besaßen beide Deletionsmutanten den Mating-Typ $\alpha$. Eine gekoppelte Übertragung von $A D K 1$ und dem für das $\alpha$-Pheromon codierende Gen während der meiotischen Teilung ist jedoch ausgeschlossen, da beide Allele auf unterschiedlichen Chromosomen lokalisiert sind (ADK1: Chromosom 4, $\alpha$ : Chromosom 3).

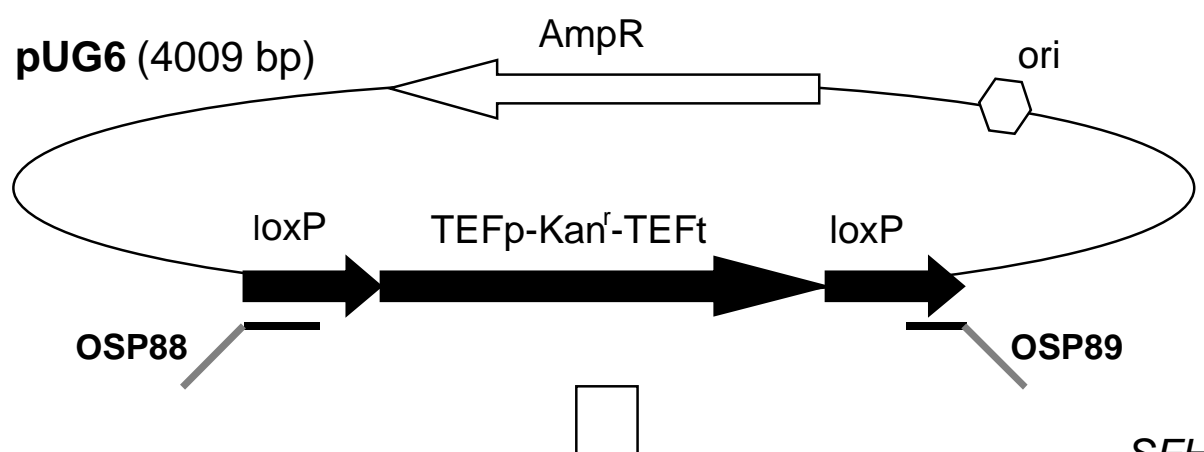

SFH PCR

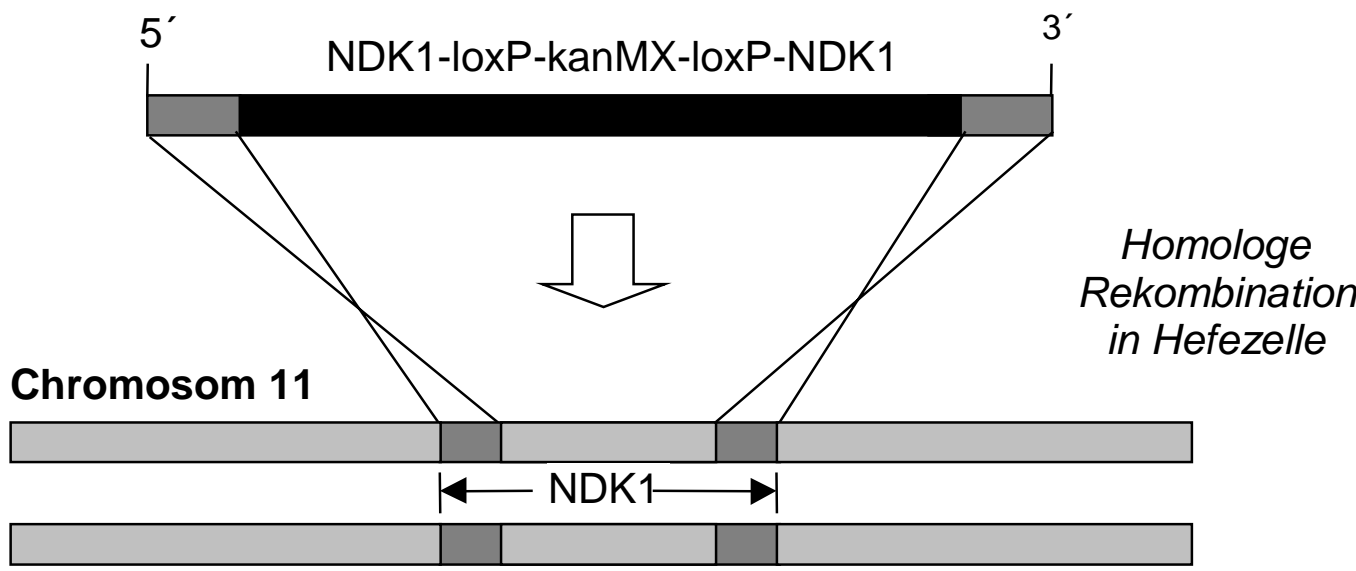<smiles>C1CC2CCC1C2</smiles>

Chromosom $11 \quad$ | loxP-kanMX-loxP|

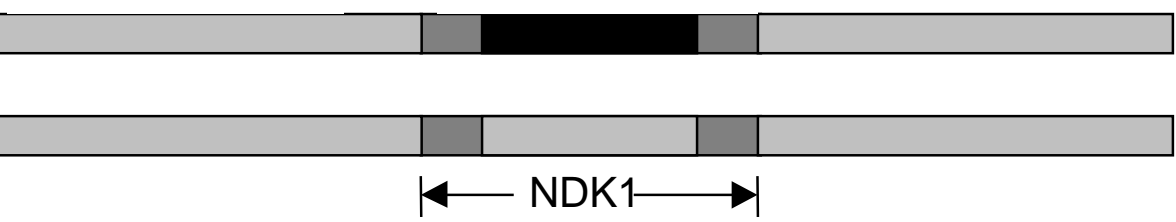

Abb. 4.8 Schema der Konstruktion eines NDK1-defizienten $S$. cerevisae-Stammes unter Verwendung der loxPkanMX-loxP-Kassette auf dem Plasmid pUG6. Zur Deletion des NDK1-Gens wurde durch SFH-PCR mit Oligonukleotiden, welche jeweils am 3'-Ende ein zur loxP-kanMX-loxP-Kassette homologes Segment und am 5'Ende zum NDK1-Gen homologe Sequenzen besitzen, ein PCR-Fragment amplifiziert. Das PCR-Fragment wurde nach Transformation durch homologe Rekombination an der Stelle des NDK1-Gens integriert, wodurch dieses deletiert wurde.

Zur Unterbrechung des NDK1-Gens in den jeweiligen haploiden Zellen AG215(a, ADK1, his3, leu2) und AG215( $\alpha$, adk1::LEU2, his3, leu2) wurde die SFH- (short flanking homology) PCR- 
Methode angewandt (Wach et al., 1994, siehe Abb. 4.8). Mit den Oligonukleotid-Primern OSP88 und OSP89 sowie dem Plasmid pUG6 (Güldener et al., 1996) als Template wurde zunächst die loxP-kanMX-loxP-Kassette mit 5'- und 3'-verlängerten Sequenzen von jeweils 39 Bp, welche homolog zu den 5'- und 3'-Enden des NDK1-Gens waren, amplifiziert. Das kanMXModul setzt sich aus dem, für das Enzym Aminoglycosid Phosphotransferase (Oka et al., 1981) codierende Gen $\mathrm{Kan}^{r}$ und einer Transkriptions-Kontrollsequenz des TEF-Gens des filamentösen Pilzes A. gossypii (Steiner, 1991; Steiner und Philippsen, 1994) zusammen. Das PCR-Fragment 5'-NDK1-loxP-kanMX-loxP-NDK1-3' wurde anschließend über ein Agarosegel gereinigt.

Zur Unterbrechung des NDK1-Gens durch homologe Rekombination wurden sechs ausgewählte Klone des haploiden Wildtyp-Stammes AG215(a, ADK1, his3, leu2) und vier Klone des haploiden Deletions-Stammes AG215( $\alpha$, adk1::LEU2, his3, leu2) direkt mit dem gereinigten PCR-Produkt transformiert und die Transformanden auf YEPG-Platten mit $4 \mathrm{ml} / \mathrm{L}$ der Geneticinlösung G418 ausplattiert. Nach 3-4tägiger Inkubation bei $30^{\circ} \mathrm{C}$ wurden Einzelkolonien erneut auf geneticinhaltigem Vollmedium ausgestrichen und nochmals für einen Tag bei $30^{\circ} \mathrm{C}$ inkubiert. Ausgewählte Kolonien wurden anschließend isoliert und durch analytische PCRs untersucht. Dazu wurde die genomische DNA aus allen zehn ausgewählten Klonen präpariert und als Template in der PCR-Reaktion mit den 5'- und 3'-terminalen NDK1spezifischen Oligonukleotid-Primern OSP90 und OSP91 sowie den internen $\mathrm{Kan}^{\mathrm{r}}$-spezifischen Primern OSP92 und OSP93 eingesetzt. Auf dem Agarose-Gelphoto in Abbildung 4.9 ist das Ergebnis der analytischen PCR dargestellt.

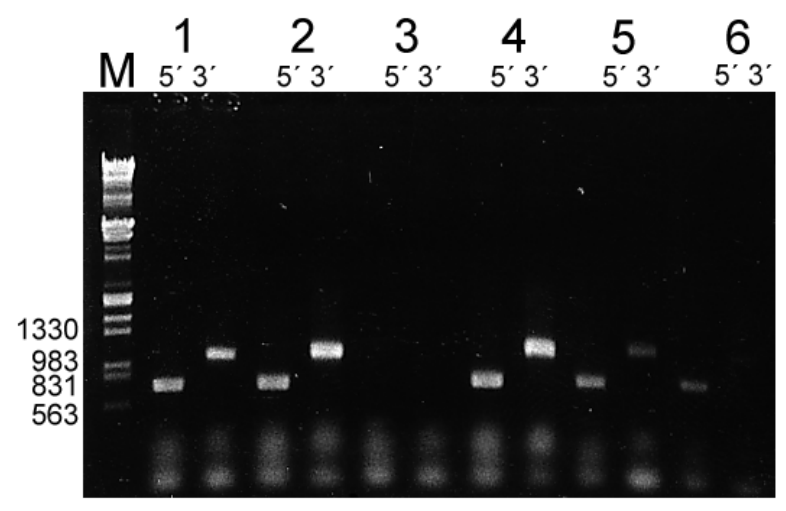

Abb. 4.9 Ethidiumbromid-gefärbtes Agarose-Gel zum Nachweis der Unterbrechung des NDK1-Gens in sechs ausgewählten Klonen des Hefestammes AG215( $\alpha$, $A D K 1$, leu2, his3) durch analytische PCR. 5', PCRFragment des 5'-Terminus von NDK1-5'-loxP-kanMXloxP-NDK1-3'. 3', PCR-Fragment des 3'-Terminus von NDK1-5'-loxP-kanMX-loxP-NDK1-3'.

Zwei Banden als Indiz für die amplifizierten 5'- (1014 Bp) und 3' (702 Bp)-Enden des integrierten Fragments $5^{\prime}$-loxP-kanMX-loxP-3', waren in 5 der 6 ausgewählten Wildtyp-Klone AG215( $\alpha, A D K 1$, leu2, his3) zu beobachten. Aus unbekannten Gründen konnte in keiner der vier Mutanten AG215(a, adk1::LEU2, his3, leu2) eine Integration des $\mathrm{Kan}^{r}$-Markergens in NDK1 durch homologe Rekombination nachgewiesen werden. Aus diesem Grund wurde die 
Doppelmutante durch Kreuzung zweier haploider Zellen hergestellt. Dazu wurden die beiden haploiden Zellen AG215(a, adk1::LEU2, his3, leu2) und AH215( $\alpha$, ndk1::Kan ${ }^{r}$, his3, leu2) gekreuzt. Nach Überstempeln auf geneticinhaltiges Minimalmedium $\left(\mathrm{SD}^{+\mathrm{HIS}, \mathrm{G} 418}\right)$ wurden die diploiden AGH430(a/ $\alpha$, ADK1/adk1::LEU2, NDK1/ndk1::Kan ${ }^{r}$, his3/his3, leu2/leu2)-Zellen isoliert und einer Tetradenanalyse unterzogen. In Abbildung 4.10 ist das Ergebnis der Tetradenanalyse dargestellt. Wie das Wachstum auf YEPG-Medium (siehe Abb. 4.10 A) zeigt, waren alle vier Sporen lebensfähig. Durch Überstempeln der Tetraden auf $\mathrm{YEPG}^{+\mathrm{G} 418}$ - und $\mathrm{SD}^{+\mathrm{HIS},+\mathrm{G} 418}$-Selektivmedium (siehe Abb. $4.10 \mathrm{~B}$ und $C$ ) konnten die haploiden Zellen der $n d k 1$ Mutante AH215(ADK1, ndk1::Kan ${ }^{r}$, his3, leu2) sowie der Doppelmutante AGH215(adk1::LEU2, ndk1::Kan ${ }^{r}$, his3, leu2) identifiziert werden. Die adkl/ndk1Doppelmutante zeichnete sich ebenso wie die adk1-Mutante AG215(adk1::LEU2, NDK1, his3, leu2) durch langsameres Wachstum aus. Die zusätzliche Deletion des NDK1-Gens erzeugte keinen offensichtlichen neuen Phänotyp (vergleiche z.B. den adk1-Phänotyp der Spore B4 mit dem $a d k 1 / n d k 1$-Phänotyp der Spore D4 in Abb. 4.10 A auf YEPG-Vollmedium).

A

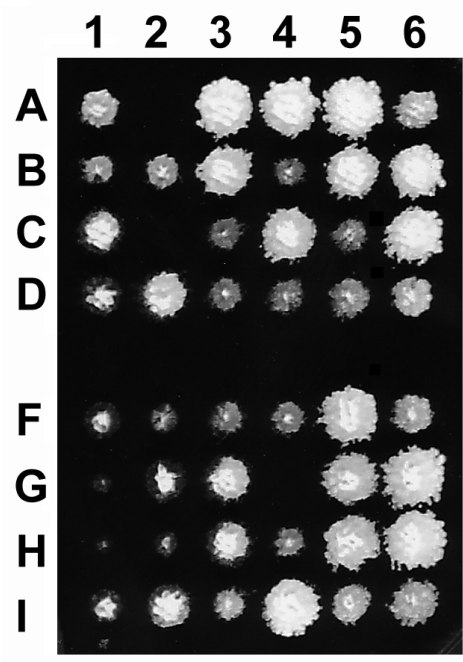

B

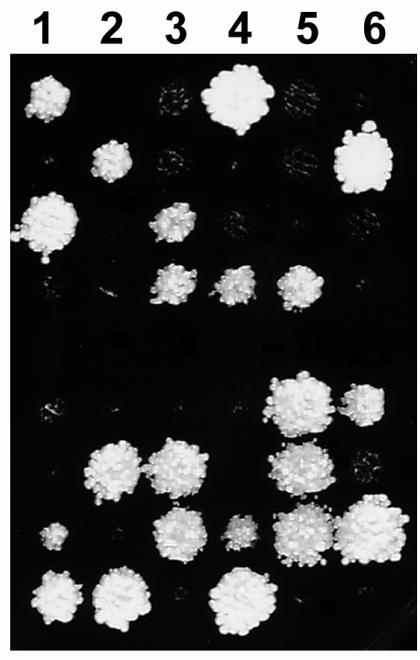

C

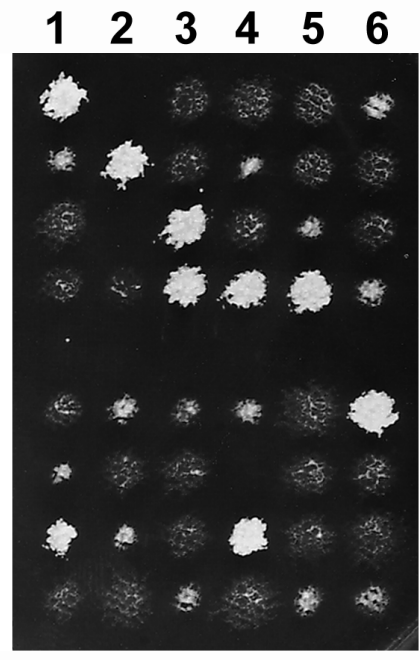

Abb. 4.10 Isolierung des adk1- und $n d k 1$-defizienten Stammes AGH215(adk1::LEU2, ndk1::Kan ${ }^{r}$, his3, leu2) nach Tetradenanalyse von AGH430(a/ $\alpha$, ADK1/adk1::LEU2, NDK1/ndk1::Kan ${ }^{r}$, his3/his3, leu2/leu2). Die Sporen der ausgewählten Tetraden wurden auf YEPG-Vollmedium $(A)$ getrennt, nach 3tägigem Wachstum auf YEPG $^{+G 418}$. Medium $(B)$ und $\mathrm{SD}^{+\mathrm{HIS}, \mathrm{G} 418}$-Medium $(C)$ überstempelt und danach für zwei weitere Tage bei $30^{\circ} \mathrm{C}$ inkubiert.

Zur Konstruktion einer $n d k l$-Deletionsmutante mit schwacher Guanylatkinase-Aktivität wurden die haploiden Zellen AH215( $\alpha, G U K 1, n d k 1:: K a n^{r}$, his3, leu2) mit Zellen des haploiden Stammes PLY220(a, bra3-3(=guk1-3), leu2, lys2, ura3) (Lecoq et al., 2000) gekreuzt. Der Stamm PLY220 besitzt eine Punktmutation im GUK1-Gen. Die Mutation hat eine reduzierte 
Guanylatkinase-Aktivität um mehr als $90 \%$ zur Folge, wodurch sich die Generationszeit der Zellen dieses Stammes um 30 - 40\% im Vergleich zu Wild-Typ-Zellen erhöht (Lecoq et al., 2000; Eine ausführliche Charakterisierung der bra3-Mutanten erfolgt unter Punkt 4.1.2). Zellen des diploiden Stamm AGP430(a/o, GUK1/guk1-3, NDK1/ndk1::Kan ${ }^{r}$, leu2/leu2, LYS2/lys2, HIS3/his3, URA3/ura3) wurden anschließend zur Sporulation gebracht und die vier Sporen einer Tetrade untersucht. Das Ergebnis der Tetradenanalyse auf YEPG-Vollmedium ist in Abbildung $4.11(A)$ dargestellt.

A

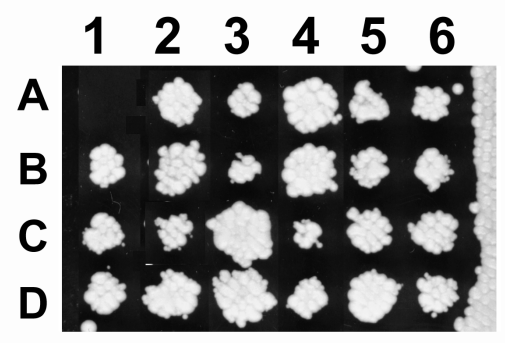

B

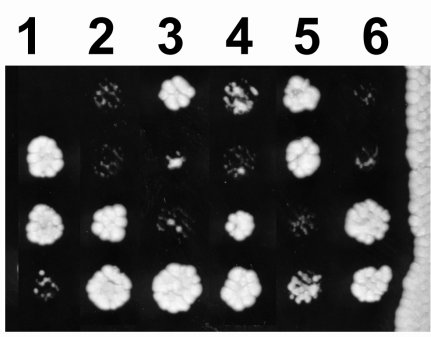

C

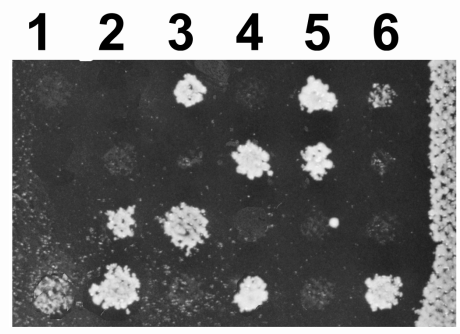

Abb. 4.11 Isolierung der guk1-3/ndk1-Doppelmutante AP215(guk1-3::LEU2, ndk1::Kan ${ }^{r}$, his3, leu2) nach Tetradenanalyse von AGP430(a/ $\alpha$, GUK1/guk1-3, NDK1/ndk1::Kan ${ }^{r}$ leu2/leu2, LYS2/lys2, HIS3/his3, URA3/ura3). Die Sporen der ausgewählten Tetraden wurden auf YEPG-Vollmedium $(A)$ getrennt, nach 3tägigem Wachstum auf $\mathrm{YEPG}^{+\mathrm{G} 418}$-Medium $(B)$ und $\mathrm{SC}^{+\mathrm{HIS}, \mathrm{G} 418}$-Medium $(C)$ überstempelt und danach für zwei weitere Tage bei $30^{\circ} \mathrm{C}$ inkubiert.

Das Wachstum aller vier Sporen einer Tetrade zeigt, daß die reduzierte GuanylatkinaseAktivität in Verbindung mit der Deletion der NDK1 nicht zur rezessiven Lethalität in der Hefe führt. Nach Überstempeln auf die Selektivmedien $\mathrm{YEPG}^{+\mathrm{G} 418}-(B)$ und $\mathrm{SC}^{-\mathrm{HIS},+\mathrm{G} 418}(C)$ konnten

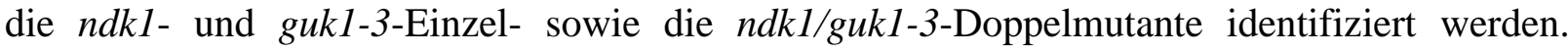
Aufgrund der Markerverteilung lassen sich den vier Sporen in Spalte 3 folgende Genotypen zuordnen: A3, AGP215(guk1-3, ndk1::Kan ${ }^{r}$, HIS3); B3, AGP215(guk1-3, NDK1, his3); C3, AGP215(GUK1, NDK1, HIS3); D4, AGP215(GUK1, ndk1::Kan ${ }^{r}$, his3).

Der Phänotyp der guk1-3-Einfachmutante (B3) unterscheidet sich nicht von jenem der gukl3/ndk1-Doppelmutante (A3). Demnach hat eine Reduktion der Guanylatkinase-Aktivität um mehr als 90\% in Verbindung mit dem Verlust der NDK1 keinen Einfluß auf das Zellwachstum.

\subsubsection{Kinetische Eigenschaften von GUK1-Mutanten mit veränderter ATP- Bindungsstelle}

In $S$. cerevisiae ist die Expression der Purin-Synthese-Gene ( $A D E$ Gene, welche an der de novo Synthese von AMP beteiligt sind) in Gegenwart von extrazellulären Purinen (Adenin und Hypoxanthin) reprimiert (Daignan-Fornier und Fink, 1992). Kürzlich wurden S. cerevisiae- 
Mutanten isoliert, in welchen die Purin-Synthese-Gene nicht mehr durch extrazelluläres Adenin reprimiert werden. Diese Mutanten wurden als bra (bypass of repression by adenine) bezeichnet, da sie durch eine Deregulation der de novo Purin-Synthese-Gene gekennzeichnet sind (Guetsova et al., 1997). Die bra-Mutanten können in mehr als zehn unterschiedliche Gruppen eingeteilt werden. Wie durch Komplementations-Analyse gezeigt wurde, handelt es sich bei den identifizierten bra3-Mutanten um Allele des GUK1-Gens (Lecoq et al., 2000). Nach Sequenzierung der GUK1-Gene aus bra3-Mutanten konnten drei verschiedene Punktmutationen im offenen Leserahmen der GUKI identifiziert werden. Die jeweiligen bra3Mutanten besitzen folgende Punktmutationen:

$\begin{array}{lll}B R A 3-1(G U K 1-1) & \Rightarrow & \mathrm{R} 132 \mathrm{~K} \\ B R A 3-2 / \text { BRA3-4 (GUK1-2) } & \Rightarrow & \mathrm{G} 12 \mathrm{~S} \\ B R A 3-3(\text { GUK1-3) } & \Rightarrow & \text { P10L }\end{array}$

Der Phänotyp der drei bra3-Mutanten ist durch einen Wachstumsdefekt (30 - 40\% erhöhte Generationszeit im Vergleich zum Wild-Typ) gekennzeichnet. Darüberhinaus beträgt die Guanylatkinase-Aktivität in Hefeextrakten der drei Mutanten nur noch weniger als $10 \%$ der Wild-Typ-Aktivität (Lecoq et al., 2000).

Bei näherer Betrachtung der drei Punktmutationen fällt auf, daß zwei von ihnen, nämlich P10L und G12S, Mutationen des Phosphat-Loops (P-Loops) (siehe Abb. 1.4) sind. Der P-Loop ist ein allen Kinasen gemeinsames Sequenzmotiv, welches an der Bindung des $\beta$ - und $\gamma$-Phosphates von ATP (oder GTP) beteiligt ist (Saraste et al., 1990). Darüberhinaus sind alle drei Aminosäuren in den bisher bekannten Guanylatkinasen verschiedener Spezies konserviert (siehe Abb. 1.4). Im Gegensatz zur G12S-Mutation sind die P10L- und R132K-Mutationen konservative Substitutionen der jeweiligen Aminosäure. Sowohl Prolin (mit sekundärer Aminogruppe), als auch Leucin besitzen hydrophobe Seitenketten. Allerdings kann die cyclische Seitenkette des Prolins signifikante Auswirkungen auf die Tertiärstruktur der GUK1 haben. Die Aminosäuren Arginin und Lysin sind bei neutralem $\mathrm{pH}-$ Wert positiv geladen. Im Gegensatz dazu wird in der G12S-Mutante ein hydrophober Rest gegen einen Rest mit hydrophilem Charakter (Hydroxyl-Gruppe in Seitenkette des Serins) ausgetauscht. Da die bra3Punktmutationen eine wesentliche Auswirkung auf die Aktivität der GUK1 haben, sollten im Folgenden alle drei Mutanten als rekombinant hergestellte Proteine biochemisch in vitro charakterisiert werden. 
Die jeweiligen Punktmutationen wurden durch PCR-Mutagenese in die GUK1-Sequenz eingeführt. Als Template für alle folgenden PCR-Reaktionen fungierte das Plasmid pJC20GUK1.1( $\triangle N d e I)$, welches das GUK1-Gen ohne die natürlich vorkommende interne NdeISchnittstelle trägt. Zur Konstruktion der Mutanten P10L und G12S wurde das GUK1-Gen in einem Schritt mit den spezifischen Oligonukleotidpaaren OSP99/OSP118 und OSP37/OSP118 amplifiziert. Die Mutation R132K wurde mittels der sehr effizienten Methode der „OverlapExtension“-PCR (siehe 3.8.1) in die GUK1-Sequenz eingeführt. Dazu wurden zunächst der 5'Megaprimer, durch Amplifikation des GUK1-Gens mit den spezifischen Oligonukleotiden OSP116 und OSP103 sowie der 3'-Megaprimer, durch Amplifikation des GUK1-Gens mit den Oligonukleotiden OSP102 und OSP118, hergestellt.

A

B
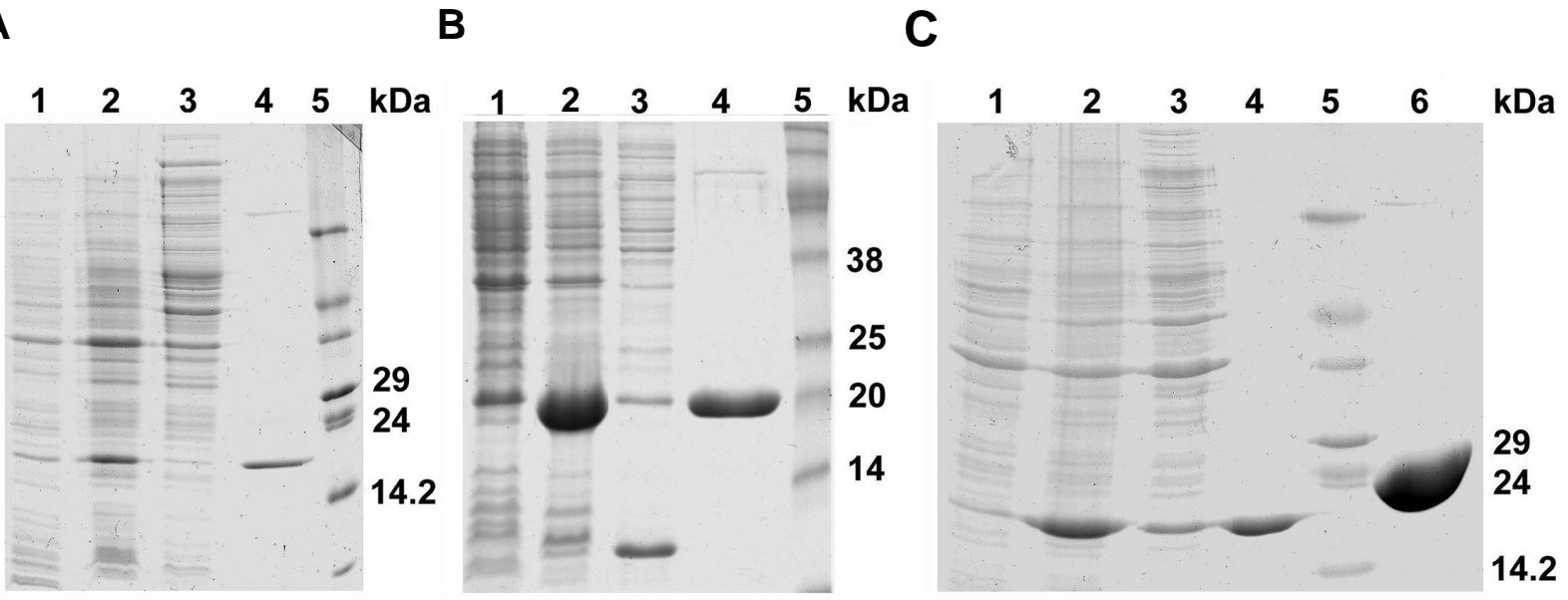

Abb. 4.12 Aufreinigung von GUK1(P10L) (A), GUK1(G12S) (B) und GUK1(R132K) (C) nach Expression in $E$. coli. Proteinproben (jeweils 5-10 $\mu \mathrm{l}$ ) der einzelnen Expressions- und Reinigungsschritte wurden in einem $12 \%$ igen SDS-Polyacrylamid-Gel elektrophoretisch aufgetrennt und die Proteine durch Coomassie-Brilliantblau R250 angefärbt. Spur 1, E. coli-Zellysat vor Induktion; Spur 2, E. coli-Zellysat nach 6stündiger Induktion; Spur 3, Proteinextrakt mit gesamten löslichem Protein; Spur 4, als His 6 -Fusionsprotein aufgereinigte GUK1-Mutante; Spur 5, Molekulargewichtsmarker (in kDa); Spur 6, aufgereinigte Wildtyp GUK1.

In einem darauffolgenden zweiten PCR-Schritt wurden die beiden überlappenden Megaprimer mit den spezifischen Oligonukleotiden OSP116 und OSP118 zu dem vollständigen Gen fusioniert. Alle drei PCR-Fragmente wurden über die Restriktions-Schnittstellen NdeI/BamHI in den Vektor pJC20[HisC] kloniert.

Die Proteine wurden anschließend in E. coli BL21(DE3) überexprimiert (siehe 3.10.2.1) und als His $_{6}$-Fusionsproteine affinitätschromatographisch über eine $\mathrm{Ni}^{2+}$-NTA-Säule aufgereinigt. Wie die Abbildung 4.12 der SDS-PAGE-Gele zeigt, waren alle drei Mutanten löslich und konnten in hoher Homogenität aufgereinigt werden. Der Ertrag lag mit 1 (GUK1(P10L)) bis 4 (GUK1(G12S)) mg Protein aus einem Liter E. coli-Kultur jedoch weit unterhalb des Ertrags von 
aufgereinigter Wild-Typ GUK1 (>100 mg/l Kultur). Alle drei Mutanten zeigten im Vergleich zum Wild-Typ eine deutlich verringerte Guanylatkinase-Aktivität.
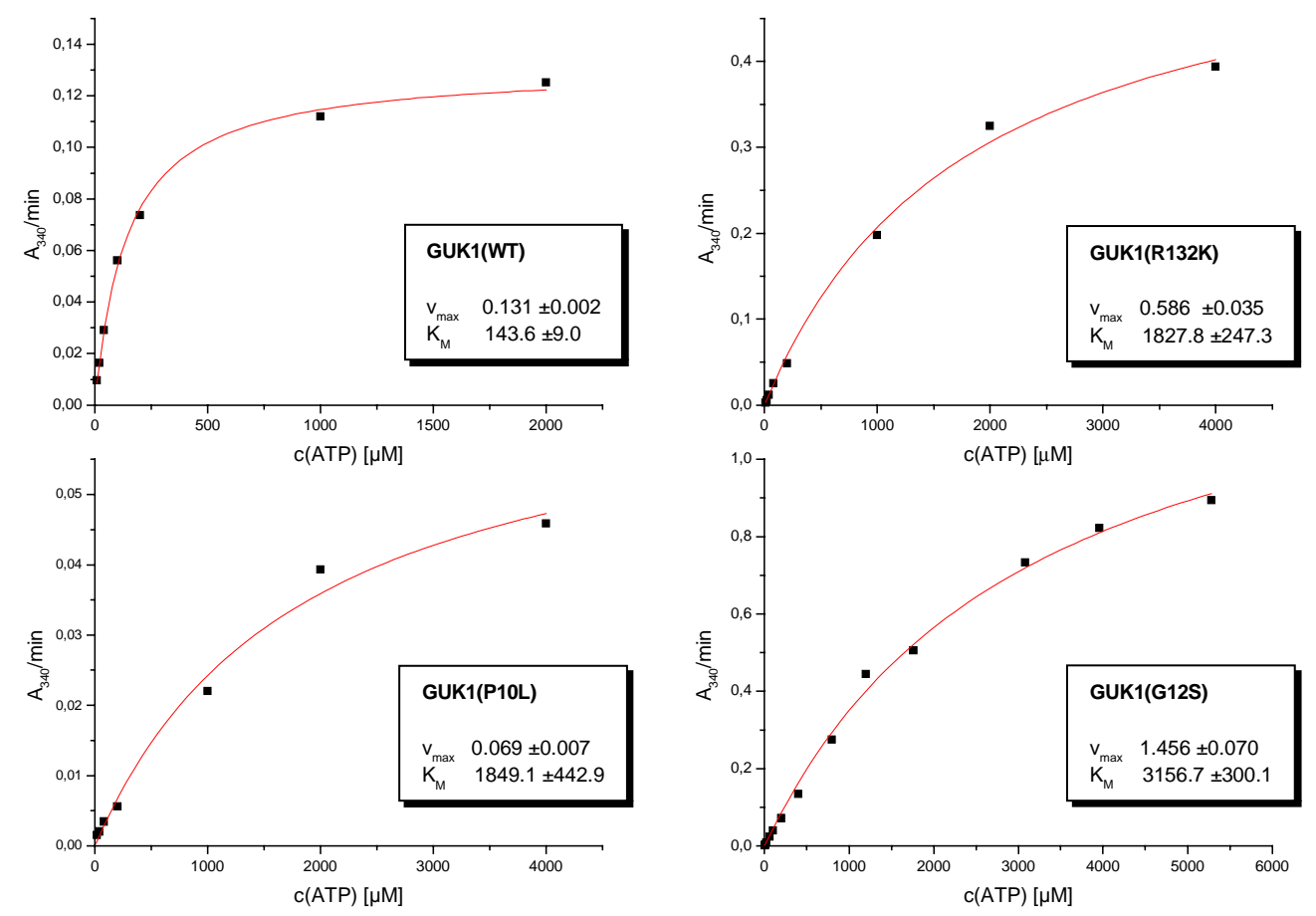

Abb. 4.13 Aktivitätskurven zur Bestimmung von $K_{M(\mathrm{ATP})}$ der Mutanten GUK1(P10L), GUK1(G12S), GUK1(R132K) sowie der Wild-Typ-GUK1. $\mathrm{c}(\mathrm{GMP})=1 \mathrm{mM}, \mathrm{c}(\mathrm{WT})=6 \mathrm{nM}, \mathrm{c}($ Mutante $)=100-400 \mathrm{nM}$.

Die Umsatzrate $\left(k_{c a t}\right)$ von GUK1(G12S) lag bei 7,8\% und die Aktivitäten von GUK1(P10L) und GUK1(R132K) bei 5,7 bzw. 3,1\% der Wild-Typ-Aktivität (siehe Tab. 4.1). Diese in vitrogemessenen Aktivitäten der aufgereinigten Proteine stehen in Einklang mit den Ergebnissen der Aktivitätsmessung von bra3-Hefeextrakten (Lecoq et al., 2000). Da zumindest zwei der drei Mutationen Aminosäure-Substitutionen in einem Motiv der GUK1-Sequenz sind, welches für die Bindung des Substrates ATP von entscheidender Bedeutung ist, sollte als nächstes untersucht werden, ob die verringerte Aktivität möglicherweise die Folge einer veränderten Affinität der GUK1-Mutanten zum Substrat ATP (oder GMP) ist. Dazu wurden die MichaelisMenten-Konstanten $\left(K_{\mathrm{M}}\right)$ der drei Mutanten für die Substrate ATP und GMP bestimmt. Die hyperbolischen Kurven der Aktivitätsmessung $\left(\Delta \mathrm{A}_{340} / \mathrm{min}\right)$ der drei GUK1-Mutanten, sowie der Wild-Typ GUK1 als Referenz, in Gegenwart ansteigender Konzentration der Substrate ATP bzw. GMP sind in Abbildung 4.13 (ATP) und 4.14 (GMP) dargestellt. Der aus den Aktivitätskurven abgeleitete $K_{\mathrm{M}}$-Wert für ATP ist in allen drei Mutanten im Vergleich zum Wild-Typ drastisch erhöht. Während der $K_{\mathrm{M}}(\mathrm{ATP})$ der GUK1(WT) 143,6 $\pm 9,0 \mu \mathrm{M}$ beträgt, liegt er für die beiden Mutanten GUK1(P10L) und GUK1(R132K) ähnlich erhöht, bei 1849,1 $\pm 442,9$ 
$\mu \mathrm{M}$ bzw. 1827,8 $\pm 247,3 \mu \mathrm{M}$. Demgegenüber zeigt die Mutante GUK1(G12S) sogar einen, gegenüber GUK1(WT), 23fach erhöhten $K_{\mathrm{M}}(\mathrm{ATP})$ von 3156,7 $\pm 300,1 \mu \mathrm{M}$.
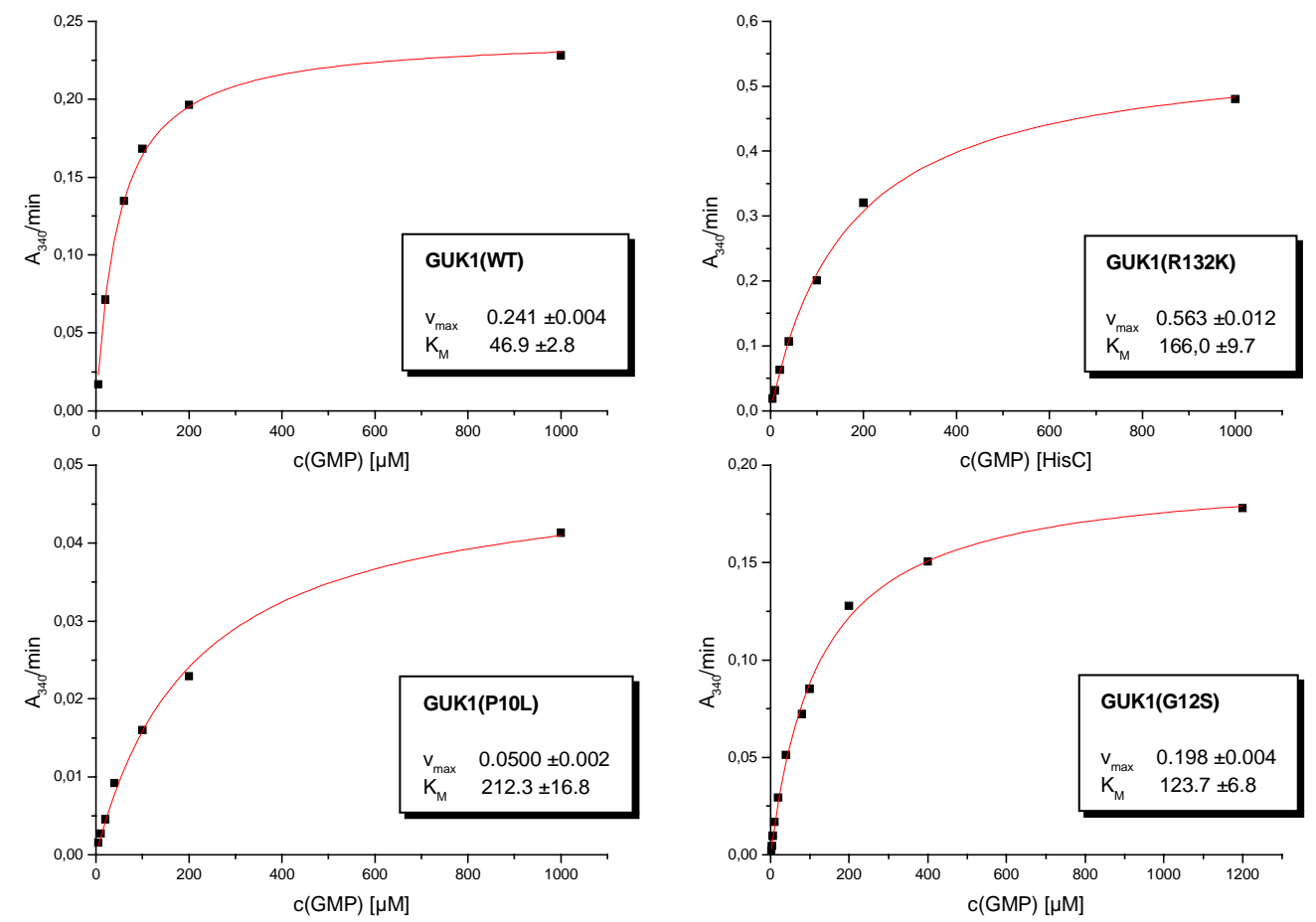

Abb. 4.14 Aktivitätskurven zur Bestimmung von $K_{M(\mathrm{GMP})}$ der Mutanten GUK1(P10L), GUK1(G12S), GUK1(R132K) sowie der Wild-Typ-GUK1. $c($ ATP $)=1 \mathrm{mM}, \mathrm{c}($ Protein $)=6 \mathrm{nM}, \mathrm{c}($ Mutante $)=100-400 \mathrm{nM}$.

Im Vergleich zu den $K_{\mathrm{M}}$-Werten für das Substrat ATP scheint der $K_{\mathrm{M}^{-}}$Wert für GMP in allen drei Mutanten (siehe Abb. 4.14) weniger stark betroffen $\mathrm{zu}$ sein. In den Mutanten GUK1(R132K) $(165,9 \pm 9,7 \mu \mathrm{M})$ und GUK1(G12S) $(123,7 \pm 6,8 \mu \mathrm{M})$ ist er um den Faktor 3 und in der Mutante GUK1(P10L) $(212,3 \pm 16,8 \mu \mathrm{M})$ um den Faktor 4 im Vergleich zur GUK1(WT) $(46,9 \pm 2,8 \mu \mathrm{M})$ erhöht. Die geringe katalytische Effizienz der drei bra3-Mutanten, als Folge einer im Vergleich zum Wild-Typ deutlich schwächeren Affinität für das Substrat ATP wird insbesondere bei Betrachtung der Spezifizitätskonstanten $k_{\mathrm{cat}} / K_{\mathrm{M} \text { (ATP) }}$ deutlich. Diese ist in allen drei Fällen um den Faktor 300 im Vergleich zum Wild-Typ erniedrigt (siehe Tab. 4.1).

Mit der Zielsetzung ein annähernd vollständiges Bild der Auswirkung von Punktmutationen im P-Loop der Hefe-Guanylatkinase zu erhalten, wurde neben den beiden zuvor beschriebenen Mutanten (P10L und G12S) noch eine dritte Aminosäure des P-Loops, der Lysinrest an Position 15, mutiert. Das konservierte Lysin ist eines der am Besten charakterisierten Reste des P-Loops von ATP- bzw. GTP-bindenden Proteinen. Die Mutation des konservierten P-Loop-Lysins in Adenylatkinasen und GTP-bindenden Proteinen hat eine zum Teil dramatisch reduzierte 
Affinität für das Substrat ATP bzw. GTP zur Folge (Reinstein et al., 1990; Tian et al, 1990; Sigal et al., 1986). In der E. coli-Adenylatkinase beispielsweise führt die Mutation K13Q zwar nur zu einer schwachen Erniedrigung der Affinität zum Substrat ATP; diese hat jedoch einen drastischen Abfall der katalytischen Aktivität zur Folge (Reinstein et al., 1990). Im Guanylatkinasekomplex mit GMP bildet der Lysinrest des P-Loops eine Salzbrücke zum Aspartatrest an Position 98. Das Aspartat seinerseits bindet das für die Katalyse notwendige $\mathrm{Mg}^{2+}$ (Stehle und Schulz, 1992). Ebenso wie in der Adenylatkinase (Reinstein et al., 1990, Tsai und Yan, 1991) und der Thymidylatkinase (Lavie et al., 1998, Ostermann et al., 2000) scheint der Lysinrest eine wichtige Rolle in der Stabilisierung des Übergangszustandes während des Transfers des Phosphatrestes zu spielen.

Im Einklang mit den konservativen Mutationen der bra3-Mutanten sollte das essentielle P-Loop-Lysin gegen ein Arginin ausgetauscht werden. Die Mutation wurde wie bereits zuvor geschildert durch PCR-Mutagenese mit den spezifischen Oligonukleotid-Primern OSP53 und OSP117 in das GUK1-Gen eingeführt und das PCR-Produkt GUK1(K15R) dann über die Schnittstellen NdeI/BamHI in den Vektor pGEX-RB kloniert. In Abbildung 4.15 ist das SDSPAGE-Gel zur Aufreinigung von GUK1(K15R) dargestellt. Die Mutante ließ sich nach Induktion mit $1 \mathrm{mM}$ IPTG gut in E. coli BL21(DE3) überproduzieren (siehe Abb. 4.15, Spur 2). GUK1(K15R) konnte nach Thrombinverdau direkt ohne GST-Anhang von der Sepharose 4BSäule eluiert werden (Abb. 4.15, Spur 3) und wurde anschließend mit dem gekoppelten EnzymAssay kinetisch untersucht.

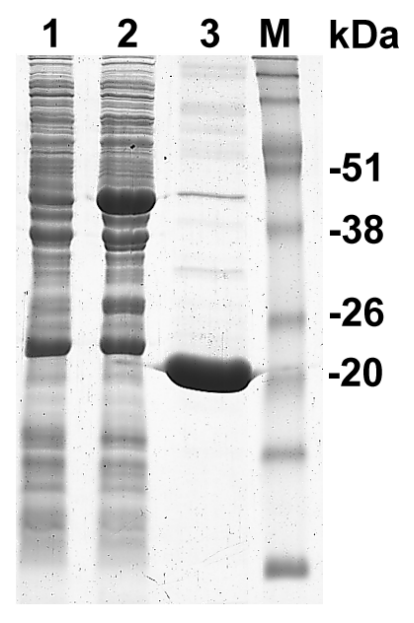
Abb. 4.15 Aufreinigung von GUK1(K15R) nach Expression in E. coli. Spur 1, E. coli-Zellysat vor Induktion; Spur 2, E. coli-Zellysat nach 6stündiger Induktion; Spur 3, nach Thrombinverdau aufgereinigte GUK1(K15R); $M$, Molekulargewichtsmarker (in kDa)

Die K15R Substitution in GUK1 hatte einen dramatischen Abfall der enzymatischen Aktivität zur Folge. Die Umsatzrate von GUK1(K15R) fiel auf einen mit dem gekoppelten Assay kaum mehr detektierbaren Wert von $0,02 \pm 0,01 \mathrm{U} / \mathrm{mg}$ (die eingesetzte Proteinkonzentration war gegenüber dem WT-Protein etwa 1000fach erhöht) ab. Dies entsprach 0,02 - 0,03\% der Wild- 
Typ-Aktivität. Die Mutationen im Phosphat-Loop haben einen drastischen Einfluß auf die Bindung des Substrats ATP. In der Mutante GUK1(K15R) stieg der $K_{\mathrm{M}}$-Wert für ATP beinahe um den Faktor 10 und der $K_{\mathrm{M}}$-Wert für GMP um das doppelte im Vergleich zur Wild-TypGUK1 an (siehe Tab. 4.1). Die kinetischen Parameter der K15R-Mutante zeigen folglich die gleiche Tendenz wie die zuvor getesteten P-Loop-Mutanten P10L und G12S. In allen vier Fällen war die Affinität der Mutante zum Substrat ATP zum Teil deutlich erniedrigt. Die schwache Affinität für beide Substrate ist vermutlich die Ursache für den dramatischen Abfall der enzymatischen Aktivität.

Tab. 4.1 Kinetische Parameter der GUK1-Mutanten

\begin{tabular}{|c|c|c|c|c|c|}
\hline Mutante & $\begin{array}{c}k_{\text {cat }} \\
{\left[s^{-1}\right]}\end{array}$ & $\begin{array}{c}K_{\mathrm{M}(\mathrm{GMP})}^{+} \\
{[\mu M]}\end{array}$ & $\begin{array}{c}K_{\mathrm{M}(\mathrm{ATP})}{ }^{*} \\
{[\mu M]}\end{array}$ & $\begin{array}{c}\boldsymbol{k}_{\mathrm{cat}} / K_{\mathrm{M}(\mathrm{GMP})} \\
{[s \cdot \mu M]^{-1}}\end{array}$ & $\begin{array}{c}k_{\mathrm{cat}} / K_{\mathrm{M}(\mathrm{ATP})} \\
{[s \cdot \mu M]^{1}}\end{array}$ \\
\hline P10L & $3,1 \pm 0,1$ & $212,3 \pm 16,8$ & $1849,1 \pm 442,9$ & $1,5 \pm 0,2 \cdot 10^{-2}$ & $0,2 \pm 0,0 \cdot 10^{-2}$ \\
\hline G12S & $7,8 \pm 0,2$ & $123,7 \pm 6,8$ & $3156,7 \pm 300,1$ & $6,3 \pm 0,5 \cdot 10^{-2}$ & $0,3 \pm 0,0 \cdot 10^{-2}$ \\
\hline $\mathrm{R} 132 \mathrm{~K}$ & $5,7 \pm 0,1$ & $166,0 \quad \pm 9,7$ & $1827,8 \pm 247,3$ & $3,4 \pm 0,2 \cdot 10^{-2}$ & $0,3 \pm 0,0 \cdot 10^{-2}$ \\
\hline $\mathrm{K} 15 \mathrm{R}$ & $0,02 \pm 0,01$ & $103,7 \pm 31,3$ & $1168,4 \pm 559,2$ & $2 \cdot 10^{-4}$ & $5 \cdot 10^{-5}$ \\
\hline WT & $100,8 \pm 1,8$ & $46,9 \pm 2,8$ & 143,6 & $2,15 \pm 0,17$ & $0,70 \pm 0,06$ \\
\hline
\end{tabular}

Neben den zuvor charakterisierten bra3-Mutanten wurde kürzlich in der Hefe eine weitere natürliche Mutation des GUK1-Gens entdeckt. Die temperatursensitive Hefemutante nes25 (neomycin-sensitive) gehört $\mathrm{zu}$ einer Gruppe von 15 isolierten nes-Mutanten, die eine verringerte Resistenz gegenüber dem Antibiotikum Neomycin aufweisen (Shimma und Uno, 1990). Durch Komplementationsanalyse wurde NES25 als GUK1-Allel identifiziert. Mutanten der nes-Komplementationsgruppen besitzen einen Glykosylierungsdefekt, der wahrscheinlich auf einen Mangel an GDP-Mannose zurückzuführen ist (Shimma et al., 1997).

In dieser Arbeit sollte die GUK1(NES25) ebenfalls als rekombinantes Protein isoliert und biochemisch charakterisiert werden. Dazu wurde das GUK1(NES25)-Gen zunächst mit den spezifischen Guanylatkinase-Primern OSP116 und OSP117 und den internen Oligonukleotid- 
Primern OSP38 und OSP39 sowie dem Plasmid pCR2.1-nes25-1 (B. Daignan-Fornier) als Template durch „Overlap-Extension“-PCR amplifiziert. Durch Sequenzanalyse konnte eine Punktmutation an Position Glu139 der GUK1-Sequenz identifiziert werden. Das Glutamat ist in NES25 durch Lysin substituiert. In der Tertiärstruktur der GUK1 liegt die Aminosäure Glu139 an der Peripherie, ist also dem Lösungsmittel zugewandt und nicht Bestandteil der aktiven Domänen. Der Austausch einer negativ geladenen Aminosäure gegen eine positiv geladene sollte drastische Auswirkungen auf die strukturelle Integrität der Guanylatkinase haben.

Die Mutante GUK1(E139K) wurde wie zuvor die BRA3-Mutanten rekombinant in E. coliBL21(DE3) überproduziert. GUK1(E139K) wurde gut als GST-Fusionsprotein überproduziert. Im Gegensatz zu den zuvor beschriebenen BRA3-Mutanten war jedoch eine Isolierung von NES25 weder als GST-Fusionsprotein noch durch Wahl anderer Aufreinigungssysteme (Überexpression als Fusionsprotein mit Histidin- oder MaltoseBindeprotein(MBP)-Anhang) möglich. In allen Fällen bildete das gesamte exprimierte Protein Einschlußkörper.

\subsubsection{Die Guanylatkinase des Menschen und der Maus}

Die Guanylatkinasen des Menschen (hGUK, 197 AS bzw. 21,7 kDa; Fitzgibbon et al., 1996) und der Maus (mGUK; 198 AS; 21,9 kDa; Brady et al., 1996) sind bisher im Vergleich zur Guanylatkinase aus S. cerevisiae (GUK1; 186 AS; 20,5 kDa; Berger et al., 1989) wenig biochemisch untersucht. Anhand von Sequenzvergleichen konnte bereits gezeigt werden, daß sowohl hGUK als auch mGUK zwar eine starke Sequenzähnlichkeit zu verwandten, aus Säugern (Rind und Schwein; Gaidarov et al., 1993; Zschocke et al., 1993) isolierten Guanylatkinasen besitzen, der Anteil an konservierter Aminosäuresequenz zu der Guanylatkinase aus S. cerevisiae (Berger et al., 1989) und E. coli (Gentry et al., 1993) allerdings weitaus geringer ist (Brady et al., 1996). Die Identität zwischen der hGUK oder mGUK und der GUK1 beträgt 52-55\%, wobei der P-Loop, also die ATP-Bindungsdomäne, sowie die an der Bindung von GMP beteiligten Aminosäuren in allen drei Enzymen konserviert sind (siehe Abb. 1.4).

Während in einer früheren Arbeit (Spangenberg, 1997) gezeigt wurde, daß sowohl hGUK, als auch mGUK die katalytische Funktion von inaktiver GUK1 in der Hefe vollständig ersetzen, lieferten erste Versuche zur Herstellung rekombinanter, aktiver hGUK und mGUK (Brady et al., 1996) keine zufriedenstellenden Ergebnisse. Die spezifischen Aktivitäten beider Enzyme nach partieller Aufreinigung aus E. coli waren mit Werten von 6,6 U/mg (hGUK) bzw. 32,9 $\mathrm{U} / \mathrm{mg}$ (mGUK) im Vergleich zur Hefe-Guanylatkinase (300 U/mg) unerwartet gering. 
Außerdem war es bisher noch nicht möglich beide Enzyme in hoher Homogenität und in Mengen über $2 \mathrm{mg}$ pro Liter E. coli-Kultur rekombinant herzustellen (Spangenberg, 1997).

Auf Basis der bisher vorliegenden Ergebnisse war eines der Ziele dieser Arbeit eine weiterführende biochemische Charakterisierung der Guanylatkinase der Maus und des Menschen. In Zusammenarbeit mit A. Lavie (University of Illinois at Chicago) wird zur Zeit die Röntgenstruktur der beiden Säuger-Enzymen entschlüsselt.

\subsubsection{Aufreinigung von hGUK und mGUK aus E. coli}

Die geringe Ausbeute an schwach aktiver rekombinanter hGUK und mGUK nach Überexpression und Aufreinigung als $\mathrm{His}_{6}$-Fusionsproteine aus E. coli war auf einen schwachen Expressionslevel der beiden Proteine zurückzuführen. Dieser deutete daraufhin, daß beide Proteine in E. coli instabil sind (Spangenberg, 1997). In dieser Arbeit sollte daher zunächst versucht werden die Löslichkeit der beiden Proteine in E. coli durch Verwendung des GSTSystems (siehe 3.10.3) zu erhöhen.

Zur Aufreinigung der beiden Säuger-Guanylatkinasen wurde die cDNA von $h G U K$ und $m G U K$ zunächst mit den entsprechenden Oligonukleotiden OSP25/OSP16a (hGUK) und OSP17/OSP18a (mGUK) sowie dem Template YEp512N-hGUK bzw. YEp512N-mGUK durch PCR amplifiziert und über die Restriktionsschnittstellen NdeI/BamHI in den Vektor pGEX-RB kloniert. Anschließend wurden beide Enzyme als GST-Fusionsproteine nach Induktion mit IPTG und anschließendem Wachstum für $6 \mathrm{~h}$ bei $37^{\circ} \mathrm{C}$ (alternativ: Induktion über Nacht bei $\left.25^{\circ} \mathrm{C}\right)$ in E. coli $\mathrm{BL} 21(\mathrm{DE} 3)$ überexprimiert.

A

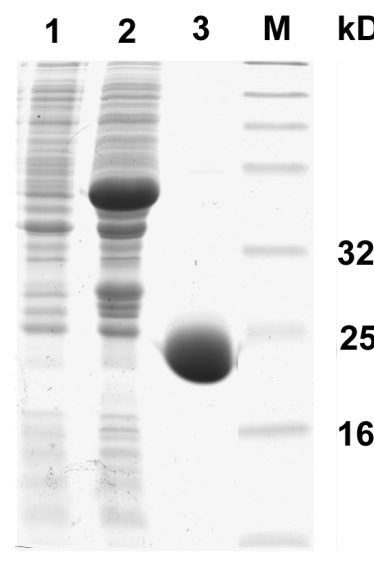

B

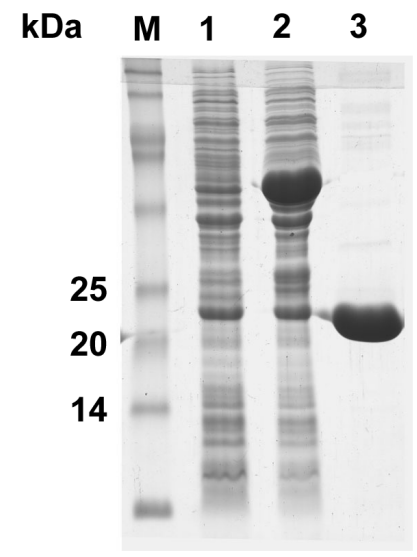

4.16 Aufreinigung von hGUK $(A)$ und mGUK $(B)$ nach Expression in E. coli. Proteinproben (jeweils 5-10 $\mu$ l) der einzelnen Expressions- und Reinigungsschritte wurden in einem 12\%igen SDS-Polyacrylamid-Gel elektrophoretisch aufgetrennt und die Proteine durch Coomassie-Brilliantblau R250 angefärbt. Spur 1, E. coliZellysat vor Induktion; Spur 2, E. coli-Zellysat nach 6stündiger Induktion; Spur 3, nach Thrombin-Verdau eluiertes Protein; $M$, Molekulargewichtsmarker (in $\mathrm{kDa}$ ) 
Die Abbildung 4.16 zeigt das SDS-PAGE-Gel zur Aufreinigung von hGUK $(A)$ und mGUK $(B)$. Die stark hervortretende Bande eines Proteins mit einem Molekulargewicht über $46 \mathrm{kDa}$ nach Induktion mit IPTG zeigt in beiden Fällen eine starke Überexpression der rekombinanten Gene in E. coli an (siehe Abb. 4.16 A und B, Spur 2). Darüberhinaus sind beide GSTFusionsproteine in hohem Maße löslich. Nach Bindung des GST-Fusionsproteins an die Sepharose-4B-Matrix wurde der GST-Anhang durch Thrombinverdau abgespalten und das jeweilige Säuger-Protein direkt von der Säule eluiert. Wie die 3. Spur des jeweiligen SDSPAGE-Gels zeigt, ist es möglich beide Proteine in einem einzigen Aufreinigungsschritt in sehr hoher Homogenität (> 95\%) zu isolieren. Aus einem Liter E. coli-Kultur konnten bis zu $120 \mathrm{mg}$ hGUK bzw. mGUK aufgereinigt werden. Vergleicht man die Ergebnisse dieser Aufreinigungen beider Proteine mit früheren Ergebnissen, so scheint der GST-Anhang in der Tat die Löslichkeit der beiden Proteine in E. coli positiv zu beeinflussen.

\subsubsection{Kinetische Eigenschaften von hGUK und mGUK}

Die spezifischen Aktivitäten, sowie die Michaelis-Menten-Parameter von aufgereinigter Mensch- und Maus-Guanylatkinase wurden mit dem gekoppelten spektrophotometrischen Assay bestimmt. Die Ergebnisse im Vergleich zur enzymatischen Aktivität von GUK1 sind in Tabelle 4.2 dargestellt. Im Gegensatz $\mathrm{zu}$ den Ergebnissen enzymatischer Aktivitätsbestimmungen von rekombinant hergestellten hGUK und mGUK früherer Arbeiten (Spangenberg, 1997; Brady et al., 1996), zeigen beide Enzyme eine mehrfach erhöhte spezifische Aktivität. Diese beträgt im Fall von hGUK 154,4 $\pm 31,1 \mathrm{U} / \mathrm{mg}$ und im Fall von mGUK 167,8 $\pm 26,6$ U/mg, also etwa 50\% der Aktivität rekombinanter Hefe-GUK1 (291 $\pm 23,5$ $\mathrm{U} / \mathrm{mg})$.

Tab. 4.2 Spezifische Aktivitäten von hGUK und mGUK im Vergleich zur GUK1

\begin{tabular}{cc}
\hline Spezies & Spezifische Aktivität \\
& $(\boldsymbol{U} / \mathbf{m g})$ \\
\hline hGUK & $154,4 \pm 31,1$ \\
mGUK & $167,8 \pm 26,6$ \\
GUK1 & $291,0 \pm 23,5$ \\
\hline
\end{tabular}

$\mathrm{c}(\mathrm{ATP})=2 \mathrm{mM}, \mathrm{c}(\mathrm{GMP})=1 \mathrm{mM}$ 
Zur Ermittlung der $K_{\mathrm{M}}$-Werte wurde die jeweilige Guanylatkinase in nanomolarer Konzentration im Assay eingesetzt. Während das erste Substrat im Überschuß (1 mM GMP bzw. 2 mM ATP) vorlag, wurde das zweite Substrat in verschiedenen Konzentration (ATP: 2 $4000 \mu \mathrm{M}$, GMP: 2 - $1000 \mu \mathrm{M}$ ), in unabhängigen Ansätzen dem Assay hinzugefügt und die Aktivitäten gemessen. Abbildung 4.17 zeigt die Aktivitätskurven (Auftragung: $\Delta \mathrm{A}_{340} / \mathrm{min} \rightarrow$ $\mathrm{c}(\mathrm{GMP})$ zur Bestimmung der Michaelis-Menten-Konstanten $K_{\mathrm{M}(\mathrm{GMP})}$ von hGUK $(A)$ und mGUK $(B)$.

A

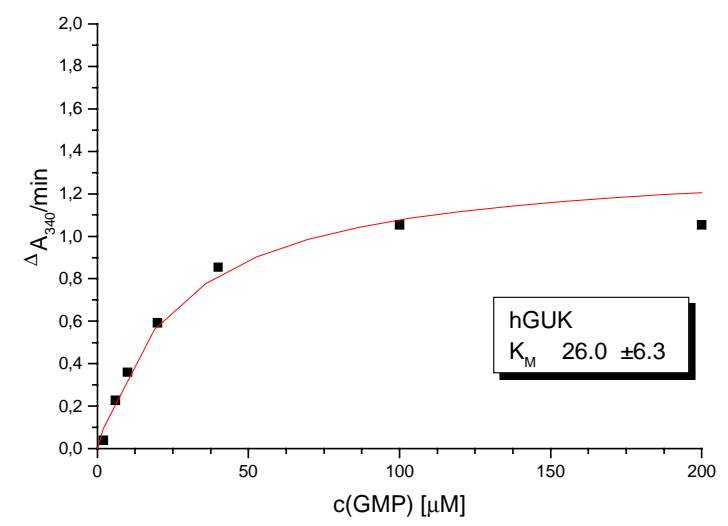

B

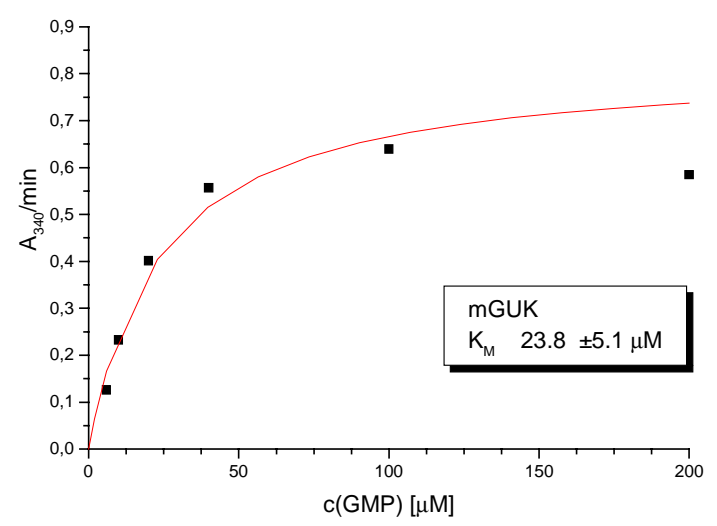

Abb. 4.17 Bestimmung des $K_{\mathrm{M}}$-Werts von hGUK $(A)$ und mGUK $(B)$ für das Substrat GMP in Gegenwart von 2 mM ATP. Oberhalb einer Konzentration von $100 \mu$ M GMP tritt Substratinhibition auf, weshalb die Aktivitätswerte höherer GMP-Konzentrationen nicht mehr in den hyperbolischen Fit mit einbezogen wurden.

Der Abfall der Kurve bei ansteigender GMP-Konzentration deutet auf eine partielle Substratinhibition hin. Bei einer GMP-Konzentration oberhalb von $100 \mu \mathrm{M}$ fällt die Reaktionsgeschwindigkeit mit ansteigender Substratkonzentration immer weiter von ihrem maximalen Wert ab. Aufgrund der Substratinhibition wurden die Michaelis-Menten-Konstanten der Mensch- und Maus-Guanylatkinasen für das Substrat GMP durch hyperbolischen Fit der Aktivitätskurve (siehe Abb. 4.17) bis zu einer maximalen GMP-Konzentration von $100 \mu \mathrm{M}$ bestimmt.

Wie aus der Tabelle 4.3 hervorgeht, weichen die $K_{\mathrm{M}}$-Werte von hGUK und mGUK für beide Substrate signifikant von jenen der Hefe-GUK1 ab. Obwohl beide Säuger-Guanylatkinasen im Vergleich zur GUK1 eine geringere spezifische Aktivität besitzen, entsprechen aufgrund der erhöhten Affinität für beide Substrate die spezifischen Konstanten $k_{\text {cat }} / K_{\mathrm{M}(\mathrm{ATP})}$ und $k_{\mathrm{cat}} / K_{\mathrm{M}(\mathrm{GMP})}$ von hGUK und mGUK in Etwa jener der GUK1. 
Tab. 4.3 Kinetische Parameter von hGUK und mGUK im Vergleich zur GUK1

\begin{tabular}{cccccc}
\hline Spezies & $\boldsymbol{k}_{\mathrm{cat}}$ & $\boldsymbol{K}_{\mathrm{M}(\mathrm{ATP})}{ }^{*}$ & $\boldsymbol{K}_{\mathrm{M}(\mathrm{GMP})}{ }^{+}$ & $\boldsymbol{k}_{\mathrm{cat}} / \boldsymbol{K}_{\mathrm{M}(\mathrm{ATP})}$ & $\boldsymbol{k}_{\mathrm{cat}} / \boldsymbol{K}_{\mathrm{M}(\mathrm{GMP})}$ \\
{$\left[\boldsymbol{s}^{-1}\right]$} & {$[\boldsymbol{\mu M}]$} & {$[\boldsymbol{\mu M}]$} & {$\left[\boldsymbol{s}^{-1} \boldsymbol{\mu} \boldsymbol{M}^{-1}\right]$} & {$\left[\boldsymbol{s}^{-1} \boldsymbol{\mu} \boldsymbol{M}^{\mathbf{1}}\right]$} \\
\hline hGUK & 52,3 & 105,0 & 26,0 & 0,50 & 2,01 \\
mGUK & 55,8 & 85,5 & 23,8 & 0,65 & 2,35 \\
GUK1 & 106,0 & 143,6 & 46,9 & 0,74 & 2,26 \\
\hline
\end{tabular}

,$+ \mathrm{c}($ ATP $)=2 \mathrm{mM} ; *, \mathrm{c}(\mathrm{GMP})=1 \mathrm{mM}$

\subsubsection{Untersuchung der Nukleotidbindung an hGUK und p2 $1^{\text {ras }}$ mit der Nano- Elektrospray-Massenspektrometrie (Nano-ESMS)}

Zur Untersuchung der Nukleotidbindung an ausgewählten Proteine wurde in Zusammenarbeit mit H. Prinz (MPI für Molekulare Physiologie, Dortmund) die Methode der Nano-ElektrosprayMassenspektrometrie (Nano-ESMS; Wilm und Mann, 1996) eingesetzt. Neben der menschlichen Guanylatkinase (hGUK) wurden auch die GTPase p21 ${ }^{\text {ras }}$ in die Bindungsstudie einbezogen (Prinz et al., 1999).

Die Nano-ESMS besitzt gegenüber herkömmlicher Elektrospray-Massenspektrometrie (ESMS) den Vorteil eines sehr stark verringerten Probe-Auftragsvolumens. Aufgrund der verringerten Tröpfchengröße ist der Salzgehalt, welcher ein kritischer Faktor in der Massenspektrometrie ist, in der Probe sehr stark reduziert. Dies ermöglicht eine Untersuchung der Proteine in wässriger Lösung ohne die Zugabe denaturierender organischer Lösungsmittel. Das Massenspektrum entspricht folglich der unter annähernd natürlichen Bedingungen erwarteten Serie an protonierten Molekülen. Zur Untersuchung der Komplexbildung wurden die Proteine in einer Konzentration von $10 \mu \mathrm{M}$ mit einer äquimolaren Menge bzw. einem Überschuß an Nukleotid für mindestens 3 Minuten bei RT inkubiert. Das Original-Massenspektrum (Relative Verteilung $\rightarrow \mathrm{m} / \mathrm{z}$ ) von hGUK zeigt eine Serie von 7 Peaks, wobei jeder einer protonierten Proteinpopulation entspricht (siehe Abb. 4.18 A). Neben den Hauptpeaks sind noch 2 weitere Peaks beobachtbar. Diese beiden entsprechen Komplexen mit einem bzw. zwei gebundenen Sulfat $\left(\mathrm{SO}_{4}{ }^{2-}\right)$-Ionen $(B)$. 

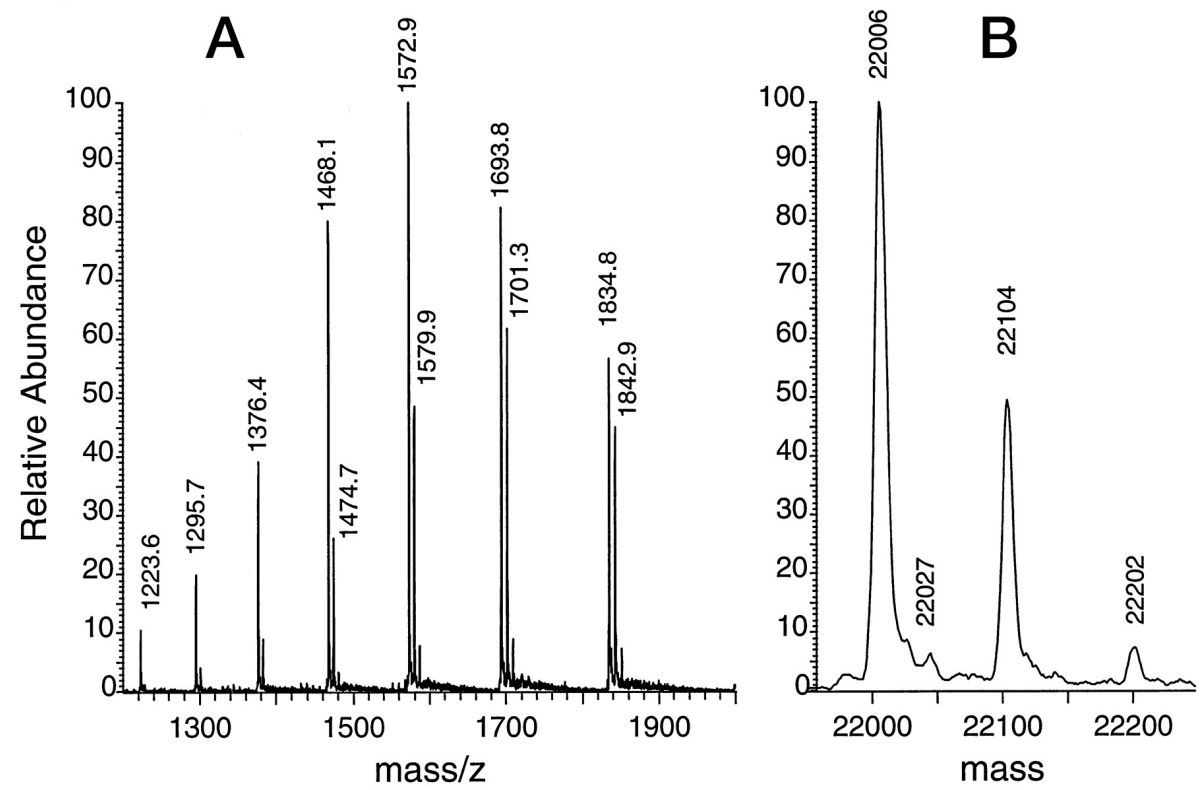

Abb. 4.18 Nano-ES-Massenspektrum von $10 \mu \mathrm{M}$ hGUK in $\mathrm{H}_{2} \mathrm{O}$. $A$, Rel. Abundance $\rightarrow m / z$. $B$, Rel. Abundance $\rightarrow$ $m$. Die Peaks entsprechen hGUK (22006), hGUK·Na ${ }^{+}$(22027), hGUK·SO ${ }_{4}{ }^{2-}$ (22104), hGUK·2SO ${ }_{4}^{2-}$ (22202) (aus Prinz et al., 1999).

Für die Bindungsstudie mit enzymatisch aktiver hGUK mussten zum Teil Nukleotidanaloga eingesetzt werden, welche nicht von dem Enzym umgesetzt werden konnten. Nach Inkubation von hGUK mit ADP $\beta S$ und GDP $\beta S$, sowie in höheren Konzentrationen AMP und GMP konnten in allen Fällen eindeutig Protein-Nukleotid-Komplexe identifiziert werden. Zusätzlich zum Ligand-freien Protein und Nukleotid-Protein-Komplex traten auch $\mathrm{SO}_{4}{ }^{2-}$-ProteinKomplexe auf. Zur Messung der Nukleotidbindung unter sättigenden Bedingungen wurde hGUK mit einer ansteigenden Konzentration an Nukleotid inkubiert. Erwartungsgemäß nahm die relative Intensität des Ligand-freien Enzym-Peaks immer weiter ab, während die Intensität des Nukleotid-Protein-Komplexspeaks zunahm. Auffällig war jedoch das Auftreten zusätzlicher Peaks, welche der Bindung von mehr als einem Nukleotid-Molekül an ein hGUK-Molekül entsprach. In Abbildung 4.19 ist das Massenspektrum von hGUK $(10 \mu \mathrm{M})$ mit einem 100fachen Überschuß an GMP (1 mM) dargestellt. 


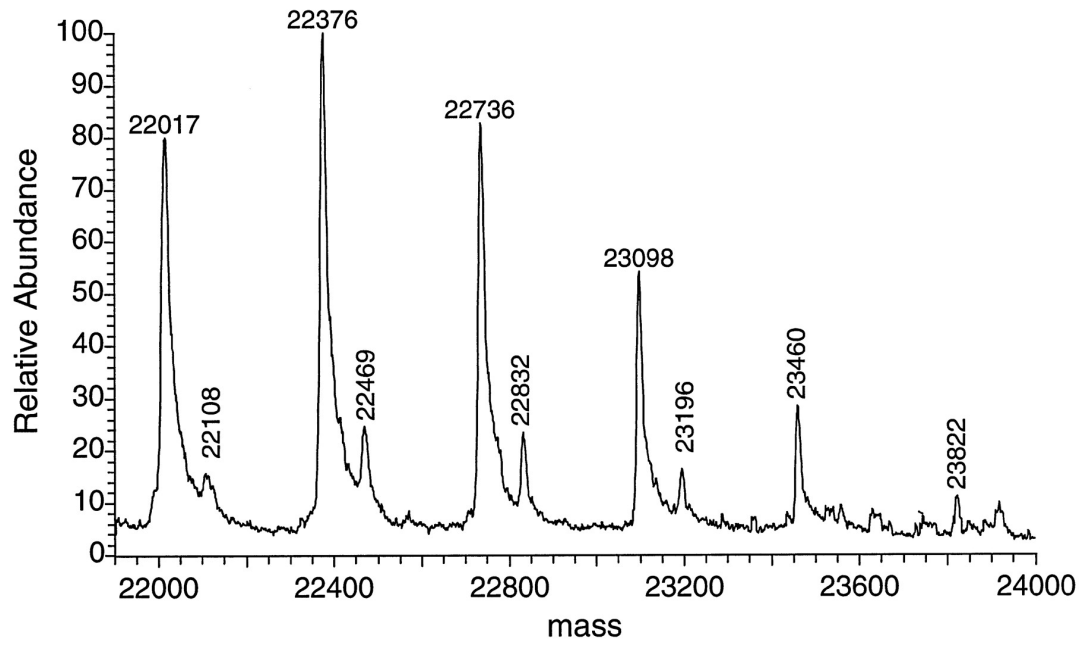

Abb. 4.19 Nano-ES-Massenspektrum von $10 \mu \mathrm{M}$ hGUK nach 30minütiger Inkubation mit $1 \mathrm{mM}$ GMP in $\mathrm{H}_{2} \mathrm{O}$. Die Peaks entsprechen hGUK (22007), hGUK.SO ${ }_{4}{ }^{2-}$ (22108), hGUK.GMP (22376), hGUK.GMP.SO ${ }_{4}{ }^{2-}$ (22469), hGUK·2GMP (22736), hGUK·2GMP.SO ${ }^{2-}$ (22832), hGUK·3GMP (23098), hGUK·3GMP.SO ${ }_{4}^{2-}$ (23196), hGUK·4GMP (23460) und hGUK·5GMP (23822) (aus Prinz et al., 1999).

Die Abnahme des Ligand-freien Protein-Peaks und das Auftreten sowie die Zunahme der GMPProtein-Komplexpeaks mit ansteigender GMP-Konzentration folgt dem hyperbolischen Verlauf einer typischen Bindungskurve. Die in Gegenwart unterschiedlicher Konzentrationen an GMP erstellten Bindungskurven in Abbildung 4.20 können mit einem simplen Modell gefittet werden, wobei alle GMP-Moleküle mit identischer Affinität an die hGUK binden.

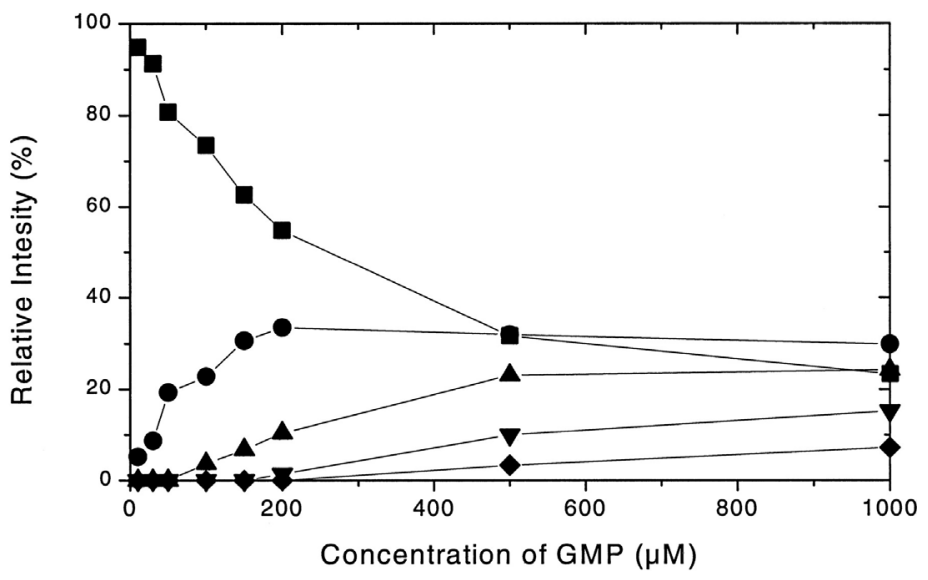

\begin{abstract}
Abb. 4.20 Bindung von GMP an $10 \mu \mathrm{M}$ hGUK unter Gleichgewichtsbedingungen. Die reletive Intensität (Fläche eines Komplex-Peaks dividiert durch die Fläche aller Komplex-Peaks multipliziert mit 100) ist gegen die die GMP-Konzentration aufgetragen. freies hGUK; - hGUK·GMP; $\boldsymbol{\Delta}$, hGUK·2GMP; $\quad \boldsymbol{\nabla}$, hGUK·3GMP; hGUK·4GMP (aus Prinz et al., 1999).
\end{abstract}

Die Anzahl und Verteilung der Peaks entsprach der Bindung von bis zu 5 GMP-Molekülen an ein Enzymmolekül. Die Bindung von bis zu 5 GMP-Molekülen an die Guanylatkinase steht jedoch im Widerspruch sowohl zu dem aktuellen Wissen über die Struktur des Enzyms (Stehle und Schulz, 1992), als auch dem Ergebnis von mit diesem Enzym durchgeführten Bindungsstudien (Li et al., 1996). Da im Massenspektrum nur echte Komplex dargestellt werden, konnte dieses unerwartete Auftreten nicht mit unspezifischen Bindung erklärt werden. Eine mögliche Erklärung für dieses Phänomen ist die Bindung von Nukleotidclustern an eine 
Bindungsstelle des Enzyms. Diese Vermutung wurde durch das Auftreten von NukleotidKomplexen in Abwesenheit des Enzyms bestätigt (Prinz et al., 1999).

Im Gegensatz zur hGUK besitzt die GTPase p21 ${ }^{\text {ras }}$ eine sehr hohe Affinität zu GTP und GDP (Goody et al., 1990), sodaß aus E. coli isoliertes Protein GDP gebunden hat. Das Massenspektrum von $\mathrm{p} 21^{\text {ras }}$ in neutraler wässriger Lösung (siehe Abb. 4.21 A) zeigte demzufolge einen dominanten Peak, welcher mit der Bindung von einem GDP-Molekül an das Protein korreliert.
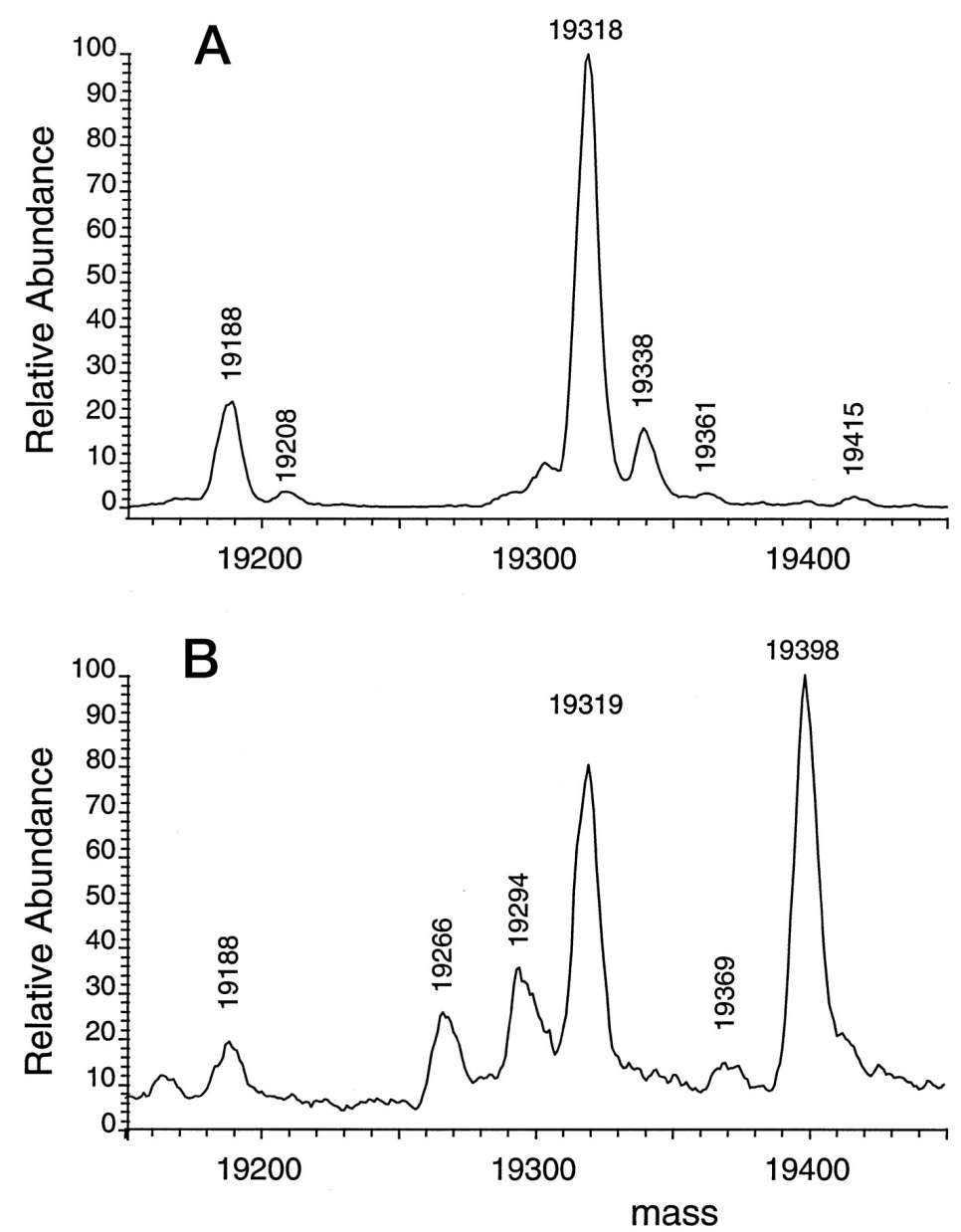

Abb. 4.21 Nano-ES-Massenspektrum von $10 \mu \mathrm{M} \mathrm{p} 21^{\text {ras }}$ in $\mathrm{H}_{2} \mathrm{O}$. A, Die Peaks entsprechen $\quad \mathrm{p} 21^{\text {ras }}(2-166) \cdot \mathrm{GDP} \cdot \mathrm{Mg}^{2+}$ (19188), $\quad \mathrm{p} 21^{\text {ras }}(2-166) \cdot \mathrm{GDP} \cdot \mathrm{Mg}^{2+} \cdot \mathrm{Na}^{+}$ (19208), p21 $1^{\text {ras }}(1-166) \cdot \mathrm{GDP} \cdot \mathrm{Mg}^{2+}$ (19318), p21 $1^{\text {ras }}(1-166) \cdot G D P \cdot \mathrm{Mg}^{2+} \cdot \mathrm{Na}^{+} \quad$ (19338), p21 ${ }^{\text {ras }}(1-166) \cdot G D P \cdot \mathrm{Mg}^{2+} \cdot 2 \mathrm{Na}^{+}$(19361) und p21 ${ }^{\text {ras }}(1-166) \cdot \mathrm{GDP} \cdot \mathrm{Mg}^{2+} \cdot \mathrm{SO}_{4}{ }^{2-}$ (19415. B, $10 \mu \mathrm{M} \mathrm{p} 21^{\text {ras }}(2-166) \cdot \mathrm{GDP}$ inkubiert mit $100 \mu \mathrm{M}$ GTP für $30 \mathrm{~min}$ in $\mathrm{H}_{2} \mathrm{O}$. Die zusätzlichen Peaks entsprechen den Komplexen p21 ${ }^{\text {ras }}(2-166) \cdot G T P \cdot \mathrm{Mg}^{2+}$ (19266), p21 $1^{\text {ras }}(1-166) \cdot G D P$ (19294) und p21 ${ }^{\text {ras }}(1-166) \cdot G T P \cdot \mathrm{Mg}^{2+}$ (19398) (aus Prinz et al., 1999).

Daneben tauchte noch ein kleinerer Peak, welcher dem GDP-Protein-Komplex ohne $\mathrm{N}$-terminales Methionin entsprach. Die Menge an Ligand-freiem Protein in der Probe war derart gering, daß es nicht mehr im Massenspektrum nachgewiesen werden konnte. Der zusätzliche Peak bei 19415 Da entsprach wieder der zuvor im Massenspektrum von hGUK (siehe Abb. 4.18) beobachteten Bindung von einem $\mathrm{SO}_{4}{ }^{2-}$-Ion (siehe Abb. 4.21 A). Die Zugabe von GTP führt zu einem relativ langsamen Ersatz des gebundenen GDP-Moleküls gegen ein GTPMolekül. Diesen zeitabhängigen Nukleotid-Austausch nach Zugabe von GTP zeigt das Massenspektrum in Abbildung $4.21 \mathrm{~B}$. Auch hier traten wieder zusätzliche Peaks auf, die der Bindung von mehr als einem Molekül GTP entsprachen. 


\title{
4.1.4 Die Arabidopsis thaliana Guanylatkinasen AGUK1 und AGUK2
}

Vollkommen neuartige, verlängerte Formen von aktiven Guanylatkinasen wurden kürzlich in Arabidopsis thaliana (siehe Abb. 4.22; Kumar et al., 2000) entdeckt. Da diese Guanylatkinasen eine neue Gruppe innerhalb der Familie der bisher bekannten authentischen Guanylatkinasen bilden und möglicherweise eine evolutionäre Verbindung $\mathrm{zu}$ den später in dieser Arbeit beschriebenen Membran-assoziierten Guanylatkinasen darstellen, wurden die A. thaliana Isozyme im Folgenden näher biochemisch und kinetisch untersucht. Die Guanylatkinasen AGUK1 (Anm: AGUK1 entspricht der Sequenz des Locus U90439 auf dem Chromosom 2 des A. thaliana Genoms, welches 1999 von Lin et al. publiziert wurde. Die Sequenz U90439 weicht jedoch in den letzten 14 Aminosäuren von AGUK1 ab) und AGUK2 aus A. thaliana, sind die ersten Guanylatkinasen einer Pflanze, die bisher beschrieben wurden. Die vollständigen cDNAs wurden von V. Kumar (Washington State University, USA) aus einer cDNA-Bank von A. thaliana-Sämlingen mit Hilfe von degenerierten Primern isoliert. In dieser Arbeit wurden AGUK1 und AGUK2 in E. coli überexprimiert und AGUK1 anschließend biochemisch charakterisiert.

Vergleicht man die Sequenzen von AGUK1 und AGUK2 mit jener der Hefe-GUK1 und Säuger-GUKs (siehe Abb. 4.22) so fällt auf, daß sie mit einer Länge von 387 bzw. 389 Aminosäuren und einem berechneten Molekulargewicht von 42,7 bzw. 42,5 kDa mehr als doppelt so groß sind. Beide Isozyme sind zu $81 \%$ identisch.

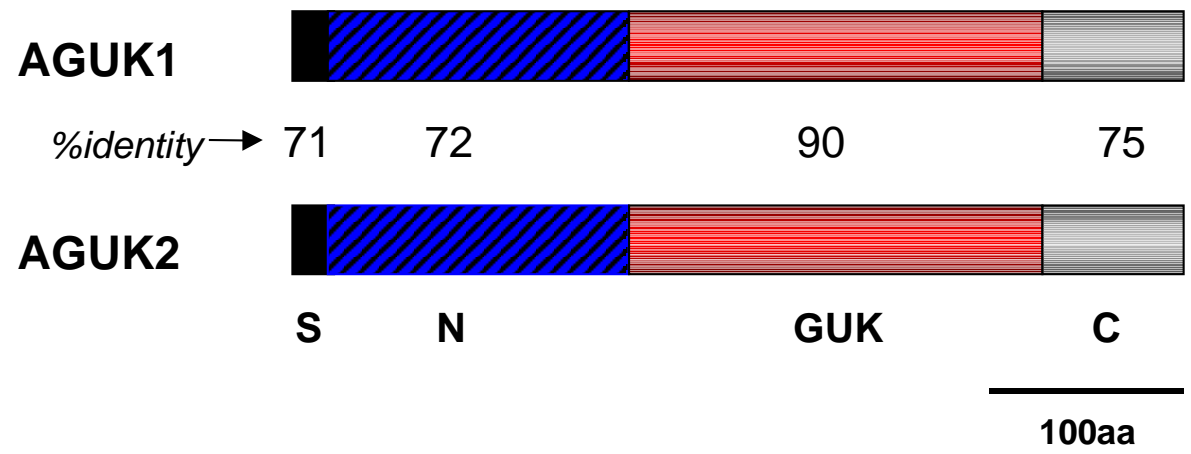

\begin{abstract}
Abb. 4.22 Schematische Darstellung der Domänen von AGUK1 und AGUK2. Eingezeichnet sind die Sequenzidentitäten der einzelnen Domänen. S, Signalsequenz; N, N-terminale Domäne; GK, GUK-Domäne; C, Cterminale Domäne; aa, Aminosäuren
\end{abstract}

Im Gegensatz zu allen bisher bekannten Guanylatkinasen besitzen sowohl AGUK1 und AGUK2 N- und C-terminale Verlängerungen, welche die zentrale GUK-Domäne umgeben (siehe Abb. 4.22). Die Funktion des N- und C-terminalen Sequenzen mit einer Länge von 184 bzw. 65 Aminosäuren in AGUK1 ist bisher ungeklärt, jedoch besitzt der hydrophobe N- 
Terminus neben einer hypothetischen Signalsequenz (Von Heijne, 1984) eine Sequenzähnlichkeit von $46 \%$ zu einem möglichen Arabidopsis Calmodulin(CaM)Bindungsprotein (NCBI-Datenbank, Zugangsnr.: 2980766).

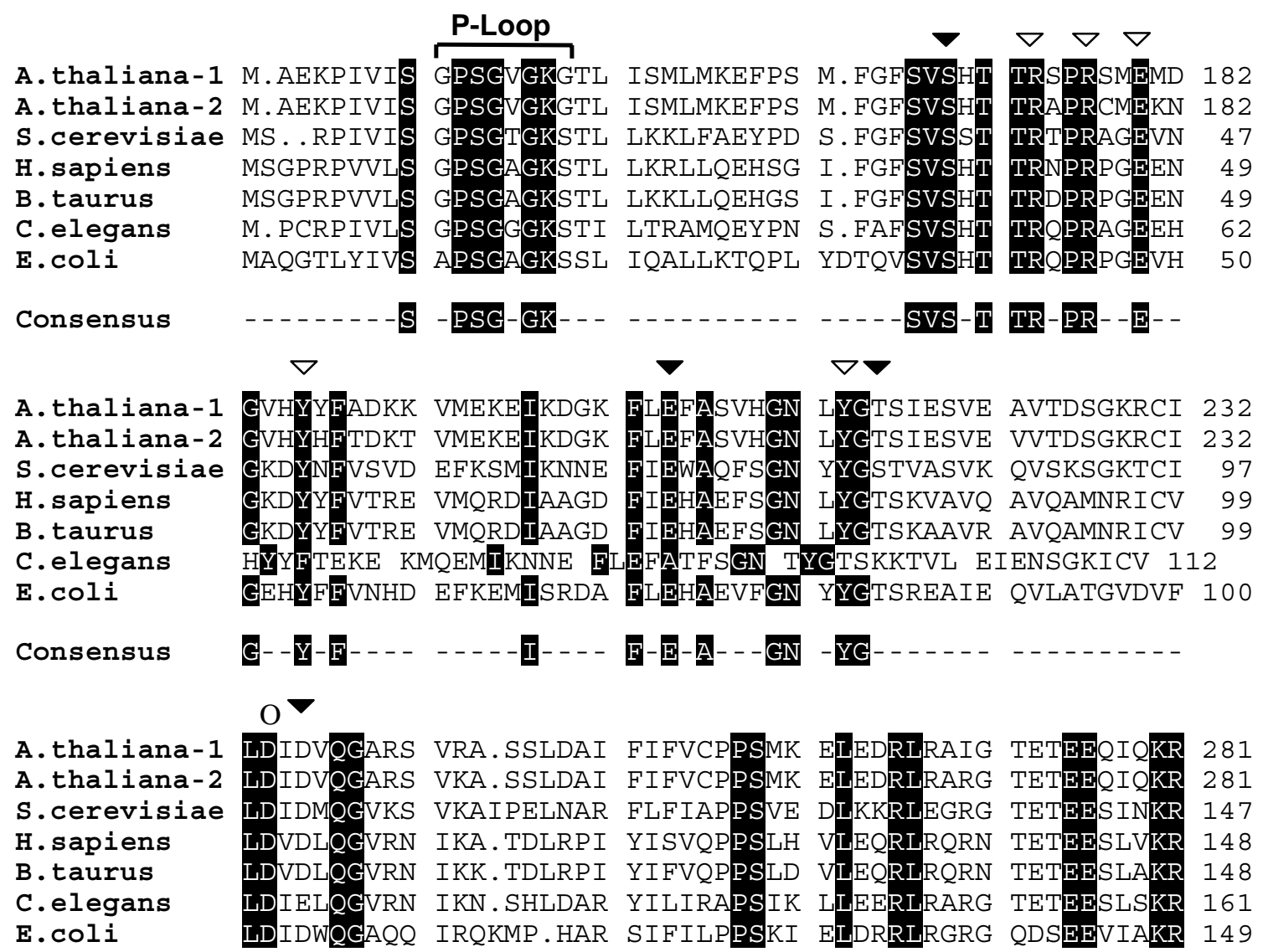

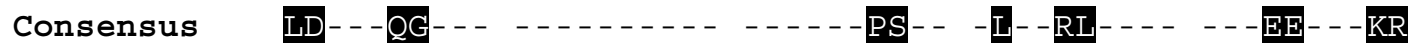

A.thaliana-1 LRNAEAEI.K EGISSGIFGL ILYNDNLEEC YKKLKNLLGL DGLAHVNGVE 330

A.thaliana-2 LRNADAEI.K AGKSSGIFEH KLYNDNLEEC YKTLKNLLGI NDLAPVNGVE 330

S.cerevisiae LSAAQAELAY A..ETGAHDK VIVNDDLDKA YKELKDFIFA EK. . . . . 187

H.sapiens LAAAQADM.E SSKEPGLFDV VIINDSLDQA YAELKEALSE EIKKAQRTGA 197

B.taurus LAAARADM.E SSKEPGLFDL IIVNDSLDKA YWALKEALSE EIKKAQGTGQ 197

C.elegans LQHASEDLVE IEKNPTLFDK VIVNDDLERA YKEFVDLLRD DLEKTSKK.. 209

E.coli MAQAVAEMSH YAE....YDY LIVNDDFDTA LTDLKTIIRA ERLRMSRQKQ 195

Consensus

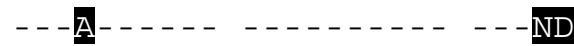

$\begin{array}{llll}\text { A.thaliana-1 } & \text { IEGINLPIEY } & \text { TV } & 342 \\ \text { A.thaliana-2 } & \text { VEGINLPKEH } & \text { TV } & 342 \\ \text { S.cerevisiae } & \ldots \ldots \ldots \ldots \ldots & \ldots & 187 \\ \text { H.sapiens } & \ldots \ldots \ldots \ldots & \ldots & 197 \\ \text { B.taurus } & \text { S. . . . . . . . . } & 198 \\ \text { C.elegans } & \ldots \ldots \ldots \ldots & \ldots & 209 \\ \text { E.coli } & \text { RHDALISKLL } & \text { AD } & 207\end{array}$

Consensus

Abb. 4.23 Sequenz-Alignment der Arabidopsis Isozyme AGUK1 und AGUK2 im Vergleich mit weiteren Guanylatkinasen. Der P-Loop umfaßt die Sequenz, welche mit dem $\beta$ - und $\gamma$-Phosphat des Substrats ATP interagiert. Aminosäuren, die mit dem Guaninring $(\boldsymbol{\nabla})$, der Phosphatgruppe $(\nabla)$ von GMP und dem komplexierten $\mathrm{Mg}^{2+}$-Ion (O) interagieren, sind markiert (aus Kumar et al., 2000). 
Die zentralen GUK-Domänen in AGUK1 und AGUK2, mit einer Länge von 184 Aminosäuren und einer Sequenz-Identität von 50 (AGUK1) bis 52\% (AGUK2) zu der Hefe-GUK1, besitzen alle für die Katalyse essentiellen Aminosäuren (siehe Abb. 4.23).

\title{
4.1.4.1 Komplementations-Analyse von AGUK1 in S. cervisiae
}

Die weiteren Untersuchungen in vivo und in vitro konzentrierten sich nur auf die Isoform AGUK1. Zum Nachweis von Guanylatkinase-Aktivität in vivo wurde zunächst das bereits zuvor beschriebene (siehe 4.1.1.1) Hefe-Testsystem eingesetzt. Unter der Voraussetzung, daß AGUKI für eine aktive Guanylatkinase codiert, sollte das Gen den letalen gukl-Phänotyp des Stammes AG430 komplementieren. Für den Komplementationstest wurde nur die zentrale GUK Domäne, d.h. AGUK1(137-330) (siehe Abb. 4.22), eingesetzt. Die cDNA wurde mit den spezifischen Primern OSP42 und OSP82 mit Hilfe des Templates pFL61-AGUK1 (Kumar et al., 2000) amplifiziert und über die Restriktionsschnittstellen $N d e \mathrm{I} /$ Bam HI in den Vektor YEp512N kloniert. Nach Transformation von AG430 mit dem Plasmid YEp512N-AGUK1(137-330) wurden die vier Sporen einer Tetrade, wie unter Punkt 4.1.1.1 dargestellt, auf YEPGal Medium vereinzelt. Nach ungefähr einer Woche zeigte die Mehrheit der untersuchten Tetraden die Aufteilung von vier lebensfähigen Sporen. Zwei der vier Sporen waren durch einen langsam wachsenden Phänotyp gekennzeichnet. Durch Überprüfung der LEU/HIS-Marker-Segregation konnten die beiden langsam wachsenden Sporen als AG215(guk1::HIS3/YEp512NAGUK1(137-330)) identifiziert werden.

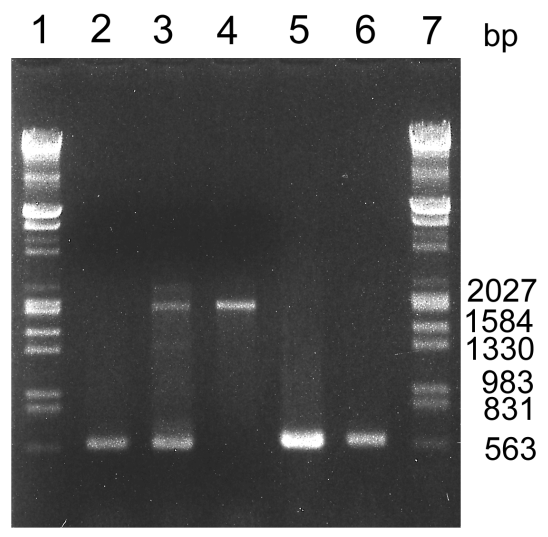

\begin{abstract}
Abb. 4.24 PCR-Analyse von AG215(guk1::HIS3) mit pCM189-AGUK1(137-330). Das Ethidiumbromid-gefärbte Agarosegel zeigt die amplifizierten PCR-Fragmente nach Verwendung der GUK1- (Spur 2, 3, 4) bzw. AGUK1(137-330)spezifischen Oliginukleotid-Primer. Als Templates wurde folgende DNA eingesetzt: Plasmid pJC20-GUK1 (Spur 2); genomische DNA des diploiden Hefestammes AG430(GUK1/guk1::HIS3) (Spur 3); genomische DNA sowie Plasmid-DNA des haploiden Hefestammes AG215(guk1::HIS3) transformiert mit YEp512N-AGUK1(137330) (Spur 4 und 6); Plasmid YEp512N-AGUK1(137-330) (Spur 5); DNA-Längenmarker (EcoRI/HindIII verdaute DNA des Phagen $\lambda$ ) (Spur 1 und 7$)$
\end{abstract}

Zur Bestätigung des Ergebnisses der Tetradenanalyse wurden die beiden langsam wachsenden haploiden Klone einer Tetrade direkt auf die Präsenz von AGUK1(137-330) getestet. Dazu wurde eine diagnostische PCR und eine Immunoblot-Analyse durchgeführt. Mit Hilfe von Oligonukleotiden OSP116 und OSP117, welche spezifisch zu den äußersten 5'- und $3^{\prime}$-Enden der GUK1-Sequenz waren, konnte mit genomischer DNA aus AG215(guk1::HIS3/YEp512N- 
AGUK1(137-330)) als Template ein ca. 2,0 kb großes Fragment amplifiziert werden (siehe Abb. 4.24, Spur 4). Dieses Fragment entsprach dem partiell deletierten GUK1-Gen (0,4 kb) und integriertem HIS3-Markergen (1,8 kb). Mit den spezifischen AGUK1(137-330)Oligonukleotiden und aus der gleichen haploiden Zelle, isoliertem Plasmid als Template konnte darüberhinaus ein $0,58 \mathrm{~kb}$ großes Fragment amplifiziert werden welches eindeutig AGUK1(137330) entsprach (siehe Abb. 4.24, Spur 6).

Für die Immuno-Blot-Analyse (siehe Abb. 4.25) wurden Proteinextrakte der haploiden Zellen AG215(guk1::HIS3/YEp512N-AGUK1(137-330)) sowie der diploiden Zellen AG430(GUK1/guk1::HIS3) präpariert. Zum Nachweis wurden polyklonale Anti-GUK1Antikörper eingesetzt, welche eine Kreuzreaktion gegen AGUK1(137-330) zeigten. In Proteinextrakten der haploiden Zellen konnte erwartungsgemäß nur ein Protein der Größe 22 kDa nachgewiesen werden, welches AGUK1(137-330) entsprach. Proteinextrakte der diploiden Wild-Typ-Zellen zeigten ebenfalls lediglich eine immunoreaktive Bande, welche einem Protein der Größe 20 kDa, also der authentischen Hefe-GUK1 entsprach.

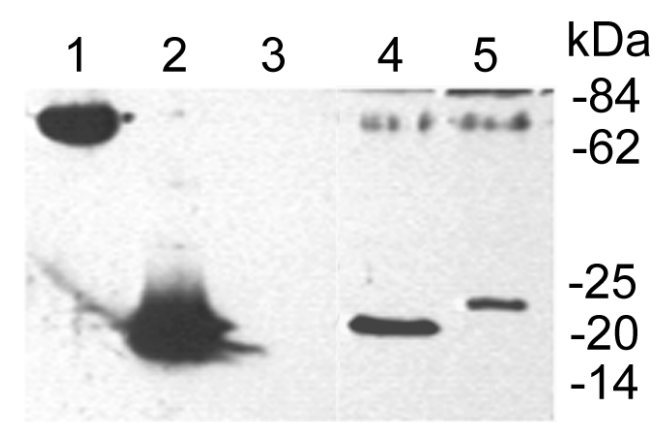

Abb. 4.25 Immuno-Blot-Analyse von AG215(guk1::HIS3) transformiert mit YEp512N-AGUK1(137-330). Die Proteine des Hefeextrakts wurden elektrophoretisch auf einem SDSPAGE-Gel aufgetrennt, auf eine Nitrozellulose-Membran transferiert und mit einem polyklonalen Kaninchen antiGUK1Antikörper markiert. Spur 1, aufgereinigtes MBP-AGUK1(137330)-Fusionsprotein $(8,0 \mu \mathrm{g})$; Spur 2, aufgereinigtes GUK1Protein (0,5 $\mu \mathrm{g})$; Spur 3, Molekulargewichtsmarker; Spur 4, Lysat von diploiden AG430(GUK1/guk1::HIS3)-Zellen; Spur 5, Lysat von haploiden AG215(guk1::HIS3/YEp512NAGUK1(137-330)-Zellen.

Die Ergebnisse in ihrer Gesamtheit zeigen, daß die GUK Domäne aus AGUK1 den letalen gukl-Phänotyp in S. cerevisiae supprimieren kann. Der durch einen Wachstumsdefekt gekennzeichnete Phänotyp von AG215(guk1::HIS3/YEp512N-AGUK1(137-330)) deutet jedoch daraufhin, daß die Guanylatkinase-Aktivität von AGUK1(137-330) schwächer ist als jene von GUK1(WT). Zur Quantifizierung der enzymatischen Aktivität von AGUK1(137-330) sowie zur Untersuchung des Einflußes der flankierenden Sequenzen in AGUK1 sollten im Folgenden beide Proteine rekombinant in E. coli überexprimiert und aufgereinigt werden.

\subsubsection{Aufreinigung von AGUK1 und AGUK1(137-330) aus E. coli}

Im Gegensatz zu den bisher biochemisch untersuchten Guanylatkinasen der Hefe und aus Säugern war es nicht möglich die Proteine AGUK1 und AGUK2 rekombinant als GSTFusionsproteine aufzureinigen. Sowohl AGUK1, als auch AGUK2 konnten zwar sehr gut in 
E. coli überproduziert werden, jedoch waren beide Proteine unlöslich und bildeten Einschlußkörper. Deshalb wurde ein neues Expressionssystem, das Maltose-Bindeprotein (MBP) -System (siehe 3.10.4), ausgewählt. Das MBP-System wurde bereits mehrfach zur Aufreinigung von Proteinen, welche zur Aggregation neigen, eingesetzt und scheint einige Vorteile gegenüber dem GST-System zu besitzen (Kapust und Waugh, 1999).

Zur Untersuchung der enzymatischen Eigenschaften sowohl des gesamten AGUK1, als auch der zentralen GUK-Domäne alleine, wurden die beiden DNA-Fragmente AGUK1 und die verkürzte Form AGUK1(137-330) über die Schnittstellen NdeI/BamHI in den Vektor pMAL-c2( $\Delta N d e I)$ HsTK kloniert und die Proteine AGUK1 (42,7 kDa) und AGUK1(137-330) (22,2 kDa) zunächst in E. coli DH5 $\alpha$ nach 2stündiger Induktion mit 0,5 $\mathrm{mM}$ IPTG als MBP-Fusionsprotein überexprimiert und anschließend über eine Amylose-Säule gereinigt. Die Abbildung $4.26 \mathrm{~A}$ zeigt das SDS-PAGE Gel zur Aufreingung der Fusionsproteine MBP-AGUK1(137-330) (64,7 kDa) und MBP-AGUK1 (85,2 kDa) in einem affinitätschromatographischen Schritt.

A

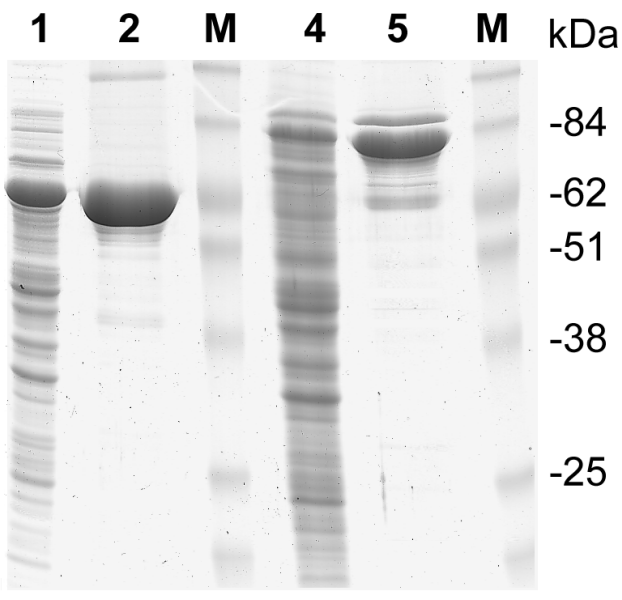

B

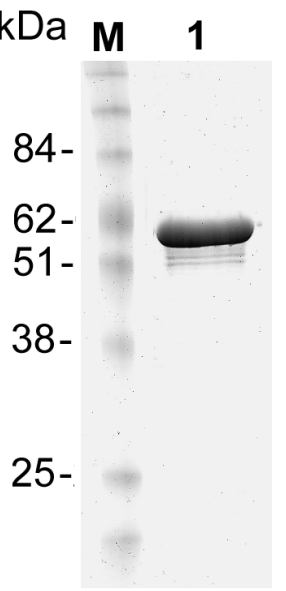

\begin{abstract}
Abb. 4.26 Aufreinigung von MBP-AGUK1(137-330) und MBP-AGUK1 nach 2stündiger Expression bei $37^{\circ} \mathrm{C}$ in E. coli (A) nach einem affinitätschromatographischen Schritt sowie Aufreinigung von MBP-AGUK1(137-330) (B) nach zusätzlichem zweiten Reinigungsschritt über die Amylose-Matrix. Die Proteinproben wurden auf einem 12\%igen SDS-PAGE-Gel elektrophoretisch aufgetrennt und die Proteine durch Coomassie-Brilliantblau R250 angefärbt. A; Spur 1, Zellysat von E. coli DH5 $\alpha$ transformiert mit pMAL-AGUK1(137-330) und induziert mit IPTG; Spur 2, eluiertes MBP-AGUK1(137-330)-Fusionsprotein; M, Molekulargewichtsmarker (kDa); Spur 4, Zellysat von E. coli DH5 $\alpha$ transformiert mit pMAL-AGUK1; Spur 5, eluiertes MBP-AGUK1-Fusionsprotein; $B$; Spur 1, zweifach aufgereinigtes MBP-AGUK1(137-330).
\end{abstract}

In beiden Fällen wurde das Protein nach Induktion mit IPTG sehr gut in E. coli überexprimiert (siehe Abb. 4.26, Spur 2 und 5) und konnte anschließend mit $10 \mathrm{mM}$ Maltose in löslicher Form als Fusionsprotein eluiert werden. Zusätzliche Banden nach Aufreinigung von MBPAGUK1(137-330) bzw. MBP-AGUK1 deuten auf eine unspezifische Bindung 
kontaminierender Proteine an die Amylose-Matrix hin. In einem zweiten affinitätschromatographischen Reinigungsschritt, nach Dialyse des zuvor eluierten Proteins, konnten diese zusätzlichen Banden entfernt werden (siehe Abb. 4.26 B).

Zur Untersuchung des Einflußes der N- und C-terminalen Sequenzen auf die zentrale GUKDomäne war es notwendig das Protein AGUK1(137-330) ohne den störenden Einfluß eines zur affinitätschromatographischen Reinigung benötigten Anhangs zu isolieren. Alle Versuche zur Isolierung von AGUK1(137-330) und AGUK1 ohne MBP-Taq scheiterten jedoch, da der Faktor Xa nicht nur spezifisch den MBP-Taq vom Rest des Proteins trennte, sondern auch unspezifisch AGUK1(137-330) spaltete. Deshalb wurde in einem weiteren Versuch das GST-System zur Aufreinigung von AGUK(137-330) eingesetzt. Die Abbildung 4.27 zeigt das SDS-PAGE Gel zur affinitätschromatographischen Reinigung von AGUK(137-330) nach 6stündiger Überexpression als GST-Fusionsprotein bei $37^{\circ} \mathrm{C}$ in E. coli BL21(DE3).

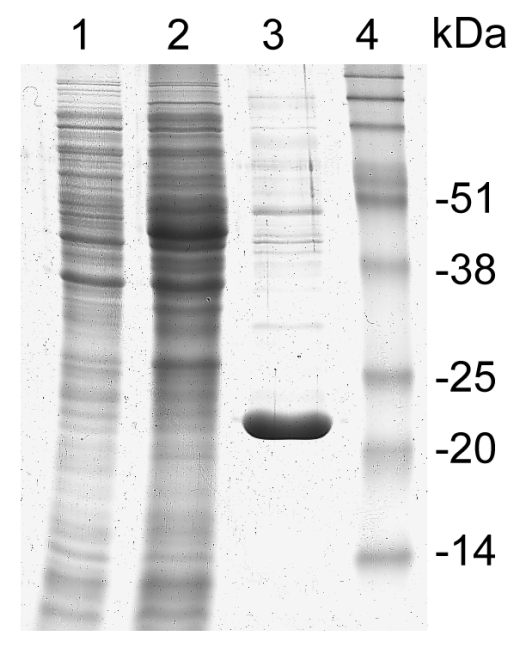

\begin{abstract}
Abb. 4.27 Aufreinigung von AGUK1(137-330) nach Expression in E. coli. Proteinproben des Expressions- und Aufreinigungsschrittes wurden in einem 12\%igem SDS-PAGE-Gel elektrophoretisch aufgetrennt und die Proteine durch Coomassie-Brilliantblau R250 angefärbt. Spur 1, E. coli-Lysat vor Induktion; Spur 2, E. coliLysat nach Induktion; Spur 3, aufgereinigtes AGUK1(137-330); Spur 4, Molekulargewichtsmarker (kDa).
\end{abstract}

Wie bereits zuvor im Fall der Aufreinigung von hGUK und mGUK (siehe 4.1.3.1) konnte AGUK1(137-330) nach Thrombineinwirkung über Nacht direkt von der Sepharose 4B-Säule eluiert werden. Eine Isolierung von AGUK1(137-330) in hoher Homogenität (> 95\%) war somit bereits in einem Aufreinigungsschritt möglich.

\title{
4.1.4.3 Kinetische Eigenschaften von AGUK1 und AGUK1(137-330)
}

Die Substrat-Spezifität von AGUK1(137-330) (hier: MBP-Fusionsprotein) wurde mit dem spektrophotometrischen Assay in Gegenwart verschiedener Substrate bestimmt. Die Ergebnisse des Aktivitätstests sind in Tabelle 4.4 dargestellt. AGUK1(137-330) zeigte die höchste enzymatische Aktivität von 3,75 $\pm 1,20 \mathrm{U} / \mathrm{mg}$ mit ATP als Phosphoryldonor und GMP oder (d)GMP als Akzeptor. Die spezifische Aktivität mit dem Substratpaar ATP/GMP war im 
Vergleich zu allen weiteren getesteten Substratpaaren bis zu 1000fach erhöht. ATP ist im Vergleich zu GTP der weitaus bessere Phosphoryldonor. Die zentrale GUK1 Domäne aus AGUK1 zeigte demnach die typische Substratspezifität einer Guanylatkinase. Die Rate der Umsetzung von ATP und GMP zu ADP und GDP war jedoch um den Faktor 25 geringer als für die Hefe-GUK1 (siehe Tab. 4.5).

Tab. 4.4 Substratspezifität von AGUK1(137-330)

\begin{tabular}{lc}
\hline Spezies & Spezifische Aktivität \\
& $(\boldsymbol{U} / \mathbf{m g})$ \\
\hline ATP $:$ AMP & $0,003 \pm 0,001$ \\
ATP $:$ TMP & $0,003 \pm 0,001$ \\
ATP : UMP & $0,005 \pm 0,001$ \\
ATP : CMP & $0,004 \pm 0,001$ \\
ATP : GMP & $3,750 \pm 1,200$ \\
ATP : dGMP & $1,350 \pm 0,280$ \\
GTP $:$ AMP & $0,004 \pm 0,001$ \\
GTP $:$ GMP & $0,022 \pm 0,006$
\end{tabular}

$\mathrm{c}(\mathrm{ATP})=2 \mathrm{mM}, \mathrm{c}(\mathrm{GMP})=1 \mathrm{mM}$

Die Michaelis-Menten-Konstante von AGUK1(137-330) für die Substrate ATP und GMP wurde, wie unter Punkt 4.1.4.2 beschrieben, bestimmt. Die kinetischen Parameter aller getesteten Guanylatkinasen sind in Tabelle 4.5 zusammengefasst. Der $K_{\mathrm{M}^{-}}$Wert für ATP $(50,6 \mu \mathrm{M})$ lag um den Faktor 3 unter jenem von Hefe-GUK1 $(143,6 \mu \mathrm{M})$ und war halb so groß wie jener von Mensch- $(105,0 \mu \mathrm{M})$ oder Maus-GUK $(85,5 \mu \mathrm{M})$. Der $K_{\mathrm{M}}$-Wert für das Substrat GMP lag mit 6,4 $\mu \mathrm{M}$ noch deutlicher unter jenen von Hefe- $(46,9 \mu \mathrm{M})$, Mensch- $(26,0 \mu \mathrm{M})$ und Maus-GUK $(23,8 \mu \mathrm{M})$. Aus den gemessenen kinetischen Parametern ergeben sich die Spezifizitäts-Konstanten $k_{\mathrm{cat}} / K_{\mathrm{M}}$ des jeweiligen Substrats. Die Spezifitäts-Konstante von AGUK(137-330) für das Substrat ATP $\left(0,08 \mu \mathrm{M} \cdot \mathrm{s}^{-1}\right)$ ist ungefähr um den Faktor 9 kleiner als jene von Hefe-GUK1 und 8fach kleiner als jene von hGUK oder mGUK. Die Spezifitätskonstante für das Substrat GMP $\left(0,61 \mu \mathrm{M} \cdot \mathrm{s}^{-1}\right)$ ist hingegen 4 fach geringer als jene der Hefe- und Säuger-Guanylatkinasen (siehe Tab. 4.5). 
Tab. 4.5 Kinetische Parameter der AGUK1 im Vergleich zu hGUK, mGUK und GUK1

\begin{tabular}{cccccc}
\hline Spezies & $\begin{array}{c}\boldsymbol{k}_{\mathrm{cat}} \\
{\left[\boldsymbol{s}^{-1}\right]}\end{array}$ & $\begin{array}{c}\boldsymbol{K}_{\mathrm{M}(\mathrm{ATP})}{ }^{*} \\
{[\boldsymbol{\mu M}]}\end{array}$ & $\begin{array}{c}\boldsymbol{K}_{\mathrm{M}(\mathrm{GMP})}{ }^{+} \\
{[\boldsymbol{\mu M}]}\end{array}$ & $\begin{array}{c}\boldsymbol{k}_{\mathrm{cat}} / \boldsymbol{K}_{\mathrm{M}(\mathrm{ATP})} \\
{\left[\boldsymbol{s}^{-1} \boldsymbol{\mu} \boldsymbol{M}^{-1}\right]}\end{array}$ & $\begin{array}{c}\boldsymbol{k}_{\mathrm{cat}} / \boldsymbol{K}_{\mathrm{M}(\mathrm{GMP})} \\
{\left[\boldsymbol{s}^{-1} \boldsymbol{\mu} \boldsymbol{M}^{-1}\right]}\end{array}$ \\
\hline AGUK1 & 3,9 & 50,6 & 6,4 & 0,08 & 0,61 \\
hGUK & 52,3 & 105,0 & 26,0 & 0,50 & 2,01 \\
mGUK & 55,8 & 85,5 & 23,8 & 0,65 & 2,35 \\
GUK1 & 106,0 & 143,6 & 46,9 & 0,74 & 2,26 \\
\hline
\end{tabular}

$+, \mathrm{c}($ ATP $)=2 \mathrm{mM}, *, \mathrm{c}(\mathrm{GMP})=1 \mathrm{mM}$

MBP-AGUK1 und AGUK(137-330) zeigten spezifische Guanylatkinase-Aktivitäten von 2,51 $\pm 0,2$ bzw. 2,95 $\pm 1,0 \mathrm{U} / \mathrm{mg}$. Beide Werte wichen nicht signifikant von der MBP-AGUK1(137330)-Aktivität ab. Aus den zusätzlichen Aktivitätstests kann folglich geschlossen werden, daß weder die $\mathrm{N}$ - und C-terminalen Verlängerungen in AGUK1 noch der MBP-Anhang einen inhibitorischen Einfluß auf die katalytische Aktivität der zentralen GUK Domäne ausüben. 


\subsection{Die Membran-assoziierten Guanylatkinasen SAP97 und hCASK}

Die Familie Membran-assoziierter Guanylatkinasen (MAGUKs) umfaßt MultidomänenProteine, welche in der C-termianlen Domäne (GK-Domäne) eine hohe Sequenzidentität zu den authentischen Guanylatkinasen aufweisen und an Zell-Zell-Kontaktstellen identifiziert wurden (Woods und Bryant, 1991). In dieser Arbeit sollten die Säuger-Proteine SAP97 (Müller et al., 1995), aus der Unterfamilie der Dlg-ähnlichen und hCASK (Cohen et al., 1998), aus der Unterfamilie der Lin2-ähnlichen MAGUKs näher untersucht werden.

Die cDNA des Synapsen-assoziierten Proteins 97 (SAP97) wurde von Müller et al. (1995) aus einer $\lambda$ gtll Expressions-Bibliothek mit Hilfe polyklonaler Antikörper, gerichtet gegen synaptische Kontaktstellen des Rattenhirns, isoliert. Das Genprodukt SAP97 hat eine Länge von 878 Aminosäuren und ein Molekulargewicht von 97 kDa. Die Guanylatkinase-Domäne von SAP97 ist 179 Aminosäuren lang und besitzt eine 33 und 37\%ige Identität zu der Guanylatkinase von S. cerevisiae und des Menschen (Müller et al., 1995). Obwohl beispielsweise die Aminosäuren Asp98, Arg38, Arg41, Glu44, Tyr50 und Tyr78, die in GUK1 an der Bindung von $\mathrm{Mg}^{2+}$ und der Phosphatgruppe von GMP beteiligt sind (Stehle und Schulz, 1992) auch in SAP97 konserviert vorliegen (Asp816, Arg755, Arg758, Glu761, Tyr767 und Tyr796; siehe Abb. 1.7), ist das charakteristische Bindungsmotiv GXXGXGK(S/T) (Saraste et al., 1990; Reste 9 - 16 in GUK1 und 728-732 in SAP97), welches den P-Loop zur Bindung der $\beta$ - und $\gamma$-Phosphatreste von ATP bildet, nur teilweise vorhanden (siehe Abb. 4.28; Müller et al., 1995).

Die vollständige cDNA von hCASK wurde von Cohen et al. (1998) aus humanen cDNABanken der Lunge, Leber und des Hirns mit Hilfe degenerierter Oligonukleotid-Primer isoliert. hCASK hat eine Länge von 886 Aminosäuren. Die Besonderheit aller Mitglieder der CASKUnterfamilie (Hata et al., 1996; Hoskins et al., 1996; Dimitriatos et al., 1997) besteht darin, daß sie im Gegensatz zu den weiteren Mitgliedern der MAGUK-Familie, neben einer PDZ-, der SH3- und der C-terminalen GK-Domäne zusätzlich eine N-terminale Domäne mit hoher Sequenz-Identität $(45 \%)$ zu den bekannten $\mathrm{Ca}^{2+} / \mathrm{CaM}$-abhängigen Proteinkinasen besitzen (Hanson und Schulman, 1992). Diese Domäne ist katalytisch nicht aktiv, besitzt jedoch das aus der Klasse der $\mathrm{Ca}^{2+} / \mathrm{CaM}$-abhängigen Proteinkinasen bekannte CaM-Bindungsmotiv und ist in der Lage Calmodulin zu binden (Hata et al., 1996). Die GK-Domäne von hCASK besitzt eine 30 und 33\%ige Sequenzidentität zu den Guanylatkinasen von S. cerevisiae und des Menschen. Im Gegensatz zu SAP97 ist in hCASK das potentielle ATP-Bindungsmotiv, der P-Loop, nicht deletiert. Der P-Loop besitzt jedoch anstelle des für die Katalyse essentiellen Lysins ein Arginin 
(R717, siehe Abb. 4.28). Von den 9 Aminosäuren, welche in der Hefe-Guanylatkinase mit GMP interagieren, sind in hCASK 6 konserviert. Ebenso wie in SAP97 sind in hCASK die Aminosäuren Ser34 (Ser751 in SAP97 bzw. Ser732 in hCASK) und Asp100 (Ser817 in SAP97 bzw. Asp798 in hCASK), welche in dem GUK1-GMP-Komplex mit dem Guaninring interagieren, durch Prolin bzw. Glutamat ersetzt (siehe Abb. 1.7). Darüber hinaus besitzt hCASK jedoch eine zusätzliche, in SAP97 nicht vorhandene konservative Substitution des Arginins an Position 41 (Arg739 in hCASK) gegen ein Lysin (siehe Abb. 1.7).

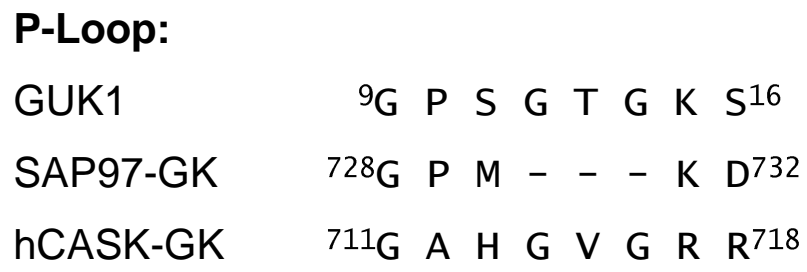

Abb. 4.28 Vergleich der ATP-Bindungsregion von GUK1, SAP97-GK und hCASK-GK

Aufgrund des Fehlens von sowohl für die Bindung von ATP, als auch die katalytische Übertragung des $\gamma$-Phosphatrestes essentiellen Aminosäuren, musste eine Funktion von SAP97 bzw. hCASK als enzymatisch aktive Guanylatkinase in Frage gestellt werden. Die vorliegende Arbeit sollte zur weiteren Aufklärung der Funktion der MAGUK-Proteine SAP97 und hCASK beitragen. Im Folgenden soll sich zunächst auf die C-terminale GK-Domäne der beiden MAGUK-Proteine konzentriert werden, während später auch der Einfluß der N- und Cterminalen Sequenzen auf die GK-Domäne von SAP97 untersucht werden soll.

\subsubsection{Biochemische und hefegenetische Untersuchungen zum Nachweis von Guanylatkinase-Aktivität der GK-Domänen von SAP97 und hCASK}

Erste Schritte zur biochemischen Charakterisierung der GK-homologen Domäne von SAP97 wurden bereits in einer früheren Arbeit unternommen (Kuhlendahl et al., 1998; Spangenberg, 1997). Allerdings erwies sich sowohl das rekombinant als His 6 -Fusionsprotein aus E. coli aufgereinigte Protein SAP97-GK(+22N), als auch die Mutante SAP97-GK(P-Loop), in welcher der P-Loop nach Vorlage der S. cerevisiae-Guanylatkinase rekonstruiert wurde (genauer: die Unterbrechung ${ }^{9} \mathrm{GPM}$ - - - KD ${ }^{13}$ in der GK-Domäne wurde durch ${ }^{9}$ GPSGTGKD ${ }^{16}$ ersetzt), als enzymatisch nicht aktiv (Kuhlendahl et al., 1998; Spangenberg, 1997). Wie bereits anhand der Untersuchungen an den Säuger-Guanylatkinasen (siehe 4.1.3) zuvor gezeigt wurde, kann die Strategie der Aufreinigung rekombinanter Proteine einen nicht zu unterschätzenden Einfluß auf die anschließende Charakterisierung haben. Als His 6 -Fusionsprotein aus E. coli aufgereinigte 
Säuger-Guanylatkinasen hGUK und mGUK waren beispielsweise im Vergleich zu mit GSTAnhang aufgereinigter hGUK und mGUK um ein Vielfaches weniger aktiv (siehe 4.1.3.1). Da die GST-Fusionsproteine zudem eine eindeutig verbesserte Löslichkeit gegenüber den His6Fusionsproteinen besaßen, mußte demnach eine falsche bzw. nicht vollständige Faltung der rekombinanten $\mathrm{His}_{6}$-Fusionsproteine ein entscheidender Grund für die drastisch verringerte enzymatische Aktivität sein. In Analogie zu den Ergebnissen der Säuger-Guanylatkinasen war es durchaus möglich, daß auch das zuvor als His $_{6}$-Fusionsprotein partiell aufgereinigte inaktive Protein SAP97-GK(P-Loop) durch eine verbesserte Löslichkeit veränderte enzymatische Eigenschaften zeigt. Aus diesem Grund sollten zunächst neben den nativen GK-Domänen von SAP97 und hCASK auch die Mutante SAP97-GK(P-Loop) als GST-Fusionsproteine aufgereinigt und mit dem gekoppelten Assay auf enzymatische Aktivität getestet werden. Vorausgesetzt die Proteine sind enzymatisch nicht aktiv wäre der nächste Schritt eine Überprüfung der drei Gene auf Suppression des letalen gukl-Phänotyps einer hapoloiden Hefemutante.

Zur Konstruktion des Plasmids pGEX-RB-SAP97-GK wurde zunächst das Fragment SAP97-GK mit den spezifischen Oligonukleotid-Primern OSP3 und OSP25 nach Vorlage des Templates pJC20-SAP97-GK(+22N) amplifiziert und anschließend über die Schnittstellen NdeI/BamHI in den Vektor pGEX-RB kloniert. Zur Konstruktion von pGEX-RB- $h C A S K-G K$ wurde die Methode der „Overlap-Extension“-PCR eingesetzt, um eine interne NdeI-Schnittstelle zu eliminieren. Dazu wurden zunächst der 5'- und 3'-Megaprimer mit den OligonukleotidPrimerpaaren OSP54/OSP57 bzw. OSP56/OSP59 mit Hilfe des Templates pCR2.3-hCASK amplifiziert. Das gesamte Fragment hCASK-GK wurde anschließend in einer zweiten PCR mit den 5'- und 3'-terminalen Oligonukleotiden OSP54 und OSP59 durch Fusion der beiden Megaprimer hergestellt und ebenfalls über die Schnittstellen NdeI/BamHI in pGEX-RB kloniert. Das Plasmid pGEX-RB-SAP97-GK(P-Loop) resultierte aus der Ligation des zuvor aus pJC20-SAP97-GK(P-Loop) isolierten Fragments SAP97-GK(P-Loop)(NdeI/BamHI) und pGEX$\mathrm{RB}(N d e \mathrm{I} / B a m \mathrm{HI})$.

Die Proteine SAP97-GK, SAP97-GK(P-Loop) und hCASK-GK konnten sehr gut als GSTFusionsproteine in E. coli BL21(DE3) überproduziert werden. Wie die SDS-PAGE-Gele in Abbildung 4.29 zeigen, waren nach 12stündiger Induktion der Proteinexpression bei $25^{\circ} \mathrm{C}$ jeweils stark hervortretende Banden des erwarteten Molekulargewichts erkennbar $(A, B$ und $C$, Spuren 1). Aus den aufgetragenen Proteinextrakten (Spuren 2) geht jedoch hervor, daß nur die nativen Formen der beiden GK-homologen Domänen, SAP97-GK und hCASK-GK, vollständig 
als GST-Fusionsproteine löslich waren. Die Mutante SAP97-GK(P-Loop) bildete unter den gegebenen Bedingungen zum größten Teil Einschlußkörper (C, Spur 2). Die Ausbeute der nach Thrombinverdau von der Sepharose 4B-Matrix in hoher Homogenität (> 95\%) isolierten Proteine SAP97-GK und hCASK-GK ( $A$ und $B$, Spuren 3) betrug 100 - 120 mg aus einem Liter E. coli-Kultur. Obwohl annähernd das gesamte exprimierte Protein GST-SAP97-GK(P-Loop) als Einschlußkörper vorlag, konnte dennoch ein geringer Teil $(<2 \mathrm{mg})$ der Mutante nach Elution mit 10 mM Glutathion partiell (50 - 60\%ige Homogenität) als GST-Fusionsprotein isoliert werden $(C$, Spur 3). Durch direkten Thrombinverdau des an die Matrix gebundenen GST-Fusionsproteins konnten keine nachweisbaren Mengen an SAP97-GK(P-Loop) isoliert werden.

A

B

C

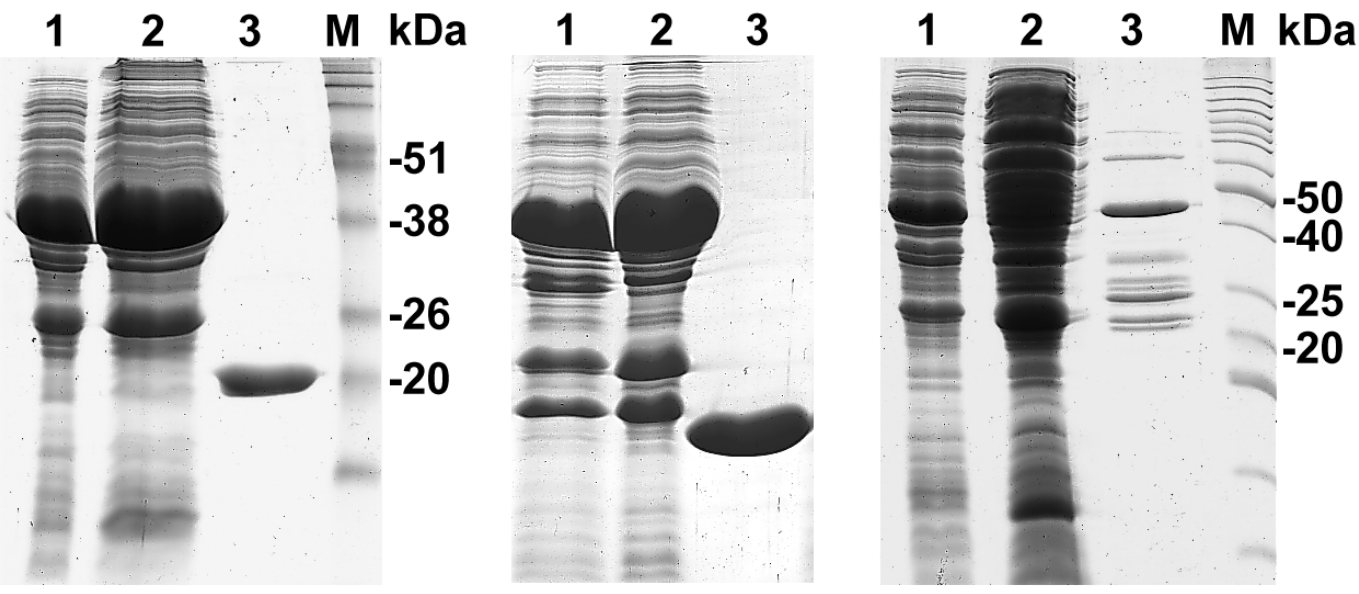

Abb. 4.29 Aufreinigung von SAP97-GK $(A)$, hCASK-GK $(B)$ und GST-SAP97-GK(P-Loop) $(C)$ nach Expression bei $25^{\circ} \mathrm{C}$ in E. coli. Die Proteinproben wurden auf einem 12\% igen SDS-PAGE-Gel elektrophoretisch aufgetrennt und mit Coomassie-Brilliantblau R250 angefärbt. Spur 1, E. coli-Zellysat über Nacht induziert; Spur 2, Extrakt mit löslichem Protein; Spur 3, nach Thrombinverdau $(A$ und $B$ ) bzw. als GST-Fusionsprotein $(C)$ aufgereinigtes Protein; $M$, Molekulargewichtsmarker (in kDa)

Weder die nativen GK-homologen Domänen der MAGUK-Proteine SAP97 und hCASK noch die Mutante GST-SAP97-GK(P-Loop) waren enzymatisch aktiv. Die Guanylatkinase-Aktivität lag in allen Fällen nicht signifikant über dem Hintergrund der ATPase-Aktivität (vor Zugabe des zweiten Substrats GMP; siehe Tab. 4.6).

Die Membran-assoziierten Guanylatkinasen SAP97 und hCASK sind Säugerproteine. Insofern kann nicht ausgeschlossen werden, daß sie zu ihrer Aktivierung posttranslational modifiziert werden müssen. Diese Möglichkeit der posttranslationalen Modifizierung ist in prokaryotischen Zellen nicht gegeben. Darüberhinaus ist es denkbar, daß die hypothetische enzymatische Aktivität der GK-Domänen derart schwach ist, daß sie in dem gekoppelten Enzym-Assay nicht detektiert werden kann. Aus diesen Gründen sollten die beiden GK-homologen Proteine 
SAP97-GK und hCASK-GK ebenso wie die Mutante SAP97-GK(P-Loop) auf Komplementation des letalen gukl-Phänotyps der Hefemutante AG430(guk1::HIS3/GUK1) überprüft werden. Zur Konstruktion von YEp512N-SAP97-GK, sowie YEp512N-SAP97-GK(PLoop) und YEp512N-hCASK wurden die Fragmente SAP97-GK, SAP97-GK(P-Loop) und hCASK durch NdeI/BamHI-Verdau aus den Plasmiden pGEX-RB-SAP97-GK, pGEX-RBSAP97-GK(P-Loop) und pGEX-RB- $h C A S K$ isoliert und in den Vektor YEp512N subkloniert. Nach Transformation des Hefestammes AG430(guk1::HIS3/GUK1) wurden einige ausgewählte Transformanden einer Tetradenanalyse auf YEPGal-Vollmedium unterzogen. Die Abbildung 4.30 zeigt das Ergebnis der Tetradenanlyse der Transformande AG430(guk1::HIS3/GUK1/YEp512N-SAP-GK(P-Loop )).

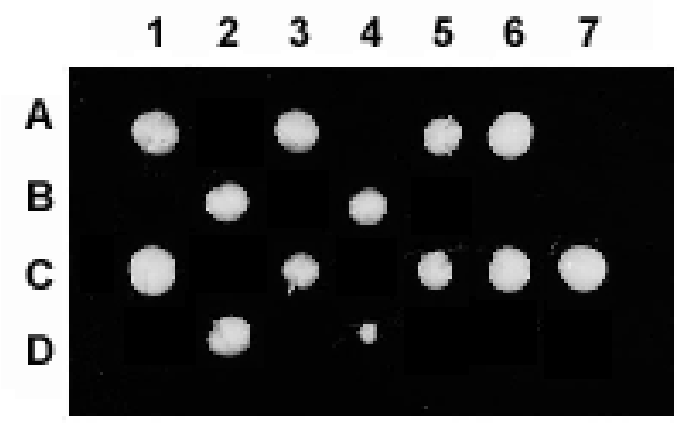

Abb 4.30 Tetradenanalyse zur Überprüfung der Komplementation des deletierten GUK1-Gens in S. cerevisiae AG430(GUK1/guk1::HIS3) durch SAP97$G K(P$-Loop). Sporenwachstum auf YEPGal-Medium.

Nach Segregation der vier Sporen sind nur zwei Sporen auf YEPGal-Medium lebensfähig, ein eindeutiger Hinweis darauf, daß SAP97-GK(P-Loop) den letalen gukl-Phänotyp nicht komplementieren kann. Die Komplementations-Analyse bestätigt folglich das Ergebnis des in vitro-Aktivitäts-Assays. Keines der drei getesteten Konstrukte, SAP97-GK, SAP97-GK(P-Loop) und $h C A S K$ war in der Lage, den gukl-Defekt in AG430(GUKl/guk1::HIS3) zu supprimieren.

\subsubsection{Versuch der Rekonstruktion einer aktiven Guanylatkinase aus SAP97-GK}

\subsubsection{Biochemische Charakterisierung von SAP97-GK-Mutanten}

Erste Versuche zur Umwandlung der inaktiven GK-Domäne von SAP97 in ein aktives Enzym durch Rekonstruktion des P-Loops waren erfolglos (siehe 4.2.1; Spangenberg, 1997). Im Folgenden sollte deshalb versucht werden durch systematische ortsspezifische Mutagenese die inaktive GK-Domäne von SAP97 in ein aktives Enzym zu überführen. In einem ersten Schritt wurde zunächst das ATP-Bindungsmotiv, der P-Loop, von SAP97 weiter verändert. In der zuvor (siehe 4.2.1) beschriebenen Mutante SAP97-GK(P-Loop) wurde der P-Loop nach Vorlage der S. cerevisiae Guanylatkinase rekonstruiert. Vergleicht man die Sequenz mit der PLoop-Sequenz authentischer Guanylatkinasen, so fehlen in SAP97-GK(P-Loop) noch weitere 
konservierte Reste (siehe Abb. 4.28 und Abb. 1.7). Dies sind das Serin und Threonin an den Positionen 16 und 17 der Hefe-Guanylatkinase (in SAP97: Asp732, Arg733). Die Substitutionen D16S und R17T wurden durch ortsspezifische Mutagenese in SAP97-GK(PLoop) eingeführt.

Die Mutante SAP97-GK(P-Loop, ST) wurde mit den Oligonukleotid-Primern OSP74 und OSP25 und dem Plasmid pJC20[HisC]-SAP97-GK(P-Loop) durch PCR amplifiziert. Das PCRFragment wurde anschließend über die Schnittstellen NdeI/BamHI in den Vektor pGEX-RB kloniert. Die Mutante SAP97-GK(P-Loop, ST) konnte in E. coli BL21(DE3) nach 6stündiger Induktion mit $1 \mathrm{mM}$ IPTG bei $37^{\circ} \mathrm{C}$ gut als GST-Fusionsprotein überexprimiert werden.

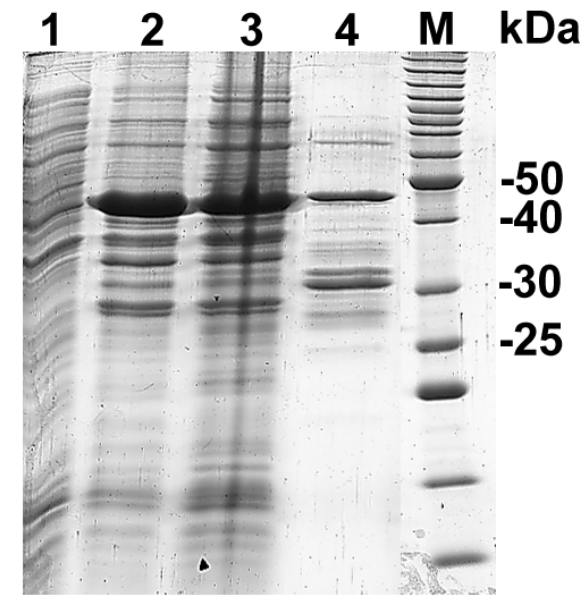

\begin{abstract}
Abb. 4.31 Aufreinigung von SAP97-GK(P-Loop, ST) nach 6stündiger Expression bei $37^{\circ} \mathrm{C}$ in E. coli. Die Proteinproben wurden in einem 12\%igen SDS-PAGE-Gel elektrophoretisch aufgetrennt und durch Coomassie-Brilliantblau R250 angefärbt. Spur 1, E. coli-Zellysat vor Induktion; Spur 2, E. coli-Zellysat nach 6stündiger Induktion; Spur 3, Extrakt mit gesamten löslichen Protein; Spur 4, als GST-Fusionsprotein partiell aufgereinigtes $\quad$ SAP97-GK(P-Loop, ST); $\quad M$, Molekulargewichtsmarker (in $\mathrm{kDa}$ )
\end{abstract}

Wie das SDS-PAGE-GEL in Abbildung 4.31 dokumentiert, war die Mutante im Gegensatz zum nativen SAP97-GK beinahe unlöslich, d.h. annähernd das gesamte Protein lag im Bakterienpellet als Einschlußkörper vor (siehe Abb. 4.31, Spur 3). Das Protein SAP97-GK(PLoop, ST) konnte in sehr geringen Mengen mit $10 \mathrm{mM}$ reduziertem Glutathion als GSTFusionsprotein eluiert werden (siehe Abb. 4.31, Spur 4). Die Homogenität der Mutante im Eluat betrug ungefähr 40 - 50\%. Es war jedoch nicht möglich, gebundenes SAP97-GK(P-Loop, ST) nach Thrombinverdau direkt von der Sepharose 4B-Säule zu isolieren. In einem erneuten Versuch zur Aufreinigung von SA97-GK(P-Loop, ST) wurde die Wachstums- und Expressionstemperatur der E. coli-Kultur auf $25^{\circ} \mathrm{C}$ gesenkt. Ferner wurde die Proteinexpression nur mit 0,1 mM IPTG induziert und die postinduktive Inkubationszeit von 6 auf 3 Stunden verkürzt. Die Anpassung führte jedoch nicht zu einer verbesserten Ausbeute an SAP97-GK(PLoop, ST).

Das Fusionsprotein GST-SAP97-GK(P-Loop, ST) zeigte keine Guanylatkinase-Aktivität (siehe Tab. 4.6) im spektrophotometrischen Assay. Da die alleinige Rekonstruktion des P-Loops nicht 
ausreichend war, um die GK-Domäne von SAP97 in ein aktives Enzym zu überführen, sollten im Folgenden weitere Reste der GK-Domäne systematisch substituiert werden. Dabei wurde sich zunächst auf die zur Bindung des Substrats GMP entscheidenden Aminosäuren konzentriert. Wie der Sequenzvergleich mit authentischen Guanylatkinasen (siehe Abb. 1.7) zeigt, sind alle zur Bindung von GMP notwendigen Reste konserviert, lediglich das Serin an Position 34 und das Aspartat an Position 100 der S. cerevisiae-Guanylatkinase sind in SAP97 durch Prolin (Pro752) und Serin (Ser818) ersetzt. Zur Substitution von Ser100Asp in SAP97GK(P-Loop) wurde eine ortsspezifische PCR-Mutagenese mit dem Oligonukleotid-Primerpaar OSP95/OSP96 und den spezifischen 5'- und 3'-terminalen SAP97-GK-Oligonukleotiden OSP3 und OSP25 durchgeführt. Als Template fungierte das Plasmid pGEX-RB-SAP97-GK(P-Loop, ST). Das PCR-Fragment SAP97-GK(P-Loop, ST, S100D) wurde anschließend über die Schnittstellen NdeI/BamHI in den Vektor pGEX-RB kloniert. Zur Einführung der Pro34SerSubstitution in SAP97-GK(P-Loop, ST, S100D) wurde der Mutagenese-Kit (QUIKchange Kit) von Stratagene (siehe 3.8.1) verwendet. Die PCR wurde mit dem spezifischen OligonukleotidePrimerpaar OSP97/OSP98 und dem zuvor konstruierten Plasmid pGEX-RB-SAP97-GK(PLoop, ST, S100D) als Template durchgeführt.
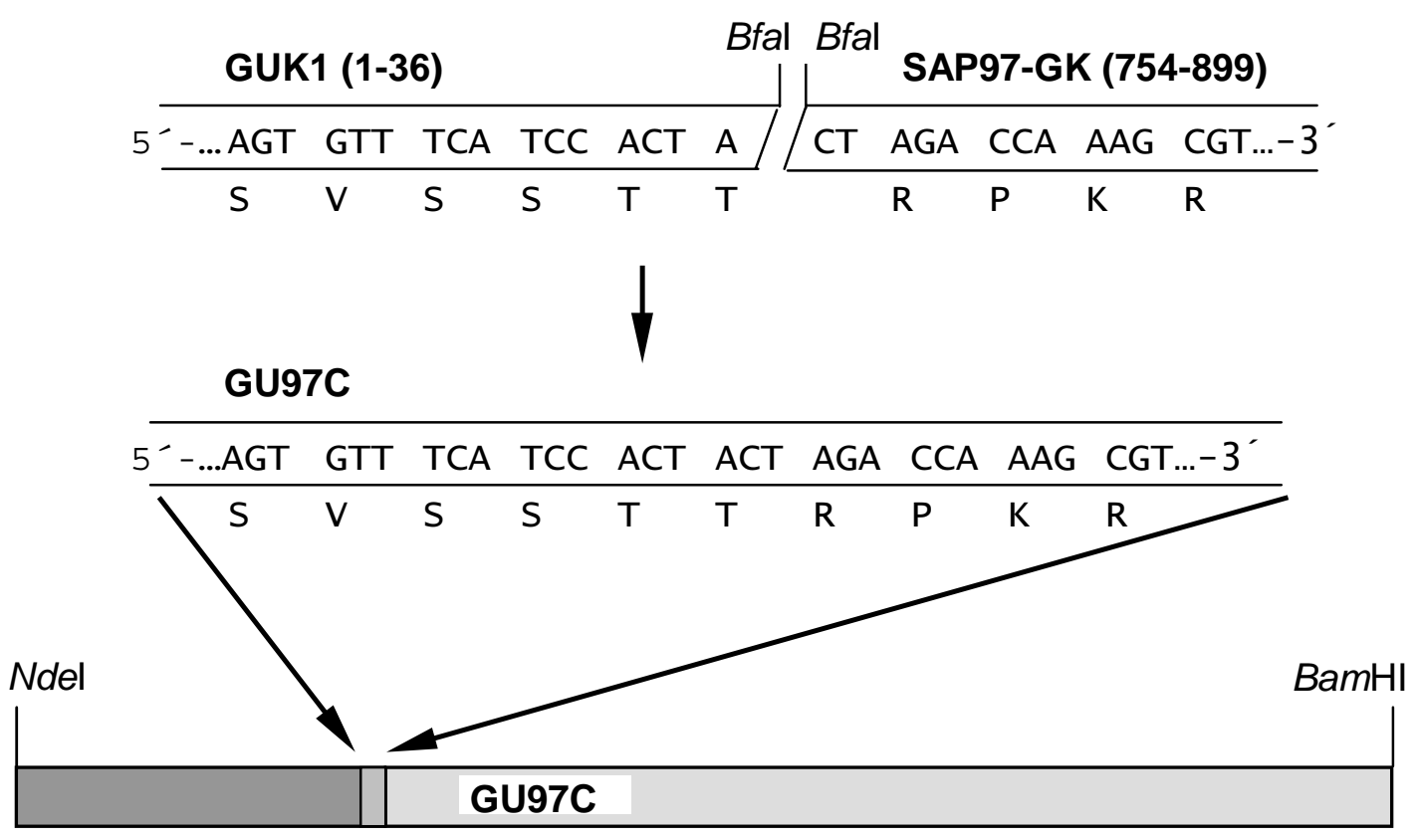

Abb. 4.32 Klonierungsschema zur Konstruktion von GU97C aus GUK1 und SAP97-GK

Zum Abschluß der systematischen Mutagenese wurde eine Proteinchimäre aus dem N-Terminus der Hefe-GUK1 und dem C-Terminus von SAP97-GK konstruiert. Die Schnittstelle des Übergangs sollte direkt in der unter allen Guanylatkinasen und MAGUK-Proteinen 
konservierten Consensussequenz TTRXXRXXEXXGXXYX(F/Y)(L/I/V/M) (siehe Abb. 1.7) liegen. Durch Vergleich der Sequenzen von GUK1 und SAP97-GK an diesem Übergang wurde

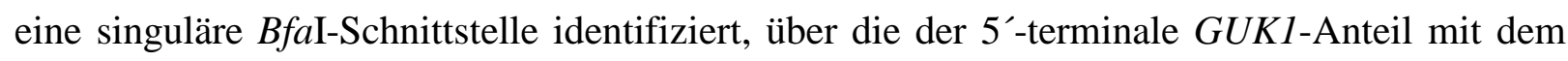
3'-terminalen SAP97-GK-Anteil verknüpft werden konnte, ohne dabei einen Fehler im Leserahmen der neu konstruierten Proteinchimäre zu verursachen. Die Klonierungsstrategie ist in Abbildung 4.32 dargestellt. Zur Konstruktion von GU97C wurden die beiden Fragmente GUK1.1(NdeI/BamHI) (aus NdeI/BamHI-Verdau von pJC20[HisN]-GUK1.1) und SAP97-GK(PLoop, ST)(NdeI/BamHI) (aus NdeI/BamHI-Verdau von pGEX-RB-SAP97-GK(P-Loop, ST) zunächst mit $B f a \mathrm{I}$ verdaut und die verdauten Fragmente isoliert. Die Fragmente GUK1.1(NdeI/BfaI) und SAP97-GK(P-Loop, ST)(BfaI/BamHI) wurden anschließend in den zuvor NdeI/BamHI-verdauten Vektor pGEX-RB ligiert.

Wie das SDS-PAGE-Gel in Abbildung 4.33 A zeigt, wurden die Mutanten SAP97-GK(P-Loop, ST, S100D), SAP97-GK(P-Loop, ST, P34S, S100D) und GU97C nach 4 bis 6stündiger Induktion mit $1 \mathrm{mM}$ IPTG bei $37^{\circ} \mathrm{C}$ gut als GST-Fusionsproteine in E. coli BL21(DE3) (siehe Abb. 4.33 A, Spuren 2-4) überexprimiert.

A

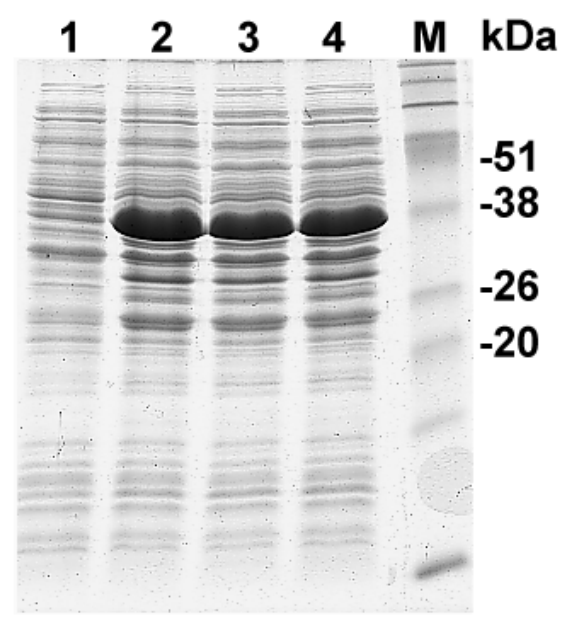

B

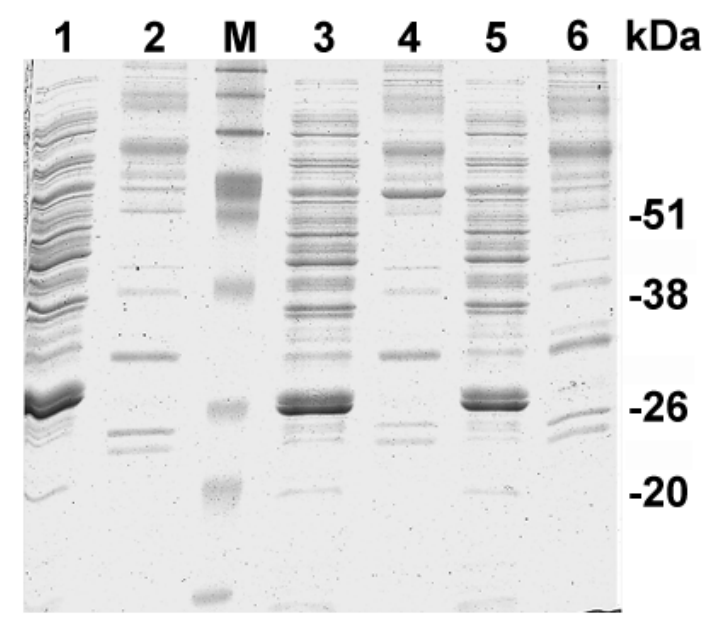

\begin{abstract}
Abb. 4.33 Expression $(A)$ und Aufreinigung $(B)$ von SAP97-GK(P-Loop, ST, S100D), SAP97-GK(P-Loop, ST, P34S, S100D) und GU97C aus E. coli. (A) Spur 1, E. coli-Zellysat vor Induktion; Spur 2, 3 und 4, E. coli-Zellysat nach 6stündige Expression von SAP97-GK(P-Loop, ST, S100D) (Spur 1), SAP97-GK(P-Loop, ST, P34S, S100D) (Spur 2), GU97C (Spur 3) bei $37^{\circ} \mathrm{C}$. (B) Spur 1, 3 und 5, Überstand mit gesamten löslichen Protein SAP97-GK(PLoop, ST, S100D) (Spur 1), SAP97-GK(P-Loop, ST, P34S, S100D) (Spur 3) und GU97C (Spur 5); Spur 2, 4 und 6 , entsprechendes Eluat nach direktem Thrombinverdau an der Sepharose 4B-Matrix; $M$, Molekulargewichtsmarker (in $\mathrm{kDa}$ ).
\end{abstract}

Die Abwesenheit der Expressionsbande im Überstand mit dem gesamten löslichen Protein (siehe Abb. 4.33 B) deutet jedoch bereits an, daß alle drei GST-Fusionsproteineunter nativen Bedingungen unlöslich waren. Die Abwesenheit eines Proteins mit einem Molekulargewicht 
von $20 \mathrm{kDa}$ im Eluat ( $B$, Spuren 2, 4 und 6 ) deutet daraufhin, daß das gesamte produzierte Protein in allen drei Fällen Einschlußkörper bildete.

Zur Überprüfung auf das Vorhandensein von geringsten Mengen an löslichem Protein, wurden die Proteinextrakte auf Guanylatkinase-Aktivität getestet. Eine über dem Hintergrund (ATPaseAktivität ohne GMP) liegende enzymatische Aktivität war in allen drei Fällen mit dem gekoppelten Assay nicht detektierbar (spezifische Aktivität < 0,01 U/mg, siehe Tab. 4.6). Der Wechsel des Expressionsstammes von E. coli BL21(DE3) zu E. coli C41(DE3), einem Stamm, der insbesondere bei der heterologen Expression von, für die E. coli-Zelle, toxischen Proteinen einen Vorteil besitzt (Miroux und Walker, 1996, C. Monnerjahn, I. Paarman, persönliche Mitteilung), führte zu keiner Verbesserung des Ergebnisses.

Da eine Aufreinigung der drei SAP97-GK-Mutanten unter nativen Bedingungen nicht möglich war, sollte im Folgenden eine Denaturierungs-Renaturierungsstrategie angewendet werden. Dazu wurden die Protein-Einschlußkörper zunächst unter denaturierenden Bedingungen aus dem jeweiligen Bakterienpellet isoliert. Zur Solubilisierung mit N-Lauroylsarcosin und der anschließenden Renaturierung der Proteine durch Dialyse gegen einen neutralen Redox-Puffer (mit dem Redoxsystem GSH-GSSG) wurde der „Protein Refolding Kit“ von Novagen (Madison, USA) verwendet.

B

C

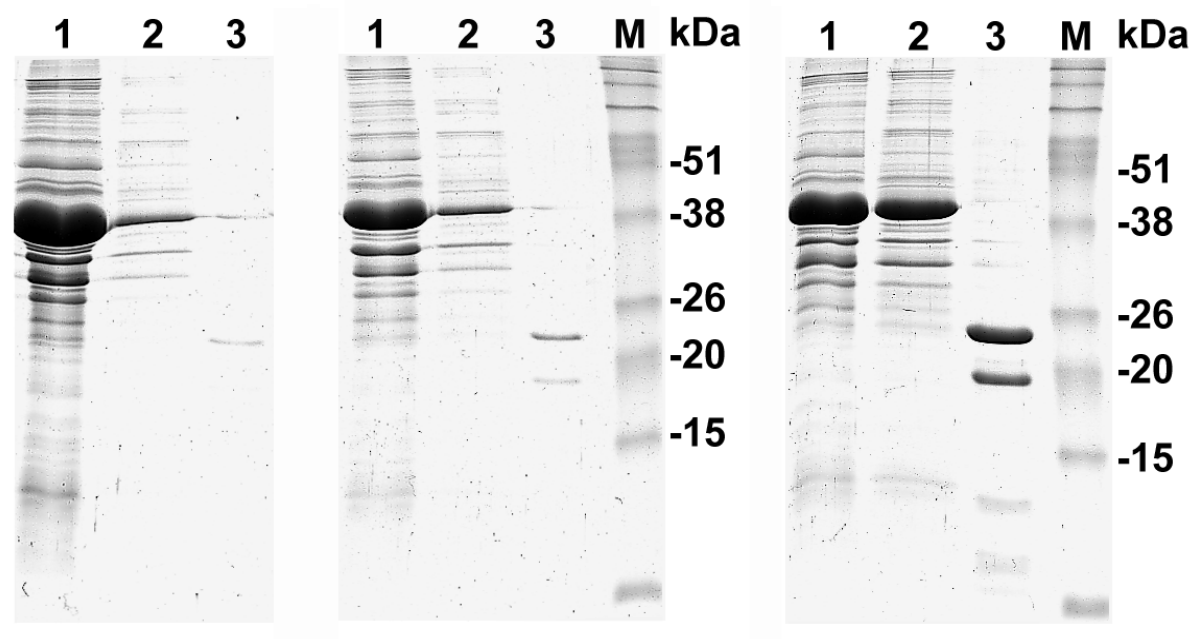

Abb. 4.34 Aufreinigung von SAP97-GK(P-Loop, ST, S100D) (A), SAP97-GK(P-Loop, ST, P34S, S100D) (B) und GU97C $(C)$ aus Einschlußkörpern nach Denaturierung-Renaturierung. Spur 1, E. coli-Pellet mit Einschlußkörpern; Spur 2, solubilisiertes Protein; Spur 3, nach Thrombinverdau von der Bindungsmatrix eluiertes natives Protein; $M$, Molekulargewichtsmarker (in $\mathrm{kDa}$ )

Die renaturierten Proteine wurden zum Schluß zur Aufreinigung über die Sepharose 4B-Matrix geschickt und nach Bindung an diese durch Thrombinverdau versucht $\mathrm{zu}$ eluieren. Die verschiedenen Stufen der Denaturierung und Renaturierung der drei SAP97-GK-Mutanten sind 
anhand der SDS-PAGE-Gele in Abbildung 4.34 dokumentiert. Alle drei Mutanten konnten gut aus den Bakterienpellets isoliert werden und lagen auch nach der Renaturierung weiterhin in Lösung vor. Darüberhinaus war es möglich die drei Proteine durch Thrombinverdau von der Sepharose 4B-Matrix zu eluieren, wie die zum Teil schwache Bande (siehe Abb. 4.34 A, B und C, Spuren 3) eines Proteins mit dem erwarteten Molekulargewicht von $20 \mathrm{kDa}$ andeutet. Das Auftreten einer zusätzlichen Bande eines Proteins mit einem Molekulargewicht von ca. 24 kDa in allen Ansätzen deutet auf eluiertes GST hin, welches vermutlich aufgrund fehlerhafter Rückfaltung nicht mehr an die Sepharose 4B-Matrix binden konnte. Es ist jedoch auch möglich, daß die größere Bande unvollständig bzw. falsch zurückgefaltetem Protein der jew. SAP97-GKMutante entspricht, welches durch ein verändertes Laufverhalten auf dem SDS-PAGE-Gel gekennzeichnet ist. Die Menge an isoliertem Protein entsprach insbesondere im Fall der Mutante SAP97-GK(P-Loop, ST, S100D) jedoch nicht der im Renaturierungspuffer vorliegenden Menge (siehe Abb. 4.34 C, Spur 2), was daraufhin deutete, daß nur ein Teil des denaturierten Fusionsproteins vollständig renaturiert wurde.

Die Aktivität von SAP97-GK(P-Loop, ST, S100D) und SAP97-GK(P-Loop, ST, P34S, S100D) lag ebenso wie die zuvor gemessene Guanylatkinase-Aktivität von SAP97-GK(P-Loop, ST) nicht signifikant über dem Hintergrund der ATPase-Aktivität, vor Zugabe des Substrats GMP.

Tab. 4.6 Spezifische Aktivität von Mutanten der GK-Domäne aus SAP97 und hCASK

\begin{tabular}{cc}
\hline Mutante & $\begin{array}{c}\text { Spezifische Aktivität } \\
(\boldsymbol{U} / \mathbf{m g})\end{array}$ \\
\hline hCASK-GK(WT) & 0,006 \\
SAP97-GK(WT) & 0,005 \\
P-Loop & 0,005 \\
P-Loop, ST & 0,026 \\
P-Loop, ST, S100D & 0,025 \\
P-Loop, ST, P34S, S100D & 0,021 \\
GU97C & 0,005 \\
\hline
\end{tabular}

Auch die Proteinchimäre GU97C schien nicht enzymatisch aktiv zu sein. Der mit dem gekoppelten Assay bestimmte Aktivitätswert lag weder über dem Hintergrund der ATPaseAktivität, noch war er höher als die Guanylatkinase-Aktivität des zuvor in der Hefe auf 
Komplementation (siehe 4.2.1) getesteten inaktiven Proteins SAP97-GK. Einen Überblick der GK-Konstrukte und der zugehörigen gemessenen Aktivitäten gibt die Tabelle 4.6.

\subsubsection{Komplementations-Analyse von SAP97-GK-Mutanten in S. cerevisiae}

Die im photometrischen Enzym-Assay nicht detektierbare Guanylatkinase-Aktivität, ist kein ausreichendes Kriterium zur Beurteilung der Mutanten SAP97-GK(P-Loop, ST, P34S, S100D) und GU97C(S100D). Einerseits ist der gekoppelte photometrische Assay nicht sehr sensitiv und andererseits kann gerade die Isolierung eines unbekannten rekombinanten Proteins durch Denaturierung mit abschließender Rückfaltung in den vermeintlich nativen Zustand zu einem Protein mit veränderten Eigenschaften führen. Im Fall der SAP97-GK-Mutanten war es durchaus denkbar, daß die Proteine aufgrund einer unvollständigen Rückfaltung während des Renaturierungsschrittes nicht ihre native Tertiärstruktur einnehmen konnten und folglich katalytisch inaktiv waren. Da aus den oben genannten Gründen eine in vitro-Charakterisierung der SAP97-GK-Mutanten nicht möglich war, sollten abschließend die Mutante SAP97-GK(PLoop, ST, P34S, S100D) und die Chimäre GU97C auf ihre Fähigkeit hin überprüft werden, den letalen gukl-Phänotyp des Hefestammes AG430(GUK1/gukl::HIS3) zu komplementieren.

Zur Überprüfung auf Komplementation in AG430 wurden die DNA-Fragmente SAP97-GK(PLoop, ST, P34S, S100D) (NdeI/BamHI) und GU97C (NdeI/BamHI) aus den Expressionsplasmiden pGEX-RB-SAP97-GK(P-Loop, ST, P34S, S100D) und pGEX-RBGU97C isoliert und über die Schnittstellen NdeI/BamHI in den Vektor YEp512N kloniert. Nach Transformation von AG430 wurden einige ausgewählte Transformanden durch Tetradenanalyse auf YEPGal-Medium analysiert.

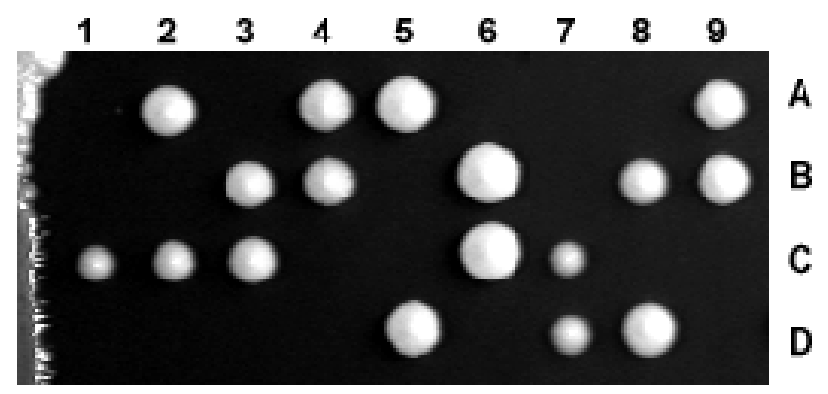

Abb. 4.35 Tetradenanalyse zur Überprüfung von deletiertem GUK1-Gen durch GU97C im Hefestamm AG430(GUK1/guk1::HIS3).

Im Fall der Komplementation sollten alle vier Sporen eines Ascus auf dem YEPGalVollmedium überleben. Das Ergebnis der Tetradenanlyse der Transformande AG215(guk1::HIS3/YEp512N-GU97C(S100D)) ist in Abbildung 4.35 dargestellt. Das Wachstum von nur zwei Sporen in allen ausgelegten Tetraden zeigt eindeutig, daß GU97C die gukl-Deletion nicht supprimieren konnte, folglich enzymatisch nicht aktiv ist. Eine Sporen- 
Segregation von $2: 2$ war auch das Ergebnis der Tetradenanlyse mit SAP97-GK(P-Loop, ST, P34S, S100D). Die Ergebnisse der Komplementationsanalyse in vivo stimmen mit den Ergebnissen des in vitro-Aktivitäts-Assays (siehe Tab. 4.6) überein.

Das Ergebnis der Mutagenese-Studie zeigt folglich, daß eine Substitution sämtlicher, aus der Kristallstruktur der Hefe-GUK1 abgeleiteter, mit den Substraten ATP und GMP interagierender Aminosäurereste nicht ausreichend ist, die inaktive GK-Domäne von SAP97 in ein aktives Enzym zu überführen.

\subsubsection{Nukleotidbindungs-Eigenschaften von SAP97-GK}

\subsubsection{Untersuchung der Bindung einzelner Nukleotide an SAP97-GK mit der Nano- ESMS}

Die GK-homologen Domänen der beiden Membran-assoziierten Guanylatkinasen SAP97 und hCASK sind katalytisch nicht aktiv. Eine systematische Rekonstruktion des P-Loop Motivs und der zur Bindung von ATP und GMP sowie Übertragung des Phosphatrestes von ATP auf GMP notwendigen Reste durch ortsspezifische Mutagenese war offensichtlich nicht ausreichend, um die inaktive GK-Domäne von SAP97 in eine aktive Form zu überführen (siehe 4.2.2).

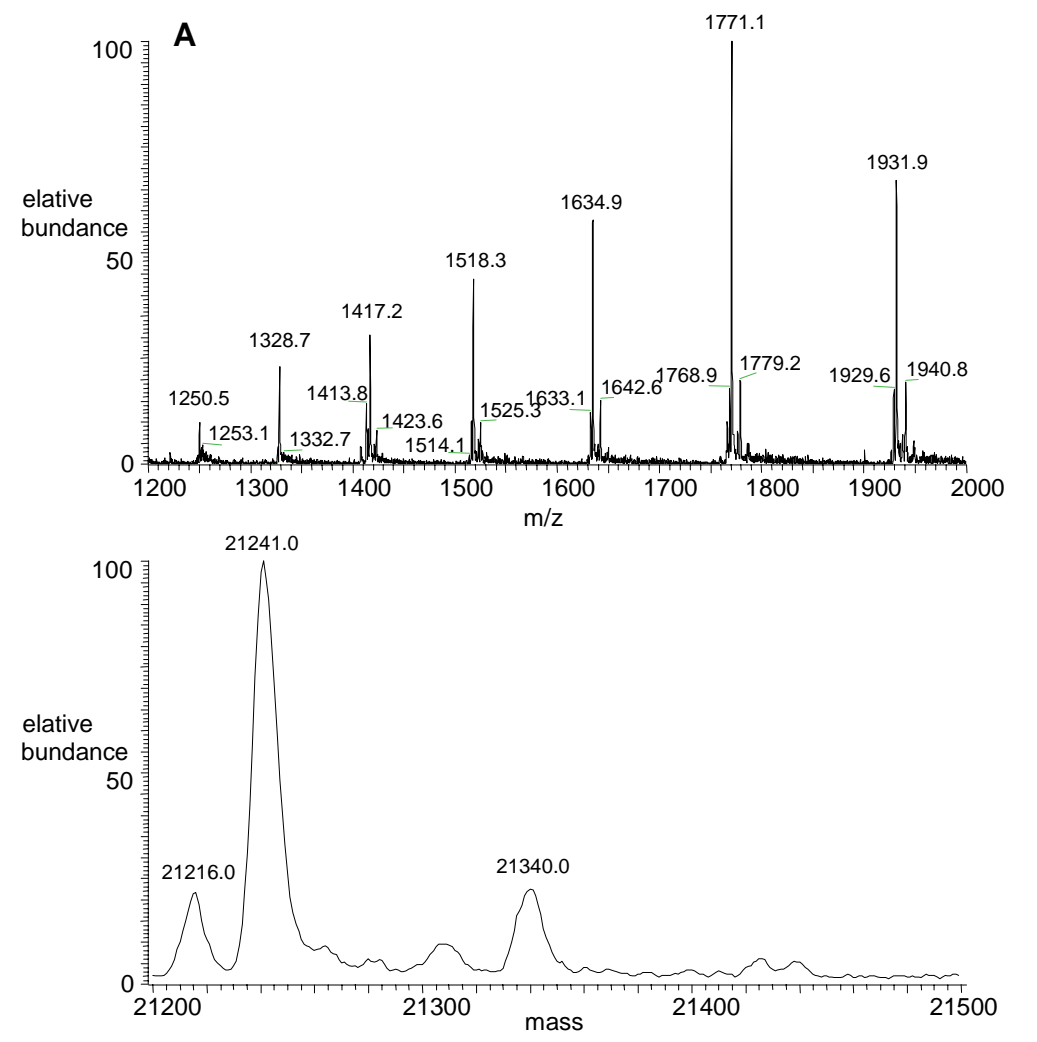

Abb. 4.36 Nano-Elektrospray (ES)-
Massenspektren von SAP97-GK in
$\mathrm{H}_{2} \mathrm{O} \quad A$, Original-Massenspektrum
(Auftragung: Rel. Verteilung $\rightarrow \mathrm{m} / z)$.
$B$, Massenspektrum nach Umwandlung
(Auftragung: Rel. Verteilung $\rightarrow$
Masse). Die Peaks in $B$ entsprechen
Ligand-freiem SAP97-GK (21241),
SAP97-GK·SO ${ }_{4}^{2-}(21340)$. c(Protein)
$=10 \mu \mathrm{M}$.

Aufgrund des hohen Konservierungsgrades an Aminosäuren, die in der Hefe-GUK1Kristallstruktur mit GMP interagieren (Stehle und Schulz, 1992; siehe Abb. 1.7), war es 
dennoch denkbar, daß die GK-Domänen von SAP97 und hCASK zumindest die Fähigkeit zur Bindung von Purin-Nukleotiden nicht verloren hatten.

Zur Untersuchung der Nukleotidbindung an die GK-Domäne von SAP97 wurde die NanoElektrospray-Massenspektrometrie (Nano-ESMS), welche zuvor bereits zur erfolgreichen Detektion von Guanylatkinase-Nukleotid-Komplexen in wässriger Lösung eingesetzt wurde (siehe 4.1.3.3), angewandt. Für die Untersuchung mit der Nano-ESMS wurde das Protein SAP97-GK zunächst durch mehrmalige Gelfiltration und Ultrafiltration entsalzt und anschließend in $\mathrm{H}_{2} \mathrm{O}$ untersucht. Abbildung 4.36 A zeigt das Original-Massenspektrum (Auftragung: Relative Verteilung $\rightarrow \mathrm{m} / \mathrm{z}$ ) von SAP97-GK. Das Profil zeigt die Serie der protonierten Moleküle einer dominanten Proteinspezies. Neben einem Hauptpeak sind mehrere kleinere Peaks mit veränderter Ladungsverteilung zu erkennen. Das umgewandelte Spektrum (siehe Abb. 4.36 B) zeigt neben dem Hauptpeak von 21241,0 kDa, der erwarteten Masse von SAP97-GK, zwei weitere Peaks von schwächerer Intensität bei 21216,0 und 21340,0 kDa.
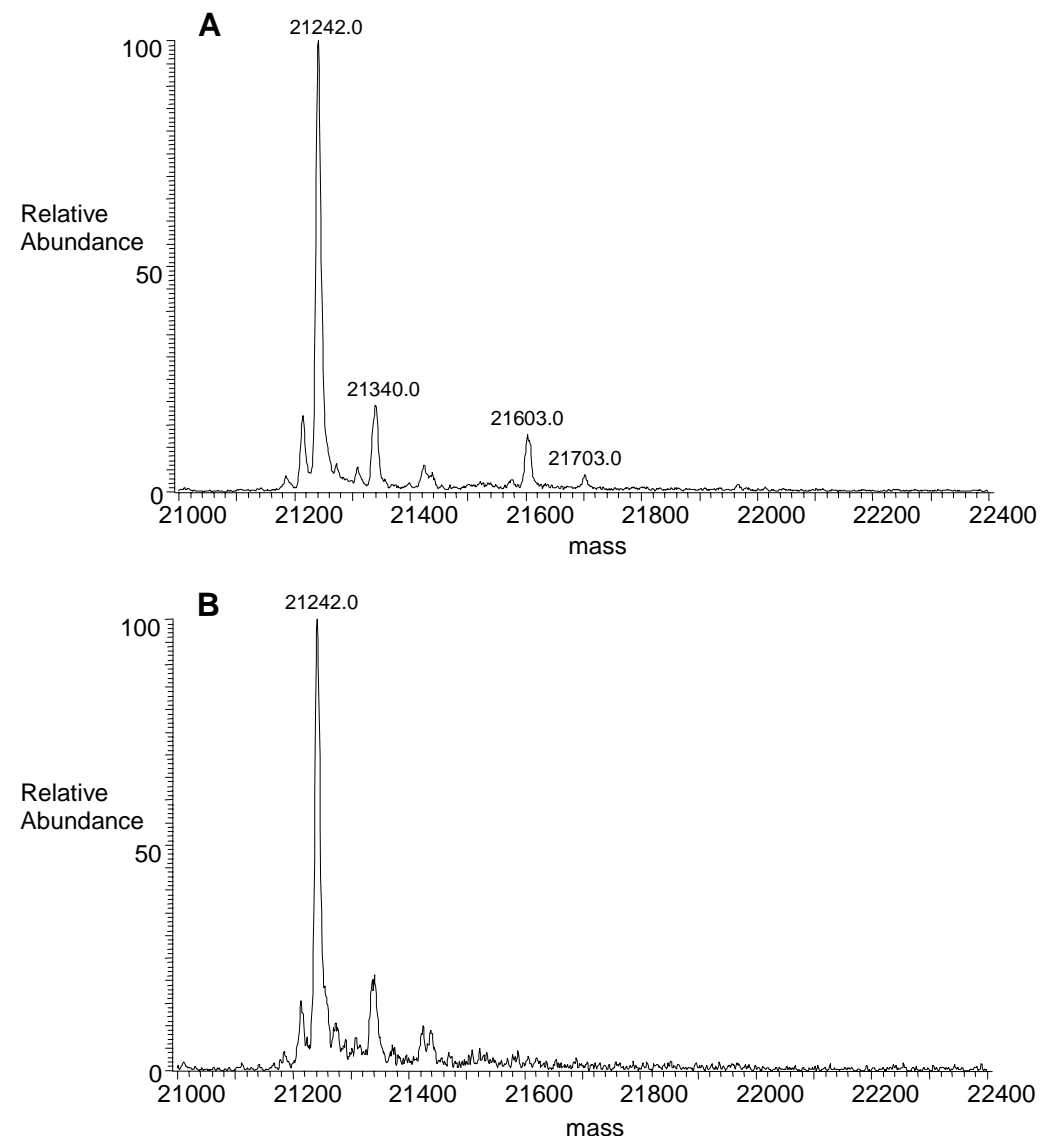
Abb. 4.37 Nano-ES-Massenspektren von SAP97-GK inkubiert für $5 \mathrm{~min}$ mit GMP $(A)$ und AMP $(B)$. Die Peaks entsprechen SAP97-GK (21242), SAP97-GK· $\mathrm{SO}_{4}{ }^{2-}$ (21340), SAP97- GK.GMP (21603), SAP97- $\mathrm{GK} \cdot \mathrm{GMP} \cdot \mathrm{SO}_{4}{ }^{2-}(21703)$. $\mathrm{c}($ Protein $)=$ $10 \mu \mathrm{M}, \mathrm{c}(\mathrm{NMP})=10 \mu \mathrm{M}$.

Während es sich bei dem kleineren Protein vermutlich um ein modifiziertes Produkt (evtl. Substitution des N-terminalen Methionins durch ein Homoserin) handelt, entspricht die Massendifferenz (von 98 Da) der größeren Proteinspezies der zuvor auch bei der 
Nukleotidbindungsanalyse von hGUK (siehe 4.1.5) beobachteten Bindung eines Sulfat $\left(\mathrm{SO}_{4}{ }^{2-}\right)-$ Ions.

Zur Untersuchung der Nukleotidbindung wurden $10 \mu \mathrm{M}$ SAP97-GK und $10 \mu \mathrm{M}$ des Nukleotids in $\mathrm{H}_{2} \mathrm{O}$ gemischt und für mindestens 5 Minuten bei RT inkubiert. In Abbildung 4.37 sind die Massenspektren von SAP97-GK nach Inkubation mit den Purinnukleotiden GMP $(A)$ und AMP (B) in einer Konzentration von $10 \mu \mathrm{M}$ dargestellt. Neben den erwarteten Peaks von Ligandfreiem SAP97-GK und den Komplexen mit $\mathrm{SO}_{4}{ }^{2-}$ ist nur nach Inkubation mit GMP ein zusätzlicher SAP97-GK-Nukleotid-Komplex erkennbar. Die Verlängerung der Inkubationszeit von 5 Minuten auf 1 Stunde führte nicht zu einer Verstärkung des Bindungspeaks von SAP97GK·GMP, was daraufhin deutete, daß bereits nach 5 Minuten das gesamte GMP an das Protein gebunden hatte. Eine Erhöhung der Konzentration an freiem GMP bei gleichbleibender Konzentration an SAP97-GK führte zu einem Anstieg des Protein-GMP-Komplexes, wie er zuvor auch bei der Bindung von Substrat an die Guanylatkinase beobachtet wurde (siehe 4.1.3.3). Der hyperbolische Kurvenverlauf entsprach dem einer typischen Bindungskurve.

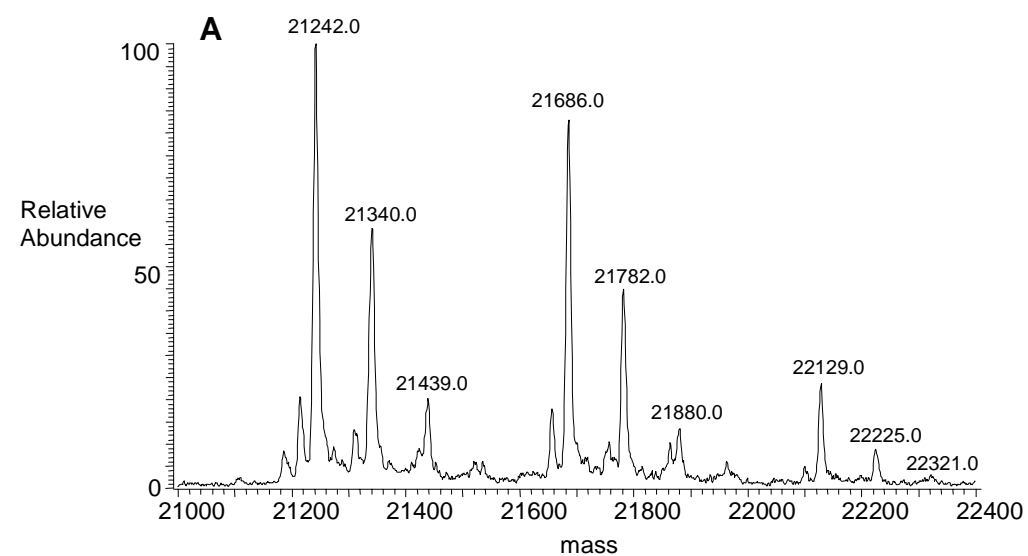
Abb. 4.38 Nano-ES-Massenspektren von SAP97-GK inkubiert für $1 \mathrm{~h}$ mit GDP $(A)$ und ADP $(B)$. Die Peaks entsprechen SAP97-GK (21242), SAP97-GK· $\mathrm{SO}_{4}^{2-}$ (21340), SAP97- $\mathrm{GK} \cdot 2 \mathrm{SO}_{4}{ }^{2-}(21439)$, SAP97-GK.GDP (21686), SAP97-GK.GDP. $\mathrm{SO}_{4}{ }^{2-}$ (21782), SAP97-GK·GDP.2SO ${ }_{4}^{2-}$ (21880), SAP97-GK·2GDP (22129), SAP97-GK·2GDP. $\mathrm{SO}_{4}{ }^{2-} \quad(22225)$, SAP97-GK·2GDP.2SO ${ }_{4}^{2-} \quad(22321)$, SAP97-GK·ADP (21669), SAP97- $\mathrm{GK} \cdot \mathrm{ADP} \cdot \mathrm{SO}_{4}{ }^{2-}(21767)$. $\mathrm{c}($ Protein $)=$ $10 \mu \mathrm{M}, \mathrm{c}(\mathrm{NDP})=10 \mu \mathrm{M}$.

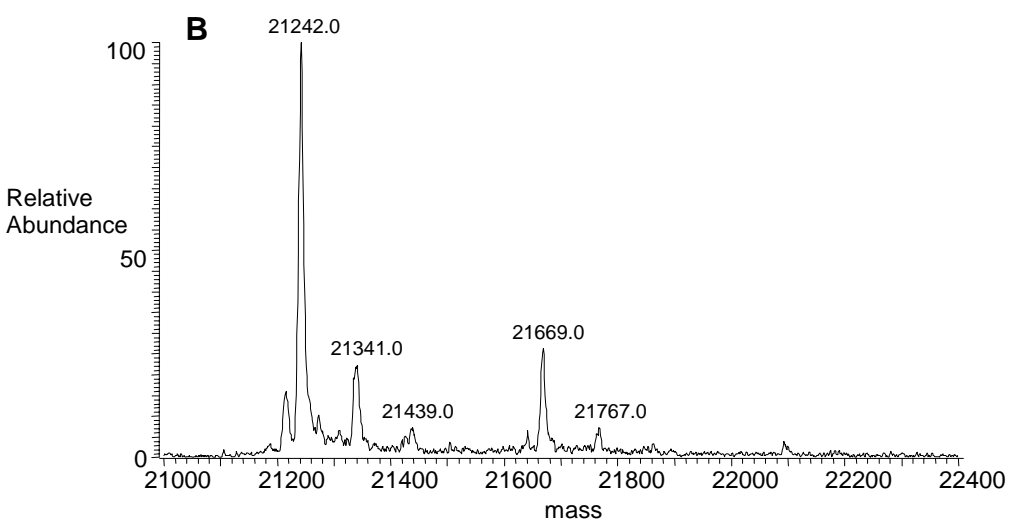

Als nächstes wurde die Bindung der beiden Purinnukleosid-Diphosphate überprüft. Jeweils $10 \mu \mathrm{M}$ SAP97-GK wurden mit $10 \mu \mathrm{M}$ GDP und ADP in $\mathrm{H}_{2} \mathrm{O}$ für 5 Minuten bzw.1 Stunde bei RT inkubiert. Die beiden Massenspektren sind in Abbildung $4.38 A$ (GDP) und $B$ (ADP) 
dargestellt. Neben den erwarteten Peaks des Proteins SAP97-GK sind in beiden Ansätzen Protein-Nukleotid-Komplexe nachweisbar. Im einzelnen waren nach Inkubation mit GDP 2 zusätzliche SAP97-GK-GDP-Peaks, nach Inkubation mit ADP jedoch nur ein zusätzlicher schwacher SAP97-GK-ADP Peak zu beobachten. Die Anzahl von 2 gebundenen Nukleotiden muß wieder unter dem Vorbehalt der zuvor mit authentischer Guanylatkinase beobachteten Bindung von Nukleotidclustern an eine Bindungsstelle der GK-Domäne gesehen werden.
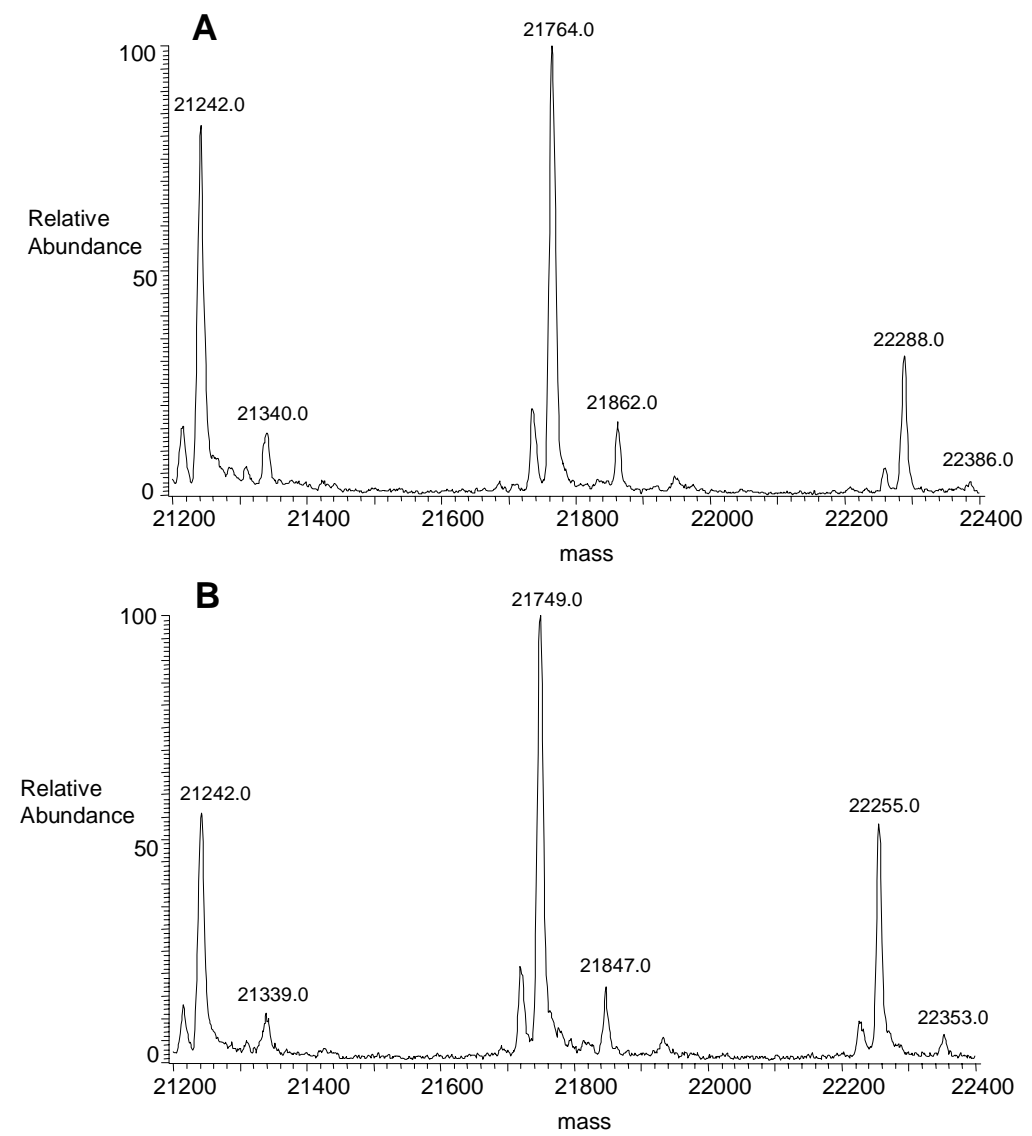

Abb. 4.39 Nano-ES-Massenspektren von SAP97-GK nach Inkubation mit $10 \mu \mathrm{M}$ GTP $(A)$, ATP $(B)$ und UTP $(C)$. Die Peaks entsprechen SAP97GK (21242), SAP97-GK·SO ${ }_{4}^{2-}$ (21340), SAP97-GK·GTP (21764),

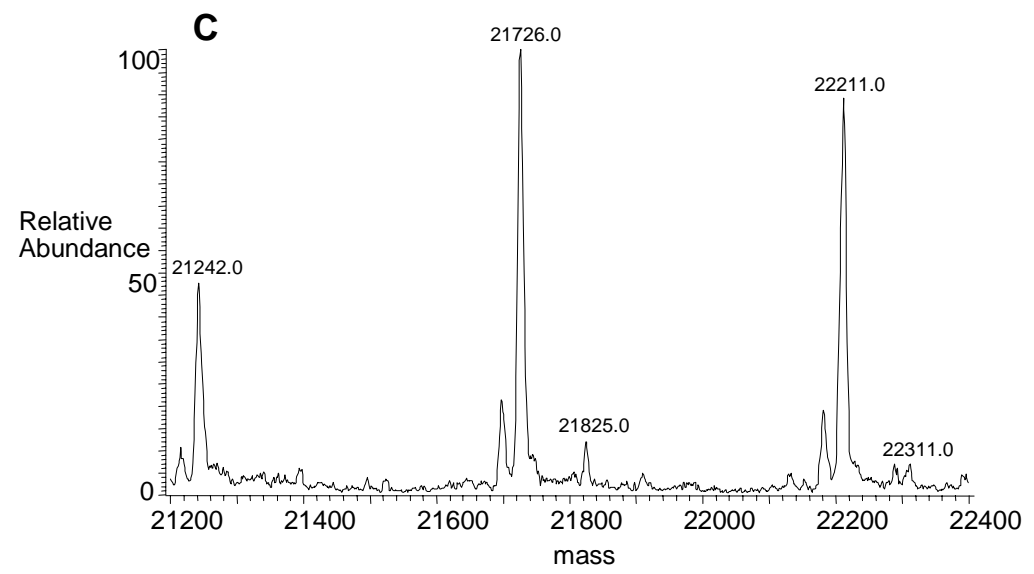
SAP97-GK·GTP.SO ${ }_{4}{ }^{2-} \quad$ (21862), SAP97-GK·2GTP (22288), SAP97GK·2GTP. $\mathrm{SO}_{4}{ }^{2-} \quad$ (22386), SAP97GK·ATP (21749), SAP97-GK ATP.SO ${ }_{4}^{2-}$ (21847), SAP97-GK 2ATP (22255), SAP97-GK 2ATP. $\mathrm{SO}_{4}{ }^{2-}$ (22353), SAP97-GK·UTP (21726), SAP97-GK·UTP.SO ${ }_{4}^{2-}$ SAP97-GK·2UTP (22211), SAP97GK·2UTP. $\mathrm{SO}_{4}{ }^{2-}$ (22311). $\mathrm{c}($ Protein $)=$ $10 \mu \mathrm{M}$

Neben den Protein-Nukleotid-Komplex-Peaks sind auch hier zusätzliche Peaks, resultierend aus der Protein- $\mathrm{SO}_{4}{ }^{2-}$-Komplexbildung, nachweisbar. Die Anzahl der $\mathrm{SO}_{4}{ }^{2-}$-Peaks differiert jedoch in Abhängigkeit von der Art des eingesetzten Liganden. Während im Massenspektrum mit ADP 
(siehe Abb. 4.38 B) den Hauptpeaks von Ligand-freiem SAP97-GK und jenem des ProteinADP-Komplexes nur ein zusätzlicher $\mathrm{SO}_{4}{ }^{2-}$-Komplex-Peak folgt, sind in dem Massenspektrum mit GDP (siehe Abb. 4.38 A) neben jedem Hauptpeak (SAP97-GK, SAP97-GK·GDP, SAP97GK·2GDP) jeweils 2 Peaks der Komplexe mit $\mathrm{SO}_{4}{ }^{2-}$ erkennbar. Die relative Intensität des ternären $\mathrm{SO}_{4}{ }^{2-}$-Komplex (SAP97-GK·NDP·SO ${ }_{4}{ }^{2-}$ )-Peaks im Vergleich zum Protein-NDPHauptpeak war jedoch sowohl mit GDP, als auch mit ADP nicht geringer als die des binären $\mathrm{SO}_{4}{ }^{2-}-$ Komplexes SAP97-GK· $\mathrm{SO}_{4}{ }^{2-} \mathrm{zu}$ dem Hauptpeak von Ligand-freiem Protein. Dies deutet daraufhin, daß die Purinnukleosid-Diphosphate nicht mit dem $\mathrm{SO}_{4}{ }^{2-}$-Ion um die Bindungsstelle an SAP97-GK konkurrieren. Für den Fall, daß GDP (bzw. ADP) und $\mathrm{SO}_{4}{ }^{2-}$, die gleiche Bindungsstelle des Proteins einnähmen, wäre ein starker Abfall der Intensität des jeweiligen ternären Bindungskomplex-Peaks zu beobachten gewesen und das Verhältnis der KomplexPeaks SAP97-GK·NDP : SAP97-GK·NDP·SO ${ }_{4}{ }^{2-}$ hätte sich beträchtlich zu Gunsten des ProteinNDP-Peaks verschieben müssen.

Zur Vervollständigung der Purinnukleotid-Bindungsstudie in wässriger Lösung wurden im nächsten Schritt die Nukleosid-Triphosphate getestet. Wie in den Ansätzen zuvor wurden jeweils $10 \mu \mathrm{M}$ des Proteins SAP97-GK mit $10 \mu \mathrm{M}$ GTP und ATP und als Kontrolle UTP für 5 Minuten bis 1 Stunde bei RT inkubiert. Die Ergebnisse der Purinnukleosid-Triphosphatbindung (1 h Inkubationszeit) sind in der Abbildung 4.39 dargestellt. Neben dem Ligand-freien Protein SAP97-GK und den Protein-SO ${ }_{4}{ }^{2-}-$ Komplexen sind mit GTP (siehe Abb. 4.39 A), ATP (B) und UTP $(C)$ zwei zusätzliche Proteinnukleotid-Komplex-Peaks erkennbar, diese korrespondieren mit dem Molekulargewicht der Komplexe aus einfach und zweifach gebundenem Nukleotid. Auch hier sind die Verhältnisse SAP97-GK : SAP97-GK·SO ${ }_{4}{ }^{2-}$ und SAP97-GK·NTP : SAP97GK·NTP. $\mathrm{SO}_{4}{ }^{2-}$ identisch. Dies ist ein weiterer Hinweis dafür, daß die getesteten NukleosidTriphosphate und das $\mathrm{SO}_{4}{ }^{2-}$-Ion nicht die identischen Bindungspositionen in SAP97-GK einnehmen. Eine Erhöhung der Nukleotidkonzentration führte erwartungsgemäß zu einer Abnahme des Liganden-freien Proteins und zu einer Zunahme der Protein-NukleotidKomplexe. Wie auch die Bindung von GMP, GDP und ADP zuvor folgt die Bindung von GTP und ATP an SAP97-GK dem Verlauf einer hyperbolischen Kurve.

Eine Verringerung der NTP-Konzentration von 10 auf $5 \mu \mathrm{M}$ bei gleichbleibender Proteinkonzentration hat eine drastische Veränderung der Peak-Intensitäten zur Folge (siehe Abb. 4.40). In Abbildung 4.40 sind die Massenspektren von SAP97-GK (10 $\mu \mathrm{M})$ nach Inkubation mit den Purinnukleotiden GTP $(A)$, ATP $(B)$ und UTP $(C)$ in einer Konzentration 
von $5 \mu \mathrm{M}$ dargestellt. Im Gegensatz zu den Massenspektren in Abbildung 4.39 ist in allen drei Fällen der Peak des Ligand-freien Proteins dominant. Ein zweiter, dem jeweiligen Protein-NTPKomplex entsprechender Peak ist nur noch in den Spektren mit GTP und ATP erkennbar. Die Affinität von SAP97-GK zu UTP scheint demnach im Vergleich zu GTP und ATP derart schwach zu sein, daß unter den gegebenen Bedingungen ein Komplex von SAP97-GK und UTP nicht mehr detektiert werden kann.
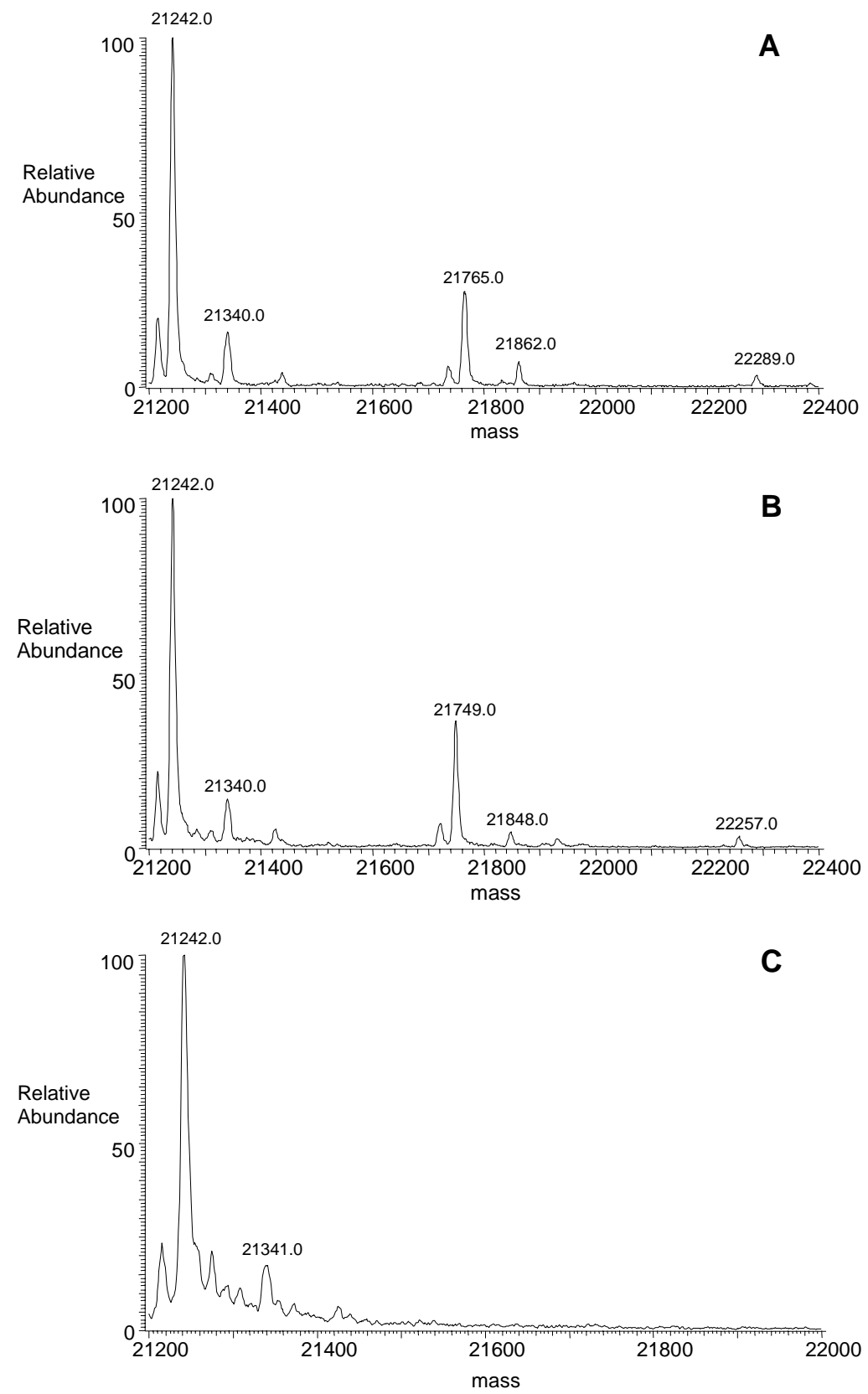
Abb. 4.40 Nano-ES-Massenspektren von SAP97-GK nach Inkubation mit $5 \mu \mathrm{M}$ GTP $(A)$, ATP $(B)$ und UTP $(C)$. Die Peaks entsprechen SAP97- GK (21242), SAP97-GK·SO ${ }^{2-}$ (21340), SAP97-GK·GTP (21765), SAP97-GK·GTP.SO ${ }_{4}{ }^{2-} \quad$ (21862), SAP97-GK·2GTP (22289), SAP97- GK·ATP (21749), SAP97-GK ATP.SO ${ }_{4}^{2-} \quad$ (21848), SAP97-GK 2ATP $(22257)$. $c($ Protein $)=10 \mu \mathrm{M}$.

Die Methode der Nano-Elektrospray-Massenspektrometrie erlaubt folglich eine eindeutige Diskriminierung zwischen der nichtkovalenten Bindung der Purinnukleotide GTP und ATP und der nichtkovalenten Bindung des Pyrimidinnukleotids UTP an SAP97-GK. 
In einem abschließenden Schritt wurde die Bindung der cyclischen Monophosphate cGMP und cAMP an die GK-Domäne von SAP97 überprüft. Dazu wurden wie in den Bindungsstudien zuvor $10 \mu \mathrm{M}$ des Proteins SAP97-GK mit $10 \mu \mathrm{M}$ der Nukleotide cGMP und cAMP für 5 Minuten bei RT inkubiert. In Abbildung 4.41 sind die Massenspektren von SAP97-GK und cGMP $(A)$ sowie cAMP $(B)$ dargestellt. Die Massenspektren der Bindung von cGMP bzw. cAMP entsprechen jenen der Bindung von GMP (siehe Abb. 4.37 A) bzw. AMP (B).
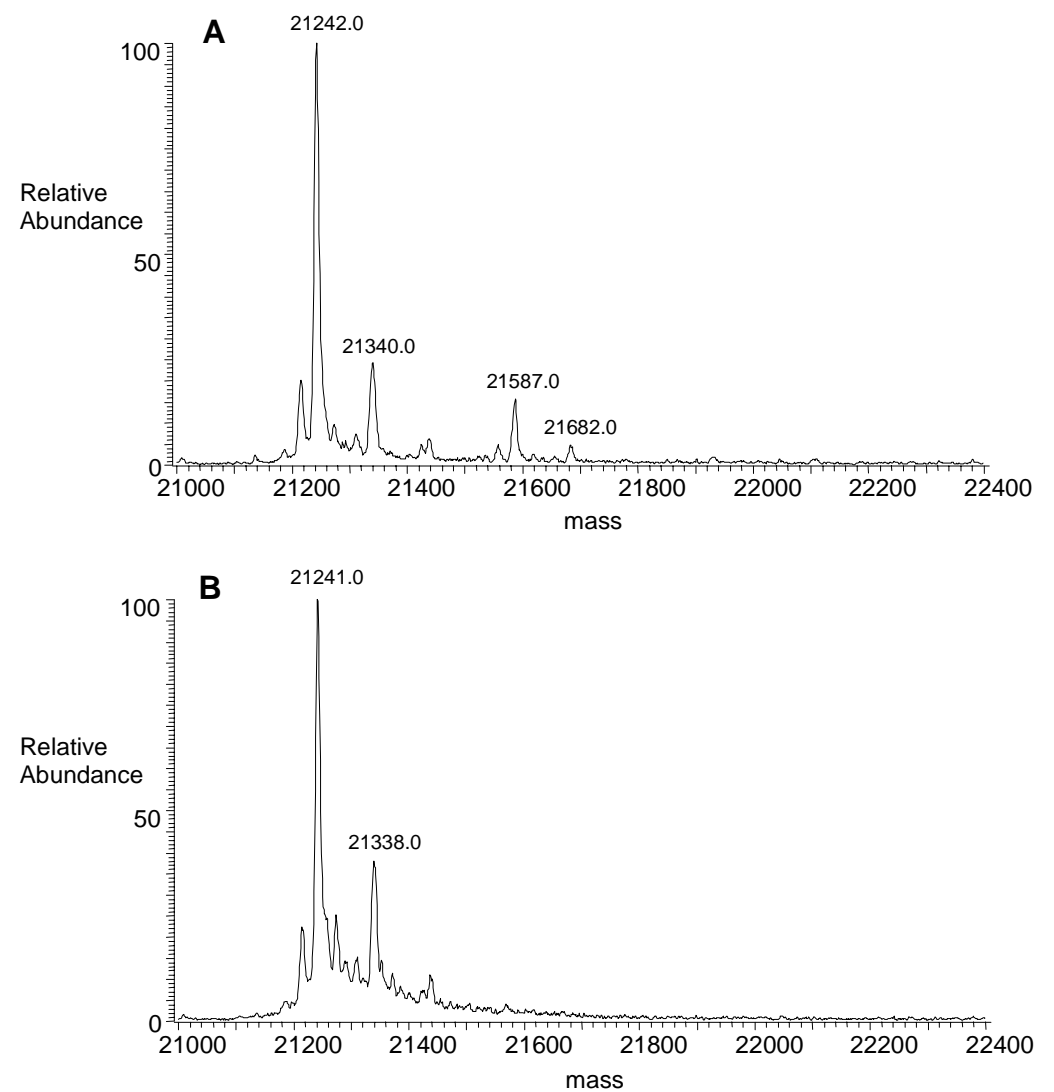

\begin{abstract}
Abb. 4.41 Nano-ES-Massenspektren von SAP97-GK inkubiert für 5 min mit cGMP (A) und cAMP (B). Die Peaks entsprechen SAP97-GK (21242), SAP97-GK·SO ${ }_{4}^{2-}$ (21340), SAP97-GK·cGMP (21587), SAP97$\mathrm{GK} \cdot \mathrm{cGMP} \cdot \mathrm{SO}_{4}{ }^{2-}$ (21682). c(Protein) $=10 \mu \mathrm{M}, \mathrm{c}(\mathrm{NMP})=10 \mu \mathrm{M}$.
\end{abstract}

Das Ergebnis der Massenspektrometrie zeigt, daß SAP97-GK nur mit cGMP einen Komplex bildet. Der Peak des SAP97-GK·cGMP-Komplexes entspricht in der Intensität jenem von gebundenem GMP (siehe Abb. 4.41 A). Im Massenspektrum mit cAMP ist neben dem Ligandfreien Protein-Peak nur noch jener des Komplexes mit $\mathrm{SO}_{4}{ }^{2-}$ erkennbar.

\title{
4.2.3.2 Identifikation der Nukleotidbindungsstellen von SAP97-GK mit der Nano- ESMS
}

In den zuvor beschriebenen Experimenten wurde die Methode der NS-MS zum Nachweis der Nukleotidbindung an die GK-homologe Domäne von SAP97 angewendet. Dazu wurde jeweils die Bindung einzelner Nukleotide untersucht. Die folgenden Versuche hatten zum Ziel eine mögliche NMP- und NTP-Bindungsstelle in SAP97-GK zu identifizieren. Dazu wurde das Protein nun mit unterschiedlichen Nukleotidpaaren (beide Nukleotide lagen gleichzeitig in der 
Lösung vor) für 5 Minuten bei RT inkubiert. Es wurden folgende Nukleotidpaare getestet: ATP/GMP, ATP/AMP und GTP/GMP. Für die Nukleotidbindungsstudien wurden jeweils 10 $\mu \mathrm{M}$ des Proteins, $5 \mu \mathrm{M}$ des Nukleosid-Triphosphats und $20 \mu \mathrm{M}$ des Nukleosid-Monophosphats eingesetzt. In dem Massenspektrum mit ATP/AMP (siehe Abb. 4.42 B) war neben dem Ligandfreien SAP97-GK-Peak und dem $\mathrm{SO}_{4}{ }^{2-}$-Komplex-Peak nur ein zusätzlicher, dem Komplex aus SAP97-GK und ATP entsprechender, Peak erkennbar. In den beiden Massenspektren mit ATP/GMP (siehe Abb. 4.42 A) und GTP/GMP (siehe Abb. 4.42 C) waren alle Peaks der zuvor bereits in den Einzel-Bindungsstudien (siehe 4.2.3.1) identifizierten GMP- und ATP- bzw. GTP-Komplexe in übereinstimmender Intensität nachweisbar.
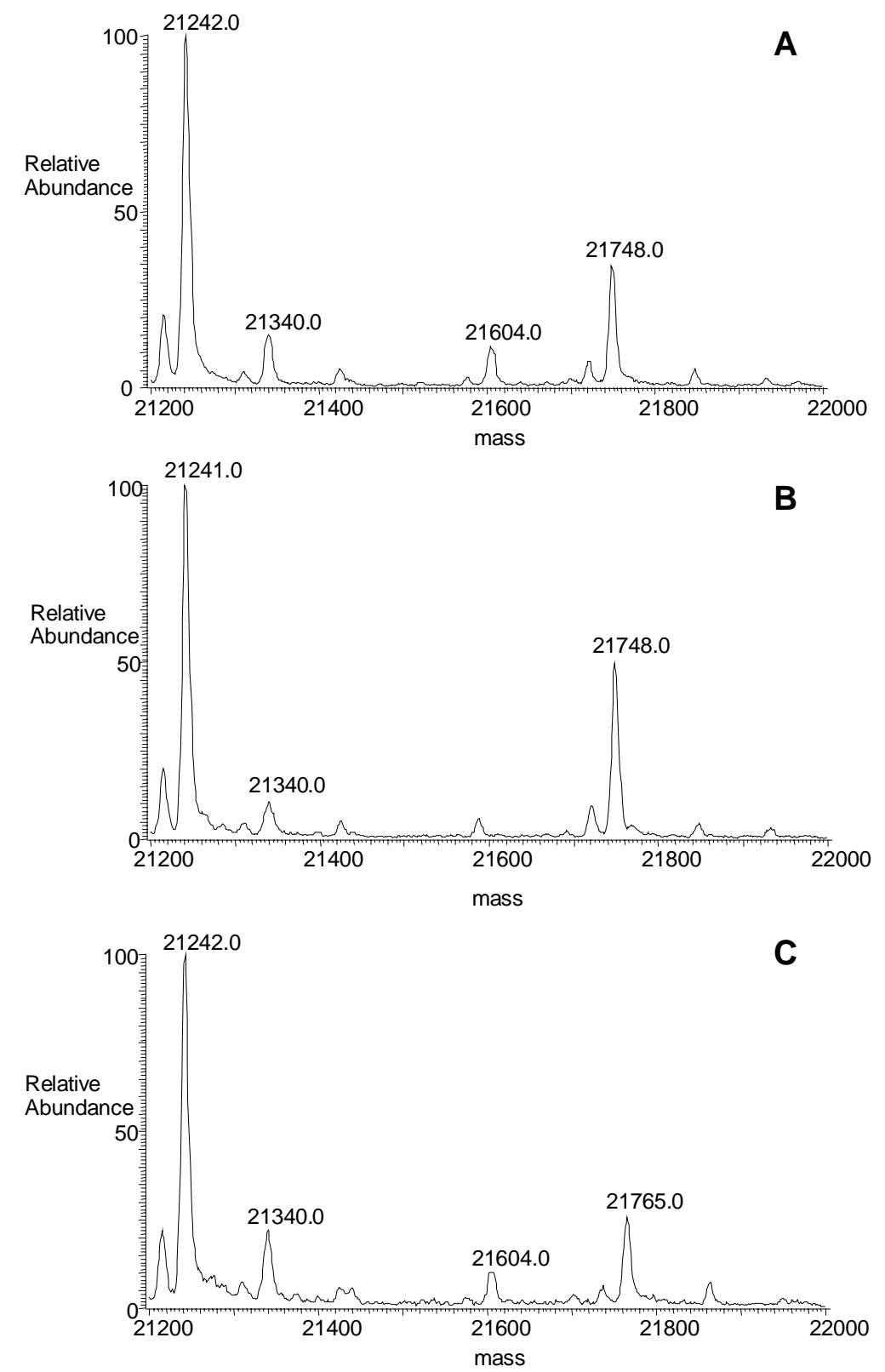

Abb. 4.42 Nano-ES-Massenspektren von SAP97-GK nach Inkubation für 5 Minuten mit $5 \mu \mathrm{M}$ ATP und $20 \mu \mathrm{M}$ GMP $(A)$, mit $5 \mu \mathrm{M}$ ATP und $20 \mu \mathrm{M}$ AMP $(B)$ und $5 \mu \mathrm{M}$ GTP und $20 \mu \mathrm{M}$ GMP $(C)$. Die Peaks entsprechen SAP97-GK (21242), SAP97-GK·SO ${ }_{4}^{2-}$ (21340), SAP97-GK·GMP (21604), SAP97-GK·ATP (21748), SAP97GK·GTP (21765). 
Zusätzliche, z.B. den Komplexen SAP97-GK·GDP bzw. SAP97-GK·ADP entsprechende Peaks, welche auf eine enzymatische Aktivität der GK-homologen Domäne hätten schließen lassen können, traten auch nach ausgedehnter Inkubationszeit (bis zu 1 h) nicht auf. Darüberhinaus war in beiden Ansätzen ein ternärer Komplex, resultierend aus der Bindung beider Substrate, also ATP und GMP bzw. GTP und GMP an das Protein nicht eindeutig detektierbar. Die Ergebnisse der Bindungsstudie mit Nukleotidpaaren deuten daraufhin, daß sowohl ATP und GTP, als auch GMP die gleiche Bindungsstelle in dem Protein SAP97-GK einnehmen. Aus der Bildung von Nukleotid-Komplexen mit allen getesteten Guanosin-Nukleotiden nicht jedoch mit allen Adenosin-Nukleotiden (kein AMP, cAMP) kann auf eine selektive Affinität der GKDomäne zum Guaninring geschlossen werden.

In den zuvor dargestellten Spektren zur Nukleotidbindung von Proteinen fällt auf, daß die Intensität der Komplex-Peaks in der Reihenfolge vom Monophosphat, über das Diphosphat zum Triphosphat zunimmt. Dieser Effekt beruht vermutlich auf der unterschiedlichen Ionisierung. Unter nicht standardisierten Bedingungen gibt folglich die Intensität eines Protein-Ligand-Peaks nicht die tatsächliche Konzentration des Komplexes in der Suspension wieder. Zur quantitativen Untersuchung der Nukleotibindung an die GK-homologen Domänen von SAP97 und hCASK mußten deshalb andere Methoden eingesetzt werden.

\subsubsection{Bestimmung der Dissoziationskonstanten für die Nukleotid-Bindung an SAP97-GK und hCASK-GK}

Die Dissoziationskonstanten von SAP97-GK und hCASK-GK für die unter Punkt 4.2.3.1 getesteten Nukleotide wurden mit den zwei unterschiedlichen Methoden des NitrozelluloseFilter-Assays und der Gleichgewichtsdialyse bestimmt. Ebenso wie der Filter-Assay ist auch die Gleichgewichtsdialyse eine direkte Methode zur Bestimmung von Bindungsparametern. Gegenüber dem Filter-Assay besitzt sie jedoch den Vorteil, daß mit ihr Protein-NukleotidKomplexe in Lösung detektiert werden können. Eine mögliche, das Meßergebnis beeinflußende, Interaktion mit der Oberfläche einer festen Phase, z.B. jener des NitrozelluloseFilters, ist folglich auszuschließen. Zum Vergleich der beiden Methoden untereinander, aber auch mit den Ergebnissen der Nano-ES-Massenspektrometrie (siehe 4.2.3.1) wurden die Experimente in niedrig-ionischen Puffer (20 mM Tris- $\mathrm{HCl}, \mathrm{pH} 7,5$, (100 mM KCl)) ohne $\mathrm{MgCl}_{2}$ durchgeführt. Für den Filter-Assay wurde Protein in einer Konzentration von 1 und $10 \mu \mathrm{M}$ eingesetzt. Die in der Gleichgewichtsdialyse eingesetzte Proteinkonzentration lag zwischen 1 und $5 \mu \mathrm{M}$. Während im Filter-Assay alle zuvor getesteten Nukleotide, also $\left[\alpha^{32} \mathrm{P}\right] \mathrm{GTP},\left[\alpha^{32} \mathrm{P}\right] \mathrm{ATP},\left[{ }^{3} \mathrm{H}\right] \mathrm{GMP},\left[{ }^{3} \mathrm{H}\right] \mathrm{AMP},\left[{ }^{3} \mathrm{H}\right] \mathrm{cGMP}$ und $\left[{ }^{3} \mathrm{H}\right] \mathrm{cAMP}$ eingesetzt wurden, 
beschränkte sich die Gleichgewichtsdialys auf die Nukleotide GMP, cGMP, GTP und ATP. Die Bindung der Nukleotide an SAP97-GK wurde zunächst qualitativ mit dem Filter-Assay bestimmt. Dazu wurden $10 \mu \mathrm{M}$ Protein mit 0,5 $\mu \mathrm{M}$ des jeweiligen Nukleotids inkubiert. Der Anteil des radioaktiv markierten Nukleotids lag im Fall der Nukleosid-Triphosphate $\left[\alpha^{32} \mathrm{P}\right]$ ATP und $\left[\alpha^{32} \mathrm{P}\right] \mathrm{GTP}$ bei $0,016 \mu \mathrm{M}$ (entspricht 1,25 $\mu \mathrm{Ci}$ ) und im Fall der Nukleosid-Monophosphate und cyclischen Monophosphate zwischen 0,3 ([ $\left.{ }^{3} \mathrm{H}\right] \mathrm{AMP},\left[{ }^{3} \mathrm{H}\right] \mathrm{cAMP}$ entspricht $\left.0,3 \mu \mathrm{Ci}\right)$ und 0,8 $\left(\left[{ }^{3} \mathrm{H}\right] \mathrm{cGMP}\right.$, entspricht $\left.0,12 \mu \mathrm{Ci}\right)$ bzw. $1\left(\left[{ }^{3} \mathrm{H}\right] \mathrm{GMP}\right.$, entspricht $\left.0,1 \mu \mathrm{Ci}\right) \mu \mathrm{M}$. Nach mindestens 15minütiger Inkubation wurde das freie Nukleotid von dem an das Protein gebundene getrennt und die Menge des gebundenen Nukleotids mit dem Szintillationszähler bestimmt. Eine signifikant über dem Hintergrund des Kontrollansatzes von Nukleotid ohne Protein liegende Radioaktivität konnte nur in den Probeansätzen mit GTP und GMP nachgewiesen werden. Aus der Differenz der Radioaktivität des ungewaschenen und gewaschenen Filters konnte der Anteil des gebundenen Nukleotids an der Gesamtkonzentration des eingesetzten Nukleotids errechnet werden. Dieser Wert lag bei 7 (GTP) bzw. 10\% (GMP) d. h. von den eingesetzten 0,5 $\mu \mathrm{M}$ Nukleotid wurden nur $0,05 \mu \mathrm{M}$ gebunden.

Aufgrund der genannten Vorteile wurde zur Bestimmung der Bindungsparameter von SAP97GK und hCASK-GK die Methode der Gleichgewichtsdialyse angewandt. In Abbildung 4.43 sind als Beispiel die Bindungskurven zur Bestimmung der Dissoziationskonstanten $\left(K_{\mathrm{d}}\right)$ von SAP97-GK $(A)$ und hCASK-GK $(B)$ für die Nukleotide GTP und GMP dargestellt. Die Dissoziationskonstante von SAP97-GK für GTP betrug 0,5 $\pm 0,1 \mu \mathrm{M}$ und jene von hCASK-GK für GMP 0,3 $\pm 0,1 \mu \mathrm{M}$ (siehe Abb. $4.43 B$ ).
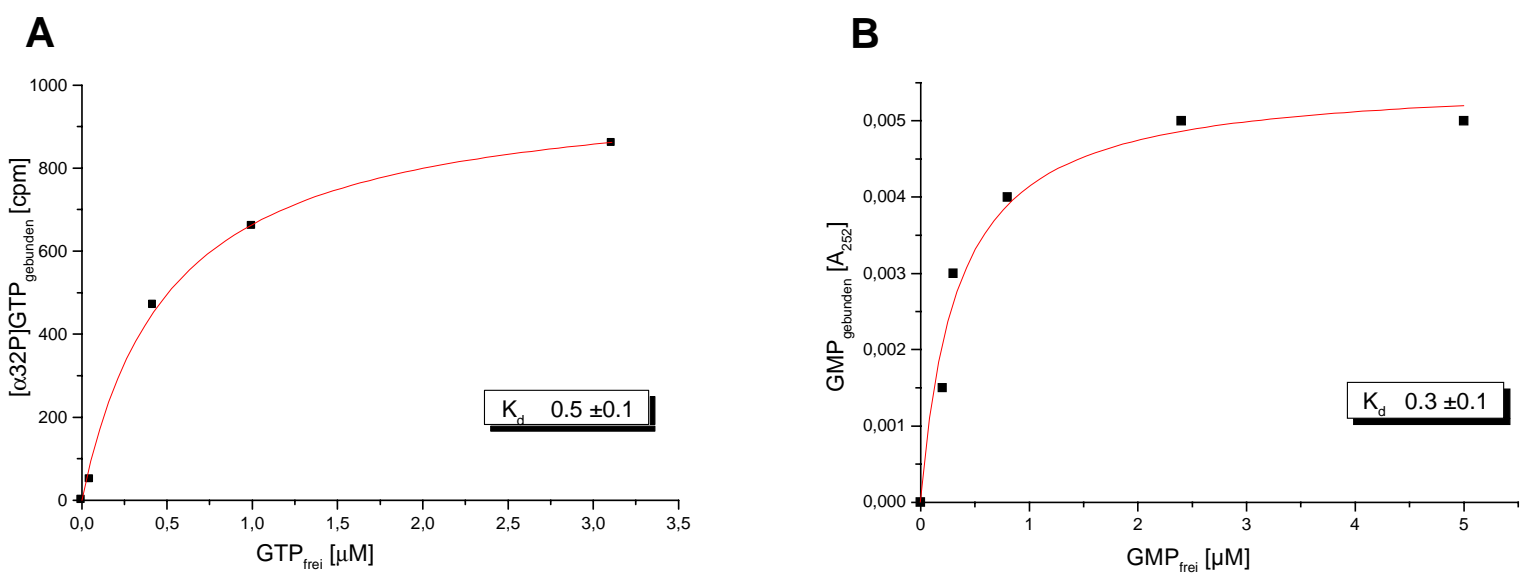

Abb. 4.43 Bindung von GTP an SAP97-GK $(A)$ und GMP an hCASK-GK $(B)$. Die Bindung wurde mit der Gleichgewichtsdialyse gemessen. $A$, Bindung von radioaktiv markierten $\left[\alpha^{32}\right.$ PGTP] an SAP97-GK; $B$, Bindung von GMP an hCASK-GK. Die Proteine wurden in Konzentrationen von $1 \mu \mathrm{M}$ eingesetzt. 
Im Gegensatz zu dem Ergebnis des Filter-Assays konnte mit der Gleichgewichtsdialyse neben der Bindung von GMP auch die Bindung von cGMP an SAP97-GK und hCASK-GK nachgewiesen werden. Daneben wurde durch Gleichgewichtsdialyse in einem radioaktiven Ansatz auch die Bindung von GTP an SAP97-GK nachgewiesen. Die Dissoziationskonstante der cGMP-Bindung war im Vergleich zur GMP-Bindung für beide Proteine um den Faktor 10 erhöht. Eine Bindung von ATP konnte mit beiden Methoden weder für SAP97-GK noch für hCASK-GK nachgewiesen werden. Die mit der Gleichgewichtsdialyse bestimmte Dissoziationskonstante für ATP $\left(K_{\mathrm{d}(\mathrm{ATP})}\right)$ lag für beide Proteine über $10 \mathrm{mM}$. Unter der Voraussetzung, daß die in Geweben von Säugern gemessenen ATP-Konzentrationen zwischen 2,6 (Rattenhirn) und 8,1 mM (Rattenmuskel) liegen (Lehninger, 1982), ist davon auszugehen, daß die GK-homologen Domänen der MAGUK-Proteine SAP97 und hCASK kein ATP binden. Die Tabelle 4.7 gibt eine Übersicht der mit der Gleichgewichtsdialyse ermittelten Bindungsparameter.

Die Bindungsstudien mit den zwei unabhängigen Methoden des Filter-Assays und der Gleichgewichtsdialyse bestätigen das Ergebnis der massenspektrometrischen Untersuchung nur zum Teil. Mit allen drei Methoden war eine Bindung von GMP und GTP an die GK-Domäne von SAP97 nachweisbar. Die Bindung von cGMP an SAP97-GK wurde hingegen nur mit der Gleichgewichtsdialyse, nicht jedoch mit dem Filter-Assay nachgewiesen. Der mit der Nano-ESMassenspektrometrie detektierte Komplex aus SAP97-GK und ATP konnte mit keiner der beiden Methoden verifiziert werden.

Tab. 4.7 Nukleotid-Bindungsparameter der GK-Domänen von SAP97 und hCASK

\begin{tabular}{lcccc}
\hline & \multicolumn{3}{c}{$K_{\mathrm{d}}$} \\
\hline GK-Domäne & GMP & cGMP & GTP & ATP \\
& {$[\mu \mathrm{M}]$} & {$[\mu \mathrm{M}]$} & {$[\mu \mathrm{M}]$} & {$[\mathbf{m M}]$} \\
SAP97-GK & $<0,1$ & 3,0 & $0,5 \pm 0,1$ & $>10$ \\
hCASK-GK & $0,3 \pm 0,1$ & 0,4 & n.b. & $>10$ \\
\hline
\end{tabular}

n.b., nicht bestimmt

Das heterogene Ergebnis der Bindungsstudien reflektiert die Empfindlichkeit der einzelnen Methoden zur Detektion einer Protein-Nukleotid-Komplexbildung. Mit dem Filter-Assay können nur sehr starke Bindungen (mit Dissoziationskonstanten im unteren nanomolaren bis 
picomolaren Bereich) nachgewiesen werden. Er ist deshalb im Vergleich zur Gleichgewichtsdialyse und Nano-ES-Massenspektrometrie die unempfindlichste Methode zur Detektion einer Nukleotid-Bindung. Die mit der Methode der Gleichgewichtsdialyse bestimmte Dissoziationskonstante von 3,0 für die Bindung von cGMP an SAP97-GK ist anscheinend zu schwach, um mit dem Filter-Assays nachgewiesen werden zu können. Im Vergleich zu allen getesteten Nukleotiden binden beide GK-Domänen das Nukleosid-Monophosphat GMP mit Dissoziationskonstanten von 0,1 - 0,3 $\mu \mathrm{M}$ am stärksten. Der Wert liegt an der Nachweisgrenze der mit der Methode der Gleichgewichtsdialyse bestimmbaren Bindungsintensität mit nichradioaktiven Nukleotiden; es ist folglich durchaus möglich, daß die Bindungskonstante noch kleiner ist. Die mit dem Filter-Assay detektierte schwache Bindung von GMP spricht dem allerdings entgegen. Dennoch deuten die Ergebnisse des Filter-Assays und der Gleichgewichtsdialyse in ihrer Gesamtheit daraufhin, daß die Affinität der GK-Domäne von SAP97 zu den getesteten Nukleotiden in der folgenden Reihenfolge abnimmt: GMP > GTP > cGMP.

\subsection{Intramolekulare Interaktion zwischen SH3 und GK in SAP97}

\subsubsection{Konstruktion eines Sensormoleküls}

Die lineare Anordnung der einzelnen Domänen ist ein auffälliges Merkmal aller Mitglieder der Familie Membran-assoziierter Guanylatkinasen. Sie deutet daraufhin, daß die Lokalisation der einzelnen Domänen eine wichtige Rolle für die Funktion der Proteine spielt. Insbesondere die direkte Nachbarschaft der SH3-Domäne zu der nachfolgenden Kinase-Domäne ist ein bekanntes strukturelles Motiv einiger Signalproteine. In Tyrosinkinasen der Src-Familie (Brown und Cooper, 1996) bindet die SH3-Domäne im Zusammenspiel mit einer SH2-Domäne an die nachfolgende Kinase-Domäne und inhibiert deren Aktivität (Moarefi et al., 1997; Sicheri et al., 1997; Xu et al., 1997). In Analogie zur Funktion der Src-Tyrosinkinasen war es denkbar, daß auch in MAGUK-Proteinen die Funktion der GK-Domäne (hier: die Interaktion mit Proteinpartnern in trans) durch eine intramolekulare Interaktion zwischen der SH3/U5- und der GK-Domäne bzw. die GK-Domäne umgebenden Sequenzen reguliert wird. Zum Zweck des Nachweises einer möglichen intramolekularen Interaktion wurde versucht durch Austausch der GK-Domäne in SAP97 gegen die authentische Guanylatkinase der Hefe (GUK1) ein Sensormolekül zu konstruieren. Es ist bekannt, daß das Enzym GUK1 nach Bindung der Substrate ATP und GMP eine starke Umlagerung vollzieht (Stehle und Schulz, 1992). Vorausgesetzt, daß die SH3-Domäne mit dem C-Terminus von SAP97 interagiert, sollte nach 
unseren Überlegungen diese flexible Konformationsänderung innerhalb des GUK1-Moleküls im günstigsten Fall nicht oder nur noch eingeschränkt möglich sein. Diese Inhibition könnte dann durch einen Abfall der enzymatischen Aktivität dokumentiert werden. Zur Konstruktion des Sensormoleküls wurde sich nur auf den die Domänen SH3 und GK umfassenden C-terminalen Teil des MAGUK-Proteins SAP97 beschränkt.
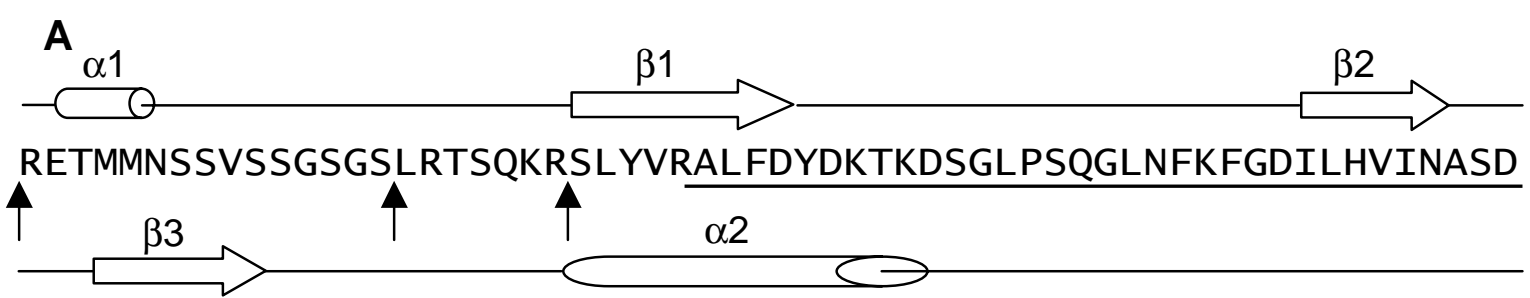

DEWWQARQVTPDGESDEVGVIPSKRRVEKKERARLKTVKFNSKTRGDKGEIPDDMGSKGL

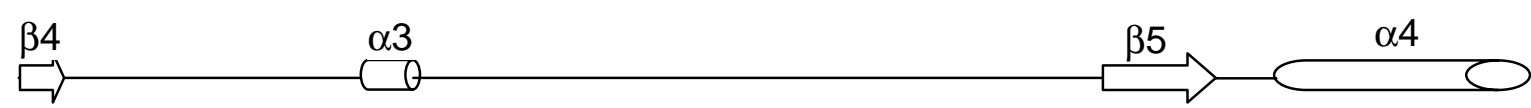

KHVTSNASDSESSYHEYGCSKGGQEEYVLSYEPVNQQEVNYTRPVIILGPMKDRVNDDLI

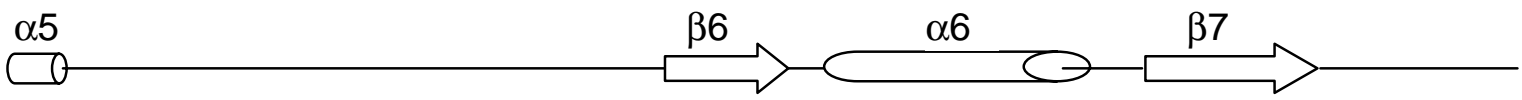

SEFPDKFGSCVPHTTRPKRDYEVDGRDYHFVTSREQMEKDIQEHKFIEAGQYNNHLYGTS

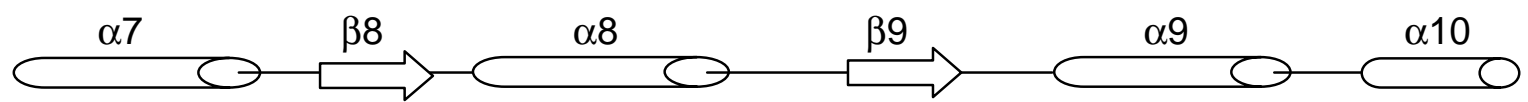

VQSVRAVAEKGKHCILDVSGNAIKRLQIAQLYPISIFIKPKSMENIMEMNKRLTDEQARK

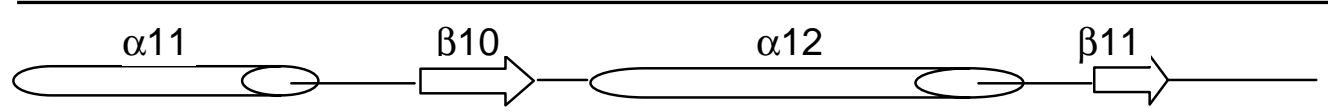

TFERAVRLEQEFTEHFTAIVQGDTLEDIYNQVKQIIEEQSGPYIWVPAKEKL

B

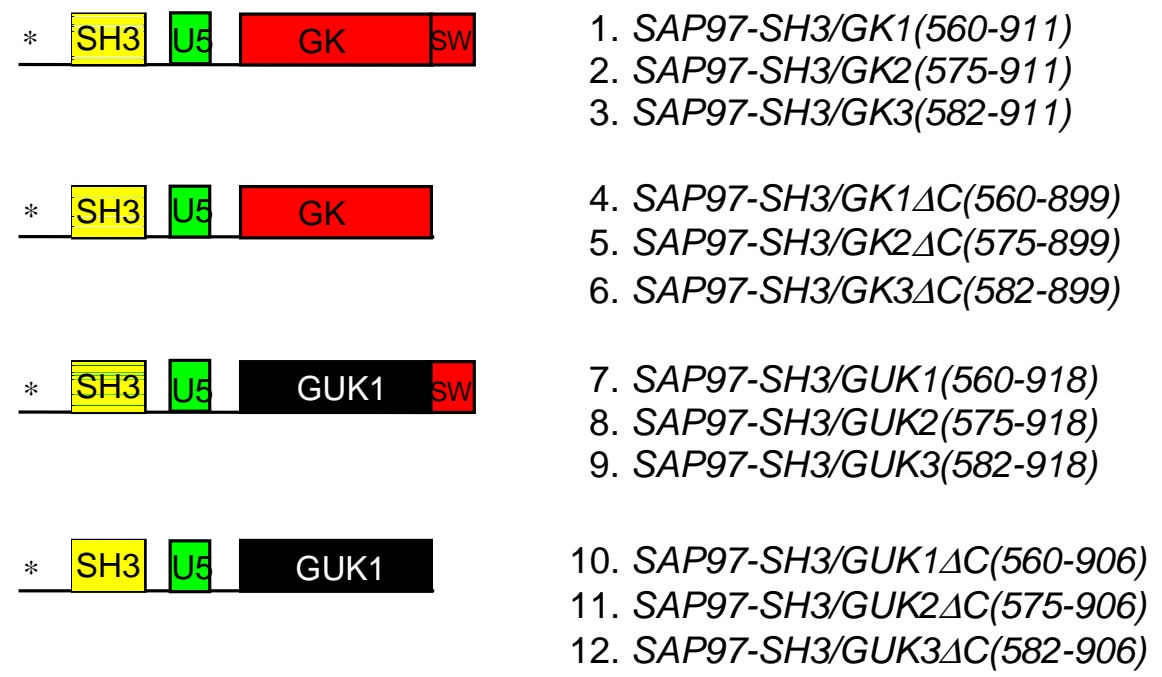

Abb. 4.44 Auf Grundlage der Sekundärstruktur $(A)$ von SAP97-SH3/GK1(560-911) hergestellte SH3/GKFusionskonstrukte $(B)$. A; Sekundärstruktur von SAP97-SH3/GK1(560-911) (Programm PHD). Die SH3-Domäne ist einfach und die GK-Domäne doppelt unterstrichen. Abkürzungen: $\alpha, \alpha$-Helix; $\beta, \beta$-Faltblatt. $B$, In der ersten Spalte ist das Schema der verschiedenen Konstruktklassen mit allen Domänen (SH3, U5 und GK bzw. GUK1 für die Chimären) abgebildet. Für jede Klasse wurden drei unterschiedliche Konstrukte mit variablen N-Termini (*) hergestellt. sw, letzte 12 Aminosäuren aus SAP97. Die Pfeile in A zeigen den Beginn der 3 Konstrukte an. 
Es wurden unterschiedliche Konstrukte hergestellt, wobei sich die Wahl des Beginns des jeweiligen SH3-GK-Konstrukts nach veröffentlichten Kristallstrukturen der SH3-Domäne sowie Sekundärstruktur-Vorhersagen richtete. Die SH3-Domäne in der SAP97-Sequenz beginnt an Position 587 und endet an Position $645\left({ }^{587}\right.$ ALFDY.....PSKRR $\left.{ }^{645}\right)($ siehe Abb. 4.44 A).

In der Literatur sind bisher mehrere Kristallstrukturen von Src-Tyrosinkinasen beschrieben worden; der Beginn der zugrundeliegenden Polypeptidketten lag jeweils 3 bis 20 Aminosäuren vor der SH3-Domäne (Yu et al., 1994; Musacchio et al., 1992; Koyama et al., 1993). Laut Sekundärstrukturvorhersage bildet die Aminosäurensequenz von Position 560 bis 574 einen Loop aus. Direkt an diesen Loop schließt sich ein $\beta$-Faltblatt an (siehe Abb. 4.44 A). Für den Beginn der Konstrukte wurden die Positionen Arg560, Leu575 und Ser582 (die erste Aminosäure des $\beta$-Faltblatts) (siehe Abb. 4.44 A) ausgewählt. Im Einzelnen wurden 12 native und chimäre Konstrukte hergestellt (siehe Abb. 4.44 B). Neben den vollständigen wurden jeweils um 12 AS am C-Terminus verkürzte Konstrukte hergestellt. Diese C-terminale Verkürzung ist von physiologischer Bedeutung. In dem SAP97-Homologen Dlg aus Drosophila hat die entsprechende Deletion der gesamten C-terminalen Sequenz, direkt hinter der GKDomäne, einen Verlust der Proliferisationskontrolle einhergehend mit Ausbildung von Tumoren an den Imaginalscheiben sowie undifferenzierte neuromuskuläre Verbindungen zur Folge. Die Mutante mit diesem Tumor-Phänotyp wird als $d l g^{s w}$ bezeichnet ( $s w$ steht für $\underline{\text { swivelled-willie) }}$ (Woods und Bryant, 1991; Woods et al., 1996). Alle Konstrukte wurden durch PCRAmplifikation hergestellt.

Ausgangskonstrukt für alle weiteren nativen SAP97-SH3/GK-Fragmente war SAP97SH3/GK1(560-911) (siehe Abb. 4.44 B, Konstrukt Nr. 1). Als Template zur Konstruktion von SAP97-SH3/GK1(560-911) fungierte das Plasmid pBluescriptKSII(+)-SAP97. Da die SAP97Sequenz noch die interne BamHI-Schnittstelle besaß, mußte das Fragment in 2 PCR-Schritten durch „Overlap-Extension“-PCR hergestellt werden. Der N-Terminus wurde mit den spezifischen Oligonukleotid-Primern OSP110 und OSP5, der C-Terminus mit den spezifischen Primern OSP4 und OSP115 amplifiziert. Die beiden terminalen Sequenzen wurden anschließend in einer zweiten PCR mit den spezifischen endständigen Primern OSP110 und OSP115 zu dem Konstrukt Nr. 1 vereinigt. Das DNA-Fragment wurde dann über die Schnittstellen NdeI/BamHI in den Vektor pGEX-RB kloniert. Das Plasmid pGEX-RB-SAP97SH3/GK1(560-911) fungierte nun als Template zur Amplifikation der Konstrukte Nr. 2 bis 6. Die Fragmente SAP97-SH3/GK2(575-911) (siehe Abb. 4.44 B, Konstrukt Nr. 2) und SAP97SH3/GK3(582-911) (Nr. 3) wurden mit den spezifischen Oligonukleotid-Primern 
OSP111/OSP115 bzw. OSP112/OSP115 amplifiziert. Die deletierten Konstrukte SAP97SH3/GK1 $\triangle C(560-899) \quad$ (Nr. 4), SAP97-SH3/GK2 $\triangle C(575-899) \quad$ (Nr. 5), SAP97SH3/GK3 $\Delta C(582-899)$ (Nr. 6) wurden mit den spezifischen Primern OSP110/OSP25, OSP111/OSP25 und OSP112/OSP25 hergestellt. Zur Amplifikation des Ausgangskonstrukts SAP97-SH3/GUK1(560-918) (siehe Abb. 4.44 B, Konstrukt Nr. 7) zur Herstellung der chimeren Fragmente wurde ebenfalls die Methode der „Overlap-Extension“-PCR eingesetzt. Der Nterminale Megaprimer wurde mit den spezifischen Oligonukleotiden OSP110 und OSP114 sowie mit dem Template pBluescriptKSII(+)-SAP97, der C-terminale Megaprimer mit den spezifischen Oligonukleotiden OSP113 und OSP 115 sowie mit dem Template pGEX-RB$G U K 1^{s w}$ hergestellt. In einem zweiten PCR-Schritt wurden die beiden Megaprimer dann mit Hilfe der endständigen Oligonukleotide OSP110 und OSP115 zu dem Konstrukt Nr. 7 vereinigt. Dieses wurde anschließend über die Schnittstellen NdeI/BamHI in den Vektor pGEX-RB kloniert. Das Plasmid pGEX-RB-SAP97-SH3/GUK1(560-918) fungierte nun wiederum als Template zur Konstruktion der weiteren Chimären Nr. 8 bis 12. Die Fragmente SAP97SH3/GUK2(575-918) (Nr. 8) und SAP97-SH3/GUK3(582-918) (Nr. 9) wurden mit den spezifischen Oligonukleotid-Primern OSP111/OSP115 bzw. OSP112/OSP115 und die deletierten Konstrukte SAP97-SH3/GUK1 $\triangle C(560-906)$ (Nr. 10), SAP97-SH3/GUK2 $\Delta C(575-$ 906) (Nr. 11), SAP97-SH3/GK3 $\triangle C(582-906)$ (Nr. 12) mit den spezifischen Primern OSP110/OSP117, OSP111/OSP117 und OSP112/OSP117 amplifiziert.

\subsubsection{Biochemische Charakterisierung von SAP97-SH3/GK und SAP97-SH3/GUK}

Die 12 Fusionsproteine wurden nach Induktion mit $1 \mathrm{mM}$ IPTG für 6 bis 8 Stunden bei $37^{\circ} \mathrm{C}$ bzw. alternativ über Nacht bei $25^{\circ} \mathrm{C}$ in E. coli BL21(DE3) überexprimiert. Obwohl sich alle rekombinanten Proteine gut in E. coli überexprimieren ließen, ergab eine analytische Aufreinigung in kleinem Kultur-Maßstab, daß sie nur zum Teil löslich waren. Tabelle 4.8 zeigt eine Übersicht der Löslichkeit der unterschiedlichen nativen und chimären Fusionsproteine.

Tab. 4.8 Löslichkeit von SH3/GK- bzw. SH3/GUK-Fusionskonstrukten

\begin{tabular}{cccc}
\hline Nr & Konstrukte & Expression & Löslichkeit \\
\hline 1 & GST-SH3/GK1(560-911) & +++ & - \\
2 & GST-SH3/GK2(575-911) & +++ & +++ \\
3 & GST-SH3/GK3(582-911) & +++ & +++ \\
\hline
\end{tabular}




\begin{tabular}{|c|c|c|c|}
\hline 4 & GST-SH3/GK1 $\Delta \mathrm{C}(560-899)$ & +++ & - \\
\hline 5 & GST-SH3/GK2 CC(575-899) & +++ & - \\
\hline 6 & GST-SH3/GK3 CC(582-899) & +++ & - \\
\hline 7 & GST-SH3/GUK1(560-918) & +++ & $(+)$ \\
\hline 8 & GST-SH3/GUK2(575-918) & +++ & +++ \\
\hline 9 & GST-SH3/GUK3(582-918) & +++ & +++ \\
\hline 10 & GST-SH3/GUK1 $1 \Delta$ (560-906) & +++ & - \\
\hline 11 & GST-SH3/GUK2 $\Delta \mathrm{C}(575-906)$ & +++ & + \\
\hline 12 & GST-SH3/GUK3 $\Delta$ C(582-906) & +++ & + \\
\hline
\end{tabular}

Es fällt auf, daß insbesondere die chimären SH3/GUK-Konstrukte (Nr. 10 - 12) sowie die nativen SH3/GK-Konstrukte (Nr. 4 - 6), in denen die C-terminale Sequenz fehlte, unter nativen Bedingungen nur sehr schlecht, im letzteren Fall sogar überhaupt nicht löslich waren.

A

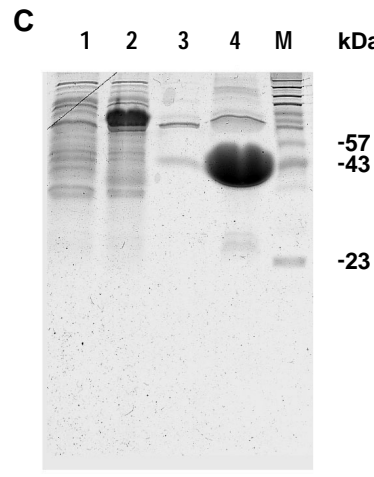

E

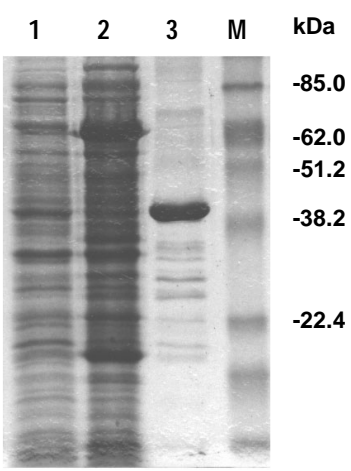

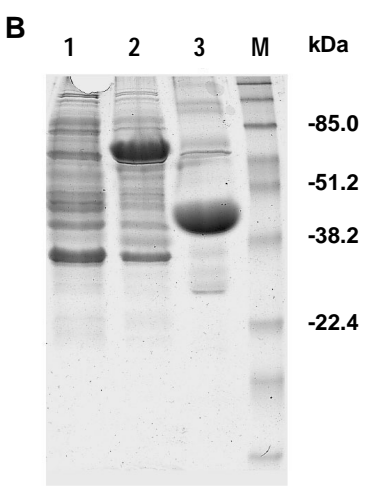

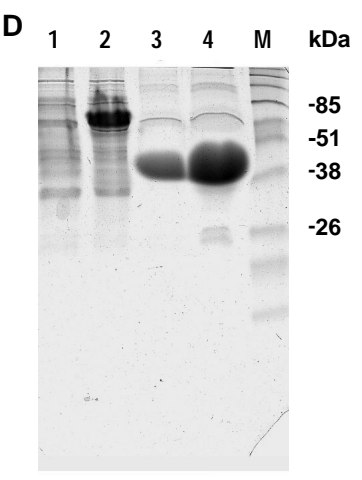

$\mathbf{F}$

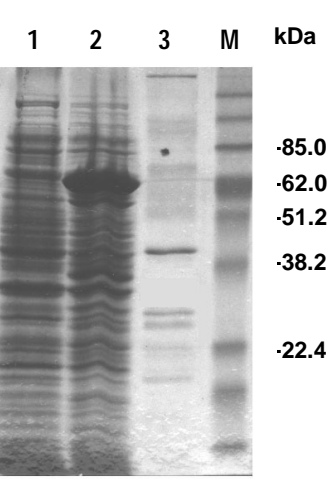

Abb. 4.45 Aufreinigung von SAP97SH3/GK2 (A), SAP97-SH3/GK3 (B), SAP97-SH3/GUK2 $(C), \quad$ SAP97SH3/GUK3 (D), SAP97-SH3/GUK2 $\Delta \mathrm{C}$ $(E)$ und SAP97-SH3/GUK3 $\Delta \mathrm{C}(F)$ nach Expression in E. coli. Proteinproben (jeweils 5-10 $\mu \mathrm{l}$ ) der einzelnen Expressions- und Reinigungsschritte wurden in einem 12\%igen SDSPolyacrylamid-Gel elektrophoretisch aufgetrennt und die Proteine durch Coomassie-Brilliantblau R250 angefärbt. Spur 1, E. coli-Zellysat vor Induktion; Spur 2, E. coli-Zellysat nach 6stündiger Induktion bei $37^{\circ} \mathrm{C}$; Spuren 3 und 4, nach Thrombin-Verdau eluiertes Protein; $M$, Molekulargewichtsmarker (in $\mathrm{kDa}$ ). 
Die drei Konstrukte Nr. 4 bis 6 bildeten ausnahmslos unter den gewählten Bedingungen nach Überexpression in E. coli Einschlußkörper. Die Konstrukte Nr. 11 und 12, sowie Nr. 2, 3, 8 und 9 wurden affinitätschromatographisch über eine GST-Sepharose 4B-Säule in präparativen Maßstab aufgereinigt und nach Thrombinverdau von der Säule eluiert. Die nativen und die chimären Konstrukte Nr. 2, 3, 8 und 9 (siehe Abb. 4.45 A, B, C und D, Spuren 3 und 4) konnten im Vergleich zu den C-terminal deletierten Konstrukten Nr. 11 und 12 (siehe Abb. $4.45 E$ und F, Spur 3) in höherer Homogenität und Ausbeute isoliert werden. Die Ergebnisse der Löslichkeitsstudie deuten daraufhin, daß einerseits der N-terminale Loop (Aminosäuren 560 bis 574) einen störenden Einfluß auf die Löslichkeit aller getesteten Konstrukte hat, sich andererseits jedoch auch das Fehlen der letzten 12 Aminosäuren negativ auf die Löslichkeit der Proteine auswirkt. Der Austausch der GK-Domäne gegen die authentische Guanylatkinase GUK1 scheint diesen Effekt in den C-terminal deletierten Konstrukten jedoch zum Teil aufzuheben. Zur weiteren Untersuchung des Einflußes der die GUK1 umgebenden Sequenzen also die SH3/U5-Domäne sowie die C-terminale Sequenz $s w$ - wurden die enzymatischen Aktivitäten der 6 aufgereinigten Proteine bestimmt.

\subsubsection{Katalytische Aktivität von SAP97-SH3/GK und SAP97-SH3/GUK}

Die N-terminale Fusion der SH3-Domäne an die Hefe-GUK1 führte zu einer dramatischen Abnahme der Guanylatkinase-Aktivität. Die Aktivität der Konstrukte SAP97-SH3/GUK2(575918) (8,7 U/mg) und SAP97-SH3/GUK3(582-918) (9,0 U/mg) betrug nur noch 3\% der katalytischen Wild-Typ-Aktivität (300 U/mg). Interessanterweise scheinen die letzten 12 Aminosäuren eine wichtige Rolle zu spielen, denn die C-terminal verkürzten Konstrukte SAP97-SH3/GUK2 $\Delta \mathrm{C}(575-906)$ und SAP97-SH3/GUK3 $\Delta \mathrm{C}(582-906)$ zeigten ebensowenig eine signifikante Abnahme der Wild-Typ-Aktivität wie GUK1 ${ }^{\text {sw }}$. Die Konstrukte 2 und 3 waren erwartungsgemäß katalytisch inaktiv. Abbildung 4.46 gibt einen Überblick der spezifischen Aktivitäten aller getesteten Konstrukte.

Die Abnahme der Guanylatkinase-Aktivität könnte mit einer intramolekularen Wechselwirkung zwischen der SH3/U5-Domäne und GUK $1^{\text {sw }}$ in den Konstrukten Nr. 8 und 9 erklärt werden. Die Hypothese einer intramolekularen Interaktion von SH3- und GK-Domäne wurde in zwei kürzlich erschienen Arbeiten (McGee und Bredt, 1999; Shin et al., 2000) in dem Synapsenassoziierten Protein SAP90 bestätigt. Shin et al. (2000) wiesen darüberhinaus nach, daß diese Wechselwirkung mit der GK-Domäne nicht über das klassische Bindungsmotiv PXXP (minimale Consensussequenz zur Bindung von SH3-Domänen in Tyrosinkinasen) verläuft. Die 
hier erhaltenen Resultate zeigen eindeutig, daß an der intramolekulare Wechselwirkung in SAP97 die GK-Domäne umgebende Sequenzen beteiligt sind.

\section{Konstrukt}

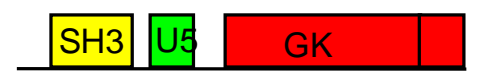

GUK1

\begin{tabular}{llll}
\hline $\mathrm{SH} 3$ & U5 & GUK1 \\
\hline & \\
$\mathrm{SH} 3$ & U5 & GUK1 & $\mathrm{sW}$ \\
\hline
\end{tabular}

GUK1

\section{Spezifische Aktivität \\ [U/mg]}

SAP97-SH3/GK2

SAP97-SH3/GK3

$<0,1$

$<0,1$

240,0

278,0

295,0

SAP97-SH3/GUK3 $\Delta C$

SAP97-SH3/GUK2

SAP97-SH3/GUK3

8,7

9,0

300,0

\begin{abstract}
Abb. 4.46 Einfluß der N- und C-terminalen Sequenzen von SAP97 auf die enzymatische Aktivität der GUK1. Die rekombinanten Proteine wurden aus E. coli aufgereinigt und im spektrophotometrischen Assay auf GuanylatkinaseAktivität überprüft. Die spezifischen Aktivitäten von Wild-Typ SAP97-SH3/GK und den Chimären GUK1 $1^{\text {sw }}$, SAP97-SH3/GUK $\Delta$ C und SAP97-SH3/GUK sind angezeigt. Die Aktivität der Hefe-GUK1 wurde zum Vergleich bestimmt.
\end{abstract}

Die weiteren Schritte dieser Arbeit konzentrierten sich auf die biophysikalischen Eigenschaften der intramolekularen Interaktion in SAP97. Das nächste Ziel war herauszufinden, ob möglicherweise durch Bindung von Purin-Nukleotiden an die GK-Domäne die intramolekulare Wechselwirkung in SAP97 moduliert und eine offene oder geschlossene Konformation des Moleküls begünstigt wird. Diese Konformationsänderung innerhalb des Moleküls hätte dann vermutlich direkte Auswirkungen auf die intermolekulare Interaktion mit den spezifischen Bindungspartnern der SH3- und GK-Domäne. Es war demzufolge denkbar, daß durch Bindung eines Effektormoleküls, z.B. GMP, Bindungsregionen auf beiden Domänen wieder zugänglich waren und eine Selbst-Assoziation von 2 oder mehr SH3-GK-Konstrukten in trans ermöglicht wurde. 


\subsubsection{Einfluß von Purin-Nukleotiden auf intramolekulare Interaktionen in SAP97}

\subsubsection{Assoziationsverhalten von SAP97-SH3/GK in Lösung}

\subsection{Gelfiltration}

Das Assoziationsverhalten ausgewählter SH3/GK- und SH3/GUK-Fusionskonstrukte wurde in Gegenwart der Purin-Nukleotide ATP und GMP untersucht. ATP und GMP sind die natürlichen Substrate der aktiven Guanylatkinasen. In der zuvor mit den Methode der Nano-ESMassenspektrometrie und Gleichgewichtsdialyse durchgeführten Bindungsstudien wurde GMP als Ligand identifiziert, welcher mit hoher Affinität $\left(K_{\mathrm{d}}<0,1 \mu \mathrm{M}\right)$ an die GK-homologe Domäne von SAP97 bindet. Im Gegensatz zu GMP konnte mit der Gleichgewichtsdialyse keine Bindung von ATP an die GK-Domäne nachgewiesen werden. Eine möglicher Effekt von ATP wäre, wenn überhaupt nur in den chimären Fusionsproteinen zu beobachten. Zum Nachweis der Induktion einer Oligomerisation in dem rekombinanten SAP97-SH3/GK2(575-911) (Nr. 2) durch die ausgewählten Purin-Nukleotide wurde das Konstrukt nach Isolierung aus E. coli zunächst in einem zweiten Schritt durch Gelfiltration über eine PD10-Säule (Pharmacia) gereinigt. Der Oligomerisierungszustand des Moleküls in PBS-Puffer, PBS-Puffer mit $100 \mu \mathrm{M}$ GMP und PBS-Puffer mit $100 \mu \mathrm{M}$ bzw. $1 \mathrm{mM}$ ATP wurde mit den zwei unabhängigen Methoden der Gelfiltration und der analytischen Ultrazentrifugation bestimmt. Zum Vergleich des nativen mit den chimären Proteinen sollte auch der Oligomerisierungszustand der Konstrukte SAP97-SH3/GUK2(575-918) (Nr. 8) und SAP97-SH3/GUK3 CC(582-906) (Nr.11) unter den gleichen Bedingungen bestimmt werden.

Das apparente Molekulargewicht der drei ausgewählten Proteine wurde zunächst durch Gelfiltration bestimmt. Nach Gelfiltration in PBS ( $\mathrm{pH} 7,3)$ über eine Superose 12-Säule eluierten die Proteine Nr. 2 und 8 als Proteinspezies mit Molekulargewichten von 34,3 (Nr. 2) und 32,7 kDa (Nr. 8). Neben diesem Hauptpeak zeigte nur das Elutionsprofil des Konstrukts Nr. 8 einen zweiten kleineren Peak einer Proteinspezies mit einem Molekulargewicht von 140,3 kDa. Die kleineren Molekulargewichte entsprachen in Etwa den kalkulierten Molekulargewichten der Monomere von 39,1 (Nr. 2) und 38,8 kDa (Nr. 8, siehe Tab. 4.9). Ein Molekulargewicht von 140,3 kDa deutet im Fall der Chimäre Nr. 8 auf die Bildung von Tetrameren hin. Im Gegensatz zu den Konstrukten Nr. 2 und 8 eluierte das C-terminal verkürzte Konstrukt (Nr. 12) in PBS-Puffer in einem sehr breiten Peak als Proteinspezies mit einem Molekulargewicht von 54,3 kDa kDa (siehe Tab. 4.9). Dieses Molekulargewicht lag zwischen 
dem kalkulierten Molekulargewicht des Monomers von 37,5 kDa und des Dimers von 75,0 kDa. Das erhöhte Molekulargewicht von Konstrukt Nr. 11 kann einerseits auf die Assoziation von 2 Molekülen SAP97-Sh3/GUK3 $\Delta \mathrm{C}(582-906)$ zu einem Dimer hindeuten, andererseits war es jedoch auch denkbar, daß das monomere Molekül im Vergleich zu den beiden anderen Konstrukten Nr. 2 und 8 eine weniger kompakte, sondern vielmehr ausgedehntere Gestalt einnahm und folglich früher von der Gelfiltrations-Säule eluierte. Das Auftreten vieler kleinerer Peaks insbesondere in den Elutions-Profilen der chimären Konstrukte Nr. 8 und 12 deutet auf eine große Anzahl von Abbauprodukten der Masse 12 bis $14 \mathrm{kDa}$ und $5 \mathrm{kDa}$ hin (siehe auch SDS-PAGE-Gele in Abb. 4.45).

Die durch Gelfiltration in PBS mit $100 \mu \mathrm{M}$ GMP bzw. $100 \mu \mathrm{M}$ ATP bestimmten Molekulargewichte von Konstrukt Nr. 2 wichen nur geringfügig von dem Molekulargewicht in PBS ab. In Gegenwart von $100 \mu \mathrm{M}$ ATP eluierte das Protein als Monomer mit einem Molekulargewicht von 31,4 und in Gegenwart von $100 \mu \mathrm{M}$ GMP als Monomer mit einem Molekulargewicht von 32,3. Anders verhielten sich die chimären Proteine. Konstrukt Nr. 8 eluierte ebenso wie in PBS auch in PBS mit $100 \mu \mathrm{M}$ GMP oder $100 \mu \mathrm{M}$ ATP als monomere Proteinspezies mit Molekulargewichten von 28,9 (GMP) und 32,6 (ATP) kDa. Zusätzlich traten im Elutionsprofil mit ATP ein schwacher Peak einer Proteinspezies von 132,5 kDa und im Elutionsprofil mit GMP zwei Peaks, welche Proteinspezies von 126,2 kDa und 65,4 kDa entsprachen, auf. Während das Auftreten der größeren Peaks auf die bereits in PBS beobachtete Bildung von Tetrameren hindeutet entspricht der Peak bei 65,4 kDa vermutlich der Bildung eines Dimers. Die Elutionsprofile der verkürzten Chimäre (Nr. 12) in Gegenwart von ATP und GMP weichen entscheidend von jenem in PBS allein ab. Neben den Peaks der monomeren Proteinspezies mit Molekulargewichten von 27,9 (GMP) und 29,9 (ATP) kDa treten zusätzliche Peaks von Tetrameren bei 129,2 (GMP) und 134,5 (ATP) kDa auf. Der in PBS beobachtete dominante Peak einer Spezies von 54,3 kDa ist in beiden Profilen nicht nachweisbar. Während die Gegenwart der Purin-Nukleotide den proteolytischen Abbau der Chimäre Nr. 8 zu inhibieren scheint, entspricht das Auftreten und die Menge an proteolytischen Abbauprodukten der verkürzten Chimäre in PBS mit GMP bzw. ATP jener in PBS allein.

Die Ergebnisse der Gelfiltration deuten daraufhin, daß SAP97-SH3/GK2(575-911) sowohl in PBS-Puffer, als auch in PBS-Puffer mit GMP bzw. ATP unter den vorgegebenen Bedingungen ausschließlich als Monomer vorliegt. Im Gegensatz dazu scheint der Austausch der GKDomäne gegen die authentische GUK1 in SAP97-SH3/GUK2(575-918) und SAP97SH3/GUK3 $\Delta \mathrm{C}(582-906)$ die Assoziation dieser Proteine zu Homotetrameren zu begünstigen. 
Die Chimäre SAP97-SH3/GUK2(575-918) liegt in PBS als Monomer im Gleichgewicht mit einem Tetramer vor. Während die Zugabe von ATP zu keiner Veränderung des Oligomerisierungsgrades führt, scheint GMP die Dimer-Bildung von SAP97-SH3/GUK2(575918) zu induzieren. Die Ergebnisse deuten ferner daraufhin, daß der C-Terminus den kompakten, monomeren Zustand der chimären Proteine stabilisiert. Wird er wie in SAP97SH3/GUK3 $\Delta$ C(582-906) entfernt, so eluiert das Protein als Dimer oder ausgedehnteres Monomer. Die Zugabe von ATP oder GMP führt wiederum zu dem Gleichgewicht aus Monomer und Tetramer. Dimere von SAP97-SH3/GUK3 $\Delta \mathrm{C}(582-906)$ lagen unter den gegebenen Bedingungen in Gegenwart der Purin-Nukleotide nicht vor.

Ein großer Nachteil bei der Bewertung von Gelfiltrations-Ergebnissen ist die Berücksichtigung von Adsorptionskräften mit der Matrix, die ein verändertes Migrationsverhalten des Makromoleküls zur Folge haben können. So kann beispielsweise die Elution eines Proteins als Spezies mit einem höheren als dem berechneten Molekulargewicht sowohl mit der Bildung von Oligomeren, als auch mit einer asymmetrischen Gestalt (und demzufolge einem größeren hydrodynamischen Radius) des Proteins erklärt werden. Aus diesem Grund wurde die Gleichgewichtszentrifugation als zweite Methode zur Bestimmung des Oligomerisierungsgrades der ausgewählten Fusionsproteine eingesetzt. Im Gegensatz zur Gelfiltration können mit der Gleichgewichtszentrifugation das Molekulargewicht bzw. der Oligomerisierungsgrad eines Proteins direkt in Lösung bestimmt werden. Die Molekulargewichtsbestimmung erfolgt unabhängig von der Gestalt und anderer hydrodynamischer Parameter (McRorie und Völker, 1993).

\subsection{Gleichgewichtszentrifugation}

Die Gleichgewichtszentrifugation zur Bestimmung des Oligomerisierungsgrades der drei Konstrukte Nr. 2, 8 und 12 wurde unter annähernd den gleichen Bedingungen wie die Gelfiltration in PBS-Puffer ( $\mathrm{pH}$ 7,3) und mit den entsprechenden Konzentrationen der PurinNukleotide GMP und ATP bei $20^{\circ} \mathrm{C}$ durchgeführt. Das Assoziationsverhalten des jeweiligen Proteins unter den verschiedenen Bedingungen wurde in mindestens zwei unabhängigen Messungen bei unterschiedlichen Rotorgeschwindigkeiten (15000 und $18000 \mathrm{U} / \mathrm{min})$ und verschiedenen Proteinkonzentrationen ( 2 bis $20 \mu \mathrm{M}$ ) bestimmt. Zunächst wurde das Molekulargewicht der beiden Proteine SAP97-SH3/GK2(575-911) (Nr. 2) und SAP97SH3/GUK2(575-918) (Nr. 8) unter denaturierenden Bedingungen in Gegenwart von $6 \mathrm{M}$ $\mathrm{GndHCl}$ ermittelt. Unter der Annahme das beide Proteine unter denaturierenden Bedingungen 
als Monomere (Fit mit dem Modell eines Monomers, siehe Gleichung 4.3.1) vorliegen, betrug das Molekulargewicht von Konstrukt Nr. 2 39,1 $\pm 0,6$ kDa und der Chimäre Nr. 8 38,8 $\pm 0,3$ kDa. Beide Werte stimmen sehr gut mit den kalkulierten Massen überein (siehe Tab. 4.9). Zur Ermittlung des Oligomerisierungszustandes der 3 Proteine SAP97-SH3/GK2(575-911), SAP97-SH3/GUK2(575-918) und SAP97-SH3/GUK3 $\Delta \mathrm{C}(582-906)$ wurden die Absorptionsprofile $\left(\mathrm{A}_{280}\right)$ nach Einstellung des Gleichgewichts der Konzentrationsverteilung mit verschiedenen mathematischen Modellen gefittet (Vorgehensweise nach Yoo et al., 1996; Dong et al., 1995; Marfatia et al. 2000; Kim et al., 1977). Das Molekulargewicht der 3 Proteine wurde zunächst unter der Annahme, daß sie nicht assoziiert in Lösung vorliegen mit dem Modell einer monomeren, thermodynamisch idealen Spezies (siehe Gleichung 4.3.1) bestimmt.

$c_{\mathrm{r}}=c_{\mathrm{r} 0} e\left[A M\left(r^{2}-r_{0}^{2}\right)\right]+E$

Dabei ist $c_{\mathrm{r}}$ die Konzentration des Monomers am Radius $r$ (ausgedrückt als Absorption bei 280 $\mathrm{nm}$, als Funktion der radialen Position); $c_{\mathrm{r} 0}$ ist die Konzentration des Monomers am Referenzradius $r_{0}$ (Konzentration des Monomers am Boden der Meßzelle); $\mathrm{A}=(1-\bar{v} \rho) \omega^{2} /$ $2 R T$, wobei $\bar{v}$ das partielle spezifische Volumen (SAP97-SH3/GK2(575-911): 0,727 1/g; SAP97-SH3/GUK2(575-918): 0,730 1/g; SAP97-SH3/GUK3 CC(582-906): 0,728 1/g), $\rho$ die Dichte des Puffers (PBS: 1,004 g/l), $\omega$ die Winkelgeschwindigkeit, $R$ die Gaskonstante $\left(8,314 \cdot 10^{7} \mathrm{erg} / \mathrm{mol} \cdot \mathrm{K}\right), T$ die Temperatur $(293,2 \mathrm{~K})$ ist; $E$ ist der Basislinien-Korrekturterm (entspricht nicht sedimentierenden Material) und $M$ das $\mathrm{zu}$ bestimmende apparente Molekulargewicht. Die Molekulargewichte wurden zunächst nur bei einer Rotorgeschwindigkeit von $15000 \mathrm{U} / \mathrm{min}$ gemessen.

Das Molekulargewicht von SAP97-SH3/GK2(575-911) betrug in PBS-Puffer $42516 \pm 760$ Da, in PBS mit ATP $41136 \pm 2290$ Da und in PBS mit GMP $49160 \pm 2992$ Da (siehe Tab. 4.9). Die Molekulargewichte der chimären Proteine SAP97-SH3/GUK2(575-918) und SAP97SH3/GUK3 $\Delta$ C(582-906) betrugen $42205 \pm 1049$ Da (Nr. 8) und $55176 \pm 2205$ (Nr. 12) in PBSPuffer, $38237 \pm 4101 \mathrm{Da}(\mathrm{Nr} .8)$ und $65679 \pm 4160 \mathrm{Da}$ (Nr. 12) in PBS mit ATP sowie 50610 $\pm 5755 \mathrm{Da}$ (Nr. 8) und $46182 \pm 5401 \mathrm{Da}$ (Nr. 12) in PBS mit GMP (siehe Tab. 4.9). Die apparenten Molekulargewichte insbesondere der chimären Proteine wichen zum Teil drastisch von den berechneten Molekulargewichten (siehe Tab. 4.9) ab. Unter der Annahme einer SelbstAssoziation wurden die Absorptionskurven der Proteine im Einzelnen nun mit verschiedenen 
mathematischen Modellen untersucht. Zur Durchführung des jeweiligen Fits wurde das rechnerisch bestimmte Molekulargewicht für jedes der 3 Proteine (siehe Tab. 4.9) vorgegeben, während $c_{\mathrm{r} 0}, E$ und $K$ (molare Assoziationskonstante [in $\left.\mathrm{M}^{-1}\right]$ ) variable Parameter waren. Das Kriterium für die Qualität des Fits war die Varianz. Das Modell, welches die geringste Varianz (hier: < $1 \cdot 10^{-4}$ ) von der gemessenen Absorptionskurve zeigte, wurde als tatsächlicher Assoziierungszustand des Proteins in Lösung angenommen.

A
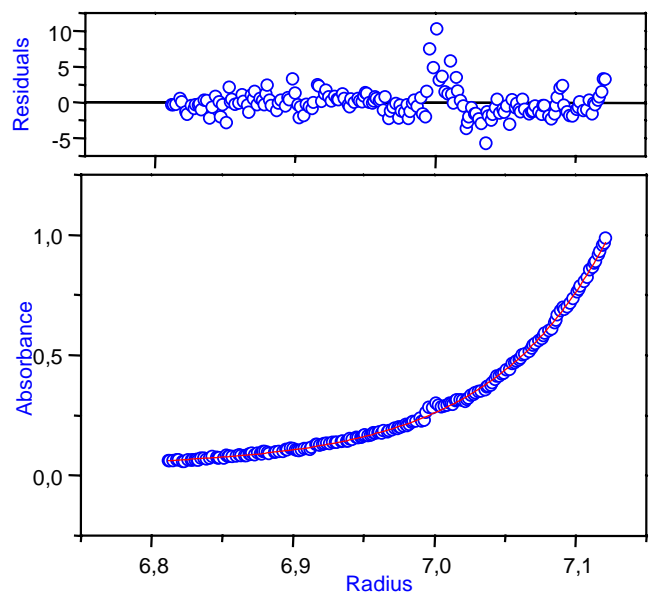

C
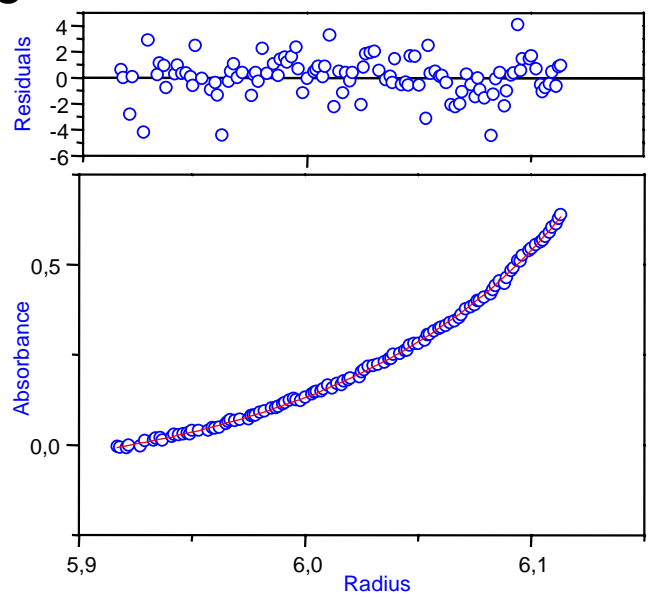

B
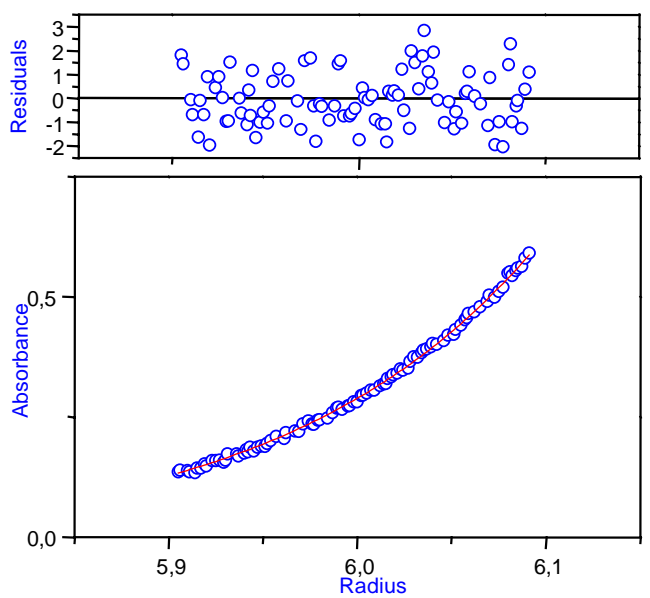

Abb. 4.47 Modell-Fit zur Bestimmung des Assoziationszustandes von WildTyp SAP97-SH3/GK2(575-911) in PBS-Puffer (A), PBS mit ATP (B) und PBS mit GMP (C). Die Kurve entspricht dem Modell mit der geringsten Varianz. Demnach liegt SAP97-SH3/GK2 in PBS und in Gegenwart der Purin-Nukleotide ausschließlich als Monomer vor.

Unter den experimentellen Bedingungen lag das Fusionsprotein SAP97-SH3/GK2(575-911) in Lösung beinahe ausschließlich als Monomer vor. Sowohl in PBS-Puffer allein, als auch in Gegenwart der Nukleotide ATP und GMP war jedoch die Tendenz zur Tetramerbildung erkennbar. In allen 3 Fällen konnte die Konzentrationsverteilung am genauesten mit dem Modell eines Monomer-Tetramer-Gleichgewichts beschrieben werden (siehe Gleichung 4.3.2):

$c_{\mathrm{r}}=c_{\mathrm{r} 0} e\left[A_{1} M_{1}\left(r^{2}-r_{0}^{2}\right)\right]+c_{\mathrm{r} 0}{ }^{4} e\left[\ln K_{1-4}-\ln \left(\varepsilon_{1-280}{ }^{3} / 4\right)+4 A_{1} M_{1}\left(r^{2}-r_{0}^{2}\right)\right]+E$ 
$M_{1}$ entspricht dem berechneten Molekulargewicht des SAP97-SH3/GK2(575-911)-Monomers (39173 kDa in PBS-Puffer und aufgrund der Bindung eines GMP-Moleküls 39537 kDa in GMP-haltigem PBS-Puffer). Der Extinktionskoeffizient $\varepsilon_{1-280}$ des Proteins (berechnet nach Gill und Hippel, 1989) beträgt $35110 \mathrm{M}^{-1} \cdot \mathrm{cm}^{-1} \cdot K_{1-4}$ ist die Assoziationskonstante der Tetramerbildung. $K_{1-4}$ betrug bei einer Rotorgeschwindigkeit von $15000 \mathrm{U} / \mathrm{min}$ in PBS-Puffer $1,4 \cdot 10^{3} \mathrm{M}^{-1}$, in Gegenwart von ATP $1,1 \cdot 10^{3} \mathrm{M}^{-1}$ und in Gegenwart von GMP 5,5 $10^{3} \mathrm{M}^{-1}$. Nach Erhöhung der Rotorgeschwindigkeit auf 18000 U/min konnte das Absorptionsprofil von SAP97-SH3/GK2(575-911) in Gegenwart der Nukleotide nicht mehr mit dem Modell des Monomer-Tetramer-Gleichgewichts (siehe Gleichung 4.3.2) sondern nur noch als Monomer (siehe Gleichung 4.3.1) gefittet werden, sodaß die Detektion der Tetramere bei geringerer Rotorgeschwindigkeit vermutlich nur auf einer unspezifischen Aggregation beruhte. Die Qualität des Fits bei 18000 U/min unter den verschiedenen Bedingungen ist in Abbildung 4.47 dargestellt.

A
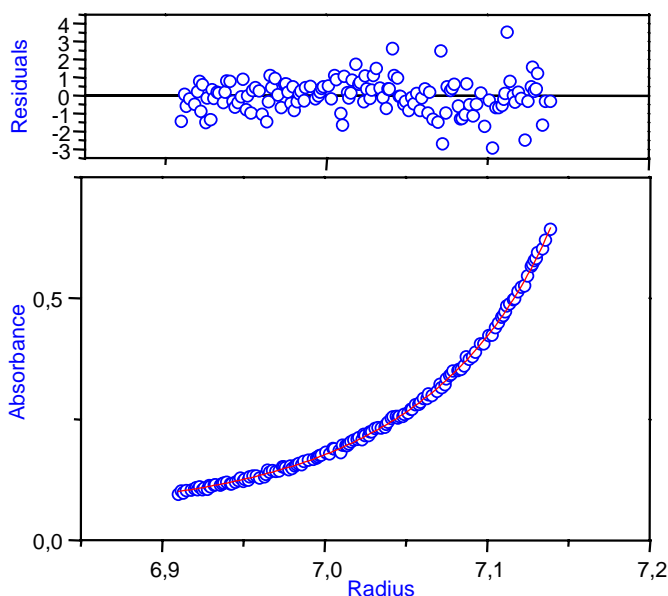

C
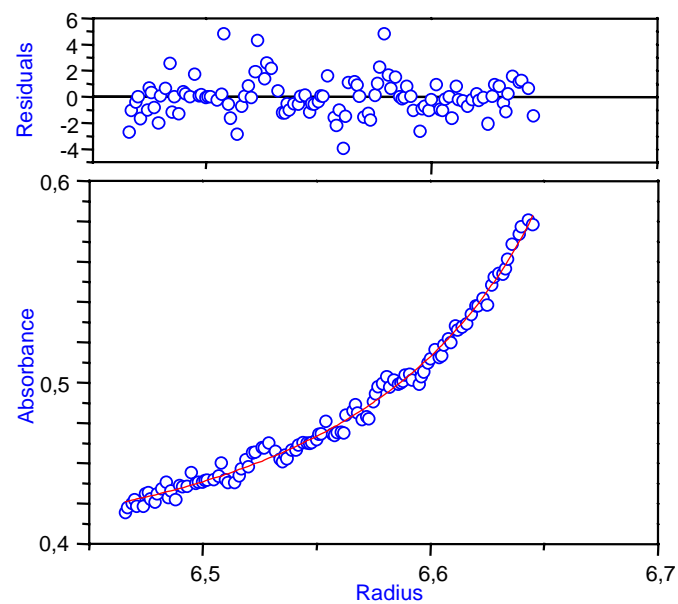

B
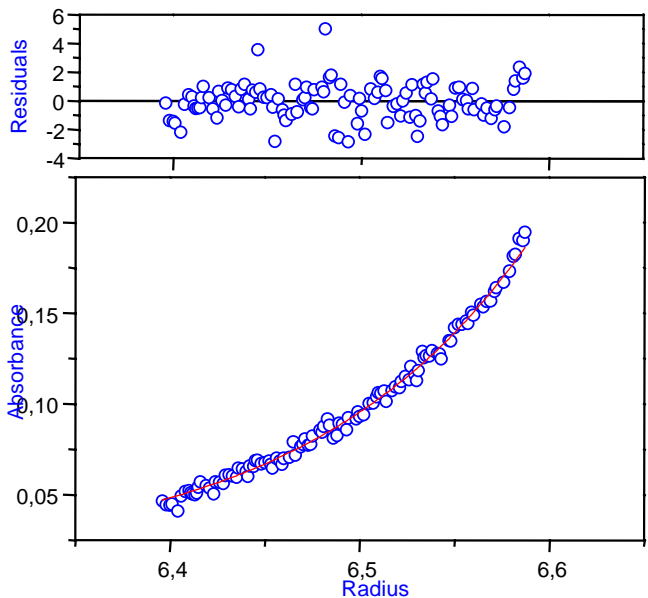

Abb. 4.48 Modell-Fit zur Bestimmung des Assoziierungszustandes von SAP97SH3/GUK2(575-918) in PBS-Puffer (A), PBS mit ATP (B) und PBS mit GMP (C). Die Kurve entspricht dem Modell mit der geringsten Varianz. Demnach liegt SAP97-SH3/GUK2 in PBS mit ATP als Monomer und in PBS allein und PBS mit GMP im MonomerTetramer-Gleichgewicht vor. 
Der Oligomerisierungszustand des chimeren Proteins SAP97-SH3/GUK2(575-918) ( $M_{\mathrm{w}, \mathrm{calc}}$ siehe Tab. 4.9, $\varepsilon_{2-280}=40800 \mathrm{M}^{-1} \cdot \mathrm{cm}^{-1}$ ) in Lösung ohne Nukleotid sowie mit ATP entsprach in etwa jenem von SAP97-SH3/GK2(575-911). Lediglich die Tendenz zur Bildung von Tetrameren war in PBS-Puffer deutlich ausgeprägter. Während bei einer Rotorgeschwindigkeit von $18000 \mathrm{U} / \mathrm{min}$ in Gegenwart von ATP das chimäre Protein ausschließlich als Monomer vorlag, betrug die Assoziationskonstante zur Bildung von Tetrameren in PBS-Puffer 1,7·10 $\mathrm{M}^{-1}$. Sie war folglich um den Faktor 10 gegenüber SAP97-SH3/GK2(575-911) erhöht. Auffällig verändert hingegen war die Situation in Gegenwart von GMP. Der Assoziierungszustand der Chimäre konnte in Gegenwart von GMP sowohl als MonomerTetramer-Modell (siehe Gleichung 4.3.2), als auch als Monomer-Dimer-Tetramer-Modell (siehe Gleichung 4.3.3) mit annähernd übereinstimmender Varianz beschrieben werden. Die Qualität der Fits bei 18000 U/min ist in Abbildung 4.48 dargestellt.

$$
\begin{aligned}
c_{r}= & c_{r 0} e\left[A_{2} M_{2}\left(r^{2}-r_{0}^{2}\right)\right]+c_{r 0}{ }^{2} e\left[\ln K_{2-2}-\ln \left(\varepsilon_{2-280} / 2\right)+2 A_{2} M_{2}\left(r^{2}-r_{0}^{2}\right)\right] \\
& +c_{r 0}{ }^{4} e\left[\ln K_{2-4}-\ln \left(\varepsilon_{2-280}{ }^{3} / 4\right)+4 A_{2} M_{2}\left(r^{2}-r_{0}{ }^{2}\right)\right]+E
\end{aligned}
$$

Während jedoch bei einer Rotorgeschwindigkeit von 18000 U/min die Assoziationskonstante der Dimerbildung mit $0,8 \cdot 10^{2} \mathrm{M}^{-1}$ unbedeutend klein ist, deutet die Assoziationskonstante der Tetramerbildung von $7,2 \cdot 10^{5} \mathrm{M}^{-1}\left(9,8 \cdot 10^{5} \mathrm{M}^{-1}\right.$ bei $\left.15000 \mathrm{U} / \mathrm{min}\right)$ an, daß unter den experimentellen Bedingungen (Proteinkonzentration: $3-4 \mu \mathrm{M}$ ) mehr als 50\% der Chimäre als Tetramer vorlag. Dieses Ergebnis stand somit in Einklang mit dem Ergebnis der GelfiltrationsAnalyse.

Eine deutliche Tendenz zur Tetramerbildung zeigte auch die verkürzte Proteinchimäre SAP97SH3/GUK3 $\Delta \mathrm{C}(582-906)\left(M_{\mathrm{w}, \text { calc }}\right.$ siehe Tab. 4.9; $\left.\varepsilon_{3-280}=33830 \mathrm{M}^{-1} \mathrm{~cm}^{-1}\right)$. Die verkürzte Chimäre liegt im Gegensatz zu den beiden zuvor beschriebenen Proteinen mit vollständigem C-Terminus in PBS-Puffer im Monomer-Dimer-Tetramer-Gleichgewicht vor (siehe Modell 4.3.3). Die Assoziationskonstanten der Dimer- $\left(K_{3-2}\right)$ und Tetramerbildung $\left(K_{3-4}\right)$ von $0,2 \cdot 10^{1}$ und 7,9.10 $0^{4} \mathrm{M}^{-1}$ zeigen, daß das Protein unter den experimentellen Bedingungen (Proteinkonzentration: $20-25 \mu \mathrm{M}$ ) nur als Monomer-Tetramer-Gleichgewicht vorlag, wobei das Monomer dominierte. Die verschwindend kleine Monomer-Dimer-Gleichgewichtskonstante deutet an, daß Dimere unter physiologischen Bedingungen nicht existieren. In Gegenwart der Purin-Nukleotide war hingegen das Monomer-Tetramer-Modell (siehe Gleichung 4.3.2) am 
Besten zur Beschreibung des Oligomerisierungsgrades von SAP97-SH3/GUK3 $\Delta$ C(582-906) geeignet. Die Abbildung 4.49 zeigt die jeweiligen Fits bei 18000 U/min. Die Assoziationskonstanten der Tetramerbildung in Gegenwart von ATP und GMP bei einer Rotorgeschwindigkeit von $18000 \mathrm{U} / \mathrm{min}$ entsprachen mit $1,0 \cdot 10^{5} \mathrm{M}^{-1}$ (ATP) bzw. $0,7 \cdot 10^{5} \mathrm{M}^{-1}$ (GMP) in Etwa der Monomer-Tetramer-Gleichgewichtskonstanten in PBS-Puffer allein. Unter den experimentellen Bedingungen (Proteinkonzentrationen von 8 bis $12 \mu \mathrm{M}$ ) lagen in Gegenwart der Purin-Nukleotide annähernd 50\% der verkürzten Chimäre als Tetramere vor. Die Assoziationskonstanten der Tetramerbildung waren bei der niedrigeren Rotorgeschwindigkeit von $15000 \mathrm{U} / \mathrm{min}$ mehr als Doppelt so groß wie bei $18000 \mathrm{U} / \mathrm{min}$. Diese Beobachtung, einhergehend mit dem Abfall des Molekulargewichts (Monomer-Fit) bei erhöhter Rotorgeschwindigkeit ist charakteristisch für die Bildung von Aggregaten, welche durch Erhöhung der Rotorgeschwindigkeit entfernt werden können.

A
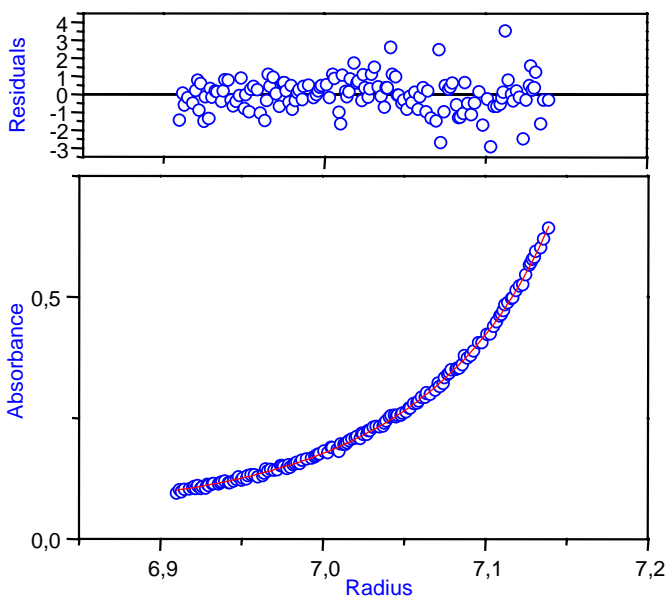

C
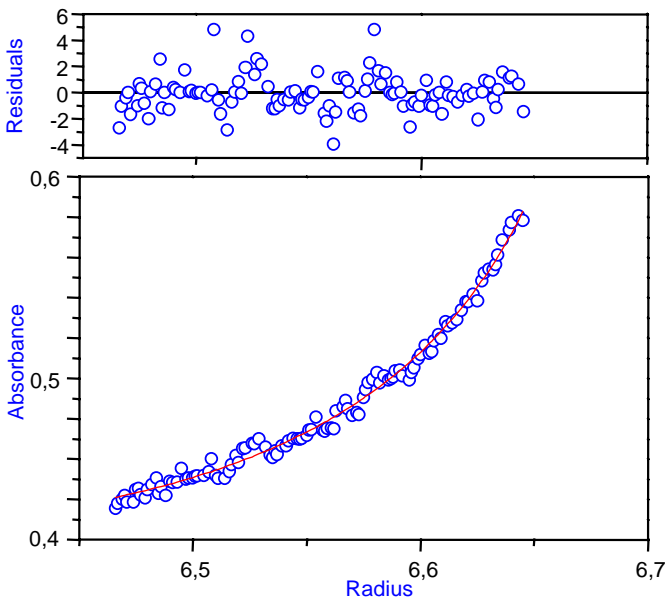

B
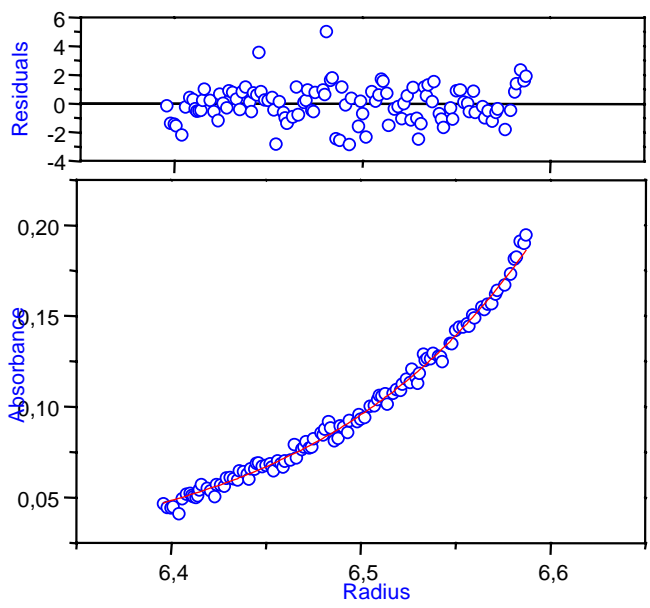

Abb. 4.49 Modell-Fit zur Bestimmung des Assoziierungszustandes von SAP97SH3/GUK3 $\Delta \mathrm{C}(582-906)$ in PBS-Puffer (A), PBS mit ATP (B) und PBS mit GMP (C). Die Kurve entspricht dem Modell mit der geringsten Varianz. Demnach liegt SAP97-SH3/GUK3 in unter allen 3 experimentellen Bedingungen im Monomer-TetramerGleichgewicht vor.

Die Ergebnisse bei höherer Rotorgeschwindigkeit von $18000 \mathrm{U} / \mathrm{min}$ geben folglich ein realistischeres Bild des Oligomerisierungsgrades der drei untersuchten Proteine in Lösung ab. 
Die Ergebnisse der Gleichgewichtszentrifugation in ihrer Gesamtheit bestätigen die Ergebnisse der Molekulargewichtsbestimmung mit der Methode der Gelfiltration. Das Fusionsprotein SAP97-SH3/GK2(575-911) scheint demnach unter physiologischen Bedingungen in mikromolarer Konzentration ausschließlich als Monomer vorzuliegen. Die Purin-Nukleotide ATP und GMP induzieren keine Assoziation der Proteine zu Homo-Oligomeren. Demgegenüber neigen die chimären Proteine SAP97-SH3/GUK2(575-918) und SAP97SH3/GUK3 $\Delta$ C(575-906) verstärkt zur Selbstassoziation. Der höchste Oligomerisierungsgrad beider Proteine ist das Tetramer.

Tab. 4.9 Einfluß von Purin-Nukleotiden auf die Assoziationszustände von SAP97-SH3/GK und SAP97-SH3/GUK

\begin{tabular}{|c|c|c|c|}
\hline Protein/ Bedingungen & $\begin{array}{c}M_{\mathrm{w}, \mathrm{calc}} \\
{[D a]}\end{array}$ & $\begin{array}{c}\text { Gelfiltration }{ }^{+} \\
\qquad M_{\mathrm{w}, \mathrm{app}} \\
{[k D a]}\end{array}$ & $\begin{array}{c}\text { Sedimentations- } \\
\text { Gleichgewicht } \\
\text { Assoziationzustand }\end{array}$ \\
\hline \multicolumn{4}{|l|}{ SAP97-SH3/GK2 (Nr. 2) } \\
\hline in PBS & 39173,9 & 34,3 & Monomer \\
\hline in PBS + ATP & 39173,9 & 31,4 & Monomer \\
\hline in PBS + GMP & 39537,1 & 32,3 & Monomer \\
\hline in $6 \mathrm{M} \mathrm{GnHCl}$ & 39173,9 & n.d. & $39139 \pm 647$ \\
\hline \multicolumn{4}{|l|}{ SAP97-SH3/GUK2 (Nr. 8) } \\
\hline in PBS & 38849,5 & 32,$7 ; 140,3$ & Monomer( $\leftrightarrow$ Tetramer $)$ \\
\hline in PBS + ATP & 39355,5 & 32,6 & Monomer \\
\hline in PBS + GMP & 39212,7 & $\begin{array}{c}28,9 ; 65,4 \\
126,2\end{array}$ & Monomer $\leftrightarrow$ Tetramer \\
\hline in $6 \mathrm{M} \mathrm{GnHCl}$ & 38849,5 & n.d. & $38848 \pm 251$ \\
\hline \multicolumn{4}{|l|}{ SAP97-SH3/GUK3 $\Delta \mathrm{C}(\mathrm{Nr} .12)$} \\
\hline in PBS & 37466,8 & 54,3 & Monomer $(\leftrightarrow$ Tetramer $)$ \\
\hline in PBS + ATP & 37972,8 & 29,$9 ; 134,5$ & Monomer( $\leftrightarrow$ Tetramer $)$ \\
\hline in PBS + GMP & 37830,0 & 27,$9 ; 129,2$ & Monomer( $\leftrightarrow$ Tetramer $)$ \\
\hline
\end{tabular}

+, apparente Molekulargewichte der im jeweiligen Elutionsprofil identifizierbaren Peaks; *, Assoziationszustand bei einer Proteinkonzentration von $2-20 \mu \mathrm{M}$; n.d., nicht gemessen. 
Während das vollständige chimäre Protein unter physiologischen Bedingungen auch in Gegenwart von ATP jedoch überwiegend als Monomer existiert, scheint das C-terminal verkürzte Protein bereits in mikromolarer Konzentration $\left(K_{\mathrm{d}}=12 \mu \mathrm{M}\right)$ auch in Gegenwart von ATP und GMP vermehrt als Tetramer vorzuliegen.

Die Ergebnisse der Gleichgewichtszentrifugation deuten zudem daraufhin, daß GMP die SelbstAssoziation des chimären Proteins SAP97-SH3/GUK2(575-918) fördert. Die Dissoziationskonstante $\left(K_{\mathrm{d}}\right)$ zur Tetramerbildung beträgt $1,4 \mu \mathrm{M}$ und weist damit den niedrigsten Wert aller getesten Proteine auf. Es gibt eine aufällige Abweichung in den Ergebnissen der Gelfiltration und der Gleichgewichtszentrifugation. Das verkürzte Protein SAP97-SH3/GUK3 $\Delta$ C(582-906) eluiert als Proteinspezies mit einem Molekulargewicht von 54,3 kDa von der Gelfiltrations-Säule. Mit der Methode der Gleichgewichtszentrifugation konnte jedoch unter den gleichen experimentellen Bedingungen kein Dimer in PBS-Puffer nachgewiesen werden. Die einzige Erklärung für das im Vergleich zu den beiden vollständigen Proteinen (Nr. 2 und Nr. 8) untypische Migrationsverhalten kann nur in einer asymmetrischen, weniger kompakten Form des verkürzten Proteins liegen. Aufgrund seines größeren hydrodynamischen Radius eluiert das Protein früher von der Gelmatrix. Durch Bindung der Purin-Nukleotide wird dieser Effekt wieder aufgehoben.

Die Tendenz zur Assoziation ist ausschließlich auf die chimären Konstrukte beschränkt. Es kann deshalb nicht ausgeschlossen werden, daß der Austausch der GK-Domäne gegen die GUK1 die Bildung von unspezifischen Aggregaten in Lösung fördert. Um eine lineare Abhängigkeit festzustellen, sind weitere Experimente bei höheren Rotorgeschwindigkeiten und veränderten Proteinkonzentrationen notwendig.

\subsubsection{Sedimentationsanalyse von SAP97-SH3/GK}

Mit der Methode der Gleichgewichtszentrifugation konnte gezeigt werden, daß die Proteine SAP97-SH3/GK2(575-911) und SAP97-SH3/GUK2(575-918) in mikromolarer Konzentration in Lösung beinahe ausschließlich als Monomere vorliegen und zumindest SAP97SH3/GK2(575-911) durch die Gegenwart der Purin-Nukleotide ATP und GMP nicht in einen assoziierten Zustand überführt werden können. Darüberhinaus deutet der Vergleich der beiden Methoden an, daß die C-terminal um 12 Aminosäuren verkürzte Chimäre SAP97SH3/GUK3 $\Delta \mathrm{C}(582-906)$ durch ein verändertes Migrationsverhalten gekennzeichnet ist. Neben der reduzierten Aktivität der Chimäre SAP97-SH3/GUK2(575-918) ist dies ein weiteres Indiz für eine regulatorische Funktion der C-terminalen Sequenz in SAP97. 
Im Folgenden sollte untersucht werden, ob die intramolekulare Interaktion in SAP97SH3/GK2(575-911) durch Bindung von GMP reguliert wird. Die analytische Ultrazentrifugation ist nicht nur eine sehr gute Methode zur Bestimmung des Molekulargewichts eines Proteins, sie kann auch sehr effizient zum Nachweis von Konformationsänderungen in Proteinen nach Liganden-Bindung eingesetzt werden (Zarutskie et al., 1999; Alley et al., 1999). In den meisten Fällen führt eine Konformationsänderung nur zu einer leichten Veränderung der Gesamtstruktur, welche ein verändertes Sedimentationsverhalten des Moleküls in Lösung zur Folge hat.

Zum Nachweis einer Konformationsänderung in SAP97-SH3/GK2(575-918) nach Nukleotidbindung wurde der Sedimentationskoeffizient in PBS ohne Purin-Nukleotid und in Gegenwart der Purin-Nukleotide ATP und GMP durch analytische Ultrazentrifugation bestimmt. Die Proteinkonzentration $(8-20 \mu \mathrm{M})$ und die Nukleotidkonzentrationen $(100 \mu \mathrm{M})$ entsprachen in Etwa jenen der Gleichgewichtszentrifugation. Die Ergebnisse der Sedimentationsanalyse sind in Tabelle 4.10 dargestellt.

Tab. 4.10 Hydrodynamische Parameter von SH3/GK-Konstrukten

\begin{tabular}{|c|c|c|c|c|c|}
\hline \multirow[t]{2}{*}{ Protein / Bedingungen } & \multirow{2}{*}{$\begin{array}{c}M_{\mathrm{w}, \mathrm{calc}} \\
{[D a]}\end{array}$} & \multirow{2}{*}{$\begin{array}{l}M_{\mathrm{w}, \mathrm{app}}{ }^{*} \\
{[k D a]}\end{array}$} & \multicolumn{3}{|c|}{ Sedimentationsanalyse } \\
\hline & & & $\begin{array}{c}s_{20, \mathrm{w}} \\
{\left[10^{-13} \mathrm{~s}\right]}\end{array}$ & $\begin{array}{c}D \\
{\left[10^{-7} \mathrm{~cm}^{2} / \mathrm{s}\right]}\end{array}$ & $\begin{array}{r}R_{\mathrm{S}} \\
{[\AA]}\end{array}$ \\
\hline SAP97-SH3/GK2 in PBS & 39173,9 & 42,5 & $3,83 \pm 0,19$ & 8,73 & 24,1 \\
\hline in PBS + ATP & 39173,9 & 41,1 & $3,81 \pm 0,22$ & 8,69 & 24,4 \\
\hline in PBS + GMP & 39537,1 & 49,2 & $3,46 \pm 0,18$ & 7,89 & 26,7 \\
\hline in $6 \mathrm{M} \mathrm{GndHCl}$ & 39173,9 & 39,1 & $1,27 \pm 0,02$ & 2,89 & 52,7 \\
\hline SAP97-SH3/GUK2 in PBS & 38849,5 & 42,2 & $3,42 \pm 0,13$ & 8,04 & 26,1 \\
\hline SAP97-SH3/GUK2 $\triangle \mathrm{C}$ in PBS & 37466,8 & 55,2 & $2,95 \pm 0,16$ & 7,02 & 30,0 \\
\hline
\end{tabular}

*, die aufgeführten apparenten Molekulargewichte $\left(M_{\mathrm{w}, \text { app }}\right)$ resultieren aus dem Modell-Fit des Monomers (siehe 4.3.2.1.2); $s_{20, \mathrm{w}}$, Sedimentationskoeffizient (bezogen auf $20^{\circ} \mathrm{C}, \mathrm{H}_{2} \mathrm{O}$ ); $D$, Reibungskoeffizient; $R_{\mathrm{s}}$, Stokes-Radius.

Ligand-freies SAP97-SH3/GK2(575-911) Protein sedimentiert schneller als die GMPgebundene Form. Die Zunahme des Sedimentations-Koeffizient von $3,46 \cdot 10^{-13} \mathrm{~s}$ (PBS + GMP) auf $3,83 \cdot 10^{-13} \mathrm{~s}(\mathrm{PBS})$ bzw. $3,81 \cdot 10^{-13} \mathrm{~s}$ (PBS + ATP) entspricht einer Abnahme des Stokes- 
Radius $\left(R_{\mathrm{s}}\right)$ von $11 \%$. Im vollständig denaturierten Zustand in Gegenwart von $6 \mathrm{M} \mathrm{GndHCl}$ beträgt der Sedimentationskoeffizient des Proteins $1,27 \cdot 10^{-13}$ s. Der Stokes-Radius des vollständig denaturierten Proteins ist mit 52,7 $\AA$ mehr als Doppelt so groß wie jener des nativen Proteins $(24,1 \AA$ ). Der größere Sedimentationskoeffizient von GMP-gebundenem SAP97SH3/GK2(575-911) deutet auf eine ausgedehntere und weniger kompakte Form im Vergleich zu Ligand-freiem Protein hin. Auffällig ist auch der stark verringerte Sedimentationskoeffizient der C-terminal verkürzten Chimäre SAP97-SH3/GUK2 $\triangle \mathrm{C}(575-906)$ im Vergleich zum vollständigen Protein SAP97-SH3/GUK2(575-918), welche seine wichtige strukturelle Funktion bestätigt.

Die Ergebnisse der Sedimentationsanalyse zeigen eindeutig, daß erstens die C-terminale Sequenz SAP97-SH3/GUK (SAP97-SH3/GK) in eine symmetrischere, kompaktere Struktur überführt und zweitens die Konformation von SAP97-SH3/GK durch Bindung von GMP verändert wird. Sowohl das Entfernen der C-terminalen 12 Aminosäuren, als auch die Bindung von GMP haben eine Ausdehnung der Tertiärstruktur des Proteins zur Folge. Interessanterweise entspricht der Sedimentationskoeffizient der Chimäre SAP97-SH3/GUK2(575-918) in Etwa GMP-gebundenem SAP97-SH3/GK2(575-911). Dieses Ergebnis kann ein Hinweis darauf sein, daß die SH3-Domäne in SAP97-SH3/GK2(575-911) an eine Bindungsstelle der GK-Domäne bindet, welche in der Guanylatkinase GUK1 nicht vorhanden ist. Durch Bindung von GMP wird diese spezifische intramolekulare Interaktion in SAP97-SH3/GK2(575-911) zwischen den beiden Domänen aufgehoben und das Protein zeigt nun das gleiche Sedimentationsverhalten wie die Chimäre. 


\section{$5 \quad$ Diskussion}

\subsection{Funktionelle Rolle der GUK1 in S. cerevisiae}

Die bisherigen Kenntnisse der Rolle der Guanylatkinase in vivo resultieren aus genetischen und physiologischen Studien an dem Modellorganismus S. cereviae. Durch Deletion eines Allels des GUK1-Gens in einem diploiden Hefestamm und anschließender Tetradenanalyse wurde bereits in einer früheren Arbeit direkt gezeigt, daß die GUK1 essentiell für das Überleben der Hefezelle ist (Konrad, 1992). Das Fehlen der GUK1 hat eine Unterbrechung der GDP- und nachfolgend der GTP-Synthese zur Folge. Dieser Mangel an GDP innerhalb der Zelle kann nicht durch katalytische Aktivität andere Nukleosid-Monophosphatkinasen supprimiert werden und unterstreicht die spezifische Funktion der GUK1 in der Phosphorylierung von GMP (Konrad, 1992). Interessanterweise scheint die GUK1 jedoch auch eine wichtige regulatorische Funktion für die Aufrechterhaltung des Purinnukleotid-Gleichgewichts in vivo zu besitzen. Durch Komplementationsanalysen wurden Mutanten des GUK1-Gens in S. cerevsiae identifiziert, welche nicht nur durch eine erhöhte Generationszeit, sondern auch durch eine erhöhte Produktion und Exkretion von Purinen gekennzeichnet waren (Lecoq et al., 2000). Der Phänotyp einer erhöhten Exkretion von Purinen ist charakteristisch für die Stoffwechselerkrankungen Hyperurikämie und Gicht des menschlichen Organismus, welcher die Folge eines Defekts des Enzyms Hypoxanthin-Guanin-Phosphoribosyltransferase (HGPRT) ist (Kelley et al., 1969). Aus den Beobachtungen an den Hefe-Mutanten wurde gefolgert, daß der lokale Anstieg des GMP-Spiegels in der Hefezelle, hervorgerufen durch eine Mutation der GUK1 direkt die Funktion der HGPRT kompetitiv inhibiert. Ein Defekt der Guanylatkinase ist demnach doppelt verhängnisvoll für die Zelle: Erstens hat die Verringerung der GDP- und folglich auch der GTP-Spiegel direkte Auswirkungen auf die DNA- und RNA-Synthese, den Energiestoffwechsel und die G-Protein gekoppelte Signal-Transduktion und zweitens wird durch den Anstieg von GMP direkt die Funktion von Enzymen des Purinnukleotid-SyntheseStoffwechsels inhibiert.

\subsection{Hefe-in vivo-System zum Auffinden von Guanylatkinasen}

\subsubsection{Konditionale Guanylatkinase-Mutanten}

Eine Möglichkeit zur funktionellen Analyse essentieller Gene in der Hefe ist die kontrollierte Expression des Gens unter einem regulierbaren Promoter. Um die Auswirkung einer 
fortschreitenden Repression der Transkription des Guanylatkinase-Gens auf die Hefezelle zu testen und ein differenzierteres Bild des Wachstums der Hefezelle in Abhängigkeit von definierten in der Zelle vorliegenden Konzentrationen an Guanylatkinase zu erhalten, wurde das GUK1-Gen in einem haploiden GUK1-defizienten Hefestamm unter Kontrolle des Tetracyclinregulierbaren Promoters tetO-tTA gestellt. Der tetO-tTA-Promoter besitzt gegenüber dem für die regulierte Expression in Hefe eingesetzten und weitverbreiteten $G A L$-Promotersystem den entscheidenden Vorteil, daß ein Wechsel der Kohlenstoffquelle von Galaktose zu Glukose zur Repression der Expression nicht notwendig ist. Ein Wechsel der Kohlenstoffquelle kann pleiotrope Effekte im zellulären Stoffwechsel zur Folge haben, welche ihrerseits wieder zu Phänotypen führen könnten, die nicht in direktem Zusammenhang mit der Repression der Genexpression stehen. Darüberhinaus ist unter Kontrolle des $G A L$-Promoters eine modulierbare Genexpression kaum möglich.

Die Wahl des tetO-tTA-Promotersystems zur kontrollierten Expression des GuanylatkinaseGens war jedoch noch aus einem weiteren Grund attraktiv. Im Idealfall der vollständigen Suppression der GUK1-Expression unter Kontrolle des tetO-tTA-Promoters konnte in der Hefe ein effizientes, weil einfach und schnell durchzuführendes in vivo-Selektionssystem zur Untersuchung von fremden Genprodukten auf Guanylatkinase-Aktivität etabliert werden. Dazu wurden diploide Hefezellen des Stammes AG430(GUK1/guk1::HIS3), in welchem ein Allel des GUK1-Gens deletiert war mit dem Plasmid pCM189-GUK1, auf welchem die Expression des GUK1-Gens der Kontrolle des tetO-tTA-Promoters unterlag, transformiert und jene haploiden Zellen AG215(guk1::HIS3/pCM189-GUK1), in welchen die chromosomale Deletion des GUK1-Gens durch das Wild-Typ-Gen auf dem Plasmid pCM189-GUK1 komplementiert wurde, durch Tetradenanalyse isoliert. Hefezellen unabhängiger Kulturen des Stammes AG215(guk1::HIS3/pCM189-GUK1), in welchem die GUK1-Expression ausschließlich durch den Promoter tet $O$-tTA reguliert wurde, zeigten im Vergleich zum diploiden Ausgangsstamm AG430(GUK1/guk1::HIS3/pCM189-GUK1) in Minimalmedium mit verschiedenen Konzentrationen des Tetracyclin-Derivats Doxycyclin einen drastischen Anstieg der Generationszeit. Bereits bei einer Konzentration von $1,0 \mu \mathrm{g} / \mathrm{ml}$ Doxycyclin war eine Verdopplung der Generationszeit des Stammes AG215(guk1::HIS3/pCM189-GUK1) im Vergleich zum Kontrollstamm AG430(GUK1/guk1::HIS3/pCM189-GUK1) zu beobachten, welcher eindeutig auf die Repression der Transkription des GUK1-Gens zurückzuführen war. Die Konzentration an Guanylatkinase entsprach in diesen Hefezellen weniger als 2\% der Konzentration in Zellen, welche in Minmalmedium ohne Doxycyclin-Zugabe gewachsen waren. 
Die Aktivität der Guanylatkinase konnte darüberhinaus durch Veränderung der DoxycyclinKonzentration im Medium moduliert werden. Bereits eine Konzentration von 0,01 $\mu \mathrm{g} / \mathrm{ml}$ war ausreichend, um die Guanylatkinase-Aktivität um 80\% im Vergleich zum Ausgangsstamm zu reduzieren. Bereits bei Erreichen einer Doxycyclin-Konzentration von $0,1 \mu \mathrm{g} / \mathrm{ml}$ ist in Zellextrakten zumindest mit dem enzymatischen Assay keine Guanylatkinase-Aktivität mehr nachweisbar, obgleich die Enzymkonzentrationen in diesen Zellen immer noch ca. 4\% der Konzentration von Zellen, welche ohne Doxycyclin im Medium gewachsen waren, betrug. Dieses Mißverhältnis zwischen der immunologisch nachweisbaren Enzymkonzentration in Hefe-Zellextrakten und der in diesen mit dem Standard-Assay detektierbaren enzymatischen Aktivität offenbart auch das Limit der Sensitivität dieser Testmethode. Überraschenderweise sind die Hefezellen auch in Gegenwart von $10 \mu \mathrm{g} / \mathrm{ml}$, also bei einer Konzentration, bei der immunologisch kein Enzym mehr nachweisbar war lebensfähig, was darauf hindeutete, daß der basale Transkriptionslevel auch unter diesen Bedingungen immer noch ausreichend hoch ist. Dieses Ergebnis erstaunt insofern, alsdaß demnach weniger als 0,1\% der Wild-Typ-EnzymKonzentration ausreichend ist, um ein Überleben der Hefezelle zu gewährleisten. Bei einer in vitro gemessenen spezifischen Guanylatkinase-Aktivität von $291 \pm 23,5 \mathrm{U} / \mathrm{mg}$ entspricht dies einem Wert von ungefähr $0,3 \mathrm{U} / \mathrm{mg}$. Dieses Ergebnis ist vergleichbar mit genetischen Untersuchungen der Hefe-Thymidylatkinase. Ebenso wie der Verlust der Guanylatkinase führt auch die Deletion der Thymidylatkinase in S. cerevisiae zu rezessiver Lethalität. Durch Komplementationsanalysen mit einem THK-defizienten haploiden Hefestamm wurde jedoch kürzlich gezeigt, daß eine THK-Mutante, welche nur noch $0,1 \%$ der Wild-Typ-Aktivität in vitro besaß, den Verlust der THK funktionell supprimieren konnte (Brundiers, 1999).

Da ein vollständiges Abschalten der GUK1-Expression unter Kontrolle des tetO-tTA-Promoters nicht möglich ist, läßt sich das tetO-tTA-Expressionssystem nur schwer als in vivo Selektionssystem zum Screen nach fremden Genen, welche den Verlust des GUK1-Gens komplementieren können, einsetzen. Zumindest für die Detektion von Genen, welche für schwach aktive Guanylatkinasen codieren ist es ungeeignet, da eine Differenzierung des Wachstums von Hefezellen aufgrund der Komplementation durch das Fremdgen vor dem Hintergrund des Wachstums von Zellen aufgrund des basalen Transkriptionslevels des GUK1Gens unter Kontrolle des tet $O$-tTA-Promoters nicht möglich ist. Um es als Alternative zu dem GAL-System zu etablieren, sind deshalb weitere Untersuchungen notwendig, wobei zunächst das Koloniewachstum der Zellen AG215(guk1::HIS3/pCM189-GUK1) - auch bei Temperaturen 
oberhalb von $30^{\circ} \mathrm{C}$ - in Gegenwart der maximal eingesetzten Doxycyclin-Konzentration von $10 \mu \mathrm{g} / \mathrm{ml}$ analysiert werden muß.

Mit dem Tetracyclin-regulierbaren Expressionsystem ist eine gezielte Modulation der GUK1Expression in der Hefe möglich. Dadurch sind die Voraussetzungen geschaffen durch gezielte Repression der Transkription des GUKl-Gens die Auswirkungen einer GDP- und GTPAbnahme auf den Energiestoffwechsel und die Nukleotid-Homeostase in der lebenden Hefezelle zu untersuchen. Dies sollte zu einem verbesserten Verständnis der biologischen Relevanz von Phosphotransfer-Reaktionen im eukaryontischen Organismus führen.

\subsection{2 adk1/ndk1- und guk1-3/ndk1-Doppelmutanten}

Über das Enzym Nukleosid-Diphosphatkinase (NDK) ist die Guanylatkinase direkt an G-Protein vermittelten Signal-Stoffwechselwegen in der eukaryontischen Zelle beteiligt. Die NDK wird als Hauptlieferant des GTP in der Zelle angesehen (Schärtl et al., 1998). Sie steht somit einerseits in enger Verbindung zu der Guanylatkinase, welche das Substrat GDP bereitstellt und andererseits übt sie über die Regulation des GDP/GTP-Verhältnisses in der Zelle einen direkten Einfluß auf G-Protein aus (Bominaar et al., 1993). Die wichtige Rolle der NDK im Prozess der durch Wachstumsfaktoren induzierten Zellproliferation ist bereits seit längerer Zeit bekannt (Ohtsuki et al., 1987; Woods und Bryant, 1991). Gemessen an ihrer wichtigen Funktion in Säugern scheint die Rolle der NDK in den Mikroorganismen E. coli und S. cerevisiae eher untergeordnet zu sein, da die Deletion des NDK1-Gens in beiden Einzellern keinen Phänotyp zur Folge hat (Lu und Inouye, 1996; Fukuchi et al., 1993). Sowohl in E. coli, als auch in S. cerevisiae kann der Funktionsverlust durch andere Kinasen supprimiert werden. Ein möglicher funktioneller Suppressor des NDK-Verlustes kann beispielsweise die Pyruvatkinase sein, welche ebenfalls ein breites Sunstratspektrum besitzt und den Phosphatrest vom Phosphoenolpyruvat auf die Nukleoitide (d)ATP, (d)GTP, (d)CTP, UTP und dTTP übertragen kann (Saeki et al., 1974).

In einer weiteren Studie wurde das Enzym Adenylatkinase (ADK1) identifiziert, welches den Verlust der NDK1 in E. coli komplementieren sollte (Lu und Inouye, 1996). Dieses Ergebnis überrascht insofern, alsdaß die Adenylatkinase als spezifische Nukleosid-Monophosphatkinase nur die Substrate AMP, ADP und ATP umsetzen kann. Einen weitereren Hinweis für die enge Kopplung von Guanylat- und Adenylat-Metabolismus in der eukaryontischen Zelle, lieferten physiologische Studien an AK1-defizienten Mäusen (Janssen et al., 2000). Der Funktionsverlust der AK1 in der Maus führte zu einer Neuordnung der Stoffwechselwege zur Produktion von ATP. Von dieser Neuorganisation war unter anderem auch der 
Guanosinnukleotid-Stoffwechsel zur Synthese von GTP betroffen. Während die Aktivität der NDK in Muskelextrakten sich nicht verändert hatte, war der steady-state Guanylat-Spiegel im Muskel signifikant erhöht. Dieser Anstieg war auf eine erhöhte Aktivität der Guanylatkinase sowie des Enzyms Succinyl-CoA-Synthetase, eines Enzyms des Citrat-Zyklus, welches die Umwandlung von Succinyl-CoA und GDP + Pi zu Succinat, CoA-SH und GTP katalysiert, zurückzuführen. Der Verlust an ATP-Umsatz nach Deletion der AK1 wurde demnach zum Teil durch eine erhöhte Produktion von GTP in der Zelle kompensiert (Janssen et al., 2000).

Zur Untersuchung der Rolle von ADK1, GUK1 und NDK1 im Nukleotidstoffwechsel der Hefezelle wurden die haploiden Doppelmutanten $a d k 1 / n d k 1$ und guk1-3/ndk1 konstruiert. Die zweite Doppelmutante besaß aufgrund einer Mutation im GUK1-Gen nur noch etwa 5 - $10 \%$ der Wild-Typ-Aktivität. Die alleinige Deletion des ADK1-Gens führt im Gegensatz zur Deletion des GUK1-Gens nicht zum Absterben der haploiden Hefezelle. In einer früheren Arbeit wurde gezeigt, daß der funktionelle Verlust der ADK1 in der haploiden Hefezelle durch die Uridylat/Cytidylatkinase, welche neben UMP und CMP auch AMP mit ATP als Phosphoryldonor umsetzen kann, supprimiert wird (Schricker et al., 1992). Der zusätzliche Verlust des NDK1Gens hatte in der haploiden Doppelmutante $a d k 1 / n d k 1$ keinen neuen Phänotyp zur Folge. Sowohl die $a d k 1$-, als auch die $a d k 1 / n d k 1$-Mutante war durch ein im Vergleich zum Wild-Typ deutlich verlangsamtes Wachstum gekennzeichnet. Die Generationszeiten der beiden Mutanten wichen jedoch nicht signifikant voneinander ab.

Auch die zusätzliche Deletion des NDK1-Gens in der haploiden Doppelmutante guk1-3/ndk1 hatte keine Veränderung des Phänotyps im Vergleich zur einfachen guk1-3-Mutante zur Folge. Die Mutante guk1-3 mit reduzierter Guanylatkinase-Aktivitätät war durch eine $30-40 \%$ erhöhte Generationszeit gekennzeichnet. Auch die Doppelmutante gukl-3/ndk1 ist durch ein verlangsamtes Wachstum gekennzeichnet. Die Generationszeit unterscheidet sich jedoch auch hier nicht signifikant von jener der gukl-3-Einfachmutante. Auch wenn die Abnahme der intrazellulären GDP-Konzentration maßgeblichen Einfluß auf das vegetative Wachstum der beiden Mutanten hatte, so konnte ein Unterschied im Prozeß der Reifung und Sporulation der beiden Mutanten im Vergleich zum Wild-Typ nicht festgestellt werden. Die Übereinstimmung im Wachstumsverhalten von Einfach- und Doppelmutante ist unerwartet. Unter der Annahme, daß die Phosphorylierungsreaktion über die Guanylatkinase und die Nukleosiddiphosphatkinase in eukaryontischen Zellen der essentielle Weg zur Herstellung von GTP ist, wäre zu erwarten gewesen, daß eine Reduktion der GDP-Spiegel eine drastischere Auswirkung auf das Zellwachstum besäße. Der übereinstimmende Phänotyp von guk1-3-Einfach- und guk1-3/ndk1- 
Doppelmutante deutet jedoch daraufhin, daß der GDP-Spiegel, obschon um über $90 \%$ reduziert, immer noch oberhalb der Affinität von Enzymen lag, welche wie z.B. die Pyruvatkinase den Funktionsverlust der NDK1 supprimieren konnten.

Wie bereits unter Punkt 5.2.1 beschrieben, sind Guanylatkinase-Aktivitäten von 0,1\% der WildTyp-Aktivität ausreichend, um ein Überleben der Hefezellen zu gewährleisten. Es wäre interessant festzustellen, ob möglicherweise in Zellen, in welchen die GDP-Konzentration nochmals 100fach im Vergleich zur guk1-3-Mutante reduziert ist, der Funktionsverlust der Nukleosiddiphosphatkinase einen Phänotyp verursacht. Sollte dies der Fall sein, so ließe sich auf Basis des unter Punkt 5.2.1 beschriebenen tetO-tTA-System bei vollständiger Inhibition der GUK1-Transkription in Kombination mit dem Ausschalten der NDK1 möglicherweise ein verbessertes in vivo Selektionssystem zum Screen nach fremden Genen, welche den Verlust des GUK1-Gens komplementieren können, etablieren. Sollte der basale Tanskriptionslevel des GUK1-Gens in Kombination mit dem Funktionsverlust der NDK1 tatsächlich ein Überleben der Hefezelle nicht mehr gewährleisten, so wäre dieses in vivo-System bestens dazu geeignet auch Gene, welche für schwach aktive Guanylatkinasen codieren zu identifizieren.

\subsection{Funktion signifikanter Aminosäuren der ATP-Bindungsregion von GUK1}

In den letzten Jahren wurden einige natürliche Mutanten der Guanylatkinase in der Hefe entdeckt, welche durch eine Vielfalt unterschiedlicher Phänotypen gekennzeichnet waren (Lecoq et al., 2000; Shimma et al., 1997). Die Klasse der bra3-Mutanten wurde ursprünglich aufgrund der Fähigkeit zur Deregulation der de novo Purin-Synthese-Gene identifiziert. Die Mutation der GUK1 führt in bra3-Mutanten zu einer Abnahme der Guanylatkinase-Aktivität um mehr als 90\% im Vergleich zu Wild-Typ-Zellen. Die temperatursensitive Hefemutante nes25 ist durch einen Glykosylierungsdefekt gekennzeichnet, der auf einem Mangel an GDPMannose beruht, dessen Ursache eine Mutation der GUK1 ist (Shimma et al., 1997).

Die in vivo identifizierten natürlichen GUK1-Mutationen der bra3- und nes25Komplementationsgruppen wurden in dieser Arbeit biochemisch und kinetisch charakterisiert. In der nes25-Mutante wurde durch Sequenzanalyse eine Substitution des Glutamatrestes an Position 139 gegen ein Lysinrest (E139K) identifiziert. Das E139 ist in allen bisher bekannten Guanylatkinasen konserviert und im Kristallstrukturkomplex GUK1·GMP an der Peripherie mit Kontakt zum Lösungsmittel lokalisiert. Die E139K-Mutante war als einzige der getesteten GUK1-Mutanten nach Überexpression in E. coli unlöslich. Dies kann ein Hinweis darauf sein, 
daß der Glutamatrest eine wichtige Rolle für die Aufrechterhaltung der Tertiärstruktur der GUK1 innehat. Der Austausch des Glutamats mit negativ geladener Seitenkette gegen das Lysin mit positiv geladener Seitenkette könnte zu eine falschen Faltung der Polypeptidketten und anschließender unspezifischer Aggregation der Mutante geführt haben.

Im Gegensatz zur nes25-Mutante waren die drei bra3-Mutanten in E. coli löslich. In den vier Mitgliedern der bra3-Komplementationsgruppe wurden durch Sequenzanalyse drei Punktmutationen der GUK1 identifiziert. In der bra3-1(gukl-1)-Mutante war der Argininrest an Position 132 gegen einen Lysinrest (R132K) ausgetauscht, bra3-2- und bra3-4-Mutanten (guk12) besaßen die gleiche G12S-Substitution und in der bra3-3(gukl-3)-Mutante war der Prolinrest an Position 10 gegen einen Leucinrest (P10L) ausgetauscht. Zwei der drei Punktmutationen, nämlich P10L und G12S sind Mutationen des charakteristischen NTP-Bindungsmotivs, dem Phosphat-Loop (P-Loop). Im Gegensatz zu den P-Loop-Mutanten P10L und G12S liegt der Argininrest an Postition 132 außerhalb der Substrat-Bindungsregionen. Sequenzvergleiche der GUK1 mit Adenylat- und Uridylatkinasen zeigen, daß das Arg132 sich im Gegensatz zu den beiden in der GUK1-Sequenz folgenden Argininresten an den Positionen 136 und 147 (korrespondieren mit Arg132 und Arg149 in der Hefe-Adenylatkinase bzw. Arg131 und Arg148 in der Dictyostelium-Uridylatkinase) außerhalb der sogenannten LID-Region befindet (Yan et al., 1990; Schlichting und Reinstein, 1997). Anhand von Mutagenese-Studien an der Adenylatund Uridylatkinase wurde bereits in früheren Arbeiten gezeigt, daß die Argininreste der LIDRegion eine Schlüsselfunktion in der Stabilisation des Übergangszustandes während der Katalyse besitzen, da sie die negative Ladung der übertragenen Phosphorylgruppe neutralisieren (Yan und Tsai, 1999; Schlichting und Reinstein, 1997). Der Austausch der beiden Arginine an den Positionen 131 und 148 gegen Methionin in der Dictyostelium-Uridylatkinase hatte einen $10^{4}$ bzw. $10^{5}$ fachen Abfall der katalytischen Effizienz $\left(k_{\text {cat }} / K_{\mathrm{M}}\right)$ zur Folge. Im Gegensatz dazu führte der Austausch des zum Arg132 der Hefe-Guanylatkinase korrespondierenden Arg127, welches in der Dictyostelium-Uridylatkinase ebenfalls außerhalb der LID-Region positioniert ist, nur zu einem moderaten Abfall der katalytischen Effizienz (Schlichting und Reinstein, 1997). Die Konservierung dieses Argininrestes in allen bisher bekannten NukleosidMonophosphatkinasen weist vermutlich auch ihm eine wichtige Rolle in der Stabilisierung des Übergangszustandes während des Phosphoryl-Transfers zu.

Die drei GUK1-Mutanten ließen sich als Fusionsproteine mit Histidinanhang aus E. coli aufreinigen. Ihre Löslichkeit lag jedoch weit unterhalb jener von Wild-Typ-GUK1. Alle drei Mutanten zeigten darüberhinaus im Vergleich zum Wild-Typ eine deutlich reduzierte 
Guanylatkinase-Aktivität. Die Umsatzraten lagen bei 3,1 (R132K), 5,7 (P10L) und 7,8\% (G12S) der Wild-Typ-Aktivität. Die in vitro-gemessenen enzymatischen Aktivitäten entsprachen folglich den in Hefezell-Extrakten gemessenen spezifischen Aktivitäten von 5 $10 \%$, woraus geschlossen werden konnte, daß die reduzierte Aktivität nicht auf eine unkorrekte Faltung der Polypeptidkette während der heterologen Überexpression in E. coli zurückzuführen war. Alle drei Reste besitzen eine wichtige Funktion in der Katalyse-Reaktion, denn der Anstieg der Michaelis-Menten-Konstanten für das Substrat ATP $\left(K_{\mathrm{M}(\mathrm{ATP})}\right)$ um den Faktor 13 in den Mutanten P10L und R132K sowie den Faktor 23 in der Mutante G12S im Vergleich zum WildTyp deutet daraufhin, daß die schwächere Aktivität auf eine verringerte Affinität der Mutanten zum Substrat ATP zurückzuführen ist. Dies wird durch den 300fachen Abfall der Spezifitätskonstanten $k_{\mathrm{cat}} / K_{\mathrm{M}(\mathrm{ATP})}$ aller drei Mutanten im Vergleich zum Wild-Typ bestätigt. In Analogie zur Hefe-Guanylatkinase hat der Austausch der korrespondierenden Prolin- und Glycinreste gegen Leucin (P9L) bzw. Valin (G10V) im P-Loop der E. coli-Adenylatkinase einen annähernd übereinstimmenden Anstieg der $\mathrm{K}_{\mathrm{M}(\mathrm{ATP})}$-Werte um den Faktor 15 im Vergleich zum Wild-Typ zur Folge. Im Gegensatz zur Guanylatkinase führten beide Mutationen allerdings nur zu einer schwachen Abnahme der spezifischen Aktivität. Der $k_{\text {cat }}$-Wert der P9L-Mutante lag bei $70 \%$ und jener der G10V-Mutante bei $25 \%$ des Wild-Typs (Reinstein et al., 1988). Aus dem Vergleich der kinetischen Parameter mit der E. coli-Adenylatkinase kann gefolgert werden, daß beide P-Loop-Aminosäuren in der Guanylatkinase eine wichtigere Rolle in der Katalyse besitzen. Interessanterweise haben die Mutationen des ATP-Bindungsmotivs auch einen Einfluß auf die Bindung des zweiten Substrats GMP. Wenngleich die drei- bis vierfache Erhöhung der $K_{\mathrm{M}}$-Werte für die Bindung von GMP in allen drei Mutanten im Vergleich zu jener der Bindung von ATP nur moderat ausfällt, so scheint dies kein Einzelfall in NMPkinasen zu sein. Auch in den Adenylatkinasen aus E. coli und dem Hühnermuskel sowie den Cytidylat-/Uridylatkinasen aus E. coli- und Arabidopsis hatten Mutationen des P-Loops verringerte Affinitäten für das Substrat NMP zur Folge (Reinstein et al., 1990; Byeon et al., 1995; Bucurenci et al., 1996; Zhou und Thornburg, 1998).

Während die funktionellen Reste der GMP-Bindungsregion anhand der Kristallstruktur der GUK1 in Komplex mit GMP identifiziert sind, liegen bisher erst wenig Daten zur funktionellen Signifikanz bestimmter Reste der ATP-Bindungsregion von Guanylatkinasen vor. Um ein möglichst vollständiges Bild der Auswirkung von Punktmutationen des P-Loops zu erhalten, wurde neben den beiden zuvor untersuchten natürlichen Mutanten auch der kritische Lysinrest an Position 15 der GUK1-Sequenz mutiert. Das konservierte Lysin des P-Loops ist eine der am 
eingehendsten untersuchten Aminosäuren ATP- und GTP-bindender Proteine (Reinstein et al., 1990; Tian et al., 1990; Byeon et al., 1995; Sigal et al., 1986). Es bindet direkt an die Phosphatgruppe von ATP und GTP und spielt eine entscheidende Rolle in der Katalyse von Kinasen. Während der Phosphortransferreaktion von Adenylatkinasen sowie Uridylatkinasen interagiert das invariante Lysin des P-Loops zusammen mit den katalytischen Argininen der LID-Region (s.o.) sowie dem $\mathrm{Mg}^{2+}$-Ion mit der übertragenen Phosphorylgruppe und stabilisiert dadurch den Übergangszustand (Byeon et al., 1995; Schlichting und Reinstein, 1997; Yan und Tsai, 1999). In Analogie zur Kristallstruktur von AK3 im Komplex mit AMP (Diederichs und Schulz, 1991) interagiert das P-Loop-Lysin im GUK1·GMP-Komplex über eine Salzbrücke mit Asp98 (Asp88 in AK3). Das Asp98 (Asp93 in AK1) bindet über eine elektrostatische Interaktion das katalytische $\mathrm{Mg}^{2+}$-Ion, welches für die korrekte Positionierung des Phosphatgruppen-Donors und -Akzeptors in der Adenylatkinase während der Katalyse verantwortlich ist (Yan und Tsai, 1991; Byeon et al., 1995).

Zur Untersuchung der funktionellen Rolle des Lysinrestes in Guanylatkinasen wurde in die GUK1-Sequenz die K15R-Mutation durch Mutagenese eingeführt. In Analogie zu den bra3Mutanten ließ sich auch die K15R-Mutante in E. coli überexprimieren und aufreinigen. Die konservative Substitution des P-Loop-Lysins gegen ein Arginin hatte einen dramatischen Abfall der enzymatischen Aktivität zur Folge. Die spezifische Aktivität fiel auf 0,03\% der Wild-TypAktivtität. Darüberhinaus zeigte die Mutante eine im Vergleich zum Wild-Typ um den Faktor 8 verringerte Affinität zum Substrat ATP. Vergleicht man die Spezifitätskonstante $k_{\text {cat }} / K_{\mathrm{M}(\mathrm{ATP})}$ aller vier GUK1-Mutanten miteinander, so weicht jene der K15R-Mutante um den Faktor $10^{4}$ vom Wild-Typ und um den Faktor $10^{2}$ von den bra3-Mutanten ab. Von den vier mutierten Resten besitzt demnach das Lysin des P-Loops im Vergleich zu P10, G12 und R132 die mit Abstand wichtigste Funktion in der Katalyse. Im Gegensatz zu der katalytischen Effizienz weicht der $K_{\mathrm{M}(\mathrm{ATP})}-$ Wert der K15R-Mutante nicht signifikant von jenen der P10L und R132KMutanten ab. Der drastische Abfall der Guanylatkinase-Aktivität der K15R-Mutante kann folglich nur zum Teil mit einer verringerten Affinität für das Substrat ATP erklärt werden. Da in der K15R-Mutante die Anzahl an positiven Ladungen, welche die negative Ladung der Phosphorylgruppe im Übergangszustand neutralisieren weiterhin konstant bleibt, beruht der drastische Abfall der Guanylatkinase-Aktivität vermutlich weniger auf der Instabilität des Übergangszustandes, sondern eher auf signifikanten sterischen Veränderungen der ATPBindungsregion hervorgerufen durch die im Vergleich zum Lysin verlängerte ArgininSeitenkette. Es ist auch denkbar, daß in der K15R-Mutante die Interaktion mit Asp98 
unterbrochen ist, was negative Auswirkungen auf die korrekte Positionierung der beiden Substrate während der Katalyse haben sollte. Die hier getroffenen Aussagen müssen an weiteren Kristallstrukturen der Guanylatkinase, insbesondere im Komplex mit ATP und Substratanaloga überprüft werden. Sie konzentrieren sich im wesentlichen auf vergleichbaren MutageneseStudien sowie Struktur-Funktionsuntersuchungen an Adenylatkinasen und Uridylat/Cytidylatkinasen (Reinstein et al., 1990; Zhou und Thornburg, 1998; Scheffzek et al., 1996; Schlichting und Reinstein, 1997; Byeon et al., 1995). Die Mutation des konservierten P-LoopLysins in der E. coli-Adenylatkinase gegen ein Glutamin (K13Q) hatte einen drastischen Abfall der spezifischen Aktivität um den Faktor $10^{4}$ zur Folge, welcher ebenfalls auf einer lokalen Konformationsänderung der ATP-Bindungsregion des Enzyms und der daraus folgenden erniedrigten Affinität für das Substrat ATP zurückzuführen war (Reinstein et al., 1990). Durch Mutation des P-Loop-Lysins gegen ein Arginin (K21R) in der Adenylatkinase aus dem Hühnermuskel wurde ferner mit NMR-Studien gezeigt, daß der Abfall der katalytischen Effizienz $\left(k_{\text {cat }} / K_{\mathrm{M}}\right)$ um den Faktor $10^{5}$ im Vergleich zum Wild-Typ auf einer strukturellen Veränderung des P-Loops und der daraus folgenden Aufhebung wichtiger Interaktionen der katalytischen Aminosäuren mit den Substraten und dem $\mathrm{Mg}^{2+}$-Ion beruhte (Byeon et al., 1995). Die Übereinstimmung mit den Ergebnissen kinetischer Untersuchungen an Mutanten der Adenylatkinase deuten daraufhin, daß das konservierte Lysin des P-Loops in Guanylatkinasen eine ähnlich entscheidende Rolle im Katalysemechanismus spielt. Im Vergleich zur K27RMutante der Uridylat-/Cytidylatkinase aus Arabidopsis, welche noch 50\% der Wild-TypAktivität besaß (Zhou und Thornburg, 1998), ist der Austausch des invarianten P-Loop-Lysins in der Hefe-Guanylatkinase in Übereinstimmung zu den Adenylatkinasen allerdings ungleich dramatischer.

Zur Unterscheidung von strukturellen und funktionellen Rolle der mutierten Aminosäuren in der Guanylatkinase sind weitere spektroskopische, aber auch thermodynamische Untersuchungen zur Stabilität der Mutanten notwendig.

\subsection{Säuger-Guanylatkinasen}

Aufgrund ihrer essentiellen Funktion im Nukleotid-Stoffwechsels ist die Guanylatkinase aufgrund der Fähigkeit zur Aktivierung von Nukleosid-Analoga ein Zielenzym der Behandlung viraler Infektionen. Durch Arbeiten unserer Arbeitsgruppe in Zusammenarbeit mit A. Lavie (University of Illinois at Chicago, USA) an der Thymidylatkinase wurde kürzlich gezeigt, daß die ineffiziente Phosphorylierung des Nukleosid-Analogs 3'-Azido-3'-Desoxythymidin (AZT)Monophosphats (AZT-MP), eines häufig in der HIV-Therapie eingesetzten Medikaments, durch 
Mutagenese von wenigen katalytisch entscheidenden Aminosäuren deutlich erhöht werden kann (Lavie et al., 1997; Brundiers et al., 1999). In Analogie zur Thymidylatkinase ist eines unserer Ziele die Kristallstruktur der therapeutisch relevanten Guanylatkinasen von Säugern aufzuklären; sie ist wie zuvor am Beispiel der Thymidylatkinase geschildert ein wertvolles Hilfsmittel zur Konstruktion eines Enzyms mit erhöhter Umsatzrate von Guanosin-Analoga. In dieser Arbeit wurden die beiden Säuger-Guanylatkinasen der Maus (mGUK) und des Menschen (hGUK) näher biochemisch und kinetisch charakterisiert. Die Guanylatkinasen der Maus und des Menschen besitzen eine 52 - 54\%ige Übereinstimmung zur Aminosäuresequenz der Hefe-Guanylatkinase (GUK1). Säuger- und Hefe-Guanylatkinasen besitzen den höchsten Grad an Sequenzidentität in den Substratbindungsregionen, während jene Sequenzen, welche im Kristallstrukturkomplex GUK1.GMP in der Peripherie vorliegen stark voneinander abweichen. Dies deutet auf einen übereinstimmenden strukturellen Aufbau von Mensch-, Mausund Hefe-Guanylatkinase hin. Während bisherige Versuche zur Isolierung von rekombinanter Säuger-Guanylatkinase in hoher Homogenität wenig erfolgreich waren (Brady et al., 1996), gelang es durch Verwendung des GST-Expressionsystems erstmalig beide SäugerGuanylatkinasen in großen Mengen von mehr als $120 \mathrm{mg}$ aus einem Liter E. coli-Kultur in löslicher und aktiver Form mit einer Homogenität von mehr als 95\% aufzureinigen. Die spezifischen Aktivitäten beider Säuger-Guanylatkinasen waren in Etwa gleich groß und entsprachen $50 \%$ der spezifische Aktivität der Hefe-GUK1. Die Michaelis-Menten-Konstanten $\left(K_{\mathrm{M}}\right)$ beider Enzyme für die Substrate ATP und GMP waren ebenfalls annähernd identisch und im Vergleich zur GUK1 zweifach erhöht. Als Konsequenz einer verringerten Umsatzrate und einer erhöhten Substrat-Affinität waren die Spezifitätskonstanten $k_{\text {cat }} / K_{\mathrm{M}(\mathrm{ATP})}$ und $k_{\mathrm{cat}} / K_{\mathrm{M} \text { (GMP) }}$ beider Säuger-Guanylatkinasen annähernd identisch zu jenen der Hefe-GUK1. Die SubstratAffinitäten der beiden rekombinanten Säuger-Enzyme wichen nicht signifikant von den kinetischen Parametern von aus Säuger-Gewebe aufgereinigten Enzymen ab (Agarwal et al., 1978). Die $K_{\mathrm{M}}$-Werte für das Substrat GMP von aus der Ratten-Leber und menschlichen Erythrozyten aufgereinigter Guanylatkinasen lagen mit Werten von 10 und $18 \mu \mathrm{M}$ im Bereich jener der rekombinanten Säuger-Enzyme lag. Aus dieser weitestgehenden Übereinstimmung der kinetischen Parameter kann geschlossen werden, daß beide Säuger-Enzyme nach heterologer Überexpression in E. coli in ihrerer enzymatisch aktiven Tertiärstruktur vorlagen. 


\subsection{Guanylatkinasen der Pflanze}

Die kürzlich in Arabidopsis identifizierten Guanylatkinase-Isozyme AGUK1 und AGUK2 sind die ersten Guanylatkinasen einer Pflanzen, welche bisher beschrieben wurden. AGUK1 und AGUK2 zeigen auffällige strukturelle Unterschiede $\mathrm{zu}$ den bisher bekannten echten Guanylatkinasen. Mit einem Molekulargewicht von 42,7 bzw. 42,5 kDa sind sie ungefähr doppelt so groß wie Guanylatkinasen aus E. coli (Gentry et al., 1993), der Hefe (Konrad, 1992) und Säugern (Brady et al., 1996). Im Gegensatz zu allen bisher bekannten Guanylatkinasen besitzen beide pflanzlichen Isozyme $\mathrm{N}$ - und C-terminale Verlängerungen, welche die zentrale GUK-Domäne (52 - 54\%ige Sequenzidentität zu Säuger-Guanylatkinasen) umgeben. Diese Nund C-terminalen Sequenzen der AGUK1 sind mit einer Länge von 138- und 65 Aminosäuren ungleich länger als die aus den E. coli- und Säuger-Guanylatkinasen bekannten C-terminalen Verlängerungen. Obwohl das Vorhandensein N- und C-terminaler Verlängerungen ein typisches Merkmal von pflanzlichen Enzymen, u.a. der NDK und ATP-Sulfurylase zu sein scheint (Zimmermann et al., 1999; Logan et al., 1996), ist die biologische Funktion dieser Sequenzen in den genannten Enzymen bisher ungeklärt.

Durch Komplementationsanalyse in der Hefe wurde gezeigt, daß die zentrale GK-Domäne aus AGUK1 den Funktionsverlust der GUK1 komplementieren konnte. Zur Bestimmung der enzymatischen Aktivität der GUK-Domäne von AGUK1 sowie ferner zur Überprüfung eines möglichen regulatorischen Einfluß der N- und C-terminalen Verlängerungen auf die enzymatische Aktivität der zentralen GUK-Domäne wurde versucht die zentrale GUK-Domäne sowie das gesamte Protein rekombinant aus E. coli aufzureinigen. Im Gegensatz zu der GUKDomäne aus AGUK1 war das vollständige Protein AGUK1 unter den gleichen Expressionsbedingungen als GST-Fusionsproteine unlöslich. Erst durch Expression als MBPFusionsprotein war es möglich AGUK1 aus E. coli aufzureinigen. Die N- und C-terminalen Sequenzen schienen demnach die Löslichkeit der zentralen enzymatischen Domäne negativ zu beeinflussen.

Die zentrale GUK-Domäne zeigte in dem Aktivitäts-Assay die höchste spezifische Aktivität mit den Substratpaaren ATP/GMP und ATP/(d)GMP. Diese war im Vergleich zu den weiteren getesten Substratpaaren um den Faktor 1000 erhöht. Die zentrale GUK1-Domäne aus AGUK1 besaß folglich die typische Substratspezifität einer Guanylatkinase. Unerwarteterweise war sie jedoch 50- bzw. 100fach weniger aktiv als die Guanylatkinasen von Säugern und der Hefe. Die Michaelis-Menten-Konstanten $\left(K_{\mathrm{M}}\right)$ für die Substrate ATP und GMP waren im Vergleich zur Guanylatkinase der Hefe um den Faktor 3 (ATP) bzw. 8 (GMP) deutlich erniedrigt. Aus der 
deutlich schwächeren enzymatischen Aktivität und den erhöhten Affinitäten für beide Substrate ergaben sich die Spezifitätskonstanten $k$ cat $/ K_{\mathrm{M}(\mathrm{ATP})}$ und $k$ cat $/ K_{\mathrm{M}(\mathrm{GMP})}$, welche um den Faktor 9 bzw. 4 kleiner als jene der Hefe-GUK1 waren. Die spezifische Aktivität der gesamten AGUK1 wich nicht signifikant von jener der zentralen GUK-Domäne ab, sodaß ein hypothetischer regulatorischer Einfluß der N- und C-terminalen Domäne auf die enzymatische Aktivität der zentralen GUK-Domäne ausgeschlossen werden konnte. Die Funktion der N- und C-terminalen Domänen in AGUK1 ist bisher nicht geklärt. In Analogie zur kurzen C-terminalen Sequenz der Guanylatkinase aus E. coli ist es denkbar, daß auch die zusätzlichen Sequenzen von AGUK1 die Oligomerisation des Proteins induzieren oder verantwortlich für eine mögliche kooperative Substratbindung sind, welche in der zentralen GUK1-Domäne nicht beobachtet wurde.

\subsubsection{Die Arabidopsis-Guanylatkinase als evolutionäres Bindeglied zwischen aktiven Guanylatkinasen und inaktiven MAGUK-Proteinen}

Die sehr geringe spezifische Guanylatkinase-Aktivität sowohl des gesamten Proteins AGUK1, als auch der GUK-Domäne erscheint auf den ersten Blick überraschend. Aufgrund der hohen Aminosäuresequenz-Identität mit Säuger-Guanylatkinasen und strenger Konservierung der für die Substratbindung und Katalyse essentiellen Reste, war zunächst eine höhere spezifische Aktivität erwartet worden. Da die die zentrale GUK-Domäne der AGUK1 in E. coli sehr gut löslich war, kann die schwache enzymatische Aktivität nur schwer mit einer möglichen falschen Faltung der Tertiärstruktur des Enzyms erklärt werden. Der Grund für die schwache Aktivität ist deshalb vermutlich weniger in der Strategie der Aufreinigung, sondern vielmehr in der Struktur des Proteins an sich zu suchen. Die Situation der AGUK steht in Analogie zur menschlichen Thymidylatkinase (TMPK). Die menschliche TMPK ist in vitro 50fach weniger aktiv als die TMPKs von S. cerevisiae und E. coli (Brundiers et al., 1999, Lavie et al., 1997b; Lavie et al., 1998). Es wurde deshalb vermutet, daß in der Zelle ein Cofaktor existiert, welcher mit der menschlichen TMPK interagiert und das Enzym durch strukturelle Veränderung in den katalytisch kompetetenten Zustand überführt (Ostermann et al., 2000). Dieser Cofaktor könnte in der AGUK Calmodulin sein. Der N-Terminus besitzt eine 46\%ige Sequenz-Ähnlichkeit zu einem möglichen Calmodulin (CaM)-bindenden Protein (NCBI Zugangs-Nummer 2980766). Calmodulin ist ein $\mathrm{Ca}^{2+}$-bindendes Protein und sowohl in Säugern, als auch in Pflanzen an der Modulierung zellulärer Signal-Transduktions-Prozesse beteiligt (Snedden und Fromm, 1998). Pflanzen besitzen eine hohe Anzahl an CaM-bindenden und CaM-regulierten Proteinen. Eine zur Bindung von Calmodulin charakteristisches Konsensussequenz konnte bisher noch nicht identifiziert werden. Es ist nur bekannt, daß Calmodulin mit sehr hoher Affinität an Regionen 
mit einer Länge von 17 bis 25 Aminosäuren, welche eine amphipatische $\alpha$-helicale Sekundärstruktur ausbilden, bindet (Crivici et al., 1995; Rhoads und Friedberg, 1997). In der Pflanze sind bisher einige Enzyme bekannt, deren Aktivität durch Calmodulin in Gegenwart von $\mathrm{Ca}^{2+}$ reguliert wird. So wird beispielsweise die spezifische Aktivtität der NAD-Kinase durch $\mathrm{Ca}^{2+} / \mathrm{CaM}$ moduliert und auch die Aktivität von rekombinanter Glutamat-Decarboxylase konnte annähernd um das 100 fache in Gegenwart von $\mathrm{Ca}^{2+}$ und CaM stimuliert werden (Lee et al., 1997; Baum et al., 1996).

Zur Überprüfung eines hypothetischen regulatorischen Einflusses von Calmodulin wurde die spezifische Aktivität von AGUK1 in Gegenwart verschiedener millimolarer (1-5 $\mathrm{mM})$ Konzentrationen an Calcium und mikromolarer (1-5 $\mu \mathrm{M})$ Konzentrationen an Calmodulin (aus Spinat) bestimmt. Eine signifikante Erhöhung der spezifischen Guanylatkinase-Aktivtät von AGUK1 in Abhängigkeit von $\mathrm{Ca}^{2+} / \mathrm{CaM}$ wurde unter den gewählten Bedingungen ( $\mathrm{pH} 7,5$, $25^{\circ} \mathrm{C}$ ) jedoch nicht beobachtet. Das negative Ergebnis muß einen möglichen modulierenden Einfluß von Calmodulin auf die Aktivität der AGUK1 dennoch nicht ausschließen. Dazu müßte zunächst geklärt werden, ob das aus der Spinat-Pflanze isolierte artfremde Calmodulin überhaupt an die N-terminale Sequenz der AGUK1 binden kann. Darüberhinaus besitzen gerade Pflanzen besitzen eine große Vielfalt an Calmodulin- und Calmodulin-ähnlichen Proteinen (Sneddon und Fromm, 1998).

Sollte sich die Fähigkeit zur Bindung von Calmodulin bewahrheiten so ließe sich daraus eine Verwandtschaft der vollständigen AGUKs zu Mitgliedern der Familie Membran-assoziierter Guanylatkinasen (MAGUKs) ableiten (siehe 1.2). In vorangegangenen Studien wurde gezeigt, daß die C-terminale Guanylatkinase-ähnliche Domäne, welche enzymatisch nicht mehr aktiv ist (Kuhlendahl et al., 1998) in MAGUK-Proteinen eine neuartige strukturelle Rolle als ProteinBindungsdomäne besitzt (siehe 1.3.2.3). Darüberhinaus besitzt auch die N-terminale Domäne von Mitgliedern der Lin2-ähnlichen MAGUK-Subfamilie eine hohe Sequenzähnlichkeit zur $\mathrm{Ca}^{2+} / \mathrm{CaM}$-abhängigen Proteinkinase II (CaMKII; Hoskins et al., 1995; Hata et al., 1996). Ebenso wie die C-terminale GK-Domäne ist auch die N-terminale CaMKII-Domäne katalytisch nicht aktiv, besitzt allerdings noch die Fähigkeit zur Bindung von Calmodulin. Der Aufbau der Arabidopsis-Guanylatkinasen aus multiplen Domänen ähnelt jenem der Lin2-ähnlichen MAGUK-Proteine und könnte ebenfalls auf eine strukturelle Rolle der pflanzlichen Guanylatkinasen ähnlich jener von MAGUK-Proteinen als Gerüstproteine hindeuten. Sollte sich dies bestätigen könnten die pflanzlichen Guanylatkinasen als evolutionäres Bindeglied zwischen den kleinen, enzymatisch aktiven Guanylatkinasen und den großen, Multidomänen 
MAGUK-Proteinen, welche ihre Guanylatkinase-Aktivität verloren haben, eingeordnet werden. Zum gegenwärtigen Stand der Forschung kann über eine neuartige Funktion der enzymatisch aktiven Pflanzen-Guanylatkinasen nur spekuliert werden. Auffällige strukturelle und kinetische Besonderheiten deuten diese neuartige Funktion jedoch zumindest an.

\subsection{Funktionelle Charakterisierung der GK-Domäne von SAP97 und hCASK}

\subsubsection{In vitro-Analyse zum Nachweis von Guanylatkinase-Aktivität}

Die Membran-assoziierten Guanylatkinasen (MAGUKs) SAP97 und hCASK sind Multidomänen Proteine mit einer 33 bis 37\%igen Sequenzidentität in der C-terminalen Domäne (GK-Domäne) zur Guanylatkinase aus $S$. cerevisiae. Im Gegensatz zu den intensiv untersuchten PDZ-Domänen ist die physiologische Rolle der GK-Domänen von Membran-assoziierten Guanylatkinasen bisher noch weitestgehend ungeklärt. Erste Hinweise auf eine physiologische Funktion der GK-Domäne lieferten genetische Studien an dem Tumorsuppressor-Genprodukt Dlg aus Drosophila. Das Protein wurde in den septate junctions der epithelialen Zellen der Imaginalscheiben von Drosophila-Larven lokalisiert. Woods und Bryant identifizierten verschiedene mutierte Allele der GUK-Domäne von Dlg. Die Phänotypen $d l g^{v 59}$ und $d l g^{s w}$, mit partiellen internen sowie C-terminalen Deletionen der GK-Domäne, waren durch Wucherungen der Epithelien sowie undifferenzierte neuromuskuläre Verbindungen gekennzeichnet. Der vollständige Funktionsverlust von Dlg in der genetischen Nullmutante $d^{2 g^{m 52}}$ führte zur Ausbildung massiven Tumorgewebes an den Imaginalscheiben, welche den Tod der Larve zur Folge hatte. Aus diesen Beobachtungen wurde geschlossen, daß dlg eine wichtige Rolle in der Regulation der Proliferationskontrolle in den Epithel-Zellen der Imaginalscheiben spielt (Woods und Bryant, 1991; Woods et al., 1996). Basierend auf der Annahme, daß dlg für eine katalytisch aktive Guanylatkinase codiert, wurde von Woods und Bryant (1991) ein Modell zur Wirkungsweise von Dlg vorgeschlagen. Grundlage ihrer Hypothese war, daß die morphologischen Veränderungen der septate junctions auf einem Guanosinnukleotidvermittelten Signal-Transduktions-Weg beruhen. Da die Guanylatkinase ein essentielles Enzym des cGMP-Zyklus (Hall und Kühn, 1986) ist, könnte es folglich einen regulatorischen Einfluß auf die Synthese von GTP haben und auf diese Weise durch Veränderung des GTP/GDPVerhältnisses auch die Aktivität von GTP-bindenden Proteinen (G-Proteinen) regulieren (Bourne et al., 1990). 
Da sowohl in hCASK als auch in SAP97 annähernd alle Aminosäuren konserviert sind, welche nach der Struktur der Hefe-Guanylatkinase zur Bindung von $\mathrm{Mg}^{2+}$ und GMP notwendig sind, (Müller et al., 1995; Stehle und Schulz, 1992) lag die Annahme nahe, daß hCASK und SAP97 eine von der GMP-Bindung abhängige Funktion bei der Bildung von multimolekularen Komplexen an Zell-Zell-Kontaktstellen besitzen. Allerdings weisen beide MAGUK-Proteine im Vergleich zur Guanylatkinase auffällige strukturelle Unterschiede im charakteristischen ATPBindungsmotiv der GUK1, welches den P-Loop zur Bindung der $\beta$ - und $\gamma$-Phosphatreste bildet auf. Das charakteristische ATP-Bindungsmotiv ist in der GK-Domäne von SAP97 partiell deletiert und hCASK besitzt anstelle des katalytischen Lysins ein Arginin. Wie bereits zuvor gezeigt (siehe Tab. 4.1), kann die katalytische Funktion des P-Loop-Lysins in der HefeGuanylatkinase (GUK1) nicht durch ein Arginin ersetzt werden. Aufgrund des Fehlens sowohl für die Bindung von ATP, als auch die katalytische Übertragung des $\gamma$-Phosphatrestes essentiellen Aminosäuren, musste eine Funktion von SAP97 bzw. hCASK als enzymatisch aktive Guanylatkinase in Frage gestellt werden. Diese Vermutung wurde durch formale Überprüfung der beiden einzelnen GK-Domänen auf Guanylatkinase-Aktivität bestätigt. Weder als GST-Fusionsprotein aufgereinigtes SAP97-GK noch hCASK-GK zeigten eine über dem Hintergrund des enzymatischen Assays liegende Guanylatkinase-Aktivität. Darüberhinaus waren beide Proteine nicht in der Lage den Funktionsverlust von GUK1 in einer haploiden Hefemutante zu komplementieren. Diese Ergebnisse vervollständigen die Daten einer früheren Arbeit unserer Arbeitsgruppe in Zusammenarbeit mit C.C. Garner (University of Alabama at Birmingham, USA) zur funktionellen Untersuchung von SAP97 (Kuhlendahl et al., 1998) und zeigen, daß die Tumorentwicklung in den Drosophila-Mutanten nicht die Folge einer fehlenden Guanylatkinase-Aktivität der C-terminalen Domäne war.

Bisher wurde einzig in rekombinant aus E. coli aufgereinigtem GST-p55 von einer schwachen Guanylatkinase-Aktivität berichtet, welche um den Faktor 190 niedriger als jene von SäugerGuanylatkinasen war (Marfatia und Chisti, 1995). Da allerdings auch in der Sequenz von p55 das invariante Lysin des P-Loops fehlt, muß dieses Ergebnis aufgrund der hier gewonnen Erkenntnisse in Frage gestellt werden. Die Identifikation diverser Bindungspartner der GKDomänen von Dlg-ähnlichen MAGUK-Proteinen, wie z.B. GKAP/SAPAPs, deutet vielmehr auf eine eher strukturelle Rolle dieser Domäne ähnlich jener von PDZ-Domänen hin. Die inaktive GK-Domäne könnte im Laufe der Evolution aus der aktiven Guanylatkinase hervorgegangen sein, wobei für ihre gegenwärtige Funktion in MAGUK-Proteinen vermutlich nur noch das dreidimensionale Grundgerüst des ehemals aktiven Enzyms von Nutzen ist. 


\subsubsection{Rekonstruktion der Guanylatkinase-Aktivität in SAP97-GK}

In einem weiteren Schritt sollte zunächst geklärt werden, ob ein einfacher Austausch jener Reste, welche offensichtlich an der Substrat-Bindung in der Guanylatkinase involviert sind, in der GK-Domäne jedoch Fehlen ausreichend ist, um die inaktive GK-Domäne wieder in ein aktives Enzym zu überführen. Eine Rekonstruktion der Guanylatkinase-Aktivität in SAP97-GK durch die Substitution einiger signifikanter Reste ist aus zwei Gründen aufschlußreich. Zum einen würde sie die Hypothese einer übereinstimmenden globalen Struktur und somit einer nahen Verwandtschaft der GK-Domäne zu den authentischen Guanylatkinasen bestätigen und zweitens ließen sich auf diesem, im Vergleich zu Mutagenese-Studien an dem aktiven Enzym, umgekehrten Weg wichtige Informationen über die funktionelle Signifikanz der mutierten Reste gewinnen.

Nach Vorlage der Hefe-Guanylatkinase wurde zunächst das P-Loop-Motiv in SAP97-GK und danach die aus dem GUK1-GMP-Kristallkomplex identifizierten Aminosäuren der GMPBindungsregion durch Mutagenese in SAP97-GK rekonstruiert. Weder die beiden Mutanten SAP97-GK(P-Loop), mit vollständigem ATP-Bindungsmotiv und SAP97-GK(P-Loop, ST), mit vollständigem P-Loop und den in allen Guanylatkinasen konservierten katalytischen Resten Ser15 und Thr16 der Hefe-GUK1 (korrespondieren mit Asp735 und Arg736 in SAP97) noch die Mutanten SAP97-GK(P-Loop, ST, S100D), mit Austausch des im GUK1-GMP-Komplex mit dem Guaninring interagierenden Asp100 (korrespondiert mit Ser818 in SAP97) und SAP97-GK(P-Loop, ST, P34S, S100D), mit vollständiger Rekonstruktion aller an der Substratbindung in der Hefe-GUK1 beteiligten Reste, zeigten im Enzym-Assay eine über dem Hintergrund liegende Guanylatkinase-Aktivität (siehe Tab. 4.6). Im Gegensatz zu den P-LoopMutanten waren die beiden Mutanten der GMP-Bindungsregion unter nativen Bedingungen nach Expression als GST-Fusionsprotein in E. coli unlöslich, sodaß zu ihrer Isolierung eine Denaturierungs-Renaturierungs-Strategie angewendet werden mußte. Die Wahl eines solchen Verfahrens zur Aufreinigung von Proteinen birgt das Problem in sich, daß denaturierte Polypeptidketten sich nicht unbedingt in ihre native Tertiärstruktur zurückfalten. Die Ursache für die Inaktivität von SAP97-GK(P-Loop, ST, S100D) und SAP97-GK(P-Loop, ST, P34S, S100D) im in vitro-Assay konnte folglich darin liegen, daß beide Mutanten nicht in ihrer enzymatisch kompetenten Konformation vorlagen. Aus diesem Grund wurde die Mutante SAP97-GK(P-Loop, ST, P34S, S100D) auch auf die Fähigkeit zur Komplementation des rezessiv letalen Phänotyps einer GUK1-defizienten haploiden Hefemutante überprüft. Sie war jedoch nicht in der Lage den Verlust der GUK1 zu supprimieren. In einem abschließenden 
Schritt wurde eine Chimäre aus dem N-terminalen (Aminosäuren 1 bis 37), den P-Loop umfassenden Teil der GUK1 und dem C-terminalen Teil (Aminosäuren 38 bis 183) von SAP97GK(P-Loop, ST, S100D) hergestellt. Die Chimäre GU97C besaß eine Übereinstimmung in der Aminosäure-Sequenz von $46 \%$ zur Hefe-GUK1. Dennoch zeigte sie die gleichen biochemischen und kinetischen Eigenschaften wie die beiden SAP97-GK-Mutanten der GMPBindungsregion. Weder war sie unter nativen Bedingungen löslich noch war das denaturierte und renaturierte Protein enzymatisch aktiv; auch konnte sie den letalen Phänotyp der GUK1defizienten Hefemutante nicht supprimieren.

Wenngleich die Mutagenese-Experimente zur Rekonstruktion einer aktiven Guanylatkinase aus der inaktiven GK-Domäne von SAP97 nicht erfolgreich waren, so lassen sich aus ihnen dennoch wichtige Rückschlüsse ziehen. Eine einfache Rekonstruktion aller aus der Hefe-GUK1 bekannten an der Substratbindung und Katalyse beteiligten Aminosäuren ist demnach nicht ausreichend, um SAP97-GK in eine aktive Guanylatkinase zu überführen. Wenngleich in der Chimäre GU97C alle an der Substratbindung und der Katalyse der aktiven Hefe-GUK1 beteiligten essentiellen Aminosäuren vorliegen, so muß dies nicht bedeuten, daß diese auch in der dreidimensionalen Struktur korrekt zum Substrat positioniert sind. Wie der Sequenzvergleich mit der GUK1 beispielsweise zeigt (siehe Abb. 1.7), besitzt die GK-Domäne von SAP97 zwar zwei Arginine in der LID-Region (Arg132 und Arg139), diese sind jedoch im Vergleich zu den essentiellen katalytischen Arg136 und Arg147 der GUK1 näher zueinander angeordnet. Die Mutation der katalytischen Arginine der LID-Region in der Uridylatkinase führt zum vollständigen Verlust der enzymatischen Aktivität (Schlichting und Reinstein, 1997). Darüberhinaus deutet insbesondere die äußerst geringe Sequenz-Identität von unter $20 \%$ in den C-terminalen 80 Aminosäuren von SAP97-GK und GUK1 (Zum Vergleich: SäugerGuanylatkinasen besitzen eine über 50\%ige Sequenz-Identität zur GUK1 in dem gleichen Bereich) an, daß die Tertiärstruktur der GK-Domäne wahrscheinlich doch in größerem Maße von der dreidimensionalen Struktur der Guanylatkinase abweicht. Diese strukturelle Abweichung ist vermutlich nicht durch den Austausch einzelner C-terminaler Aminosäuren zu kompensieren.

\subsection{Nukleotidbindungs-Eigenschaften von SAP97-GK}

Die GK-Domänen der beiden MAGUK-Proteine SAP97 und hCASK sind katalytisch nicht aktiv. Aufgrund des hohen Konservierungsgrades von Aminosäuren, welche in der Kristallstruktur der Hefe-GUK1 mit GMP interagieren (Stehle und Schulz, 1992), lag die Vermutung nahe, daß die GK-Domänen zumindest die Fähigkeit zur Bindung von 
Guanosinnukleotide nicht verloren hatten. Zur Untersuchung der NukleotidBindungseigenschaften der GK-Domäne von SAP97 wurde neben klassischen biochemischen Bindungs-Assays die neue Methode der Nano-Elektrospray-Massenspektrometrie (NanoESMS) eingesetzt. Bereits in einer früheren Studie unserer Arbeitsgruppe in Zusammenarbeit mit H. Prinz (MPI für molekulare Physiologie, Dortmund) konnte am Beispiel der Guanylatkinase und der GTPase p21 ${ }^{\text {ras }}$ gezeigt werden, daß die Methode zur Untersuchung der Nukleotidbindung an Proteine geeignet ist (Prinz et al., 1999; siehe Punkt 4.1.3.3). Mit Hilfe der Nano-ESMS konnten SAP97-GK-Nukleotid-Komplexe in wässriger Lösung identifiziert werden. Im einzelnen war eine Bindung der Purin-Nukleotide GMP, cGMP, GDP, ADP, ATP und GTP an SAP97-GK zu beobachten. Im Gegensatz dazu war keine Bindung von AMP bzw. cAMP nach Zugabe in äquimolaren Konzentration an SAP97-GK nachweisbar. Darüberhinaus konnte auch eindeutig zwischen der unspezifischen Bindung von UTP im Vergleich zu ATP und GTP unterschieden werden. Mit Ausnahme der Bindung von cGMP ähneln die Bindungseigenschaften der GK-Domäne jener von aktiven Guanylatkinasen (Prinz et al., 1999). Aufgrund der strukturellen Besonderheiten der GK-Domäne überrascht die Bindung an ein derart breites Spektrum von Nukleotiden. Wenngleich die Bindung von GMP und auch GDP aufgrund der konservierten GMP-Bindungsregion von SAP97-GK nachvollzogen werden konnte, so war eine Interaktion von SAP97-GK mit ATP aufgrund der partiellen Deletion des PLoops zunächst nicht erwartet worden. Das Fehlen essentieller Reste der ATP-Bindungsregion läßt auf eine veränderte Faltungstopologie des P-Loops schließen. Insofern muß davon ausgegangen werden, daß ATP im Vergleich zur Guanylatkinase in anderer Weise und vermutlich mit einer verringerten Affinität an die GK-Domäne bindet.

In allen Fällen konnten neben den erwarteten SAP97-GK-Nukleotid-Komplex-Peaks zusätzliche der Bindung von $\mathrm{SO}_{4}{ }^{2-}$-Ionen entsprechende Peaks im jeweiligen Massenspektrum identifiziert werden. Die Bindung von $\mathrm{SO}_{4}{ }^{2-}$-Ionen ist ein charakteristisches Merkmal Nukleotid-bindender Proteine. Beispielsweise wurden in den Kristallstrukturen von HefeGuanylatkinase und p21 ${ }^{\text {ras }}$ gebundene $\mathrm{SO}_{4}{ }^{2-}$-Ionen identifiziert, welche in der positiv geladenen ATP-Bindungstasche (gebildet unter anderem aus Resten des P-Loops und den katalytischen Argininen der LID-Region) lokalisiert waren und dort vermutlich zur Stabilität der Nukleotidfreien Konformation des Proteins beitragen (Stehle und Schulz, 1992; Scheffzek et al., 1999). In Übereinstimmung mit den Ergebnissen der früheren Studie an der Guanylatkinase und p21 ras (Prinz et al., 1999) war auch in SAP97-GK eine gemeinsame und keine konkurrierende Interaktion von Purin-Nukleotiden und $\mathrm{SO}_{4}{ }^{2-}$-Ionen $\mathrm{zu}$ beobachten. Die Identifizierung von 
gebundenen $\mathrm{SO}_{4}{ }^{2-}$-Ionen an SAP97-GK ist ein weiteres Hinweis dafür, daß die bisher in den Kristallstrukturen bekannter ATP- oder GTP-bindender Proteine identifizierte positiv geladene Substrat-Bindungstasche (das sog. giant anion hole in Adenylat- und Guanylatkinasen; Stehle und Schulz, 1992) in ähnlicher Konformation auch in der GK-Domäne von SAP97 konserviert sein muß.

\subsubsection{Selektivität der GK-Domäne}

Aus den bisher vorliegenden Bindungsdaten kann keine ausgeprägte Nukleotid-Selektivität der GK-Domäne abgeleitet werden. Nichtsdestotrotz deutet die Bindung aller getesteten Guanylate (GMP, cGMP, GDP und GTP) zumindest auf eine vorherrschende Selektivität zum Guaninring hin. Darüberhinaus läßt die Bindung von SAP97-GK an ADP und ATP, nicht jedoch AMP und cAMP, auf eine zusätzliche Affinität für die negativ geladene Polyphosphatkette von PurinNukleotiden schließen. In der Tat deutet die zunehmende Intensität der Komplex-Peaks in der Reihenfolge vom Monophosphat, über das Diphosphat zum Triphosphat an, daß die Bindungsaffinität vom unterschiedlichen Ionisierungsgrad der drei Nukleotide abhängig ist (vergleiche Abb. 4.37, 4.38 und 4.39).

Für die Beurteilung der Nukleotid-Selektivität erschwerend kommt hinzu, daß nach Inkubation mit den Nukleotidpaaren ATP/GMP und GTP/GMP in dem jeweiligen Massenspektrum zwar die einzelnen Protein-Nukleotid-Komplexe (SAP97-GK·ATP, SAP97-GK·GMP, SAP97GK·GTP, SAP97-GK·AMP) jedoch kein ternärer Komplex, bestehend aus SAP97GK·ATP·GMP bzw. SAP97-GK·GTP·GMP zu identifizieren war, die GK-Domäne demnach im Gegensatz zur aktiven Guanylatkinase nur eine Nukleotid-Bindestelle zu besitzen scheint. Die Ergebnisse der Nano-ESMS in Verbindung mit strukturellen Kenntnissen der SubstratBindungsmotive von Guanylatkinasen lassen sich $\mathrm{zu}$ drei allgemeinverbindlichen Schlußfolgerungen zur Nukleotid-Selektivität der GK-Domäne zusammenfassen: 1.) Die Bindung aller getesteten Guanylate zeigt, daß die GK-Domäne von SAP97 noch eine intakte GMP-Bindungsstelle besitzt. Dafür spricht auch die Konservierung annähernd aller an der Bindung von GMP beteiligten, aus dem GUK1-GMP-Komplex bekannten Aminosäuren in SAP97-GK. 2.) Wenngleich die globale strukturelle Konformation der ATP-Bindungsregion der Guanylatkinase nicht in der GK-Domäne konserviert zu sein scheint, so deutet die Bindung der Phosphatgruppen von ADP und ATP und des $\mathrm{SO}_{4}{ }^{2-}$-Ions doch auf die Existenz einer Art positiv geladener ATP-Bindungstasche in der GK-Domäne hin, welche jedoch in ihrer Konformation aufgrund des Fehlens essentieller Reste vermutlich signifikant von jener der Guanylatkinase 
abweicht. 3.) Die GK-Domäne ist nicht mehr in der Lage die beiden Substrate ATP und GMP der Guanylatkinase gleichzeitig $\mathrm{zu}$ binden. Dies ist ein Indiz für eine signifikante Konformationsänderung der Substratbindungsregion in SAP97-GK, möglicherweise hervorgerufen durch die partielle Deletion des P-Loops.

\subsubsection{Bindungsparameter}

Die Methode der Nano-ESMS erlaubt nur die qualitative Untersuchung der LigandenbindungsEigenschaften von Proteinen. Aufgrund unterschiedlicher Ionisierungs- und Desorptionseffekte können z.B. absolute Mengen verschiedener Ionen eines Proteins, in Abhängigkeit von der Sequenz und Größe der Peptide im Massenspektrum um mehr als den Faktor 2 varriieren (Jesperson, 1995; Dunayevskiy et al., 1995; Cohen und Chait, 1996). In LigandenbindungsUntersuchungen scheinen darüberhinaus neben der Assoziationskonstanten weitere Faktoren für die Bildung des Protein-Ligand-Komplexes mitentscheidend zu sein, wie die Untersuchung des ras-GTP-Komplexes mit der Ionenspray-Massenspektrometrie zeigte (Ganguly et al., 1993). Unter nicht standardisierten Bedingungen gibt folglich die Intensität eines Protein-Ligand-Peaks nicht die tatsächliche Konzentration des Komplexes in der Suspension wieder. Zur quantitativen Untersuchung der Nukleotibindung an die GK-homologen Domänen von SAP97 und hCASK mußten deshalb andere Methoden eingesetzt werden.

Die Dissoziationskonstanten der Nukleotidbindung an die GK-Domänen von SAP97 und hCASK wurden mit den zwei unterschiedlichen klassischen Methoden des Filter-Assays und der Gleichgewichtsdialyse bestimmt. Die heterogenen Ergebnisse der Bindungsstudien sind vermutlich auf die unterschiedlichen Sensitivitäten der eingesetzten Methoden zurückzuführen. Beide GK-Domänen interagierten mit allen getesteten Guanylaten, wobei die Affinitäten von SAP97-GK in der folgenden Reihenfolge abnahmen GMP > GTP > cGMP. Die mit der Methode der Gleichgewichtsdialyse bestimmten Dissoziationskonstanten für GMP betrugen $<0,1 \mu \mathrm{M}$ im Fall von SAP97-GK bzw. 0,3 $\mu \mathrm{M}$ im Fall von hCASK-GK. Im Gegensatz zu hCASK $\left(K_{\mathrm{d}(\mathrm{cGMP})}=0,4 \mu \mathrm{M}\right)$ war die Dissoziationskonstante von SAP97-GK $\left(K_{\mathrm{d}(\mathrm{cGMP})}=3,0\right.$ $\left.\mu \mathrm{M}, K_{\mathrm{d}(\mathrm{GTP})}=0,5 \mu \mathrm{M}\right)$ für GTP und cGMP um den Faktor 5 bzw. 30 erhöht. Die Bindungskonstanten für GMP sind annähernd identisch mit früheren NukleotidBindungsstudien an vollständigem SAP90 (Kistner et al., 1995). Während in dieser älteren Studie jedoch nur GMP-Bindung an das vollständige MAGUK-Protein nachgewiesen wurde, ist mit den hier vorliegenden Bindungsdaten der formale Nachweis erbracht, daß tatsächlich die GK-Domäne der MAGUK-Proteine GMP bindet. Im Gegensatz zur Bindung aller Guanylate 
konnte mit beiden Methoden keine Bindung von ATP, AMP und cAMP an SAP97-GK und hCASK-GK nachgewiesen werden. Aus den Bindungsdaten der biochemischen Assays in Verbindung mit jenen der Nano-ESMS ergibt sich ein vollständiges Bild der NukleotidBindungseigenschaften von SAP97-GK. Demnach hat die im Massenspektrum detektierte Bindung der GK-Domäne zu ATP eher einen unspezifischen Charakter und beruht vermutlich auf der Wechselwirkung der negativ geladenen Phosphatgruppen mit der positiven Ladungsdichte innerhalb der rudimentären ATP-Bindungstasche. Die Interaktion ist derart schwach, daß sie mit beiden klassischen Bindungs-Assays nicht nachweisbar ist. Die Ergebnisse der verschiedenen Methoden deuten daraufhin, daß die GK-Domänen von SAP97 und hCASK selektiv an die Base von Guanylaten bindet. Unter allen getesteten Guanylaten ist GMP der Ligand mit der höchsten Affinität.

Wie bereits in früheren Bindungsstudien an ATP- und GTP-bindenden Proteinen gezeigt wurde, bindet das freie Purin-Nukleotid stärker an das Protein, als der Mg.ATP-Komplex (Huang et al., 1998; John et al., 1990). Dieses Bindungsverhalten wurde mit der unterschiedlichen Anzahl an negativen Ladungen von $\mathrm{NTP}^{4-}$ und $\mathrm{Mg} \cdot \mathrm{NTP}^{2-}$ begründet (Huang et al., 1998). Da die Bindungsstudien mit der Nano-ESMS in Abwesenheit von $\mathrm{Mg}^{2+}$ durchgeführt wurden, wäre es interessant festzustellen, ob die Zugabe von $\mathrm{Mg}^{2+}$-Ionen die Bildung der NTP-Protein- bzw. NDP-Protein-Komplexe beeinflußt. Beruht die Interaktion von ATP mit der GK-Domäne tatsächlich nur auf einer schwachen Assoziation mit der negativ geladenen Polyphosphatkette, so sollte nach Zugabe von $\mathrm{Mg}^{2+}$-Ionen in Übereinstimmung mit den Ergebnissen der Bindung von zweifach negativ geladenem AMP im Massenspektrum kein Mg.ATP-Protein-KomplexPeak mehr detektierbar sein.

In Zusammenarbeit mit A. Lavie (University of Illinois at Chicago, USA) wird zur Zeit versucht die Kristallstruktur von SAP97-GK und hCASK-GK im Komplex mit verschiedenen GuanosinNukleotiden aufzuklären. Die dreidimensionale Struktur der GK-Domäne von SAP97 in Komplex mit den identifizierten Nukleotid-Liganden könnte aufgrund der strukturellen Besonderheiten der GK-Domäne Einblicke in ein möglicherweise von der Guanylatkinase abweichendes Bindungsschema gewähren.

\subsection{Intramolekulare Interaktion der SH3/U5- und GK-Domäne in SAP97}

Die konservierte Anordnung einer SH3-Domäne in direkter Nachbarschaft zu einer nachfolgenden Kinase-Domäne in allen Mitgliedern der MAGUK-Familie ist ein bekanntes 
strukturelles Motiv von Rezeptor-Tyrosinkinasen der Src-Familie. In den Tyrosinkinasen Src und Hck bindet die SH3-Domäne im Zusammenspiel mit einer SH2-Domäne an die nachfolgende Kinase-Domäne und inhibiert deren Aktivität. Diese intramolekulare Interaktion wird wieder aufgehoben und die enzymatische Aktivität reaktiviert, wenn die SH3- oder die SH2-Domäne an einen Protein-Ligand in trans bindet (Moarefi et al., 1997; Sicheri et al., 1997; Xu et al., 1997).

Durch Konstruktion eines Sensormoleküls, bestehend aus dem C-Terminus von SAP97, in welchem die GK-Domäne durch die aktive Guanylatkinase aus S. cerevisiae (GUK1) ersetzt wurde, konnte in dieser Arbeit gezeigt werden, daß tatsächlich eine intramolekulare Interaktion zwischen der SH3/U5- und der GK-Domäne in SAP97 besteht. Die N- und C-terminale Fusion der SH3/U5-Domäne sowie der C-terminalen 12 Aminosäuren an die GUK1 hatte einen dramatischen Abfall der Guanylatkinase-Aktivität zur Folge. Die Aktivität der Chimären SAP97-SH3/GUK1 (in allen Aktivitätstests wurden mehrere Chimären getestet, siehe Abb. 4.44) betrug nur noch 3\% der Wild-Typ-Aktivität. Interessanterweise scheinen die letzten 12 Aminosäuren von SAP97 eine wichtige regulatorische Rolle zu spielen, da die GuanylatkinaseAktivität der C-terminal verkürzten Chimären SAP97-SH3/GUK1 $(\Delta C)$ nicht signifikant von jener der Wild-Typ-Aktivität abwich. Darüberhinaus deutet die Unlöslichkeit bzw. schwache Löslichkeit der Deletionsmutanten SAP97-SH3-GK $(\Delta C)$ und SAP97-SH3/GUK1 $(\Delta C)$ nach heterologer Überexpression in E. coli daraufhin (siehe Tab. 4.8), daß die Präsenz der letzten 12 Aminosäuren sowohl in nativem SAP97-SH3/GK, als auch in SAP97-SH3/GUK1 vor der unspezifischen Zusammenlagerung und Aggregation der Proteine schützt, also eine wichtige Rolle in der Aufrechterhaltung der nativen Tertiärstruktur spielt. Die hier erhaltenen Resultate zeigen eindeutig, daß an der intramolekularen Wechselwirkung in SAP97 die GK-Domäne umgebende Sequenzen beteiligt sind. Darüberhinaus konnte durch Gelfiltration und Gleichgewichtszentrifuhation nachgewiesen werden, daß sowohl SAP97-SH3/GK2, als auch SAP97-SH3/GUK2 unter physiologischen Bedingungen als Monomere vorlagen und auch durch Zugabe von GMP oder ATP nicht in einen höheren Oligomerisierungszustand überführt wurden. Aus den Ergebnissen kann gefolgert werden, daß die intramolekulare Interaktion der SH3- und GK-Domäne in SAP97 unter physiologischen Bedingungen über eine mögliche intermolekulare Interaktion der beiden Domänen dominiert.

Einen weiteren eindeutigen Hinweis auf die signifikante strukturelle Rolle des C-Terminus lieferten Untersuchungen zum Migrationsverhalten der C-terminal verkürzten Proteinchimäre SAP97-SH3/GUK3( $\Delta \mathrm{C})$. Die Deletionsmutante eluierte als eine Proteinspezies mit einem 
Molekulargewicht von $54,3 \mathrm{kDa}$ von der Gelfiltrations-Säule. Mit der Methode der Gleichgewichtszentrifugation konnte jedoch unter den gleichen experimentellen Bedingungen kein Dimer in PBS-Puffer nachgewiesen werden. Das im Vergleich zu den beiden vollständigen Proteinen SAP97-SH3/GK2 und SAP97-SH3/GUK2 untypische Migrationsverhalten konnte nur mit einer asymmetrischen, weniger kompakten Form des verkürzten Proteins erklärt werden. Diese Vermutung wurde durch die Ergebnisse der Sedimentationsanalyse bestätigt. Demnach besitzt die Deletionsmutante SAP97-SH3/GUK2 $(\Delta \mathrm{C})$ im Vergleich zum vollständigem Protein SAP97-SH3/GUK2 einen um 15\% verringerten Sedimentationkoeffizient. Aufgrund seines größeren hydrodynamischen Radius eluiert das Protein früher von der Gelmatrix. Der in der verkürzten Chimäre beobachtete Effekt konnte nicht direkt in einer der nativen Deletionsmutanten SAP97-SH3/GK $(\Delta \mathrm{C})$ nachgewiesen werden, da alle C-terminal verkürzten nativen Konstrukte nach Expression in E. coli unlöslich waren. Aus den Vergleichen des Assoziationsverhalten von SAP97-SH3/GUK3( $\Delta$ C) und SAP97SH3/GUK2 sowie SAP97-SH3/GK2 und SAP97-SH3/GUK2 ist zu erwarten, daß auch die Mutante SAP97-SH3/GK $(\Delta \mathrm{C})$ aufgrund des Fehlens der C-terminalen 12 Aminosäuren in einer weniger kompakten Form vorliegt.

Das Ergebnis einer Reaktivierung der Kinase-Aktivität durch Verlust des C-Terminus in SAP97-SH3/GUK1-Chimären erinnert an Ergebnisse der Untersuchungen an SrcTyrosinkinasen. Die katalytische Aktivität dieser Enzyme wird unter anderem durch die Cterminale Sequenz moduliert. Fehlt der C-Terminus, so ist die intramolekulare Interaktion aufgehoben und die Enzyme bleiben in einem aktiven Zustand (Moarefi et al., 1997). In Übereinstimmung zu Src-Tyrosinkinasen ist auch der C-Terminus in MAGUK-Proteinen physiologisch relevant. Die Deletion der C-terminalen Aminosäuren von Dlg hat die Tumorbildung in Drosophila zur Folge (Woods und Bryant, 1991). Die hier gezeigten Ergebnisse legen den Schluß nahe, daß der C-Terminus eine wichtige negativ regulatorische Funktion in den Dlg-ähnlichen MAGUK-Proteinen besitzt. Vermutlich führt sein Verlust zur Aufhebung der geschlossenen Konformation der SH3/GK-Region, sodaß beide Domänen wieder frei zugänglich für die intermolekulare Interaktion mit ihren spezifischen Bindungspartnern, wie z.B. GKAP oder SAPAPs, sind. Diese Analogie zur Familie der SrcTyrosinkinasen läßt vermuten, daß auch die Funktion der SH3/U5- und GK-Domänen, genauer die Interaktion beider Domänen mit ihren jeweiligen spezifischen Bindungspartnern in trans, durch eine intramolekulare Wechselwirkung dieser beiden Domänen reguliert wird. 
Im Verlauf dieser Arbeit wurde die intramolekulare Interaktion der SH3- und der GK-Domäne auch in den MAGUK-Proteinen PSD-95, hDlg, hCASK und p55 von drei unabhängigen Forschungsgruppen bestätigt ( McGee und Bredt, 1999; Shin et al., 2000; Nix et al., 2000). Sie scheint somit in allen MAGUK-Subfamilien konserviert zu sein.

\subsubsection{Die intramolekulare SH3/GK-Interaktion in SAP97 verläuft über ein untypisches SH3-Bindungsmotiv}

SH3-Domänen binden im Allgemeinen an spezifische kurze Peptidsequenzen, welche Polyprolin-Helices der Klasse I (Konsensussequenz RLXLPP(L/R)PXX, X steht für jede beliebige Aminosäure) und Klasse II (XXXPPLPXR) (Cohen et al., 1995) ausbilden. Sowohl SAP97, als auch allen anderen MAGUK-Proteine, in denen bisher eine intramolekulare SH3/GK-Interaktion identifiziert werden konnte, fehlt jedoch die minimale Konsensussequenz PXXP in der GK-Domäne. Aus diesem Grund wird vermutet, daß die SH3-Domänen der MAGUK-Proteine eine untypische Bindungsspezifität besitzen. In einer Mutagenese-Studie an PSD-95 wurde überdies gezeigt, daß der Austausch der Prolinreste von drei Klasse II-ähnlichen Sequenzmotiven XXXPXR/K der GK-Domäne, welche als hypothetische SH3-Bindungsmotive fungieren konnten, nicht zur Aufhebung der intramolekularen Interaktion führte (Shin et al., 2000).

Durch molekulare Modellierung von SAP97 wurde kürzlich nachgewiesen, daß die SH3Domäne eine zur ATP-Bindungstasche der aktiven Guanylatkinase kompatible dreidimensionale Struktur aufweist (Wu et al., 2000). Deshalb wurde von den Autoren vorgeschlagen, daß die Bindung der SH3-Domäne nicht über ein spezifisches Sequenzmotiv, sondern über eine Interaktion mit der Oberfläche der ursprünglichen ATP-Bindungsregion verläuft (siehe Abb. 5.1). Die Ergebnisse der hier durchgeführten Nukleotid-Bindungsstudien an der GK-Domäne von SAP97 stützen diese Hypothese aus zwei Gründen: Erstens bindet die GK-Domäne von SAP97 nicht mehr spezifisch an ATP und zweitens deutet die Detektion von SAP97-GK-SO ${ }_{4}{ }^{2-}-$ Komplexen im Massenspektrum an, daß eine positiv geladene rudimentäre ATP-Bindungstasche in der GK-Domäne (welche aufgrund der angesprochenen strukturellen Besonderheiten jedoch vermutlich signifikant von jener der authentischen Guanylatkinase abweicht) noch $\mathrm{zu}$ existieren scheint. All diese Beobachtungen gehen mit der derzeitigen grundlegenden Annahme konform, daß die GK-Domäne aus der aktiven Guanylatkinase hervorgegangen ist und in Mehrzellern nur noch eine strukturelle Funktion besitzt.

In den Tyrosinkinasen Src und Hck bindet die SH3-Domäne an ein unvollständiges TypII Polyprolin-Segment (Feng et al., 1994; ebenfalls ohne minimale Consensussequenz PXXP, X 
steht für jede beliebige Aminosäure) des SH2-Kinase-Linkers und interagiert zusätzlich direkt mit der Kinase-Domäne. Die SH2-Domäne bindet ihrerseits an ein Phosphotyrosin des, der Kinase-Domäne folgenden, C-Terminus. In Analogie zu den Tyrosinkinasen deuten die Ergebnisse dieser Arbeit an, daß an der intramolekularen Interaktion in SAP97-SH3/GK sowohl interne Regionen der GK-Domäne, als auch die der GK-Domäne nachfolgende C-terminale Sequenz beteiligt sind. Wu et al. (2000) wiesen in ihrer Studie zur intramolekularen Interaktion in SAP97 nach, daß sowohl die SH3-Domäne, als auch das I3-Insert der U5-Helix mit der GKDomäne interagiert.

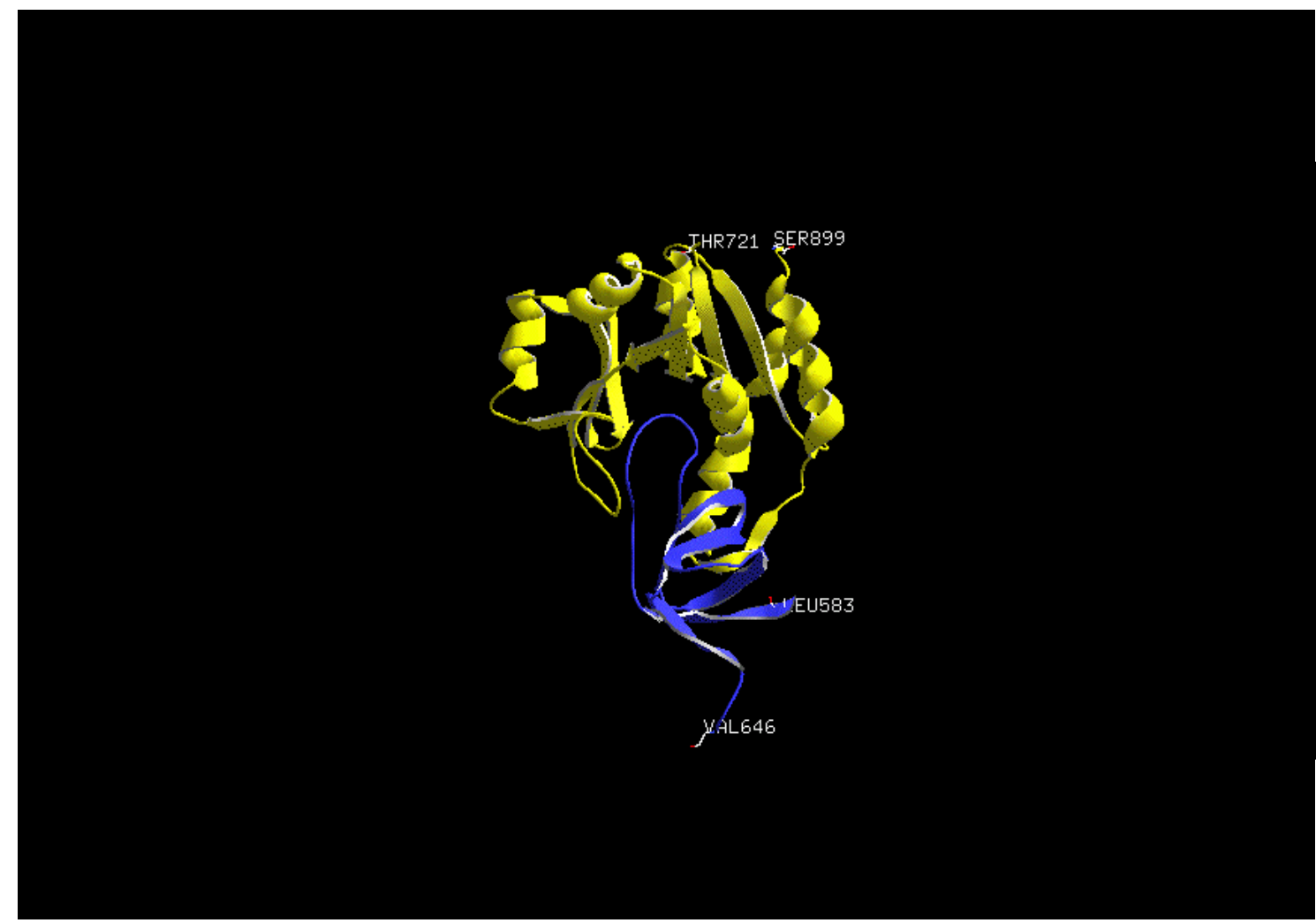

Abb. 5.1 Modell der Interaktion von SH3- (blau) und GK-Domäne (gelb) in SAP97. Die SH3-Domäne bildet einen Loop, welcher direkt in die ursprüngliche ATP-Bindungstasche hineinragt. Die SH3-Domäne wurde nach Vorlage der SH3-Domäne des growth factor bound protein 2 (1GRI) und die GK-Domäne nach Vorlage der Hefe-GUK1 (1GKY) modelliert. Abkürzungen 1GRI und 1GKY siehe Brookhaven Protein-Datenbank.

Die hier vorliegenden Ergebnisse lassen den Schluß zu, daß die geschlossen Konformation der SH3/GK-Region über mindestens zwei Bindungen erreicht wird. Die erste Interaktion verläuft über die SH3-Domäne und eine interne Region der GK-Domäne, dies könnte die ursprüngliche ATP-Bindungstasche sein. Darüberhinaus existiert vermutlich eine zweite Interaktion zwischen der U5-Sequenz und dem C-Terminus von SAP97. Diese Hypothese wird auch zusätzlich durch 
das Modell von SAP97 gestützt, in welchem die U5-Helix der C-terminalen Sequenz sehr nahe kommt (Wu et al., 2000).

\section{$5.9 \quad$ Funktionelle Rolle von GMP}

Obwohl die GK-Domänen von SAP97 und hCASK GMP mit hoher Affinität binden, ist bisher nicht geklärt, ob die Bindung eine physiologische Rolle in MAGUK-Proteine spielt. Es ist denkbar, daß durch die Bindung von GMP die Struktur der GK-Domäne stabilisiert wird. Andererseits könnt GMP jedoch auch als Effektormolekül wirken, welches die intramolekulare Interaktion von SH3/U5- und GK-Domäne moduliert. Wie bereits zuvor geschildert induzierte GMP nicht die Oligomerisation von nativem SAP97-SH3/GK. Dennoch war das Protein in Gegenwart von GMP durch ein im Vergleich zum Ligand-freien Protein signifikant verlangsamtes Sedimentationsverhalten gekennzeichnet. Die Abnahme des Sedimentationskoeffizienten von $3,83 \cdot 10^{-13} \mathrm{~s}$ auf $3,46 \cdot 10^{-13} \mathrm{~s}$ entsprach einer Zunahme des Stokes-Radius $\left(R_{\mathrm{S}}\right)$ von $11 \%$. Der geringere Sedimentationskoeffizient von GMP-gebundenem SAP97-SH3/GK deutet auf eine ausgedehntere und weniger kompakte Form im Vergleich zu Ligand-freiem Protein hin. In vielen Fällen wird eine durch Ligandenbindung induzierte Konformationsänderung durch eine 1-5\%ige Abweichung des Sedimentationskoeffizienten angezeigt (Durchschlag et al., 1996). Abweichungen darüberhinaus entsprechen größeren durch Bindung von Liganden induzierten Bewegungen von Domänen (Roustan et al., 1980) oder globalen Umlagerungen (Zarutskie et al., 1999; Skehel et al., 1982). Sowohl das Entfernen der C-terminalen 12 Aminosäuren (15\%ige Abweichung), als auch die Bindung von GMP bewirkt demnach eine globale Änderung der Tertiärstruktur von SAP97-SH3/GK2. Interessanterweise entspricht der Sedimentationskoeffizient der Chimäre SAP97-SH3/GUK2 $\left(s_{20, \mathrm{w}}=3,42 \cdot 10^{-13} \mathrm{~s}\right)$ in Etwa GMP-gebundenem SAP97-SH3/GK2 $\left(s_{20, \mathrm{w}}=3,46 \cdot 10^{-13} \mathrm{~s}\right)$. Diese Beobachtung könnte damit erklärt werden, daß die SH3-Domäne in SAP97-SH3/GK2 an eine Bindungsstelle der GK-Domäne bindet, welche in der Guanylatkinase GUK1 nicht vorhanden ist. Bindung von GMP an die singuläre Nukleotid-Bindestelle in SAP97-SH3/GK2 könnte die Konformation des Proteins derart verändern, daß die spezifische Interaktion zwischen der SH3- und GK-Domäne unterbrochen wird und das Protein nun das gleiche Sedimentationsverhalten wie die Chimäre zeigt. Sollte sich die Modellvorstellung der Interaktion der SH3-Domäne mit der ursprüngliche ATP-Bindungstasche experimentell bestätigen, so wäre in Übereinstimmung mit der Tatsache, daß im Massenspektrum kein ternärer Komplex von ATP.GMP·SAP97-GK detektiert wurde 
auch der Komplex SAP97-SH3/GK·GMP nicht existent. Nano-ESMS-Bindungsstudien des Fusionsproteins SAP97-SH3/GK mit GMP sollten zur Klärung dieser Frage führen.

SAP97 existiert in einer kompakten Struktur, wobei intermolekulare Bindungsstellen durch intramolekulare Interaktionen maskiert sind. Vieles spricht dafür, daß beispielsweise durch die intramolekulare Interaktion von SH3/U5- und GK-Domäne die intermolekulare Bindung an GKAP reguliert wird (Wu et al., 2000). Es ist denkbar, daß auch intermolekulare Interaktionen mit Liganden der SH3-Domäne, U5-Region und/oder der GK-Domäne die Interaktion mit GKAP, sowie weiteren Bindungspartnern der GK-Domäne, in trans beeinflußen. Die Bindung von hochaffinen Liganden, wie z.B. Calmodulin an die U5-Helix oder GMP an die GK-Domäne könnte zu einer Entfaltung der SH3/GK-Region in eine offene Konformation führen und die Domänen somit zugänglich für ihre jeweils identifizierten Interaktionspartner machen (siehe Abb. 5.2). Gestüzt wird diese Modellvorstellung durch die in dieser Arbeit beobachtete Konformationsänderung in SAP97-SH3/GK nach GMP-Bindung, welche eher einer großen Domänen-Bewegungen, als herkömmlichen strukturellen Umlagerungen nach LigandenBindung entspricht. Es ist jedoch auch denkbar, daß die intramolekulare Interaktion der GK/SH3-Region wiederum in Übereinstimmung zu den Src-Tyrosinkinasen zusätzlich durch Phosphorylierung reguliert wird.

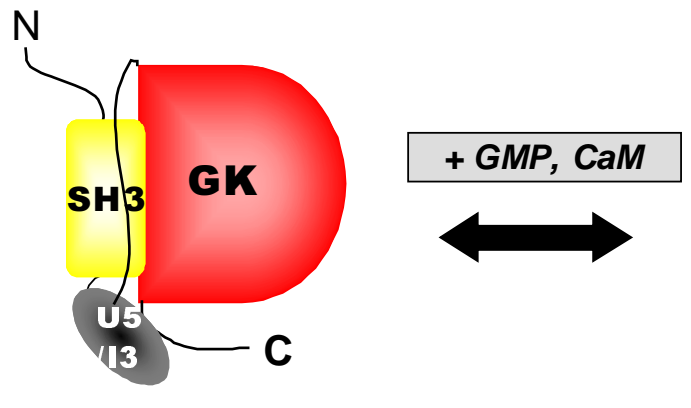

eschlossene Konformation

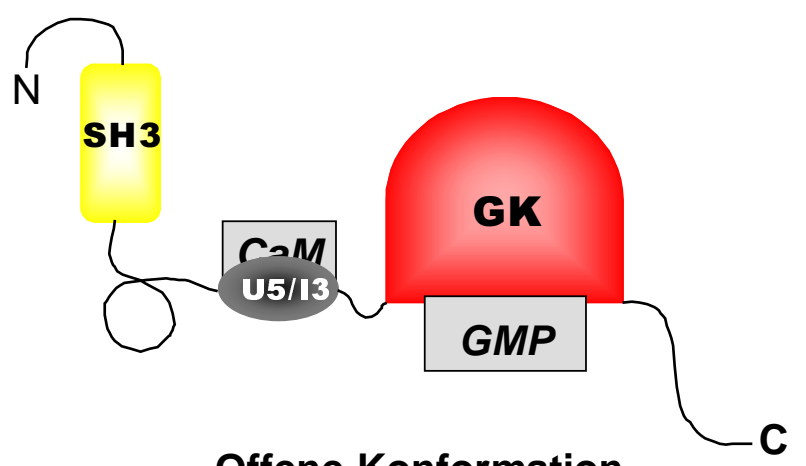

Offene Konformation

Abb. 5.2 Modell zur möglichen Regulation der intramolekularen SH3-GK-Interaktion durch Liganden der U5- und GK-Domäne. Bindung von $\mathrm{Ca}^{2+} /$ Calmodulin und/oder GMP induziert eine Konformationsänderung, welche die intramolekulare Interaktion der beiden Domänen aufhebt und das Protein in eine offene Konformation überführt.

Sollte sich die hypothetisch regulative Rolle von Liganden der U5-Region und der GK-Domäne bestätigen, so wäre dies ein weitreichender Schritt in der Aufklärung des molekularen Mechanismus, welcher der Funktion von MAGUK-Proteinen in der Zusammenlagerung von Multiprotein-Komplexen an speziellen Zell-Zell-Kontaktstellen zugrundeliegt. 


\section{Zusammenfassung}

Die Guanylatkinase ist ein essentielles Enzym des Purinnukleotid-Stoffwechsels und katalysiert die reversible Übertragung der terminalen Phosphatgruppe von Mg.(d)ATP zu (d)GMP. Zur Etablierung eines in vivo-Systems zum Auffinden von aktiven Guanylatkinasen auf Basis eines haploiden Guanylatkinase (GUK1)-defizienten Hefestammes wurde die Expression des GUK1Gens der Kontrolle des Tetracyclin-regulierbaren Promoters unterstellt. Wenngleich ein vollständiges Abschalten Promoters nicht möglich war, so eröffnet die modulierte Expression des essentiellen GUK1-Gens neue Möglichkeiten zum Studium konditionaler GUK1Hefemutanten.

Obwohl der katalytische Mechanismus der Guanylatkinase weitestgehend aufgeklärt ist, sind Daten zur Funktion und Struktur des Enzyms im Vergleich zu anderen Nukleosidmonophosphatkinasen bisher rar. In dieser Arbeit wurden die Guanylatkinasen von zwei Säugern und die erste einer Pflanze biochemisch und kinetisch untersucht. Mit der Isolierung großer Mengen aktiver Säuger- und Pflanzen-Guanylatkinasen aus E. coli sind die Voraussetzungen zur Kristallisation dieser Enzyme geschaffen. Während die katalytische Effizienz der Guanylatkinase des Menschen und der Maus ähnlich jener der Hefe ist, weicht die A. thaliana-Guanylatkinase AGUK1 sowohl strukturell, als auch kinetisch beträchtlich von den bisher bekannten Guanylatkinasen ab. Sie ist 100fach weniger aktiv als das Hefe-Enzym kann allerdings den rezessiv-letalen Phänotyp der GUK1-Deletion in der Hefe supprimieren. Zusätzliche N- und C-terminalen Verlängerungen besitzen keinen regulatorischen Effekt auf die Enzym-Aktivität. Der strukturelle Aufbau aus mehreren Domänen und die Sequenz-Ähnlichkeit des N-Terminus deuten auf eine Verwandtschaft $\mathrm{zu}$ den größeren Membran-assoziierten Guanylatkinasen hin.

Die Membran-assoziierten Guanylatkinasen wurden als Gerüstproteine an neuronalen und epithelialen Kontaktstellen von Vertebraten identifiziert. Sie besitzen eine Multidomänenstruktur und sind aus einer bis drei PDZ, einer SH3 und einer C-terminalen GKDomäne mit 33-37\%iger Sequenz-Identität zu Säuger-Guanylatkinasen aufgebaut. Während die GMP-Bindungsregion zum Teil konserviert ist, fehlen der GK-Domäne aller MAGUK-Proteine essentielle Aminosäuren der ATP-Bindungsregion Die GK-Domänen der MAGUK-Proteine SAP97 und hCASK zeigten nach Aufreinigung aus E. coli keine meßbare GuanylatkinaseAktivität und konnten den Verlust der GUK1 in der Hefe nicht komplementieren. Der Versuch die GK-Domäne von SAP97 durch systematische Rekonstruktion der Substratbindungsmotive 
in ein aktives Enzym zu überführen war nicht erfolgreich. Die GK-Domäne von MAGUKProteinen besitzt scheinbar nur noch eine strukturelle Funktion als Protein-Bindungsdomäne, ähnlich jener der PDZ-Domäne. Mit der Methode der Nano-Elektrospray-Massenspektrometrie und klassischen biochemischen Bindungs-Assays wurden mehrere Purinnukleotide als Liganden der GK-Domäne von SAP97 identifiziert. Die vorherrschende Affinität zu Guanosinnukleotiden deutet auf die Konservierung der GMP-Bindungsregion aktiver Guanylatkinasen in SAP97-GK hin. Unter allen getesteten Purinnukleotiden zeigte GMP die höchste Affinität zur GK-Domäne. Desweiteren wurde eine intramolekulare Interaktion in SAP97-SH3/GK nachgewiesen, welche über die GK-Domäne umgebende Sequenzen verläuft. Durch analytische Ultrazentrifugation konnte überdies gezeigt werden, daß die intramolekulare Interaktion im monomeren SAP97SH3/GK-Konstrukt dominiert und über mindestens zwei Interaktionsstellen verläuft. Sowohl der Verlust des C-Terminus, als auch die Bindung von GMP haben eine globale Konformationsänderung von SAP97-SH3/GK in ein weniger kompaktes Molekül zur Folge. GMP könnte die Funktion eines Effektormoleküls besitzen, welches im Zusammenspiel mit Liganden der SH3-Domäne die intramolekulare Interaktion in SH3/GK moduliert. 


\section{$7 \quad$ Anhang}

\section{Nukleotid- und Aminosäuresequenz der A. thaliana Guanylatkinase AGUK1}

(Die Sequenz von AGUK1(137-330) ist unterstrichen)

atgggagaagctccagcagtattagtggatcatccggagaacggacactccaatggtgtc 60 $\begin{array}{llllllllllllllllllll}M & G & E & A & P & A & V & L & V & D & H & P & E & N & G & H & S & N & G & V\end{array}$

tgtgtgaaatctgaaccagagaacactgagataacagtcgatgtcggcgatcgaatattt 120 $\begin{array}{lllllllllllllllllllll}C & V & K & S & E & P & E & N & T & E & I & T & V & D & V & G & D & R & I & F\end{array}$

ttgatcggtggaaatcatgaaaggaacaatttttccattggggttcagatttatgacaaa 180 $\begin{array}{lllllllllllllllllllll}L & I & G & G & N & H & E & R & N & N & F & S & I & G & V & Q & I & Y & D & K\end{array}$ atcagtaacaactggtttagtcctattgtgcttgggacaggtcctaagcccagcaagggg 240 $\begin{array}{lllllllllllllllllllll}I & S & N & N & W & F & S & P & I & V & L & G & T & G & P & K & P & S & K & G\end{array}$ tactccgcgtttgttcttgaacaaggtcggattttggttattaaaaaaggttcacctcgc 300 $\begin{array}{llllllllllllllllllll}Y & S & A & F & V & L & E & Q & G & R & I & L & V & I & K & K & G & S & P & R\end{array}$ aacgactccatctggttcctcgaggtcgatagtccttatgtgcgggaacagaagaagtta 360 $\begin{array}{lllllllllllllllllllll}N & D & S & I & W & F & L & E & V & D & S & P & Y & V & R & E & Q & K & K & L\end{array}$ ctaaggaaggaagttgttgcttggagtaaaggtgtgagaggcaatgctgagaagcctatt 420 \begin{tabular}{llllllllllllllllllll}
$\mathrm{L}$ & $\mathrm{R}$ & $\mathrm{K}$ & $\mathrm{E}$ & $\mathrm{V}$ & $\mathrm{V}$ & $\mathrm{A}$ & $\mathrm{W}$ & $\mathrm{S}$ & $\mathrm{K}$ & $\mathrm{G}$ & $\mathrm{V}$ & $\mathrm{R}$ & $\mathrm{G}$ & $\mathrm{N}$ & $\underline{A}$ & $\mathrm{E}$ & $\mathrm{K}$ & $\mathrm{P}$ & $\mathrm{I}$ \\
\hline
\end{tabular} gttataagcggtccttctggtgtgggcaaaggaacgcttatatcaatgcttatgaaggag 480 \begin{tabular}{llllllllllllllllllll}
$V$ & $I$ & $S$ & $G$ & $P$ & $S$ & $G$ & $V$ & $G$ & $K$ & $G$ & $T$ & $L$ & $I$ & $S$ & $M$ & $L$ & $M$ & $K$ & $E$ \\
\hline
\end{tabular} tttccttcaatgtttgggttctctgtgagtcacacaactcgatctccgaggtctatggag 540 $\begin{array}{lllllllllllllllllllll}F & P & S & M & F & G & F & S & V & S & H & T & T & R & S & P & R & S & M & E & \\ \text { atggacggtgttcattattactttgctgataaaaaagttatggagaaagaaatcaaagac } & 600\end{array}$ \begin{tabular}{llllllllllllllllllll}
$M$ & $D$ & $G$ & $V$ & $H$ & $Y$ & $Y$ & $F$ & $A$ & $D$ & $K$ & $K$ & $V$ & $M$ & $E$ & $K$ & $E$ & $I$ & $K$ & $D$ \\
\hline
\end{tabular} ggaagtttcttgagtttgcttctgttcacggtaatctctatggaaccagcattgagtcC 660 \begin{tabular}{llllllllllllllllllll}
$G$ & $K$ & $F$ & $L$ & $E$ & $F$ & $A$ & $S$ & $V$ & $H$ & $G$ & $N$ & L & Y & $G$ & T & $S$ & I & $E$ & $S$ \\
\hline
\end{tabular} gttgaagcggtaacagattcaggaaagagatgtattctcgacattgatgttcagggggca 720 \begin{tabular}{llllllllllllllllllll}
$V$ & $E$ & $A$ & $V$ & $T$ & $D$ & $S$ & $G$ & $K$ & $R$ & $C$ & $I$ & L & D & I & $D$ & $V$ & $Q$ & $G$ & $A$ \\
\hline
\end{tabular} aggtctgtgagagcgagttctcttgatgccatattcatattcgtatgtccccettcaatg \begin{tabular}{llllllllllllllllllll}
$\mathrm{R}$ & $\mathrm{S}$ & $\mathrm{V}$ & $\mathrm{R}$ & $\mathrm{A}$ & $\mathrm{S}$ & $\mathrm{S}$ & $\mathrm{L}$ & $\mathrm{D}$ & $\mathrm{A}$ & $\mathrm{I}$ & $\mathrm{F}$ & $\mathrm{I}$ & $\mathrm{F}$ & $\mathrm{V}$ & $\mathrm{C}$ & $\mathrm{P}$ & $\mathrm{P}$ & $\mathrm{S}$ & $\mathrm{M}$ \\
\hline
\end{tabular} aaagagcttgaagatcggctccgtgctagaggaaccgagacagaggagcaaattcaaaag

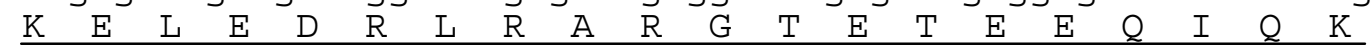
cggcttagaaatgctgaggcagagatcaaagaagggatatcctcgggtattttcggtctc 900 \begin{tabular}{llllllllllllllllllll}
$\mathrm{R}$ & $\mathrm{L}$ & $\mathrm{R}$ & $\mathrm{N}$ & $\mathrm{A}$ & $\mathrm{E}$ & $\mathrm{A}$ & $\mathrm{E}$ & $\mathrm{I}$ & $\mathrm{K}$ & $\mathrm{E}$ & $\mathrm{G}$ & $\mathrm{I}$ & $\mathrm{S}$ & $\mathrm{S}$ & $\mathrm{G}$ & $\mathrm{I}$ & $\mathrm{F}$ & $\mathrm{G}$ & $\mathrm{L}$ \\
\hline
\end{tabular} attttgtataatgacaaccttgaggaatgctacaagaagctcaagaatctcttggggcta 960 \begin{tabular}{llllllllllllllllllll}
$\mathrm{I}$ & $\mathrm{L}$ & $\mathrm{Y}$ & $\mathrm{N}$ & $\mathrm{D}$ & $\mathrm{N}$ & $\mathrm{L}$ & $\mathrm{E}$ & $\mathrm{E}$ & $\mathrm{C}$ & $\mathrm{Y}$ & $\mathrm{K}$ & $\mathrm{K}$ & $\mathrm{L}$ & $\mathrm{K}$ & $\mathrm{N}$ & $\mathrm{L}$ & $\mathrm{L}$ & $\mathrm{G}$ & $\mathrm{L}$ \\
\hline
\end{tabular} gatggactcgctcatgtcaatggtgtagaaatagaggggatcaatcttcccattgagtac 1020 $\begin{array}{lllllllllllllllllllllll}\mathrm{D} & \mathrm{G} & \mathrm{L} & \mathrm{A} & \mathrm{H} & \mathrm{V} & \mathrm{N} & \mathrm{G} & \mathrm{V} & \mathrm{E} & \mathrm{I} & \mathrm{E} & \mathrm{G} & \mathrm{I} & \mathrm{N} & \mathrm{L} & \mathrm{P} & \mathrm{I} & \mathrm{E} & \mathrm{Y}\end{array}$ acagtatctaaaatggaagataagatcattattcaagaaacaggaaaagaaacaaggaat 1080 $\begin{array}{llllllllllllllllllll}\mathrm{T} & \mathrm{V} & \mathrm{S} & \mathrm{K} & \mathrm{M} & \mathrm{E} & \mathrm{D} & \mathrm{K} & \mathrm{I} & \mathrm{I} & \mathrm{I} & \mathrm{Q} & \mathrm{E} & \mathrm{T} & \mathrm{G} & \mathrm{K} & \mathrm{E} & \mathrm{T} & \mathrm{R} & \mathrm{N}\end{array}$ aagattgtattggatatatcttcgcttaatggaggagcaccgggtagaacaagggggatt 1140 $\begin{array}{llllllllllllllllllllllllllll}K & I & V & L & D & I & S & S & L & N & G & G & A & P & G & R & T & R & G & I\end{array}$ cttgtcgacgccattaagttctag 1164

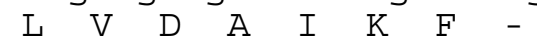




\section{Nukleotid- und Aminosäuresequenz der Membran-assoziierten Guanylatkinase SAP97}

(Dargestellt ist die SAP97-Sequenz mit dem Insert I2 (doppelt unterstrichen). Die GK-Domäne ist einfach unterstrichen)

atgccggtccggaagcaagatacccagagagcattgcatctgttggaagaatatcggtcg 60 $\begin{array}{llllllllllllllllllll}M & P & V & R & K & Q & D & T & Q & R & A & L & H & L & L & E & E & Y & R & S\end{array}$ aaactaagccaaaccgaagacagacagctcaggagttccatagagcgggttattagcata 120 $\begin{array}{llllllllllllllllllll}K & L & S & Q & T & E & D & R & Q & L & R & S & S & I & E & R & V & I & S & I\end{array}$ tttcagagcaacctctttcaggctttaatagacattcaagaattttatgaagtgacctta 180 $\begin{array}{lllllllllllllllllllllll}F & Q & S & N & L & F & Q & A & L & I & D & I & Q & E & F & Y & E & V & T & L\end{array}$ cttgataatccaaaatgtgtggatcattcaaagcagtgtgaaccggtccaacccgggaat 240 $\begin{array}{llllllllllllllllllll}L & D & N & P & K & C & V & D & H & S & K & Q & C & E & P & V & Q & P & G & N\end{array}$ ccttgggagagtggcagcctttcaagtgctgctgtgacttcagagagcctgcccggcggc 300

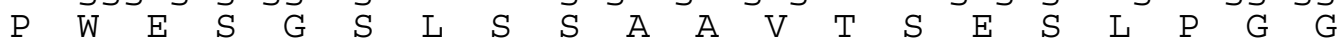
cttagccctccagtagagaaataccggtatcaggacgaagaggtgctgccttcagagcgg 360 $\begin{array}{llllllllllllllllllll}L & S & P & P & V & E & K & Y & R & Y & Q & D & E & E & V & L & P & S & E & R\end{array}$ atttccccgcaagtcccaaatgaggtgctgggtccggagctggttcacgtctcggagaag 420 $\begin{array}{lllllllllllllllllllllllllll}I & S & P & Q & V & P & N & E & V & L & G & P & E & L & V & H & V & S & E & K\end{array}$ agcctgtcagagattgagaatgtccacgggtttgtctctcactctcatatctcacccata 480 $\begin{array}{lllllllllllllllllllllll}S & L & S & E & I & E & N & V & H & G & F & V & S & H & S & H & I & S & P & I\end{array}$ aagcccacagaagctgttcctccctcctctcccattgtccctgtgacccctgccttgcca 540 $\begin{array}{llllllllllllllllllll}K & P & T & E & A & V & P & P & S & S & P & I & V & P & V & T & P & A & L & P\end{array}$ gtccctgctgagagtcctgtcgtcctgccetccacaccacaggcaatcctcctcctgtc 600 $\begin{array}{llllllllllllllllllll}V & P & A & E & S & P & V & V & L & P & S & T & P & Q & A & N & P & P & P & V\end{array}$ ctggtcaacacagacagcttggagacaccaacttatgttaatggtactgatgcagattat 660 $\begin{array}{llllllllllllllllllllll} & \mathrm{V} & \mathrm{V} & \mathrm{N} & \mathrm{T} & \mathrm{D} & \mathrm{S} & \mathrm{L} & \mathrm{E} & \mathrm{T} & \mathrm{P} & \mathrm{T} & \mathrm{Y} & \mathrm{V} & \mathrm{N} & \mathrm{G} & \mathrm{T} & \mathrm{D} & \mathrm{A} & \mathrm{D} & \mathrm{Y}\end{array}$ gaatatgaggaaatcacacttgaaaggggaaattcaggcttgggtttcagcattgcagga 720 $\begin{array}{lllllllllllllllllllll} & \mathrm{Y} & \mathrm{Y} & \mathrm{E} & \mathrm{E} & \mathrm{I} & \mathrm{T} & \mathrm{L} & \mathrm{E} & \mathrm{R} & \mathrm{G} & \mathrm{N} & \mathrm{S} & \mathrm{G} & \mathrm{L} & \mathrm{G} & \mathrm{F} & \mathrm{S} & \mathrm{I} & \mathrm{A} & \mathrm{G}\end{array}$ ggtacagacaacccacacattggagatgactcaagtattttcatcaccaaattatcacg 780 $\begin{array}{llllllllllllllllllll}G & T & D & N & P & H & I & G & D & D & S & S & I & F & I & T & K & I & I & T\end{array}$ ggaggagcagctgcccaggatggaagattgcgggtaaatgactgtatactgagagtaaat 840 $\begin{array}{lllllllllllllllllllllll}G & G & A & A & A & Q & D & G & R & L & R & V & N & D & C & I & L & R & V & N\end{array}$ gaagcagatgttcgtgatgtaacccacagcaaagcagttgaagcattgaaagaagctgga 900 $\begin{array}{lllllllllllllllllllllll}E & A & D & V & R & D & V & T & H & S & K & A & V & E & A & L & K & E & A & G\end{array}$ tcgatagtgcgattatatgtgaaaaggcggaaggccttcagaaaaaatcatgaaataaaa 960 $\begin{array}{lllllllllllllllllllll}S & I & V & R & L & Y & V & K & R & R & K & A & F & R & K & N & H & E & I & K\end{array}$ cttattaaaggccctaaaggtcttgggttcagcattgctggaggtgttggaaaccagcac 1020 $\begin{array}{llllllllllllllllllllllll} & L & I & K & G & P & K & G & L & G & F & S & I & A & G & G & V & G & N & Q & H\end{array}$ Attcctggggataacagcatctatgtaaccaaaataattgaaggaggtgcagcacacaag 1080 $\begin{array}{llllllllllllllllllllll}I & P & G & D & N & S & I & Y & V & T & K & I & I & E & G & G & A & A & H & K\end{array}$ gacggcaaacttcagattggagacaagcttctagcagtgaacagtgtctgtttagaagaa 1140 $\begin{array}{llllllllllllllllllll}D & G & K & L & Q & I & G & D & K & L & L & A & V & N & S & V & C & L & E & E\end{array}$ gttactcatgaagaagcagtgactgccttaaagaatacatctgattttgtttatttgaaa 1200 $\begin{array}{lllllllllllllllllllll}V & T & H & E & E & A & V & T & A & L & K & N & T & S & D & F & V & Y & L & K\end{array}$ gcggcaaaaccaacaagtatgtatataaatgatggctatgcaccacccgacatcactaat 1260 $\begin{array}{lllllllllllllllllllll}A & A & K & P & T & S & M & Y & I & N & D & G & Y & A & P & P & D & I & T & N\end{array}$ tcttcttctcagtctgttgacaaccatgttagcccgtcttcatacttgggccagactcca 1320 $\begin{array}{llllllllllllllllllllll}S & S & S & Q & S & V & D & N & H & V & S & P & S & S & Y & L & G & Q & T & P\end{array}$ gcgtcaccagccagatactcacccatttctaaagcagtgcttggagatgatgagatcact 1380 $\begin{array}{lllllllllllllllllllll}A & S & P & A & R & Y & S & P & I & S & K & A & V & L & G & D & D & E & I & T\end{array}$ agggaacctagaaaagttgttcttcatcgtggctcaacgggacttggtttcaacattgtg 1440 $\begin{array}{llllllllllllllllllll}R & E & P & R & K & V & V & L & H & R & G & S & T & G & L & G & F & N & I & V\end{array}$ ggaggcgaagatggagaagggatttttatctctttcatccttgctgggggacctgctgac 1500 $\begin{array}{lllllllllllllllllllll}G & G & E & D & G & E & G & I & F & I & S & F & I & L & A & G & G & P & A & D\end{array}$ ctaagcggagagctcagaaaaggagatcgcattatatcggtaaacagtgttgacctcaga 1560 $\begin{array}{lllllllllllllllllllll}L & S & G & E & \text { L } & R & K & G & D & R & I & I & S & V & N & S & V & D & L & R\end{array}$ gctgcaagtcatgaacaagcagctgccgcattaaaaaacgcaggccaagctgtcactatt 1620 $\begin{array}{lllllllllllllllllllll}A & A & S & H & E & Q & A & A & A & A & L & K & N & A & G & Q & A & V & T & I\end{array}$ gtcgcacagtatcggcctgaagagtacagtcgttttgaagctaaaattcacgacttgcgg 1680 $\begin{array}{lllllllllllllllllllll}V & A & Q & Y & R & P & E & E & Y & S & R & F & E & A & K & I & H & D & L & R\end{array}$ gagacgatgatgaacagcagtgtcagctcagggtcagggtctctccgaaccagccaaaag 1740 $\begin{array}{lllllllllllllllllllllll} & E & T & M & M & N & S & S & V & S & S & G & S & G & S & L & R & T & S & Q & K\end{array}$ 
cggtccctctatgtcagagccettttgattacgacaagactaaagacagtggccttccc 1800 $\begin{array}{lllllllllllllllllllll}R & S & L & Y & V & R & A & L & F & D & Y & D & K & T & K & D & S & G & L & P\end{array}$ agtcaagggttgaacttcaaattcggagatattctccatgttatcaatgcttctgatgac 1860 $\begin{array}{llllllllllllllllllllll}S & Q & G & L & N & F & K & F & G & D & I & L & H & V & I & N & A & S & D & D\end{array}$ gagtggtggcaggccagacaggtgaccccagatggtgagagtgacgaagttggagtaatt 1920 $\begin{array}{lllllllllllllllllll}E & W & W & A & Q & V & T & P & D & G & E & S & D & E & V & G & V & I\end{array}$ cctagtaaacgcagagttgagaagaaagaacgagcccgattaaaaacagtcaaattcaat 1980 $\begin{array}{lllllllllllllllllllll}P & S & K & R & R & V & E & K & K & E & R & A & R & L & K & T & V & K & F & N\end{array}$ tctaaaacaagaggagataaaggggagatccctgacgacatgggatcaaaaggcctgaag 2040 \begin{tabular}{llllllllllllllllllll}
$S$ & $K$ & $T$ & $R$ & $G$ & $D$ & $K$ & $G$ & $E$ & $I$ & $P$ & $D$ & $D$ & $M$ & $G$ & $S$ & $K$ & $G$ & $I$ & $K$ \\
\hline
\end{tabular} tacgtaacttctaatgccagcgatagcgaagtagttaccatgaatatggctgctcaaaa 2100 $\begin{array}{llllllllllllllllllll}H & V & T & S & N & A & S & D & S & E & S & S & Y & H & E & Y & G & C & S & K\end{array}$ ggtggtcaagaagaatatgttttatcgtatgagccggtgaatcagcaagaagttaattat 2160 $\begin{array}{llllllllllllllllllll}G & G & Q & E & E & Y & V & L & S & Y & E & P & V & N & Q & Q & E & V & N & Y\end{array}$ acccgaccagtcatcatattaggacctatgaaagacagagtaaatgatgacttaatctca 2220 \begin{tabular}{llllllllllllllllllll}
$T$ & $R$ & $P$ & $V$ & $I$ & $I$ & $L$ & $G$ & $P$ & $M$ & $K$ & $D$ & $R$ & $V$ & $N$ & $D$ & $D$ & $L$ & $I$ & $S$ \\
\hline
\end{tabular} gaatttcctgacaatttggatcctgtgtccctcatacaactagaccaagcgtgactat 2280 \begin{tabular}{lllllllllllllllllllll}
$E$ & $F$ & $P$ & $D$ & $K$ & $F$ & $G$ & $S$ & $C$ & $V$ & $P$ & $H$ & $T$ & $T$ & $R$ & $P$ & $K$ & $R$ & $D$ & $Y$ \\
\hline
\end{tabular} gaggtggatggacgagattaccattttgtgacttcaagagaacagatggagaaagatatc 2340 \begin{tabular}{clllllllllllllllllll}
$E$ & $V$ & $D$ & $G$ & $R$ & $D$ & $Y$ & $H$ & $F$ & $V$ & $T$ & $S$ & $R$ & $E$ & $Q$ & $M$ & $E$ & $K$ & $D$ & $I$ \\
\hline
\end{tabular} caggagcataaattcattgaagctggccagtataacaaccatctatacggaacgagtgtc 2400 \begin{tabular}{llllllllllllllllllll}
$\mathrm{O}$ & $\mathrm{E}$ & $\mathrm{H}$ & $\mathrm{K}$ & $\mathrm{F}$ & $\mathrm{I}$ & $\mathrm{E}$ & $\mathrm{A}$ & $\mathrm{G}$ & $\mathrm{O}$ & $\mathrm{Y}$ & $\mathrm{N}$ & $\mathrm{N}$ & $\mathrm{H}$ & $\mathrm{L}$ & $\mathrm{Y}$ & $\mathrm{G}$ & $\mathrm{T}$ & $\mathrm{S}$ & $\mathrm{V}$ \\
\hline
\end{tabular} caatctgtgcgagcagtagcagagaagggcaagcattgtatccttgatgtgtctggaaat 2460 \begin{tabular}{llllllllllllllllllll}
$O$ & $S$ & $V$ & $R$ & $A$ & $V$ & $A$ & $E$ & $K$ & $G$ & $K$ & $H$ & $C$ & $I$ & $L$ & $D$ & $V$ & $S$ & $G$ & $N$ \\
\hline
\end{tabular} gccatcaagaggttgcagattgcacagctctatccaatatctatttttattaaacccaaa 2520 \begin{tabular}{llllllllllllllllllll}
$A$ & $I$ & $K$ & $R$ & $L$ & $Q$ & $I$ & $A$ & $Q$ & $L$ & $Y$ & $P$ & $I$ & $S$ & $I$ & $F$ & $I$ & $K$ & $P$ & $K$ \\
\hline
\end{tabular} tccatggaaatatcatggaaatgaataaacgcctaacagacgaacaggccagaaaacg 2580 \begin{tabular}{llllllllllllllllllll}
$S$ & $M$ & $E$ & $N$ & $I$ & $M$ & $E$ & $M$ & $N$ & $K$ & $R$ & $L$ & $T$ & $D$ & $E$ & $O$ & $A$ & $R$ & $K$ & $T$ \\
\hline
\end{tabular} tttgagagagcagtgagactggagcaggagttcactgagcatttcacagctattgtccag 2640 \begin{tabular}{cccccccccccccccccccc}
$F$ & $E$ & $R$ & $A$ & $V$ & $R$ & $L$ & $E$ & $Q$ & $E$ & $F$ & $T$ & $E$ & $H$ & $F$ & $T$ & $A$ & $I$ & $V$ & $Q$ \\
\hline
\end{tabular} ggagacacgctggaggacatttacaatcaagtgaagcagatcatagaagagcagtctggt 2700 $\begin{array}{llllllllllllllllllll}G & D & T & L & E & D & I & Y & N & O & V & K & O & I & I & E & E & O & S & G\end{array}$ ccttacatctgggtcccagcaaagaaaattatga 2736

$\begin{array}{llllllllllll}\mathrm{P} & \mathrm{Y} & \mathrm{I} & \mathrm{W} & \mathrm{V} & \mathrm{P} & \mathrm{A} & \mathrm{K} & \mathrm{E} & \mathrm{K} & \mathrm{L} & -\end{array}$ 
Tab. I Molekulargewicht, Extinktionskoeffizienten und spezifische Volumina ausgew. Proteine

\begin{tabular}{|c|c|c|c|}
\hline Protein & $\begin{array}{c}\mathbf{M}_{\mathrm{w}, \mathrm{calc}}{ }^{*} \\
{[\mathrm{Da}]}\end{array}$ & $\begin{array}{l}\varepsilon_{M} \\
{\left[M^{-1} \cdot \mathbf{c m}^{-1}\right]}\end{array}$ & $\begin{array}{c}\bar{v} \\
{\left[\mathbf{c m}^{3} \cdot \mathbf{g}\right]}\end{array}$ \\
\hline \multicolumn{4}{|l|}{ Guanylatkinasen } \\
\hline GUK1 & 20918,6 & 13490 & n.b. \\
\hline hGUK & 22006,9 & 6520 & n.b. \\
\hline mGUK & 22199,2 & 6640 & n.b. \\
\hline AGUK1(137-330) & 22249,4 & 6760 & n.b. \\
\hline \multicolumn{4}{|l|}{ Guanylatkinase-Homologe } \\
\hline SAP97-GK & 21243,0 & 7800 & n.b. \\
\hline SAP97-SH3/GK2 (575-911) & 39173,9 & 35110 & 0,7273 \\
\hline SAP97-SH3/GK3(582-911) & 38303,9 & 35110 & 0,7280 \\
\hline SAP97-SH3/GUK2(575-918) & 38849,5 & 40800 & 0,7297 \\
\hline SAP97-SH3/GUK2 $\Delta C(575-908)$ & 37466,8 & 33830 & 0,7230 \\
\hline SAP97-SH3/GUK3(582-918) & 37979,5 & 40800 & 0,7298 \\
\hline SAP97-SH3/ GUK3 $\Delta$ C(582-908) & 35596,8 & 33830 & 0,7280 \\
\hline hCASK-GK & 20752,5 & 10240 & n.b. \\
\hline \multicolumn{4}{|c|}{$\begin{array}{l}\text { *, } \mathrm{M}_{\mathrm{w}, \text { calc }} \text { berechnet auf Grundlage der Aminosäuresequenz mit zusätzlichen Aminosäuren GSHM am N-Terminu } \\
\text { (Restsequenz von rekombinanten GST-Fusionsproteinen nach Thrombin-Abspaltung des GST-Taqs) } \\
\text { n.b., nicht berechnet }\end{array}$} \\
\hline \multicolumn{4}{|c|}{ Tab. II Extinktionskoeffizienten diverser Purinnukleotide } \\
\hline & \multicolumn{2}{|c|}{ ATP, ADP, AMP } & GMP, cGMP \\
\hline Absorptionsmaximum & \multicolumn{2}{|c|}{259} & 252 \\
\hline $\begin{array}{l}\text { Extinktionskoeffizient bei maximaler } \\
\text { Absorption }\left[\mathrm{mmol}^{-1} \cdot 1 \cdot \mathrm{cm}^{-1}\right]\end{array}$ & \multicolumn{2}{|c|}{15,4} & 3,7 \\
\hline
\end{tabular}

Einbuchstabencode für Aminosäuren:

$\begin{array}{llll}\text { A } & \text { Alanin } & \text { M } & \text { Methionin } \\ \text { C } & \text { Cystein } & \text { N } & \text { Asparagin } \\ \text { D } & \text { Asparagin } & \text { P } & \text { Prolin } \\ \text { E } & \text { Glutaminsäure } & \text { Q } & \text { Glutamin } \\ \text { F } & \text { Phenylalanin } & \text { R } & \text { Arginin } \\ \text { G } & \text { Glycin } & \text { S } & \text { Serin } \\ \text { H } & \text { Histidin } & \text { T } & \text { Threonin } \\ \text { I } & \text { Isoleucin } & \text { V } & \text { Valin } \\ \text { K } & \text { Lysin } & \text { W } & \text { Tryptophan } \\ \text { L } & \text { Leucin } & \text { Y } & \text { Tyrosin }\end{array}$


$\underline{\text { Abkürzungsverzeichnis }}$

\begin{tabular}{|c|c|c|c|}
\hline A & Adenosin & \multicolumn{2}{|c|}{ MAGUK Membran-assoziierte } \\
\hline Abb. & Abbildung & & Guanylatkinasen \\
\hline $\mathrm{ACV}$ & Aciclovir & $\min$ & Minuten \\
\hline ADK & Adenylatkinase & $\mathrm{mg}$ & Milligramm \\
\hline ADP & Adenosindiphosphat & mGUK & Guanylatkinase der Maus \\
\hline AGUK & Guanylatkinase aus $A$. thaliana & $\mathrm{M}_{\mathrm{w}}$ & Molekulargewicht \\
\hline Amp & Ampicillin & $\mathrm{M}_{\mathrm{w}, \mathrm{app}}$ & Apparentes Molekulargewicht \\
\hline APS & Ammoniumpersulfat & $\mathrm{M}_{\mathrm{w}, \text { calc }}$ & Berechnetes Molekulargewicht \\
\hline ATP & Adenosin-5'-triphosphat & NDK & Nukleosiddiphosphatkinase \\
\hline AZT & $3^{\prime}$-Azido-2'-deoxythymidin & NDP & Nukleosiddiphosphat \\
\hline $\mathrm{Bp}$ & Basenpare & NMP & Nukleosidmonophosphat \\
\hline $\mathrm{Bq}$ & Becquerel & NMK & Nukleosidmonophosphatkinase \\
\hline $\mathrm{C}$ & Cytosin & NTP & Nukleosidtriphosphat \\
\hline CDK & Cytidylatkinase & OD & Optische Dichte \\
\hline $\mathrm{Ci}$ & Curie $[1 \mathrm{Ci}=37 \mathrm{Gbq}]$ & ori & origin of replication \\
\hline$D$ & Diffusionskoeffizient & & (Replikationsstartpunkt) \\
\hline $\mathrm{Da}$ & Dalton & PAGE & Polyacrylamid-Gelektrophorese \\
\hline dNTP & 2'-Desoxynukleotid-5'-triphosphat & PBS & Phosphatgepufferte Salzlösung \\
\hline DNA & Desoxyribonukleinsäure & PEG & Polyethylenglykol \\
\hline DTT & Dithiothreitol & PEP & Phosphoenolpyruvat \\
\hline EDTA & Ethylendiamintetraacetat & PK & Pyruvatkinase \\
\hline G & Erdbeschleunigung $9,81 \mathrm{~m} \cdot \mathrm{s}^{-2}$ & PMSF & Phenylmethylsulfonylfluorid \\
\hline G-Protein & GTP-bindendes Protein & RNA & Ribonukleinsäure \\
\hline G418 & Geneticin & $\mathrm{R}_{\mathrm{S}}$ & Stokes-Radius \\
\hline Gal & Galaktose & RT & Raumtemperatur \\
\hline GCV & Ganciclovir & S & Svedberg-Einheit $\left[1 \mathrm{~S}=1 \cdot 10^{-13} \mathrm{~s}\right]$ \\
\hline GDP & Guanosindiphosphat & s & Sekunden \\
\hline GK & $\begin{array}{l}\text { Guanylatkinase-homologe } \\
\text { Domäne }\end{array}$ & $\begin{array}{l}s \\
\text { SAP }\end{array}$ & $\begin{array}{l}\text { Sedimentationskoeffizient } \\
\text { synapse-associated protein }\end{array}$ \\
\hline GUK & Guanylatkinase & SDS & Natriumdodecysulfat \\
\hline GMP & Guanosinmonophosphat & PAGE & Polyacrylamid-Gelelektrophorese \\
\hline Glu & Glukose & $\mathrm{T}$ & Thymidin \\
\hline G & Guanosin & Tab. & Tabelle \\
\hline GUK1 & Guanylatkinase aus $S$. cerevisiae & TAE & Tris/Acetat/EDTA \\
\hline $\mathrm{h}$ & Stunden & TCA & Trichloressigsäure \\
\hline HGPRT & Hypoxanthin-Guanin- & TEMED & $\mathrm{N}, \mathrm{N}, \mathrm{N}^{\prime}, \mathrm{N}^{\prime}-$ Tetramethylendiamin \\
\hline & Phosphoribosyltransferase & THK & Thymidylatkinase \\
\hline hGUK & humane Guanylatkinase & Tris & Tris-hydroxymethyl-aminomethan \\
\hline $\operatorname{Kan}^{\mathrm{r}}$ & Kanamycin-Resistenzgen & $\mathrm{U}$ & unit (Einheit der Enzymaktivität) \\
\hline$k_{\text {cat }}$ & Max. Reaktionsgeschwindigkeit & UMK & Uridylatkinase \\
\hline$K_{\mathrm{d}}$ & Dissoziationskonstante & UV & Ultraviolett \\
\hline $\mathrm{kDa}$ & Kilodalton & $\mathrm{V}$ & Volt \\
\hline$K_{\mathrm{M}}$ & $\begin{array}{l}\text { Michaelis-Menten-Konstante } 1 \\
\text { Liter }\end{array}$ & $\begin{array}{l}\mathrm{v}_{\max } \\
(\mathrm{v} / \mathrm{v})\end{array}$ & $\begin{array}{l}\text { Maximale Umsatzrate } \\
\text { Volumenverhältnis }\end{array}$ \\
\hline LB & Luria-Bertanie & & volume/volume) \\
\hline LDH & Lactatdehydrogenase & $(w / v)$ & Masse/Volumen-Verhältnis \\
\hline M & Molarität & & (weight/volume) \\
\hline
\end{tabular}




\section{Literaturverzeichnis}

Abele, U., and Schulz, G. E. (1995) High-resolution structures of adenylate kinase from yeast ligated with inhibitor $\mathrm{AP}_{5} \mathrm{~A}$, showing the pathway of phosphoryl transfer. Protein Sci. 4, 1262-1271.

Agarwal, K. C., Miech, R. P., and Parks, R. E. (1978a) Guanylate kinases from human erythrocytes, hogbrain and rat liver. Methods Enzymol. 51, 483-491.

Agarwal, R. P., Robinson, B., and Parks, R. E. (1978b) Nucleoside diphosphokinase from human erythrocytes. Methods Enzymol. 51, 376-386.

Alley, S. C., Shier, V. K., Abel-Santos, E., Sexton, D. J., Soumillion, P., and Benkovic, S. J. (1999) Sliding clamp of the bacteriophage T4 Polymerase has open and closed subunit interfaces in solution. Biochemistry 38, 7696-7709.

Anderson, J. M., Stevenson, B. R., Jesaitis, L. A., Goodenough, B. A., and Mooseker, M. S. (1988) Characterization of ZO-1, a protein component of the tight junction from mouse liver and Madin-Darby canine kidney cells. J. Cell Biol. 103, 755-766.

Anderson, J. M. (1996) Cell signaling: MAGUK magic. Curr. Biol. 6, 382-384.

Ausubel, F. M., Brent, R., Kingston, R. E., Moore, D. D., Seidmann, J. G., Smith, J. A., and Struhl, K. (1988-1997) Current Protocols in Molecular Biology Vol. 1-3, John Wiley and Sons, Chichester.

Balzarini, J., Degreve, B., and De Clerq, E. (1998) Improving AZT-efficacy. Nat. Med. 4, 132.

Baum, G., Levyadun, S., Fridmann, Y., Arazi, T., Katsnelson, H. et al. (1996) Calmodulin binding to glutamate decarboxylase is required for regulation of glutamate and GABA metabolism and normal development in plants. EMBO J. 15, 2988-2996.

Behlke, J. (1997) Recent developments of analytical ultracentrifugation in biopolymer research. Eur. Biophys. J. 25, 319-323.

Berger, A., Schlitz, E., and Schulz, G. E. (1989) Guanylate kinase from Saccharomyces cerevisiae: isolation and characterization, crystallization and preliminary X-ray analysis, amino acid sequence and comparison with adenylate kinases. Eur. J. Biochem. 184, 433-443.

Birnboim, H. C., and Doly, J. (1979) A rapid alkaline extraction procedure for screening recombinant plasmid DNA. Nucl. Acids Res. 7, 1513-1523.

Boehme, R. E. (1984) Phosphorylation of the antiviral precursor 9-(1,3-dihydroxy-2-propoxymethyl) guanine monophosphate by guanylate kinase isozymes. J. Biol. Chem. 259, 12346-12349.

Bominaar, A. A., Molijn, A. C., Pestel, M., Veron, M., and Van Haastert, P. J. (1993) Activation of Gproteins by receptor stimulated nucleoside diphosphate kinase in Dictyostelium. EMBO J. 12, 2275-2279.

Bourne, H. R., Sanders, A. D., and McCormick, F. (1990) The GTPase superfamily: a conserved switch for diverse cell functions. Nature 348, 125-132. 
Bradford, M. (1976) A rapid and sensitive method for the quantitation of microgram quantities of protein utilizing the principle of protein-dye binding. Anal. Biochem. 72, 248.

Brady, W. A., Kokoris, M. S., Fitzgibbon, M., and Black, M. E. (1996) Cloning, characterization, and modeling of mouse and human guanylate kinases. J. Biol. Chem. 271, 16734-16740.

Brenman, J. E., Chao, D. S., Gee, S. H., McGee, A. W., Craven, S. E., Santillano, D. R., Wu, Z., Huang, F., Xia, H., Peters, M. F., Froehner, S. C., and Bredt, D. S. (1996) Interaction of nitric oxide synthase with the postsynaptic density protein PSD-95 and $\alpha 1$-syntrophin mediated by PDZ domains. Cell 84, 757-767.

Brenman, J. E., Topinka, J. R., Cooper, E. C., McGee, A. W., Rosen, J., Milroy, T., Ralston, H. J., and Bredt, D. S. (1998) Localization of postsynaptic density-93 to dendritic microtubules and interaction with microtubule-associated protein 1A. J. Neurosci. 18, 8805-8813.

Broach, J. R. (1981) The yeast plasmid $2 \mu$ circle, in Strathern, J. N., Jones, E. W. and Broach, J. R. (eds.) "The molecular biology of the yeast Saccharomyces: life cycle and inheritance," pp.445-470, Cold Spring Harbor Laboratory, Cold Spring Harbor, New York.

Brundiers, R., Lavie, A., Veit, T., Reinstein, J., Schlichting, I., Ostermann, N., Goody, R. S., and Konrad, M. (1999) Modifying human thymidylate kinase to potentiate azidothymidine activation. J. Biol. Chem. 274, 35289-35292.

Brundiers, R. (1999) Protein-Design an Thymidylatkinasen zur Verbesserung des AZT-Monophosphat Umsatzes, Dissertation, Universität Göttingen.

Bucurenci, N., Sakamoto, H., Briozzo, P., Palibroda, N., Serina, L., Sarfati, R. S., Labesse, G., Briand, G., Danchin, A., Barzu, O., and Gilles, A. M. (1996) CMP kinase from Escherichia coli is structurally related to other nucleoside monophosphate kinases. J Biol Chem. 271, 2856-2862.

Bullock, W. O., Fernandez, J. M., and Short, J. M. (1987) XL1-Blue: A high efficiency plasmid transforming recA Escherichia coli strain with $\beta$-galactosidase selection. BioTechniques 5, 376-379.

Burnette, W. N. (1981) Western blotting: electrophoretic transfer of proteins from sodium dodecyl sulfate-polyacrylamide gels to unmodified nitrocellulose and radiographic detection with antibody and radioiodinated protein A. Anal. Biochem. 112, 195-203.

Butz, S., Okamoto, M., and Südhof, T. C. (1998) A tripartite protein complex with the potential to couple synaptic vesicle exocytosis to cell adhesion in brain. Cell 94, 773-782.

Byeon, L., Shi, Z., and Tsai, M. D. (1995) Mechanism of adenylate kinase. The "essential lysine" helps to orient the phosphates and the active site residues to proper conformations. Biochemistry 34 , $3172-3182$.

Cabral, J. H., Petosa, C., Sutcliffe M. J., Raza, S., Byron, O., Poy, F., Marfatia, S. M., Chisti, A. H., and Liddington, R. C. (1996) Crystal structure of a PDZ domain. Nature 382, 649-652.

Cho, K.-O., Hunt, C. A., and Kennedy, M. B. (1992) The rat brain postsynaptic density fraction contains a homolog of the Drosophila discs-large tumor suppressor protein. Neuron 9, 929942. 
Clos, J., Westwood, J. T., Becker, P. G., Wilson, S., Lambert, K., and Wu, C. (1990) Molecular cloning and expression of a hexameric Drosophila heat shock factor subject to negativ regulation. Cell 63, 1085-1097.

Cohen, A. R., Woods, D. F., Marfatia, S. M., Walther, Z., Chisti, A. H., and Anderson, J. M. (1998) Human CASK/LIN-2 binds Syndecan-2 and protein 4.1 and localizes to the basolateral membrane of epithelial cells. J. Cell Biol. 142, 129-138.

Cohen, S. L, and Chait, B. T. I. (1996) Influence of matrix solution conditions on the MALDI-MS analysis of peptides and proteins. Anal. Chem. 68, 31-37.

Crivici, A., and Ikura, M. (1995) Molecular and structural basis for target recognition by calmodulin. Annu. Rev. Biomol. Struct. 24, 85-116.

Cross, F. R. (1997) "Marker swap" plasmids: convenient tools for budding yeast molecular genetics. Yeast 13, 647-53.

Degenkolb, J., Takahashi, M., Ellestad, G. A., and Hillen, W. (1991) Structural requirements of tetracycline-Tet repressor interaction: determination of equilibrium binding constants for tetracycline analogs with the Tet repressor. Antimicrob. Agents Chemother. 35, 1591-1595.

Deguchi, M., Hata, Y., Takeuchi, M., Ide, N., Hirao, K., Yao, I., Irie, M., Toyoda, A., and Takai, Y. (1998) BEGAIN (brain-enriched guanylate kinase-associated protein), a novel neuronal PSD95/SAP90-binding protein. J. Biol. Chem. 273, 26269-26272.

Daignan-Fornier, B., and Fink, G. R. (1992) Coregulation of purine and histidine biosynthesis by the transcriptional activators BAS1 and BAS2. Proc. Natl. Acad. Sci. USA 89, 6746-6750.

Denis, V., Boucherie, H., Monribot, C., and Daignan-Fornier, B. (1998) Role of the Myb-like protein Bas1p in Saccharomyces cerevisiae: a proteome analysis. Mol Microbiol. 30, 557-566.

DeVos, A. M., Tong, L., Milburn, M. V., Matias, P., Jancarik, J., Noguchi, S., Nishimura, S., Miura, K., Ohtsuka, E., and Kim, S.-H. (1988) Three-dimensional structure of an oncogene protein: catalytic domain of human c-H-ras p21. Science 239, 888-893.

Diederichs, K., and Schulz, G. E. (1991) The refined structure of the complex between adenylate kinase from beef heart mitochondrial matrix and its substrate AMP at $1.85 \AA$ A resolution. J. Mol. Biol. 217, 541-549.

Dimitratos, S. D., Woods, D. F., Bryant, P. J. (1997) Camguk, Lin-2, and CASK: novel membraneassociated guanylate kinase homologs that also contain CaM kinase domains. Mech. Dev. 63, 127-130.

Dimitratos, S. D., Woods, D. F., Stathakis, D. G., and Bryant, P. J. (1999) Signaling pathways are focused at specialized regions of the plasma membrane by scaffolding proteins of the MAGUK family. BioEssays 21, 912-921.

Dong, F.,Gogol, E. P., and von Hippel, P. H. (1995) The phage T4-coded DNA replication helicase (gp41) forms a hexamer upon activation by nucleoside triphosphate. J. Biol. Chem. 270, 74627473.

Doyle, D. A., Lee, A., Lewis, J., Kim, E., Sheng, M., and MacKinnon, R. (1996) Crystal structures of a complex and peptide-free membrane protein-binding domain: molecular basis of peptide recognition by PDZ. Cell 85, 1067-1076. 
Dreusicke, D., Karplus, P. A., and Schulz, G. E. (1988) Refined structure of porcine cytosolic adenylate kinase at 2.1 Å resolution. J. Mol. Biol. 199, 359-371.

Dunayevskiy, Y., Vouros, P., Carell, T., Wintner, E. A., and Rebek, J. (1995) Characterization of the complexity of small-molecule libraries of electrospray ionization mass spectrometry. Anal. Chem. 67, 2906-2915.

Durchschlag, H., Zipper, P., Purr, G., and Jaenicke, R. (1996) Comparative studies of structural properties and conformational changes of proteins by analytical ultracentrifugation and other techniques. Colloid. Polym. Sci. 274, 117-137.

Elion, G. B. (1989) The purine path to chemotherapy. Science 244, 41-47.

Fanning, A. S., and Anderson, J. M. (1998) PDZ domains and the formation of protein networks at the plasma membrane. Curr. Top. Microbiol. Immunol. 228, 209-233.

Feng, S., Chen, J. K., Yu, H., Simon, J. A., and Schreiber, S. L. (1994) Two binding orientations for peptides to the Src SH3 domain: development of a general model for SH3-ligand interactions. Science 266, 1241-1247.

Fitzgibbon, J., Katsanis, N., Wells, D., Delhanty, J., Vallins, W., and Hunt, D. (1996) Human guanylate kinase (GUK1): cDNA sequence, expression and chromosomal localisation. FEBS Lett. 385, $185-188$.

Forth, W., Henschler, P., Rummel, W., and Starke, K. (1996) Pharmakologie und Toxikologie. Spektrum Akademischer Verlag, Heidelberg.

Fukuchi, T., Nikawa, J., Kimura, N., and Watanabe, K. (1993) Isolation, overexpression and disruption of a Saccharomyces cerevisiae YNK gene encoding nucleoside diphosphate kinase. Gene 129, 141-146.

Furuse, M., Itoh, M., Hirase, T., Nagafuchi, A., Yonemura, S., Tsukita, S., and Tsukita, S. (1994) Direct association of occludin with ZO-1 and its possible involvement in the localization of occludin at tight junctions. J. Cell. Biol. 124, 1617-1626.

Gaidarov, I. O., Suslov, O. N., and Abdulaev, N. G. (1993) Enzymes of the cGMP metabolism in bovine retina. I. Cloning and expression of the gene for guanylate kinase. FEBS Lett. 335, 81-84.

Ganguly, A. K., Pramanik, B. N., Huang, E. C., Tsarbopoulos, A., Girijavallabhan, V. M., and Liberles, S. (1993) Studies of the Ras-GDP and Ras-GTP noncovalent complexes by electrospray mass spectrometry. Tetrahedron 49, 7985-7996.

Garcia, E. P., Mehta, S., Blair, L. A., Wells, D. G., Shang, J., Fukushima, T., Fallon, J. R., Garner, C. C., and Marshall, J. (1998) SAP90 binds and clusters kainate receptors causing incomplete desensitization. Neuron 21, 727-739.

Gari, E., Piedrafita, L., Aldea, M., and Herrero, E. (1997) A set of vectors with a tetracyclineregulatable promoter system for modulated gene expression in Saccaromyces cerevisiae. Yeast 13, 837-848.

Garner, C. C., and Kindler, S. (1996) Synaptic proteins and the assembly of synaptic junctions. Trends Cell Biol. 6, 429-433.

Garner, C. C., Nash, J., and Huganir, R. L. (2000) PDZ domains in synapse assembly and signaling. Trends Cell. Biol. 10, 274-280. 
Gentry, D., Bengra, C., Ikehara, K., and Cashel, M. (1993) Guanylate kinase of Escherichia coli K-12. J. Biol. Chem. 268, 14316-14321.

Gill, S. C., and Hippel, P. H. (1989) Calculation of protein extinction coefficients from amino acid sequence data. Anal. Biochem. 182, 319-326.

Gietz, R. D., and Sugino, A. (1988) New yeast-Escherichia coli shuttle vectors constructed with in vitro mutagenized yeast genes lacking six-base pair restriction sites. Gene 74, 3065-3073.

Goody, R. S., Frech, M., and Wittinghofer, A. (1991) Affinity of guanine nucleotide binding proteins for their ligands: facts and artifacts. TIBS 16, 327-328.

Gossen, M., and Bujard, H. (1992) Tight control of gene expression in mammalian cells by tetracyclineresponsive promoters. Proc. Natl. Acad. Sci. 89, 5547-5551.

Gossen, M., Bonin, A. L., and Bujard, H. (1993) Control of gene activity in higher eukaryotic cells by prokaryotic regulatory elements. Trends Biochem. Sci. 18, 471-475.

Gossen, M., Freundlieb, S., Bender, G., Müller, G., Hillen, W., and Bujard, H. (1995) Transcriptional activation of tetracyclines in mammalian cells. Science $268,1766-1769$.

Guan, C., Li, P., Riggs, P. D., and Inouye, H. (1987) Vectors that facilitate the expression and purification of foreign peptides in Escherichia coli by fusion to maltose-binding protein. Gene 67, 21-30.

Guan, K. L., and Dixon, J. E. (1991) Eukaryotic proteins expressed in Escherichia coli: an improved thrombin cleavage and purification procedure of fusion proteins with glutathione $S$ transferase. Anal. Biochem. 192, 262-267.

Güldener, U., Heck, S., Fiedler, T., Beinhauer, J., and Hegemann, J. H. (1996) A new efficient gene disruption cassette for repeated use in budding yeast. Nucleic Acids Res. 24, 2519-2524.

Guetsova, M. L., Lecoq, K., and Daignan-Fornier, B. (1997) The isolation and characterization of Saccharomyces cerevisiae mutants that constitutively express purine biosynthesis genes. Genetics 147, 383-397.

Hall, S. W., and Kühn, H. (1986) Purification and properties of guanylate kinase from bovine retinas and rod outer segments. Eur. J. Biochem. 161, 551-556.

Hanson, P. I., and Schulman H. (1992) Neuronal $\mathrm{Ca}^{2+} /$ calmodulin-dependent protein kinases. Annu. Rev. Biochem. 61, 559-601.

Harrison, S. C. (1996) Peptide-surface association: the case of PDZ and PTB domains. Cell 86, 341343.

Haskins, J., Gu, L., Wittchen, E., Hibbard, J., and Stevenson, B. (1998) ZO-3, a novel member of the MAGUK protein family found at the tight junction, interacts with ZO-1 and Occludin. J. Cell Biol. 141, 199-208.

Hata, Y., Butz, S., and Südhof, T. C. (1996) CASK: a novel dlg/PSD-95 homolog with an N-terminal calmodulin-dependent protein kinase domain identified by interaction with neurexins. J. Neurosci. 16, 2488-2494.

Hata, Y., Nakanishi, H., and Takai, Y. (1998) Synaptic PDZ domain-containing proteins. Neurosci. Res. $32,1-7$. 
Ho, S. N., Hunt, H. D., Horton, R. M., Pullen, J. K., and Pease, L. R. (1989) Site-directed mutagenesis by overlap extension using the polymerase chain reaction. Gene $77,51-59$

Hochuli, E. (1990) Purification of recombinant proteins with metal chelate adsorbent. Vol.12., 87-98, in Setlow, J. K. (ed.) Genetic engineering, principle and methods, Plenum Press, New York.

Hoskins, R., Hajnal, A., Harp, S. A., and Kim, S. K. (1996) The C. elegans vulval induction gene lin-2 encodes a member of the MAGUK family of cell junction proteins. Development 122, 97-111.

Hough, C. D., Woods, D. F., Park, S., and Bryant P. J. (1997) Organizing a functional complex requires specific domains of the Drosophila MAGUK discs large. Genes Dev. 11, 3242-3253.

Huang, S.-G., Lin, Q-S., and Klingenberg, M. (1998) Slow-phase kinetics of nucleotide binding to the uncoupling protein from brown adipose tissue mitochondria. J. Biol. Chem. 273, 859-864.

Hunt, C. A., Schenker, L. J., and Kennedy, M. B. (1996) PSD-95 is associated with the postsynaptic density and not with the presynaptic membrane at forebrain synapses. J. Neurosci. 16, 13801388 .

Irie, M., Hata, Y., Takeuchi, M., Ichtchenko, K., Toyoda, A., Hirao, K., Takai, Y., Rosahl, T. W., and Südhof, T. C. (1997) Binding of Neuroligins to PSD-95. Science 277. 1511-1515.

Ito, H. F., Murata, K., and Kimura, A. (1983) Transformation of intact yeast cells treated with alkali cations. J. Bacteriol. 153, 163-168.

Janssen, E., Dzeja P. P., Oerlemans, F., Simonetti, A. W., Heerschap, A., De Haan, A., Rush, P. S., Terjung, R. R., Wieringa, B., and Terzic, A. (2000) Adenylate kinase 1 gene deletion disrupts muscle energetic economy despite metabolic rearrangement. EMBO J. 19, 6371-6381.

Jesaitis, L. A., and Goodenough, D. A. (1994) Molecular characterization and tissue distribution of ZO2, a tight junction protein homologous to ZO-1 and the Drosophila discs-large tumor suppressor protein. J. Cell Biol. 124, 949-961.

Jesperson, S., Niessen, W. M. A., Tjaden, U. R., and Van der Greef, J. (1995) Quantitative bioanalysis using matrix-assisted laser desorption ionization mass spectrometry. J. Mass. Spectrom. 30, 357-364.

John, J., Sohmen, R., Feuerstein, J., Linke, R., Wittinghofer, A., and Goody, R. S. (1990) Kinetics of interaction of nucleotides with nucleotide-free H-ras p21. Biochemistry 29, 6058-6065.

Jones, M. E. (1980) Pyrimidine nucleotide biosynthesis in animals: genes, enzymes, and regulation of UMP biosynthesis. Ann. Rev. Biochem. 49, 253-279.

Johnston, M., and Carlson, M. (1992) Regulation of carbon and phosphate utilization. In Jones, E. W., Pringle, J. R. and Broach, J. R. (eds), The Molecular Biology of the Yeast Saccharomyces, vol. 2. Cold Spring Harbor Laboratory Press, Cold Spring Harbor, NY, pp. 193-281.

Julius, D., Schekman, R., and Thorner, J. (1984) Glycosylation and processing of prepro-alpha-factor through the yeast secretory pathway. Cell 36, 309-318.

Kaech, S. M., Whitfield, C. W., and Kim, S. K. (1998) Basolateral membrane localization of the receptor tyrosine kinase LET-23 is mediated by the LIN-2/LIN-7/LIN-10 protein complex in the vulval precursor cells of $C$. elegans. Cell 94, 761-771. 
Kapust, R. B., and Waugh, D. S. (1999) Escherichia coli maltose-binding protein is uncommonly effective at promoting the solubility of polypeptides to which it is fused. Protein Sci. 8, 16681674.

Kelley, W. N., Greene, M. L., Rosenbloom, M., Henderson, J. R., and Seegmiller, J. E. (1969) Hypoxanthine-guanine phosphribosyltransferase deficiency in gout. Ann. Intern. Med. 70, 155.

Kim, E., Niethammer, M., Rothschild, A., Jan, Y. N., and Sheng, M. (1995) Clustering of shaker-type $\mathrm{K}^{+}$channels by direct interaction with a family of membrane-associated guanylate kinases. Nature 378, 85-88.

Kim, E., Cho, K.-O., Rothschild, A., and Sheng, M. (1996) Heteromultimerization and NMDA receptorclustering activity of Chapsin-110, a member of the PSD-95 family of proteins. Neuron 17, 103-113.

Kim, E., Naisbitt, S., Hsueh, Y., Rao, A., Eothschild, A., Craig, A., and Sheng, M. (1997) GKAP, a novel synaptic protein that interacts with the guanylate kinase-like domain of the PSD95/SAP90 family of channel clustering molecules. J. Cell. Biol. 136, 669-678.

Kim, H., Deonier, R. C., and Williams, J. W. (1977) The investigation of self-association reactions by equilibrium ultracentrifugation. Chem. Rev. 77, 659-690.

Kim, S. K. (1995) Tight junctions, membrane-associated guanylate kinases and cell signaling. Curr. Opin. Cell Biol. 7, 641-649.

Kistner, U., Wenzel, B. M., Veh, R. W., Cases-Langhoff, C., Garner, A., Appeltauer, U., Voss, B., Gundelfinger, E. D., and Garner, C. C. (1993) SAP90, a rat presynaptic protein related to the product of the Drosophila tumor suppressor gene $d l g$-A. J. Biol. Chem. 268, 4580-4583.

Kistner, U., Garner, C. C., and Linial, M. (1995) Nucleotide binding by the synapse associated protein SAP90. FEBS Lett. 359, 159-163.

Klenow, H., and Henningsen, I. (1970) Selective elimination of the exonuclease activity of the deoxyribonucleic acid polymerase from Escherichia coli B by limited proteolysis. Proc. Natl. Acad. Sci. USA. 65, 168-75.

Klenow, H. and Lichtler, E. (1957) On the enzymic formation and the isolation of polyphosphates of adenine deoxyribosides. Biochem. Biophys. Acta 23, 6-12.

Konrad, M. (1988) Analysis and in vivo disruption of the gene coding for adenylate kinase (ADK1) in yeast. J. Biol. Chem. 263, 19468-19474.

Konrad, M. (1992) Cloning and expression of the essential gene for guanylate kinase from yeast. J. Biol. Chem. 267, 25652-25655.

Koyama, S., Hongtao, Y., Dalgarno, D. C., Shin, T. B., Zydowsky, L. D., and Schreiber, S. L. (1993) Structure of the PI3K SH3 domain and analysis of the SH3 family. Cell 72. 945-952.

Kuhlendahl, S., Spangenberg, O., Konrad, M., Kim, E., and Garner, C. C. (1998) Functional analysis of the guanylate kinase-like domain in the synapse-associated protein SAP97. Eur. J. Biochem. 252, 305-313. 
Kumar, V., Spangenberg, O., and Konrad, M. (2000) Cloning of the guanylate kinase homologues AGK-1 and AGK-2 from Arabidopsis thaliana and characterization of AGK-1. Eur. J. Biochem. 267, 606-615.

Laemmli, U. K. (1970) Cleavage of structural proteins during the assembly of the head of the bacteriophage T4. Nature 227, 680-685.

Lavie, A., Schlichting, I., Vetter, I. R., Konrad, M., Reinstein, J., and Goody, R. S. (1997a) The bottleneck in AZT activation. Nat. Med. 3, 922-924.

Lavie, A., Vetter, I. R., Konrad, M., Goody, R. S., Reinstein, J., and Schlichting, I. (1997b) Structure of thymidylate kinase reveals the cause behind the limiting step in AZT activation. Nat. Struct. Biol. 4, 601-604.

Lavie, A., Konrad, M., Brundiers, R., Goody, R. S., Schlichting, I., and Reinstein, J. (1998) Crystal structure of yeast thymidylate kinase complexed with the bisubstrate inhibitor $\mathrm{P}^{1}$-(5'-adenosyl) $\mathrm{P}^{5}$-(5'-thymidyl) pentaphosphate $\left(\mathrm{TP}_{5} \mathrm{~A}\right)$ at $2.0 \AA$ resolution: Implications for catalysis and AZT activation. Biochemistry 37, 3677-3686.

Lecoq, K., Konrad, M., and Daignan-Fornier, B. (2000) Yeast GMP kinase mutants constitutively express AMP biosynthesis genes by phenocopying a hypoxanthin-guanine phosphoribosyltransferase defect. Genetics 156, 953-961.

Lee, C. H., Saksela, K., Mirza, U. A., Chait, B. T., and Kuriyan, J. (1996) Crystal structure of the conserved core of HIV-1 Nef complexed with a Src family SH3 domain. Cell 85, 931-942.

Lee, S. H., Seo, H. Y., Kim, J. C., Heo, W. D., Chung, W. S., Lee, K. J., Kim, M. C., Cheong, Y. H., Choi, J. Y., Lim, C. O., and Cho, M. J. (1997) Differential activation of NAD kinase by plant calmodulin isoforms - the critical role of domain I. J. Biol. Chem. 272, 9252-9259.

Lin, X. et al. (1999) Sequence and analysis of chromosome 2 of the plant Arabidopsis thaliana. Nature 402, 761-768.

Li, Y., Zhang, Y., and Yan, H. (1996) Kinetic and thermodynamic characterizations of yeast guanylate kinase. J. Biol. Chem. 271, 28038-28044.

Logan, H. M., Cathala, N., Grignon, C., and Davidian, J. C. (1996) Cloning of a cDNA encoded by a member of the Arabidopsis thaliana ATP sulfurylase multigene family- expression studies in yeast and in relation to plant sulfur nutrition. J. Biol. Chem. 271, 12227-12233.

Lu, Q., and Inouye, M. (1996) Adenylate kinase complements nucleoside diphosphate kinase deficiency in nucleotide metabolism. Proc. Natl. Acad. Sci. USA. 93, 5720-5725.

Lue, R. A, Marfatia, S. M., Branton, D., and Chisti, A. H. (1994) Cloning and characterization of hDlg : the human homologue of the Drosophila discs-large tumor suppressor binds to protein 4.1. Proc. Natl. Acad. Sci. USA. 91, 9818-9822.

Mann, M., and Wilm, M. (1995) Electrospray mass spectrometry for protein characterization. Trends Biochem. Sci. 20, 219-224.

Marfatia, S. M., Lue, R. A., Branton, D., and Chishti, A. H. (1995) Identification of the protein 4.1 binding interface on glycophorin C and p55, a homologue of the Drosophila discs-large tumor suppressor protein. J. Biol. Chem. 270, 715-719. 
Marfatia, S. M., and Chisti, A. H. (1995) Human erythroid p55 is a catalytically active guanylate kinase. Mol. Biol. Cell 6, 56a.

Marfatia, S. M., Morais-Cabral, J. H., Kim, A. C., Byron, O., and Chisti, A. H. (1997) The PDZ domain of human erythrocyte p55 mediates its binding to the cytoplasmic carboxyl terminus of glycophorin C. Analysis of the binding interface by in vitro mutagenesis. J. Biol. Chem. 272, 24191-24197.

Marfatia, S. M., Byron, O., Campbell, G., Liu, S. C., and Chisti, A. H. (2000) Human homologue of the Drosophila discs large tumor suppressor protein forms an oligomer in solution. Identification of the self association site. J. Biol. Chem. 275, 13759-13770.

Mazoyer, S., Gayther, S. A., Nagai, M. A., Smith, S. A., Dunning, A., van Rensburg, E. J., Albertsen, H., White, R., and Ponder B. A. J. (1995) A gene (DLG2) located at 17q12-q21 encodes a new homologue of the Drosophila tumor suppressor $d l g-A$. Genomics 28, 25-31.

McGee, A. W., and Bredt, D. S. (1999) Identification of an intramolecular interaction between the SH3 and guanylate kinase domains of PSD-95. J. Biol. Chem. 274, 17431-17436.

McRorie, D. K., and Völker, P. J. (1993) Self-associating systems in the analytical ultracentrifugation. Beckman.

Miech, R. P., and Parks, R. E. (1965) Adenosine triphosphate: guanosine monophosphate phosphotransferase. J. Biol. Chem. 240, 351-357.

Miller, W. H., and Miller, R. L. (1980) Phosphorylation of Acyclovir (Acyloguanosine) monophosphate by GMPkinase. J. Biol. Chem. 255, 7204-7207.

Miroux, B., and Walker, J. E. (1996) Over-production of proteins in Escherichia coli: mutant hosts that allow synthesis of some membrane proteins and globular proteins at high levels. J. Mol. Biol. 260, 289-298.

Moarefi, I., LaFevre-Bernt, M., Sicheri, F., Huse, M., Lee, C. H., Kuriyan, J., and Miller, W. T. (1997) Activation of the Src-family tyrosine kinase Hck by SH3 domain displacement. Nature 385, 650-653.

Moolten, F. L. (1986) Tumor chemosensitivity conferred by inserted herpes thymidine kinase genes: paradigm for a prospective cancer control strategy. Cancer Res. 46, 5276-5281.

Müller, B. M., Kistner, U., Veh, R. W., Cases-Langhoff, C., Becker, B., Gundelfinger, E. D., and Garner, C. C. (1995) SAP97, a novel member of the super family of brain-related guanylate kinases. J. Neurosci. 15, 2354-2366.

Müller, B. M., Kistner, U., Kindler, S., Chung, W. K., Kuhlendahl, S., Fenster, S. D., Lau, L.-F., Veh, R. W., Huganir, R. L., Gundelfinger, E. D., and Garner, C. C. (1996) SAP102, a novel postsynaptic protein that interacts with NMDA receptor complexes in vivo. Neuron 17, 255265.

Müller, C. W., and Schulz, G. E. (1992) Structure of the complex between adenylate kinase from Escherichia coli and the inhibitor $\mathrm{Ap}_{5} \mathrm{~A}$ refined at $1.9 \AA$ resolution. A model for a catalytic transition state. J. Mol. Biol. 224. 159-177.

Müller-Dieckmann, H. J., and Schulz, G. E. (1995) Substrate specificity and assembly of the catalytic center derived from two structures of ligated uridylate kinases. J. Mol. Biol. 246, 522-530. 
Musacchio, A., Noble, M., Pauptit, R., Wierenga, R., and Saraste, M. (1992) Crystal structure of a Srchomology 3 (SH3) domain. Nature 359, 851-855.

Nguyen, T., and Südhof, T. C. (1997) Binding properties of neuroligin 1 and neurexin 1beta reveal function as heterophilic cell adhesion molecules. J. Biol. Chem. 272, 26032-26039.

Niethammer, M., Kim, E., and Sheng, M. (1996) Interaction between the C terminus of NMDA receptor subunits and multiple members of the PSD-95 family of membrane-associated guanylate kinases. J. Neurosci. 16, 2157-2163.

Nishimura, A., Morita, M., Nishimura, Y., and Sugino, Y. (1990) A rapid and highly efficient method for preparation of competent Escherichia coli cells. Nucl. Acids Res. 18, 6169.

Nix, S. L., Chisthi, A. H., Anderson, J. M., and Walther, Z. (2000) hCASK and hDlg associate in epithelia, and their src-homology 3 and guanylate kinase domains participate in both intramolecular and intermolecular interactions. J. Biol. Chem. 275, 411192-41200.

Ohtsuki, K., Yokoyama, M., and Uesaka, H. (1987) Physiological correlation between nucleosidediphosphate kinases and the $21-\mathrm{kDa}$ guanine-nucleotide binding proteins copurified with the enzymes from the cell membrane fractions of Ehrlich ascites tumor cells. Biochim. Biophys. Acta 929, 231-238.

Oka, A., Sugisaki, H., and Takanami, M. (1981) Nucleotide sequences of the kanamycin resistance transposon Tn903. J. Mol. Biol. 147, 217-226.

Ostermann, N., Schlichting, I., Brundiers, R., Konrad, M., Reinstein, J., Veit, T., Goody, R. S., and Lavie, A. (2000) Insights into the phosphoryltransfer mechanism of human thymidylate kinase gained from crystal structures of enzyme complexes along the reaction coordinate. Structure 8 , 629-642.

Pai, E. F., Krengel, U., Petsko, G. A., Goody, R. S., Kabsch, W., and Wittinghofer, A. (1990) Refined crystal structure of the triphosphate conformation of H-ras-p21 at 1.35 A resolution: Implications for the mechanism of GTP hydrolysis. EMBO J. 9, 2351-2359.

Pawson, T. (1995) Protein modules and signaling networks. Nature 373, 573-580.

Prinz, H., Lavie, A., Scheidig, A. J., Spangenberg, O., and Konrad, M. (1999) Binding of nucleotides to guanylate kinase, p2 ${ }^{\text {ras }}$, and nukleoside-diphosphate kinase studied by nano-electrospray mass spectrometry. J. Biol. Chem. 274, 35337-35342.

Prusiner, S. B. (1998) Prions. Proc. Natl. Acad. Sci. USA. 95, 13363-13383.

Ralston, G. (1993) Introduction to analytical ultracentrifugation. Beckman.

Reichard, P. (1993) The anaerobic ribonucleotide reductase from Escherichia coli. J. Biol. Chem. 286, 8383-8386.

Reinstein, J., Brune, M., and Wittinghofer, A. (1988) Mutations in the nucleotide binding loop of adenylate kinase of Escherichia coli. Biochemistry 27, 4712-4720.

Reinstein, J., Schlichting, I., and Wittinghofer, A. (1990) Structurally and catalytically important residues in the phosphate binding loop of adenylate kinase of Escherichia coli. Biochemistry 29, 7451-7459. 
Reuver, S., and Garner, C. C. (1998) E-cadherin mediated cell adhesion recruits SAP97 into the cortical cytoskeleton. J. Cell Sci. 11, 1260-1271.

Rhoads, A. R., and Friedberg, F. (1997) Sequence motifs for calmodulin recognition. FASEB J. 11, 331-340.

Riggs, P.D. (1990) Expression and purification of maltose-binding protein fusions, in Current Protocols in Molecular Biology, eds. Ausubel, F. M. et al., Greene Publishing Associaltes/Wiley Interscience, New York.

Rose, M. D. (1990) Methods in Yeast Genetics-A Laboratory Course Manual. Cold Spring Harbor Laboratory Press.

Rothstein, R. J. (1983) One-step gene disruption in yeast. Meth Enzymol. 101, 202-211.

Roustan, C., Fattoum, A., Jeanneau, R., and Pradel, L.-A. (1980) Yeast 3-phosphoglycerate kinase: sulfate and substrate binding, their effect on the conformational state of the enzyme. Biochemistry 19, 5168-5175.

Rudolph, R., and Lilie, H. (1996) In vitro folding of inclusion body proteins. FASEB J. 10, 49-56.

Ruff, P., Speicher, D. W., and Husain-Chisti, C. A. (1991) Molecular identification of a major palmitoylated erythrocyte membrane protein containing the src homology 3 motif. Proc. Natl. Acad. Sci. USA 88, 6595-6599.

Saeki, T., Hori, M., and Umezawa, H. (1974) Pyruvate kinase of Escherichia coli. Its role in supplying nucleoside triphosphates in cells under anaerobic conditions. J Biochem. 76, 631-637.

Saraste, M., Sibbald, P. R., and Wittinghofer, A. (1990) The p-loop - a common motif in ATP- and GTP-binding proteins. Trends Biochem. Sci. 15, 430-434.

Satoh, K., Yanai, H., Senda, T., Kohu, K., Nakamura, T., Okamura, N., Matsumine, A., Koyabashi, S., Toyoshima, K., and Akiyama, T. (1997) DAP-1, a novel protein that interacts with the guanylate kinase-like domains of hDLG and PSD-95. Genes Cells 2, 415-424.

Schaertl, S. Konrad, M., and Geeves, M. (1998) Substrate specificity of human nucleoside-diphosphate kinase revealed by transient kinetic analysis. J. Biol. Chem. 273, 5662-5669.

Scheffzek, K., Kliche, W., Wiesmüller, L., and Reinstein, J. (1996) Crystal structure of the complex of UMP/CMP kinase from Dictyostelium discoideum and the bisubstrate inhibitor $\mathrm{P}^{1}-\left(5^{\prime}-\right.$ adenosyl) $\mathrm{P}^{5}$-(5'-uridyl) pentaphosphate $\left(\mathrm{UP}_{5} \mathrm{~A}\right)$ and $\mathrm{Mg}^{2+}$ at $2.2 \AA$ : implications for watermediated specificity. Biochemistry 35, 9716-9727.

Scheffzek, K., Kabsch, W., Schlichting, I., Pai, E. F., Lautwein, A., Frech, M., Wittinghofer, A., and Goody, R. S. (1999) Crystallization and preliminary X-ray structure analysis of thermally unstable $\mathrm{p} 21^{\mathrm{H}-r a s}$ guanosine complexes. Acta Crystallogr. Sec. D 50, 521-526.

Schein, C. H. (1989) Production of soluble recombinant proteins in bacteria. BioTechnology 7, 11411149.

Schena, M., Lloyd, A. M., and Davis, R. W. (1991) A steroid-inducible gene expression system for plant cells. Proc. Natl. Acad. Sci. USA 88, 10421-10425. 
Schlichting, I., and Reinstein, J. (1997) Structures of active conformations of UMP kinase from Dictyostelium discoideum suggest phosphoryl transfer is associative. Biochemistry 36, 92909296.

Schricker, R., Magdolen, V., Kaniak, A., Wolf, K., and Bandlow, W. (1992) The adenylate kinase family in yeast: identification of URA6 as a multicopy suppressor of deficiency in major AMP kinase. Gene 1992 2, 111-118.

Schulman, H. (1993) The multifunctional $\mathrm{Ca}^{2+} /$ calmodulin-dependent protein kinases. Curr. Opin. Cell Biol. 5, 247-253.

Schüle, T. (1997) Biochemische Untersuchungen an der Guanylatkinase der Bäckerhefe. Dissertation, Ruhr-Universität Bochum

Shimma, Y., and Uno, I. (1990) Isolation and characterization of neomycin sensitive mutants in Saccharomyces cerevisiae. J. Gen. Microbiol. 136, 1753-1761.

Shimma, Y., Nishikawa, A., Bin Kassim, B., Eto, A., and Jigami, Y. (1997) A defect in GTP synthesis affects mannose outer chain elongation in Saccharomyces cerevisiae. Mol. Gen. Genet. 256, 469-480.

Shin, H., Hsueh, Y.-P., Yang, F.-C., Kim, E., and Sheng, M. (2000) An intramolecular interaction between src homology 3 domain and guanylate kinase-like domain required for channel clustering by postsynaptic density-95/SAP90. J. Neurosci. 20, 3580-3587.

Sicheri, F., Moarefi, I., and Kuriyan, J. (1997). Crystal structure of the Src-family tyrosine kinase Hck. Nature 385, 602-609.

Sigal, I. S., Gibbs, J. B., D’Alonzo, J. S., Temeles, G. L., Wolanski, B. S., Socher, S. H., and Solnick, E. M. (1986) Mutant ras-encoded proteins with altered nucleotide binding exert dominant biological effects. Proc. Natl. Acad. Sci. USA 83, 952-956.

Skehel, J. J., Bayley, P. M., Brown, E. B., Martin, S. R., Waterfield, M. D., White, J. M, Wilson, I. A., and Wiley, D. C. (1982) Changes in the conformation of influenza virus hemagglutinin at the pH optimum of virus-mediated membrane fusion. Proc. Natl. Acad. Sci. USA. 79, 968-972.

Smith, D. B., and Johnson, K. S. (1988) Single-step purification of polypeptides expressed in Escherichia coli as fusions with glutathione $S$-transferase. Gene 67, 31-40.

Smith, S. A., Holik, P., Stevens, J., Mazoyer, S., Melis, R., Williams, B., White, R., and Albertsen, H. (1996) Isolation of a gene (DLG3) encoding a second member of the discs-large familiy on chromosome 17q12-q21. Genomics 31, 145-150.

Snedden, W. A., and Fromm, H. (1998) Calmodulin, Calmodulin-related proteins and plant responses to the environment. Trends in Plant Science 3, 299-304.

Songyang, Z., Fanning, A., Fu, C., Xu, J., Marfatia, S., Chisti, A., Crompton, A., Chan, A., and Anderson, J. M. (1997) Recognition of unique carboxy-terminal motifs by distinct PDZ domains. Science 275, 73-77.

Spangenberg, O. (1997) Guanylatkinase-Homologe: Untersuchungen zur Struktur und Funktion in vitro und in vivo. Diplomarbeit, Universität Göttingen.

Stehle, T., and Schulz, G. E. (1990) Three-dimensional structure of the complex of guanylate kinase with its substrate GMP. J. Mol. Biol. 211, 249-254. 
Stehle, T., and Schulz, G. E. (1992) Refined structure of the complex between guanylate kinase and its substrate GMP at 2.0 Å resolution. J. Mol. Biol. 224, 1127-1141.

Steiner, S., and Philippsen, P. (1994) Sequence and promoter analysis of the highly expressed TEF gene of the filamentous fungus Ashbya gossypii. Mol. Gen. Genet. 242, 263-271.

Studier, F. W., Rosenberg, A. H., Dunn, J. J., and Dubendorff, J. W. (1990) Use of T7 RNA polymerase to direct the expression of cloned genes. Methods Enzymol. 185, 60-89.

Takahisa, M., Togashi, S., Suzuki, T., Kobayashi, M., Murayama, A., Kondo, K., Miyake, T., and Ueda, R. (1996) The Drosophila tamou gene, a component of the activating pathway of extramacrochaetae expression, encodes a protein homologous to mammalian cell-cell junction-associated protein ZO-1. Genes Dev. 10, 1783-1795.

Takeuchi, M., Hata, Y., Hirao, K., Toyoda, A., Irie, M., and Takai, Y. (1997) SAPAPs. A familie of PSD-95/SAP90-associated proteins localized at postsynaptic density. J. Biol. Chem. 272, 11943-11951.

Tejedor, F. J., Bokhari, A., Rogero, O., Gorczyca, M., Zhang, J., Kim, E., Sheng, M., and Budnik, V. (1997) Essential role for $d l g$ in synaptic clustering of Shaker $\mathrm{K}^{+}$channels in vivo. J. Neurosci. $17,152-159$.

Thomas, U., Pannavong, B., Müller, B., Garner, C. C., and Gundelfinger, E. D. (1997) Functional expression of rat synapse-associated proteins SAP97 and SAP102 in Drosophila dlg-1 mutants: effects on tumor suppression and synaptic bouton structure. Mech. Dev. 62, 161-174.

Tian, G. C., Yan, H. G., Jiang, R. T., Kishi, F., Nakazawa, A., and Tsai, M. D. (1990) Mechanism of adenylate kinase. Are the essential lysines essential? Biochemistry 29, 4296-4304.

Tong, L., DeVos, A. M., Milburn, M. V., and Kim, S.-H. (1991) Crystal structures at 2.2 A resolution of the catalytic domains of normal ras protein and an oncogenic mutant complexed with GDP. J. Mol. Biol. 211, 249-254.

Tsai, M. D., and Yan, H. G. (1991) Mechanism of adenylate kinase: site-directed mutagenesis versus Xray and NMR. Biochemistry 30, 6806-6818.

Tsunoda, S., Sierralta, J., Sun, Y., Bodner, R., Suzuki, E., Becker, A., Socolich, M., and Zuker, C. S. (1997) A multivalent PDZ-domain protein assembles signaling complexes in a G-proteincoupled cascade. Nature 388, 243-249.

Van Holde, K. E. (1975) Sedimentation analysis of proteins. The Proteins, Vol. I, 225-291. New York, Academic Press.

Van Rompay, A. R., Johansson, M., and Karlsson, A. (2000) Phosphorylation of nucleosides and nucleoside analogs by mammalian nucleoside monophosphate kinases. Pharmacol. Ther. 87, 189-198.

Veron, M., Tepper, A., Hildebrandt, M., Lascu, I., Lacombe, M. L., Janin, J., Morera, S., Cherfils, J., Dumas, C., and Chiadmi, M. (1994) Nucleoside diphosphate kinase: an old enzyme with new functions? Adv. Exp. Med. Biol. 370, 607-611.

Von Heijne, G. (1984) How signal sequences maintain cleavage specificity. J. Mol Biol. 173, 243-251.

Wach, A., Brachat, A., Pohlmann, R., and Philippsen, P. (1994) New heterologous modules for classical or PCR-based gene disruptions in Saccharomyces cerevisiae. Yeast 10, 1793-1808. 
Wickner, S., Maurizi, M. R., and Gottesman, S. (1999) Posttranslational quality control: folding, refolding, and degrading proteins. Science 286, 1888-1893.

Wilm, M., and Mann, M. (1996) Analytical properties of the nanoelectrospray ion source. Anal Chem. $68,1-8$.

Woods, D. F., and Bryant, P. J. (1989) Molecular cloning of the lethal (1) discs large-1 oncogene of Drosophila. Dev. Biol. 134, 222-235.

Woods, D. F., and Bryant, P. J. (1991). The discs-large tumor suppressor gene of Drosophila encodes a guanylate kinase homolog localized at septate junctions. Cell 66, 451-464.

Woods, D. F., and Bryant, P. J. (1993) ZO-1, DlgA and PSD-95/SAP90: homologous proteins in tight, septate and synaptic cell junctions. Mech. Dev. 44, 85-89.

Woods, D. F., Hough, C., Peel, D., Callaini, G., and Bryant, P. J. (1996) Dlg protein is required for junction structure, cell polarity, and proliferation control in Drosophila epithelia. J. Cell. Biol. $134,1469-1482$.

Wu , H., Reuver, S. M., Kuhlendahl, S., Chung, W. J., and Garner, C. C. (1998) Subcellular targeting and cytoskeletal attachment of SAP97 to the epithelial lateral membrane. J. Cell Sci. 11, 23652376.

Wu, H., Reissner, C., Kuhlendahl, S., Coblentz, B., Reuver, S., Kindler, S., Gundelfinger, E. D., and Garner, C. C. (2000) Intramolecular interactions regulate SAP97 binding to GKAP. EMBO J. $19,5740-5751$.

Xu, W., Harrison, S. C., and Eck, M. (1997) Three-dimensional structure of the tyrosine kinase c-Src. Nature 385. 595-602.

Yan, H. G., Shi, Z. T., and Tsai, M. D. (1990) Mechanism of adenylate kinase. Structural and functional demonstration of arginine-138 as a key catalytic residue that cannot be replaced by lysine. Biochemistry 29, 6385-92.

Yan, H., and Tsai, M. D. (1991) Mechanism of adenylate kinase: site-directed mutagenesis versus X-ray and NMR. Biochemistry 30, 6806-6818.

Yan, H., and Tsai, M. D. (1999) Nucleoside monophosphate kinases: structure, mechanism, and substrate specificity. Adv. Enzymol. Relat. Areas Mol. Biol. 73, 103-34.

Yoo, S. H., and Lewis, M. S. (1996) Effects of $\mathrm{pH}$ and $\mathrm{Ca}^{2+}$ on heterodimer and heterotetramer formation by chromoganin A and chromoganin B. J. Biol. Chem. 271, 17041-17046.

Yu, H., Chen, J. K., Feng, S., Dalgarno, D. C., Brauer, A. W., and Schreiber, S. L. (1994) Structural basis for the binding of proline-rich peptides to SH3 domains. Cell 76, 944-945.

Zalkin, H., and Dixon, J. E. (1992) De novo purine nucleotide biosynthesis. Prog. Nucleic Acid. Res. Mol. Biol. 42, 259-287.

Zarutskie, J. A., Sato, A. K., Rushe, M. M., Chan, I. C., Lomakin, A., Benedek, G. B., and Stern, L. J. (1999) A conformational change in the human major histocompatibility complex protein HLA-DR1 induced by peptide binding. Biochemistry 38, 5878-5887. 
Zhou, L., and Thornburg, R. (1998) Site-specific mutations of conserved residues in the phosphatebinding loop of the Arabidopsis UMP/CMP kinase alter ATP and UMP binding. Arch. Biochem. Biophys. 358, 297-302.

Zimmermann, S., Baumann, A., Jaekel, K., Marbach, I., Engelberg, D., and Frohnmeyer, H. (1999) UVresponsive genes of Arabidopsis revealed by similarity to theGcn4-mediated UV response in yeast. J. Biol. Chem. 274, 17017-17024.

Zschocke, P. D., Schlitz, E., and Schultz, G. E. (1993) Purification and sequence determination of guanylate kinase from pig brain. Eur. J. Biochem. 213, 263-269. 


\section{Danksagung}

Herrn Dr. Manfred Konrad danke ich für die Überlassung des Arbeitsthemas, seine stete Diskussionsbereitschaft und die Freiheiten bei der Durchführung der Arbeiten. Insbesondere danke ich ihm für die Vermittlung der vielen wissenschaftlichen Kontakte und den wertvollen Gewinn an Auslandserfahrung.

Herrn Prof. Dr. Gallwitz möchte ich für die Bereitstellung des Arbeitsplatzes und seine Unterstützung danken.

Herrn Prof. Dr. Braus danke ich für die freundliche Befürwortung und Betreuung der Arbeit seitens der Universität Göttingen.

Bei Dr. Heino Prinz und Dr. Kaspar Zechel bedanke ich mich für die Einführung in die NanoElektrospray-Massenspektrometrie und analytische Ultrazentrifugation.

Dr. Arnon Lavie und Dr. Carsten Reissner danke ich für die uneingeschränkte Hilfestellung bei der Klärung wichtiger „struktureller“ Fragen und den regen Ideenaustausch, welcher maßgeblich zum Gelingen dieser Arbeit beigetragen hat.

Ein großer Dank geht an die jetzigen und ehemaligen Mitarbeiter von Labor 220, Christian II, Ingo, Theresa, Carolin, Sabine und Ralf für die hervorragende Zusammenarbeit und die unnachahmliche Stimmung im Labor, sowie an den „Sportsfreund“ Christian I.

Darüberhinaus möchte ich mich bei allen hier nicht namentlich genannten KollegInnen der Abteilung 150 für die gute Arbeitsatmosphäre und die Hilfe bei den vielen kleinen Dingen im Laboralltag bedanken, die ein erfolgreiches Arbeiten erst ermöglichen.

A la fin je voudrais remercier les membres des équipes de Bertrand Daignan-Fornier et Prof. Ioan Lascu qui ont fait mes sejours en France si agréables, en particulier Paty, Benoit et Philippe qui m’ont montré la vraie France.

Ein besonderer Dank gilt meinen Eltern, die mir das Studium der Biologie erst ermöglichten. 


\section{Lebenslauf}

Name:

Geburtsdatum:

Geburtsort:

Staatsangehörigkeit:

Schulbildung:

$08.1976-07.1980$

$08.1980-06.1982$

$07.1982-06.1986$

$07.1986-05.1989$

$08.1989-06.1991$

25.06.1991

Studium:

$10.1991-04.1997$

$06.1996-04.1997$

18.04.1997

ab 08.1997

Auslandsaufenthalte:

$04.1997-07.1997 /$

$10.1999-11.1999$
Oliver Spangenberg

11.10.1969

Kassel

deutsch
Grundschule in Schauenburg-Breitenbach

Grundschule mit Förderstufe in Schauenburg-Hoof

Erich-Kästner-Gesamtschule in Baunatal

Oberstufengymnasium in Kassel-Oberzehren

Ausbildung zum Biologisch-Technischen Assistenten (BTA) an den Beruflichen Schulen des Hochsauerlandkreises in Olsberg BTA-Abschluß

Studium der Fachrichtung Biologie an der Georg-August Universität in Göttingen

Diplomarbeit am Max-Planck-Institut für Biophysikalische Chemie in Göttingen, Abteilung Molekulare Genetik bei Prof. D. Gallwitz

Abschluß als Diplom-Biologe

Promotion am Max-Planck-Institut für Biophysikalische Chemie, Abteilung Molekulare Genetik 